ITAMAR ILIUK

ANÁLISE DE UM SISTEMA DE CAPTURA DE ENERGIA PIEZOELÉTRICO NÃO LINEAR E NÃO IDEAL UTILIZANDO-SE UMA ESTRUTURA APORTICADA 
ITAMAR ILIUK

\section{ANÁLISE DE UM SISTEMA DE CAPTURA DE ENERGIA PIEZOELÉTRICO NÃO LINEAR E NÃO IDEAL UTILIZANDO-SE UMA ESTRUTURA APORTICADA}

Tese apresentada à Escola Politécnica da Universidade de São Paulo para obtenção do título de Doutor em Ciências.

São Paulo 
ITAMAR ILIUK

\section{ANÁLISE DE UM SISTEMA DE CAPTURA DE ENERGIA PIEZOELÉTRICO NÃO LINEAR E NÃO IDEAL UTILIZANDO-SE UMA ESTRUTURA APORTICADA}

Tese apresentada à Escola Politécnica da Universidade de São Paulo para obtenção do título de Doutor em Ciências.

Área de concentração:

Engenharia de Sistemas

Orientador:

Prof. Dr. José Roberto Castilho Piqueira

São Paulo 


\section{Catalogação-na-publicação}

lliuk, Itamar

Análise de um sistema de Captura de energia piezoelétrico não linear e não ideal utilizando-se uma estrutura aporticada / Iliuk, I --São Paulo, 2016.

$146 \mathrm{p}$.

Tese (Doutorado) - Escola Politécnica da Universidade de São Paulo. Departamento de Engenharia de Telecomunicações e Controle.

1. Captura de Energia 2. Piezoeletricidade 3. Caos 4. Controle Passivo 5. Análise Wavelet I. Universidade de São Paulo. Escola Politécnica. Departamento de Engenharia de Telecomunicações e Controle II. t. 


\section{DEDICATÓRIA}

A minha esposa Jeane, minha razão, minha vida. É somente nas misteriosas equações do amor que qualquer lógica ou razão pode ser encontrada.(John Nash)

Ao meu pai e à minha mãe, profundos respeito, admiração e amor. Ao meu filho, meu melhor amigo. 


\section{AGRADECIMENTOS}

Agradeço Deus por me garantir a força necessária para suportar as dificuldades e superar as barreiras impostas neste mundo.

Agradeço ao professor José Roberto Castilho Piqueira a confiança em meu trabalho e os conselhos que me ajudaram a crescer pessoal e profissionalmente.

À minha esposa Jeane, a paciência e o suporte para que a finalização de mais esta etapa fosse possível. Sem o seu incentivo e seu amor, nada do que estou vivendo hoje aconteceria.

Aos meus pais, Estefano e Gerda, que nunca deixaram de acreditar em mim e me deram forças para continuar, um muitíssimo obrigado.

Agradeço ao meu filho, Itamar Júnior. Mesmo não estando tão próximo quanto eu gostaria, acompanhei seu crescimento e só posso me orgulhar do homem que está se tornando.

Aos professores da Escola Politécnica, Maurício Barbosa de Camargo Salles, Claudio Garcia, Luiz Antonio Baccala e Luiz Henrique Alves Monteiro, que muito me ensinaram em suas disciplinas, tornando possível a realização deste trabalho.

Aos meus amigos, professores José Manoel Balthazar e Ângelo Marcelo Tusset, me ajudarem com sua experiência ao longo da caminhada.

Aos meus colegas de doutorado, Cris, Rô, Diego, Osvaldo e Antônio, que estiveram comigo nas horas de descontração e nas horas de estudo. A nossa amizade é para sempre.

Agradeço à USP e à FAPESP o apoio financeiro concedido por meio de bolsa e auxílios. Ao Departamento de Engenharia de Telecomunicações e Controle e à Secretaria de Pós-Graduação da Escola Politécnica, propiciarem as melhores condições para que este trabalho fosse realizado. 
Se $A$ é sucesso na vida, então $A$ é igual a $X$ mais $Y$ mais $Z$. $X$ é trabalho, $Y$ é diversão e $Z$ é manter sua boca fechada!

(Albert Einstein) 


\section{RESUMO}

A crescente utilização de novas tecnologias, as quais necessitam de uma fonte de energia menor e mais eficiente, como os microssensores para monitoramento de sistemas e estruturas nas chamadas cidades inteligentes, torna a captura da energia do ambiente uma opção viável para alimentação de tais dispositivos. Como a energia cinética é uma fonte de energia facilmente encontrada no ambiente, os sistemas que a capturam e convertem em eletricidade têm sido amplamente estudados, especialmente os que utilizam transdutores piezoelétricos. Considerando estruturas aporticadas, como prédios, pontes etc., comumente encontradas nas cidades, este trabalho apresenta um novo modelo de sistema de captura de energia piezoelétrico com base em um pórtico não linear, sob uma excitação não ideal, por meio de uma fonte com potência limitada. Para modelar o acoplamento piezoelétrico, foram consideradas as não linearidades do material piezoelétrico. Por meio das simulações numéricas, pode-se verificar a eficiência e a viabilidade do modelo proposto. Devido ao fato de as vibrações do meio ambiente serem senoidais, aleatórias ou transitórias, surge uma dificuldade na captura de energia de forma eficiente e com um nível contínuo. A utilização de controles passivos pode melhorar a energia capturada, removendo o movimento caótico do sistema e mantendo a oscilação em uma órbita periódica estável. Assim, duas estratégias de controle passivo foram empregadas, a primeira utilizando uma subestrutura com características de absorvedor de energia não linear (NES) e a segunda pela introdução de um pêndulo. Em ambos os casos, as simulações demonstraram que o controle passivo foi eficiente em levar o sistema caótico para uma órbita periódica estável, otimizando a captura de energia do sistema. Uma análise considerando incertezas nos parâmetros foi realizada, para verificar a robustez da estratégia de controle, assim como a sensibilidade do sistema de controle a erros paramétricos. Os resultados mostraram a eficiência do controle passivo e o fenômeno do bombeamento de energia na supressão do comportamento caótico. A principal vantagem do controle passivo é não necessitar de componentes eletrônicos para controlar o sistema, sendo apenas um componente mecânico "massa", acoplado à estrutura principal. Uma análise wavelet foi realizada sobre o modelo, para identificar o comportamento oscilatório do sistema e permitir a visualização das frequências de vibração que capturam mais energia.

Palavras-chave: Captura de Energia, Piezoeletricidade, Caos, Controle Passivo, Análise Wavelet. 


\section{ABSTRACT}

The increasing use of new technologies, which have the need for smaller and more energyefficient sources, such as micro-sensors for monitoring systems and structures of the so-called smart cities, assigns environmental energy harvesting a viable option to power such devices. As kinetic energy is a source easily found in the environment, the systems that harvest and convert this type of energy into electricity have been widely studied, especially those using piezoelectric transducers. Considering framed structures, such as buildings, bridges, etc., which are commonly found in the cities, this paper presents a new model of piezoelectric energy harvesting system based on a nonlinear portal frame, under a non-ideal excitation by a source with limited power. To model Piezoelectric couplings, they were considered nonlinearities of the piezoelectric material. Through numerical simulations, the efficiency and viability of the proposed model can be verified. A difficulty arises in harvesting energy in an efficient manner, and with a continuous level, because the vibrations of the environment are sinusoidal, random or transient. However, the use of passive controls can improve the energy harvested by removing the chaotic motion of the system and maintaining the oscillation at a stable periodic orbit. Thus, two passive control strategies were employed, the first using a substructure with characteristics of nonlinear energy sink (NES), and the second by introducing a pendulum. In both cases, the simulations showed that the passive control was efficient in bringing the chaotic system to a stable periodic orbit, optimizing the energy harvest system. An analysis considering the uncertainties in the parameters was performed to verify the robustness of the control strategy, as well as the sensitivity of the control system of parametric errors. The results showed the efficiency of passive control and the energy pumping phenomenon in the suppression of the chaotic behavior. The main advantage of passive control is not to require any electronic components for controlling the system, only a mechanical component _mass_, attached to the main structure. A Wavelet Analysis was conducted on the model to identify the oscillatory behavior of the system and allowed the viewing of the vibration frequencies that harvest more energy.

Keywords: Energy Harvesting, Piezoelectricity, Chaos, Passive Control, Wavelet Analysis 


\section{LISTA DE ILUSTRAÇÕES}

Figura 1 Modelo Experimental Construído por Garzeri (2001) . . . . . . . . . . . 22

Figura 2 Esquema de um Sistema Não Ideal (NIS) e Não Linear de Captura de Energia Piezoelétrico. . . . . . . . . . . . . . . . . . . . . . 22

Figura 3 a) Efeito Piezoelétrico Direto; b) Efeito Piezoelétrico Inverso . . . . . 26

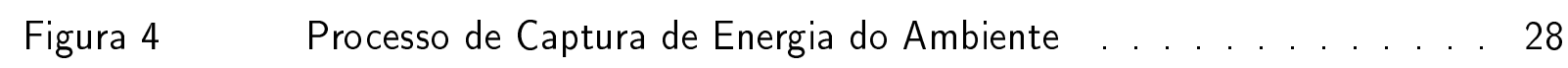

Figura 5 Modelo Esquemático do Sistema NIS . . . . . . . . . . . . . . . . . . 41

Figura 6 Modelo Físico do Sistema (NIS) . . . . . . . . . . . . . . . . . . . . . . . 42

Figura $7 \quad$ Pórtico com Controle Passivo (NES) Acoplado . . . . . . . . . . . . . . 47

Figura $8 \quad$ Modelo Físico do Oscilador com o Controle Passivo (NES) Acoplado . 48

Figura $9 \quad$ Pórtico com Controle Passivo do Tipo Pêndulo Acoplado . . . . . . . 50

Figura $10 \quad$ Modelo Físico do Oscilador com o Controle Passivo do Tipo Pêndulo Acoplado . . . . . . . . . . . . . . . . . . . . . . 50

Figura 11 Respostas do Sistema de Captura de Energia sem a Aplicação de Controle Passivo . . . . . . . . . . . . . . . . . . . . . 54

Figura 12 Diagrama de Bifurcação para o Parâmetro de Controle $e$. . . . . . . . 56

Figura $13 \quad$ Potência Média Capturada para Incrementos do Parâmetro de Controle e 57

Figura $14 \quad$ Aplicação do Controle Passivo (NES) Utilizando o Valor do Parâmetro
de Controle $e=0.4$. . . . . . . . . . . . . . . . . . . . . . . . . . . 58

Figura $15 \quad$ Aplicação do Controle Passivo (NES) Utilizando o Valor do Parâmetro de Controle $e=5.0$. . . . . . . . . . . . . . . . . . . . . . . . . . . 59

Figura 16 Deslocamento no Tempo da Transferência de Energia e da Potência

\begin{tabular}{|l}
\hline Instantânea Capturada $e=0.4$ \\
\hline
\end{tabular}

Figura 17 Zoom do Deslocamento no Tempo da Transferência de Energia e da Potência Instantânea Capturada $e=0.4$. . . . . . . . . . . . . . 61

Figura 18 Deslocamento no Tempo da Transferência de Energia e da Potência Instantânea Capturada $e=5.0$. . . . . . . . . . . . . . . 61

Figura 19 Zoom do Deslocamento no Tempo da Transferência de Energia e da Potência Instantânea Capturada $e=5.0$. . . . . . . . . . . . 62

Figura $20 \quad$ Potência Máxima Capturada para o Sistema Controlado e sem Controle 62 Figura 21 Diagramas de Bifurcação do Parâmetro $e$ para a Variação do Amorte-

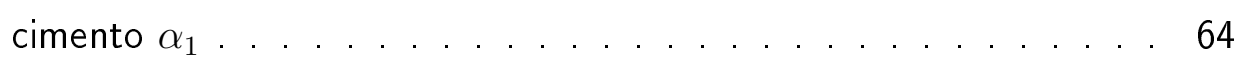

Figura $22 \quad$ Diagrama de Potência Média para o Parâmetro $\alpha_{1}$. . . . . . . . . . . . 65 
Figura $23 \quad$ Potência Média para o Parâmetro $\alpha_{1} \ldots \ldots$. . . . . . . . . . . . . 65

Figura 24 Diagramas de Bifurcação do Parâmetro $e$ para a Variação do Amortecimento $\alpha_{2} \ldots \ldots \ldots \ldots$. . . . . . . . . . . . . . 66

Figura $25 \quad$ Diagrama de Potência Média para o Parâmetro $\alpha_{2}$. . . . . . . . . . . 67

Figura $26 \quad$ Potência Média para o Parâmetro $\alpha_{2}$. . . . . . . . . . . . . . . . . . . . . 67

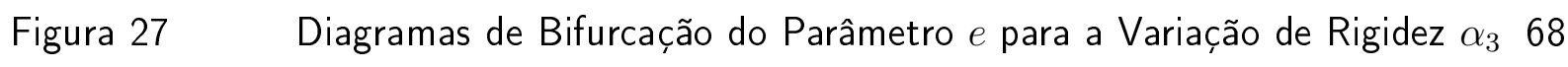

Figura $28 \quad$ Diagrama de Potência Média para o Parâmetro $\alpha_{3}$. . . . . . . . . . . . 69

Figura $29 \quad$ Potência Média para o Parâmetro $\alpha_{3} \ldots \ldots$. . . . . . . . . . . . . . . . 69

Figura $30 \quad$ Diagramas de Bifurcação do Parâmetro e para a Variação da Rigidez Não Linear $\beta_{3}$. . . . . . . . . . . . . . . . . . . . . . . . . . . 70

Figura $31 \quad$ Diagrama de Potência Média para o Parâmetro $\beta_{3}$. . . . . . . . . . . 71

Figura $32 \quad$ Potência Média para o Parâmetro $\beta_{3} \ldots \ldots$. . . . . . . . . . . . 71

Figura $33 \quad$ Diagramas de Bifurcação do Parâmetro $e$ para a Variação de $\delta_{1}$. . . . 72

Figura $34 \quad$ Diagrama de Potência Média para o Parâmetro $\delta_{1} \ldots \ldots$. . . . . . . . 73

Figura $35 \quad$ Potência Média para o Parâmetro $\delta_{1} \ldots \ldots \ldots$. . . . . . . . . . . . . . . . . 73

Figura $36 \quad$ Diagrama de Bifurcação do Parâmetro de Controle e . . . . . . . . . . . 78

Figura $37 \quad$ Potência Média Capturada para a Variação do Parâmetro $e$. . . . . . 78

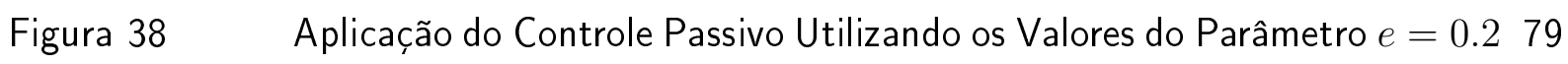

Figura $39 \quad$ Aplicação do Controle Passivo Utilizando os Valores do Parâmetro $e=$ $0.42 \ldots \ldots \ldots \ldots \ldots$

Figura $40 \quad$ Aplicação do Controle Passivo Utilizando os Valores do Parâmetro $e=0.781$

Figura 41 Deslocamento no Tempo da Transferência de Energia e da Potência Instantânea Capturada $e=0.2$. . . . . . . . . . . . . . . . . . . . . 82

Figura $42 \quad$ Zoom do Deslocamento no Tempo da Transferência de Energia e da Potência Instantânea Capturada $e=0.2 \ldots$. . . . . . . . . 83

Figura 43 Deslocamento no Tempo da Transferência de Energia e da Potência Instantânea Capturada $e=0.42$. . . . . . . . . . . . . . . 84

Figura $44 \quad$ Zoom do Deslocamento no Tempo da Transferência de Energia e da Potência Instantânea Capturada $e=0.42$. . . . . . . . . . . . . 84

Figura 45 Deslocamento no Tempo da Transferência de Energia e da Potência Instantânea Capturada $e=0.7$. . . . . . . . . . . . . . . . . 85

Figura $46 \quad$ Zoom do Deslocamento no Tempo da Transferência de Energia e da Potência Instantânea Capturada $e=0.7$. . . . . . . . . . . . . . 85

Figura $47 \quad$ Potência Máxima para o Sistema Controlado e sem Controle . . . . . 86 
Figura 48 Potência Média Capturada para a Variação do Parâmetro de Amortecimento $\alpha_{1} \ldots \ldots \ldots \ldots$. . . . . . . . . . . . . . . . . . . . . . . . . . . . 8

Figura $49 \quad$ Potência Média Capturada para os Casos do Parâmetro de Controle $e$ com Variação de $\alpha_{1}$. . . . . . . . . . . . . . . . . . . . . . . . . 88

Figura $50 \quad$ Diagramas de Bifurcação para o Paramêtro de Amortecimento $\alpha_{1}$. . . 88

Figura $51 \quad$ Potência Média Capturada para a Variação do Parâmetro de Rigidez Não Linear $\beta_{3}$. . . . . . . . . . . . . . . . . . . . . . . . . . . . . . . . . . . . . . 89

Figura $52 \quad$ Potência Média Capturada para os Casos do Parâmetro de Controle $e$ com Variação de $\beta_{3}$. . . . . . . . . . . . . . . . . . . . . . . . . . . 90

Figura $53 \quad$ Diagramas de Bifurcação para o Paramêtro de Rigidez Não Linear $\beta_{3}$. 90

Figura $54 \quad$ Matlab colormap jet . . . . . . . . . . . . . . . . . . . . 93

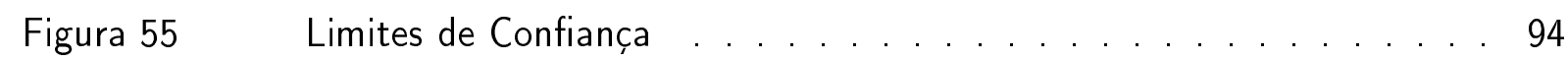

Figura $56 \quad$ Comparação entre a FFT e o Espectro Wavelet Global de um Sistema

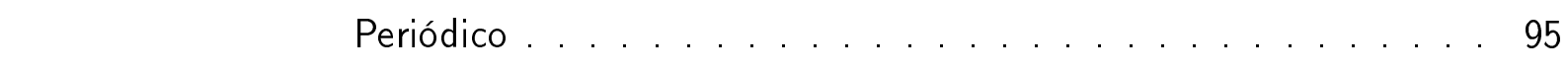

Figura $57 \quad$ Sistema Periódico: Padrão Regular das Células de Turbulência . . . . . 96

Figura 58 Sistema Caótico: Padrão Aleatório na Distribuição das Células de Turbulência . . . . . . . . . . . . . . . . . . . 96

Figura $59 \quad$ (a)Ângulo de Fase da Wavelet para um Ruído Gaussiano; (b)Ângulo de Fase da Wavelet para um Oscilador Duffing Caótico. . . . . . . . 97

Figura $60 \quad$ Aplicação da Wavelet Toolbox de Torrence e Compo (1998) - Pórtico sem Controle . . . . . . . . . . . . . . . . . . . . . . . . . . . . . . . . . 99

Figura 61 FFT - Pórtico sem Controle . . . . . . . . . . . . . . . . . . . . . . . 99

Figura $62 \quad$ Aplicação da Wavelet Toolbox ${ }^{\mathrm{TM}}$ do Matlab $\mathbb{R}$ - Pórtico sem Controle 100

Figura $63 \quad$ Aplicação da Wavelet Toolbox de Torrence e Compo (1998) - Pórtico

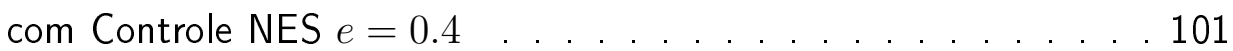

Figura $64 \quad$ FFT - Pórtico com Controle NES $e=0.4$. . . . . . . . . . . . . . . . 102

Figura $65 \quad$ Aplicação da Wavelet Toolbox ${ }^{\text {TM }}$ do Matlab® - Pórtico com Controle
NES $e=0.4 \ldots \ldots \ldots \ldots$

Figura $66 \quad$ Aplicação da Wavelet Toolbox de Torrence e Compo (1998) - Pórtico com Controle NES $e=5.0$. . . . . . . . . . . . . . . . . . . . . 104

Figura 67 FFT - Pórtico com Controle NES $e=5.0$. . . . . . . . . . . . . . . . 104

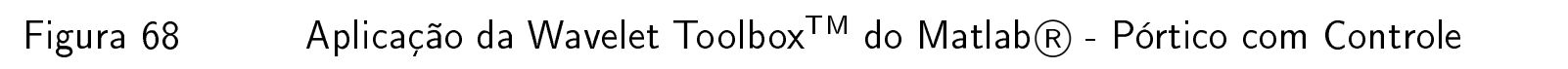
NES $e=5.0 \ldots \ldots \ldots \ldots \ldots . \ldots \ldots 10 \ldots \ldots$

Figura $69 \quad$ Aplicação da Wavelet Toolbox de Torrence e Compo, (1998) - Pórtico com Controle por Pêndulo $e=0.2$. . . . . . . . . . . . . . 106 
Figura $70 \quad$ FFT - Pórtico com Controle por Pêndulo $e=0.2$. . . . . . . . . . . . 107

Figura $71 \quad$ Aplicação da Wavelet Toolbox ${ }^{T M}$ do Matlab $\mathbb{R}$ - Pórtico com Controle

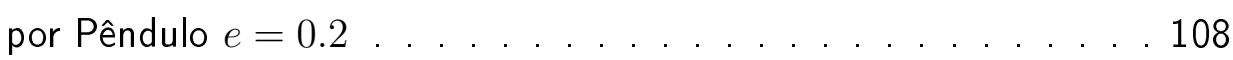

Figura $72 \quad$ Aplicação da Wavelet Toolbox de Torrence e Compo (1998) - Pórtico com Controle por Pêndulo $e=0.42$. . . . . . . . . . . . . . . 109

Figura 73 FFT - Pórtico com Controle por Pêndulo $e=0.42$. . . . . . . . . . . 109

Figura 74 Aplicação da Wavelet Toolbox ${ }^{\mathrm{TM}}$ do Matlab $\mathbb{R}$ - Pórtico com Controle por Pêndulo $e=0.42$. . . . . . . . . . . . . . . . . . 110

Figura $75 \quad$ Aplicação da Wavelet Toolbox de Torrence e Compo (1998) - Pórtico com Controle por Pêndulo $e=0.7$. . . . . . . . . . . . . . . . . . 111

Figura 76 FFT - Pórtico com Controle por Pêndulo $e=0.7$. . . . . . . . . . . . . 112

Figura $77 \quad$ Aplicação da Wavelet Toolbox ${ }^{\mathrm{TM}}$ do Matlabß - Pórtico com Controle por Pêndulo $e=0.7$. . . . . . . . . . . . . . . . . . . . . . . . . . . . . . 113

Figura $78 \quad$ Exemplos de Estruturas Aporticadas . . . . . . . . . . . . . . . . . . 114

Figura 79 Modelo Estrutural do Pórtico . . . . . . . . . . . . . . . . . . . . . . 116

Figura $80 \quad$ Excitações da Estrutura $\ldots \ldots \ldots$. . . . . . . . . . . . . . . . . . . . . . 117

Figura $81 \quad$ Configuração Final para a Resposta em Estado Estacionário . . . . . . 117

Figura 82 Discretização do MEF Adotada . . . . . . . . . . . . . . . . . . . . . 121

Figura $83 \quad$ Deslocamento no Tempo para o Caso $\Omega \approx \omega_{1} \ldots$. . . . . . . . . . . 121

Figura 84 Deslocamento no Tempo para o Caso $\Omega \approx \omega_{2}$. . . . . . . . . . . . . 122

Figura $85 \quad$ Aplicação de um Zoom no Transiente do Deslocamento no Tempo para o Caso $\Omega \approx \omega_{2} \ldots \ldots \ldots . \ldots . . \ldots 122$

Figura $86 \quad$ Proposta de um Sistema de Captura de Energia . . . . . . . . . . . . 123

Figura $87 \quad$ Histórico de Deslocamento no Tempo da Potência Proporcional para o

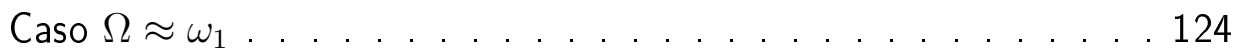

Figura $88 \quad$ Zoom no Histórico de Deslocamento no Tempo da Potência Proporci-

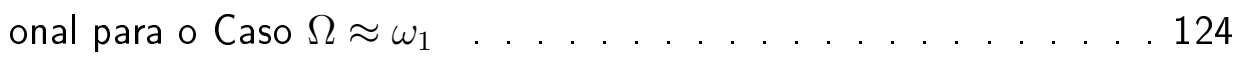

Figura $89 \quad$ Histórico de Deslocamento no Tempo da Potência Proporcional Disponível para Captura em Cada Modo para o Caso $\Omega \approx \omega_{2} \ldots . .125$

Figura $90 \quad$ Zoom na Potência Proporcional Disponível para Captura para o Caso

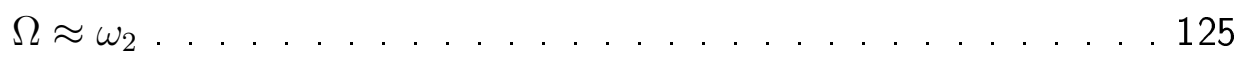

Figura $91 \quad$ Função de Referência (FR) para o Acoplamento Piezoelétrico Proposto por Triplett e Quinn (2009)] . . . . . . . . . . . . . . . . . . . 128

Figura 92 Função Proposta (FP) para o Acoplamento Piezoelétrico . . . . . . . 129

Figura 93 Efeito Sommerfeld para o Sistema Utilizando a Função de Referência . 130 
Figura $94 \quad$ Efeito Sommerfeld para o Sistema Utilizando a Função Proposta . . . 131

Figura 95 Retrato de Fase . . . . . . . . . . . . . . . . . . . . . . . . . . 131

Figura 96 Histórico de Deslocamento no Tempo . . . . . . . . . . . . . . . . . . . 132

Figura $97 \quad$ Potência Adimensional Máxima Capturada . . . . . . . . . . . . . . . . 132

Figura $98 \quad$ Potência Média Adimensional Capturada . . . . . . . . . . . . . . . . 133 


\section{LISTA DE TABELAS}

Tabela 1 Parâmetros da Simulação - Sistema de Captura sem Controle . . . . . 53

Tabela 2 Parâmetros da Simulação - Sistema com Controle NES . . . . . . . . 55

Tabela $3 \quad$ Potência Média Capturada - Sistema com Controle (NES) . . . . . . . 63

Tabela $4 \quad$ Potência Média $\alpha_{1} \ldots \ldots \ldots$. . . . . . . . . . . . . . . . . . . . . . . . . 74

Tabela $5 \quad$ Potência Média $\alpha_{2} \ldots \ldots \ldots \ldots \ldots \ldots$. . . . . . . . . . . . . . 74

Tabela $6 \quad$ Potência Média $\alpha_{3} \ldots \ldots \ldots \ldots$. . . . . . . . . . . . . . . . . . . . . . . . . . . 75

Tabela $7 \quad$ Potência Média $\beta_{3}$. . . . . . . . . . . . . . . . . . . . . . . . . . . . . . 75

Tabela $8 \quad$ Potência Média $\delta_{1} \ldots \ldots \ldots \ldots \ldots$

Tabela 9 Parâmetros da Simulação - Sistema Controlado por Pêndulo . . . . . . 77

Tabela $10 \quad$ Potência Média Capturada - Sistema com Controle por Pêndulo . . . . 86

Tabela 11 Pseudofrequência da Wavelet em $\mathrm{Hz} \times$ Frequência da FFT em Hz Pórtico sem Controle . . . . . . . . . . . . . . . . . . 101

Tabela 12 Pseudofrequência da Wavelet em $\mathrm{Hz} \times$ Frequência da FFT em $\mathrm{Hz}$ Pórtico com Controle NES $e=0.4$. . . . . . . . . . . . . . . . 103

Tabela $13 \quad$ Pseudofrequência da Wavelet em $\mathrm{Hz} \times$ Frequência da FFT em Hz Pórtico com Controle NES $e=5.0$. . . . . . . . . . . . . . 106

Tabela $14 \quad$ Pseudofrequência da Wavelet em $\mathrm{Hz} \times$ Frequência da FFT em Hz Pórtico com Controle por Pêndulo $e=0.2$. . . . . . . . . . . . . 108

Tabela 15 Pseudofrequência da Wavelet em $\mathrm{Hz} \times$ Frequência da FFT em Hz Pórtico com Controle por Pêndulo $e=0.42$. . . . . . . . . . . . 111

Tabela $16 \quad$ Pseudofrequência da Wavelet em $\mathrm{Hz} \times$ Frequência da FFT em Hz Pórtico com Controle por Pêndulo $e=0.7$. . . . . . . . . . . . . 113

Tabela 17 Características Geométricas e Físicas do Pórtico Analisado . . . . . . . . 120

Tabela 18 Valores Proporcionais Disponíveis de Potência para Captura em Cada

Modo ao Longo do Tempo . . . . . . . . . . . . . . . . . . 126

Tabela 19 Parâmetros da Simulação - Função de Acoplamento Piezoelétrico . . . 130 


$\begin{array}{ll}\text { AW } & \text { Análise Wavelet } \\ \text { BaTiO3 } & \text { Titanato de Bário } \\ \text { CC } & \text { Corrente Contínua } \\ \text { CWT } & \text { Transformada Wavelet Contínua } \\ \text { FEA } & \text { Análise por Elementos Finitos } \\ \text { FEP } & \text { Frequency Energy Plot } \\ \text { FFT } & \text { Transformada Rápida de Fourier } \\ \text { FP } & \text { Função Proposta } \\ \text { FR } & \text { Função de Referência } \\ \text { loT } & \text { Internet of Things } \\ \text { LQR } & \text { Linear-Quadratic Regulator } \\ \text { MEF } & \text { Método dos Elementos Finitos } \\ \text { MEMS } & \text { Sistema Microeletromecânico } \\ \text { NES } & \text { Nonlinear Energy Sink } \\ \text { NIS } & \text { Sistema Não ldeal } \\ \text { PVDF } & \text { Fluoreto de Polivinilideno } \\ \text { PbZrO } & \text { Zirconato de Chumbo } \\ \text { PbTiO3 } & \text { Titanato de Chumbo } \\ \text { PZT } & \text { Titanato Zirconato de Chumbo } \\ \text { SDRE } & \text { State Dependent Riccati Equation } \\ \text { TET } & \text { Targeted Energy Transfer } \\ \text { TRC } & \text { Transient Resonance Capture } \\ \text { XWT } & \text { Espectro Wavelet Cruzado } \\ & \end{array}$




\section{LISTA DE SÍMBOLOS}

\begin{tabular}{|c|c|}
\hline$a$ & Escala \\
\hline$A$ & Área da Seção \\
\hline$b, b_{1}$ & Amortecimento Linear \\
\hline$C$ & Capacitância do Material Piezoelétrico \\
\hline$d(X)$ & Coeficiente de Acoplamento Piezoelétrico \\
\hline$e$ & Parâmetro de Controle \\
\hline$E$ & Módulo de Young \\
\hline$E(x)$ & Termo de Correção da Função Logística \\
\hline$E I_{1}, E I_{2}$ & Rigidez \\
\hline$F_{a}$ & Pseudofrequência da Escala \\
\hline$F_{B}$ & Largura de Banda \\
\hline$F_{C}$ & Frequência Central da Wavelet \\
\hline$F_{s}$ & Frequência de Amostragem \\
\hline$g$ & Aceleração da Gravidade \\
\hline$h$ & Altura \\
\hline$H(\dot{\varphi})$ & Torque Resistivo \\
\hline$i$ & Grau de Liberdade ou Corrente Elétrica \\
\hline$I_{1}, I_{2}$ & Momento de Inércia da Seção \\
\hline$J$ & Momento de Inércia \\
\hline$k$ & Rigidez da Mola \\
\hline$k_{1}$ & Rigidez Não Linear do NES \\
\hline$k_{l}$ & Coeficiente da Mola Linear \\
\hline$k_{n l}$ & Coeficiente da Mola Não Linear \\
\hline$l$ & Comprimento \\
\hline$L$ & Lagrangeana ou Comprimento \\
\hline$L(\dot{\varphi})$ & Torque de Acionamento \\
\hline$m$ & Concentração na Extremidade Superior das Colunas \\
\hline$m_{0}$ & Massa Desbalanceada \\
\hline$m_{1}$ & Massa da Estrutura \\
\hline$m_{2}$ & Massa do NES ou do Pêndulo \\
\hline$M$ & Massa a Meio Vão da Viga \\
\hline$N$ & Forças Não Conservativas ou Comprimento da Série Temporal \\
\hline$P$ & Potência Elétrica Instantânea \\
\hline$P_{0}$ & Amplitude da Força \\
\hline
\end{tabular}




\begin{tabular}{|c|c|}
\hline$P_{1}, P_{2}$ & Camadas de Material Piezoelétrico \\
\hline$P_{\text {med }}$ & Potência Elétrica Média \\
\hline$q$ & Carga Elétrica \\
\hline$q_{i}$ & Coordenada Generalizada \\
\hline$\dot{q}$ & Corrente Elétrica \\
\hline$r$ & Excentricidade \\
\hline$R$ & Resistência Elétrica \\
\hline$t, \tau$ & Tempo \\
\hline$T$ & Energia Cinética \\
\hline$V$ & Tensão Elétrica ou Energia Potencial \\
\hline$V_{1}$ & Tensão Aplicada a Armadura do Motor \\
\hline$V_{2}$ & Constante Específica do Motor \\
\hline$u, v, X$ & Deslocamentos \\
\hline$y$ & Função Logística \\
\hline$\Delta$ & Período de Amostragem \\
\hline$\epsilon$ & Parâmetro Adimensional \\
\hline$\theta$ & Acoplamento Piezoelétrico Linear \\
\hline$\Theta$ & Acoplamento Piezoelétrico Não Linear \\
\hline$\mu_{1}, \mu_{2}$ & Amortecimentos \\
\hline$\rho$ & Massa Específica ou Tempo Adimensional Elétrico \\
\hline$\rho_{2}$ & Parâmetro de Controle do Motor \\
\hline$\rho_{3}$ & Parâmetro Específico do Motor \\
\hline$\sigma_{1}, \sigma_{2}$ & Parâmetros de Sintonia \\
\hline$\tau$ & Tempo Adimensional \\
\hline$\phi$ & Deslocamento Angular do Pêndulo \\
\hline$\Phi$ & Função de Acoplamento Piezoelétrico \\
\hline$\varphi(t)$ & Deslocamento Angular do Rotor \\
\hline$\Psi$ & Wavelet Mãe \\
\hline$\omega_{1}, \omega_{2}$ & Frequências Naturais \\
\hline$\Omega$ & Frequência de Excitação \\
\hline
\end{tabular}




\section{SUMÁRIO}

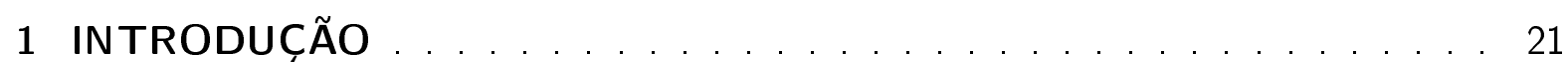

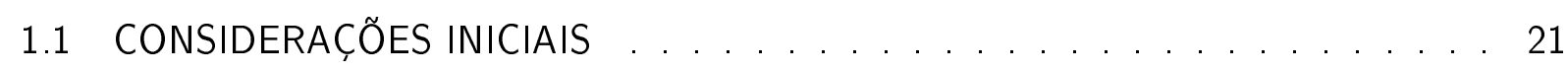

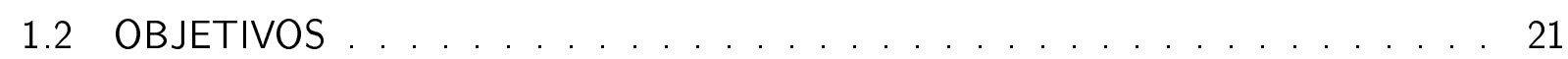

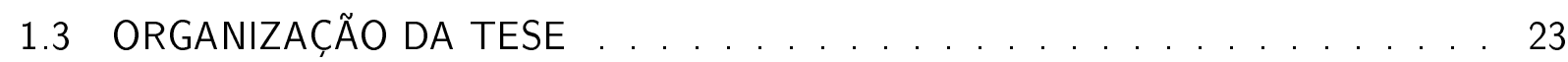

2 REVISÃO BIBLIOGRÁFICA . . . . . . . . . . . . . . . . . . . . . 25

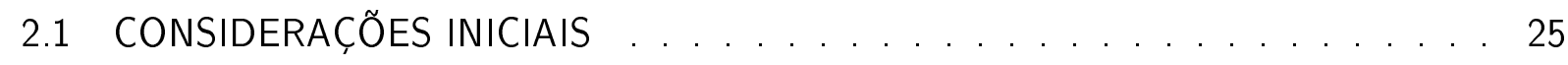

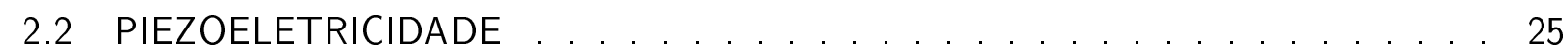

2.3 CAPTURA DE ENERGIA . . . . . . . . . . . . . . . . . . . . . . 27

2.4 SISTEMAS DE CAPTURA DE ENERGIA NÃO LINEARES . . . . . . . . . . . 30

3 MODELAGEM MATEMÁTICA DO SISTEMA . . . . . . . . . . . 41

3.1 CARACTERÍSTICAS . . . . . . . . . . . . . . . . . . . . . . . . . . . 41

3.2 EQUAÇÕES DO MOVIMENTO . . . . . . . . . . . . . . . . . . . . . . 42

3.3 CONTROLE PASSIVO DE VIBRAÇÕES . . . . . . . . . . . . . . . . . 46

3.3 .1 Pórtico com Controle Passivo (NES) . . . . . . . . . . . . . 46

3.3 .2 Pórtico com Controle Passivo por Pêndulo . . . . . . . . . . . . . . . 49

4 PÓRTICO SEM CONTROLE PASSIVO . . . . . . . . . . . . . . . . . . . 53

4.1 TRATAMENTOS PRELIMINARES $\ldots \ldots \ldots \ldots \ldots$

4.2 RESULTADOS NUMÉRICOS $\ldots \ldots \ldots \ldots \ldots$

5 PÓRTICO COM CONTROLE PASSIVO NES . . . . . . . . . . . . . . . 55

5.1 TRATAMENTOS PRELIMINARES . . . . . . . . . . . . . . . . . . 55

5.2 CONTROLE PASSIVO DAS OSCILAÇÕES UTILIZANDO O (NES) . . . . . . . 55

5.2.1 Aplicação da Estratégia de Controle Passivo (NES): Caso $e=0.4 \ldots 57$

5.2.2 Aplicação da Estratégia de Controle Passivo (NES): Caso $e=5.0 \ldots 58$

5.2 .3 Transferência de Energia . . . . . . . . . . . . . . . . . . . . 59

$5.3 \quad$ EFEITO DA VARIAÇÃO DOS PARÂMETROS . . . . . . . . . . . 63

5.3 .1 Variação do Paramâtro de Amortecimento $\alpha_{1} \ldots \ldots \ldots 63$

5.3 .2 Variação do Paramâtro de Amortecimento $\alpha_{2} \ldots \ldots$. . . . . . 66

5.3 .3 Variação do Paramâtro de Rigidez $\alpha_{3} \ldots \ldots \ldots$. . . . . . 67

5.3.4 Variação do Parâmetro de Rigidez Não Linear $\beta_{3} \ldots \ldots \ldots$

5.3 .5 Variação do Paramâtro $\delta_{1} \ldots \ldots \ldots \ldots \ldots 72$

5.4 RESUMO DOS RESULTADOS PARA O CONTROLE (NES) . . . . . . . . . 74 
6 PÓRTICO COM CONTROLE PASSIVO POR PÊNDULO . . . . . . . . 77

6.1 TRATAMENTOS PRELIMINARES . . . . . . . . . . . . . . . . . . . . . 777

6.2 CONTROLE PASSIVO DE OSCILAÇÕES USANDO UM PẾNDULO . . . . . 77

6.2.1 Aplicação da Estratégia de Controle Passivo: Caso $e=0.2 \ldots$. . . 79

6.2.2 Aplicação da Estratégia de Controle Passivo: Caso $e=0.42 \ldots$. . . . 80

6.2.3 Aplicação da Estratégia de Controle Passivo: Caso $e=0.7 \ldots 81$

6.2 .4 Transferência da Energia . . . . . . . . . . . . . . . . . 82

6.3 EFEITO DA VARIAÇÃO DOS PARÂMETROS DE RIGIDEZ E AMORTECIMENTO 87

6.3 .1 Variação do Parâmetro de Amortecimento $\alpha_{1} \ldots \ldots$. . . . . 87

6.3 .2 Variação no Parâmetro de Rigidez Não Linear $\beta_{3} \ldots \ldots$. . . . . . 89

7 ANÁLISE DINÂMICA POR WAVELETS . . . . . . . . . . . . . . . . . . 92

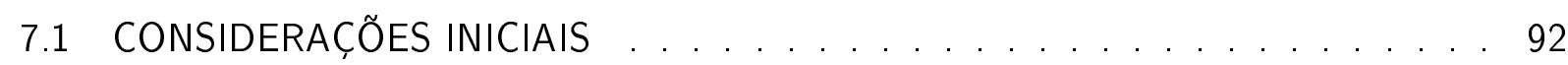

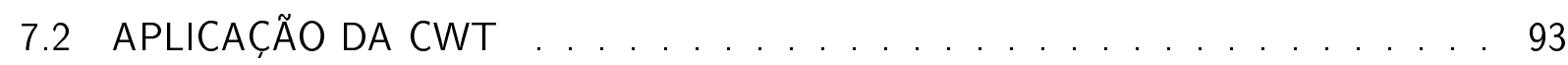

7.2.1 Modelo de Pórtico sem Controle Passivo . . . . . . . . . . . . . 98

7.2.2 Modelo de Pórtico com Controle Passivo (NES) $e=0.4$. . . . . . . 101

7.2.3 Modelo de Pórtico com Controle Passivo (NES) $e=5.0$. . . . . . . . 103

7.2.4 Modelo de Pórtico com Controle por Pêndulo $e=0.2 \ldots \ldots$

7.2.5 Modelo de Pórtico com Controle por Pêndulo $e=0.42 \ldots$. . . . . . 108

7.2.6 Modelo de Pórtico com Controle por Pêndulo $e=0.7 \ldots \ldots 11$

8 PÓRTICO COM SATURAÇÃO MODAL . . . . . . . . . . . . . . . . . 114

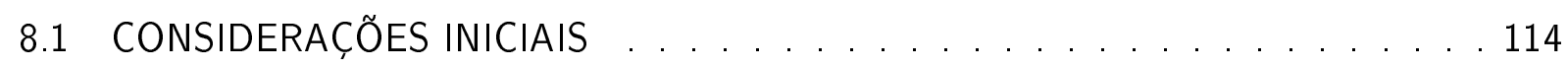

8.2 FENÔMENO DE SATURAÇÃO MODAL . . . . . . . . . . . . . . . . . 114

8.3 MODELO ESTRUTURAL . . . . . . . . . . . . . . . . . . . . 116

8.4 PROGRAMA DE ELEMENTOS FINITOS . . . . . . . . . . . . 118

8.5 RESULTADOS NUMÉRICOS . . . . . . . . . . . . . . . . . . . . . 120

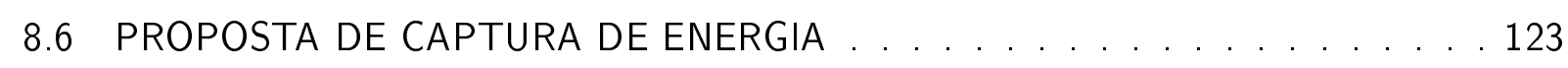

8.7 CONSIDERAÇÕES E CONCLUSÕES . . . . . . . . . . . . . . . 126

9 PROPOSTA DE UMA FUNÇÃO PARA O ACOPLAMENTO PIEZOELÉTRICO.

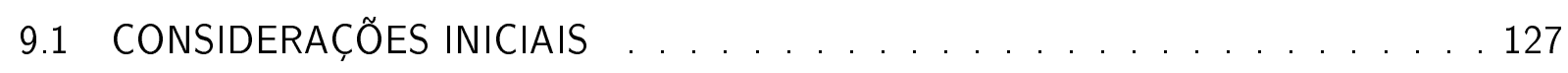

9.2 MODELO DE SISTEMA DE CAPTURA DE ENERGIA NÃO IDEAL . . . . . . 128

9.3 FUNCÃO DE APROXIMACุÃO PROPOSTA . . . . . . . . . . . . . . 128

9.4 SIMULAÇÕES NUMÉRICAS $\ldots \ldots \ldots \ldots$

10 CONCLUSÕES E TRABALHOS FUTUROS . . . . . . . . . . . 134 
10.1 CONCLUSÕES . . . . . . . . . . . . . . . . . . . . . . 134

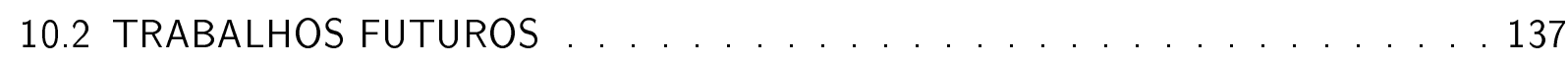

REFERÊNCIAS . . . . . . . . . . . . . . . . . . . . . . . . 138 


\section{INTRODUÇÃO}

\subsection{CONSIDERAÇÕES INICIAIS}

Inicialmente, apresentam-se neste capítulo a motivação do trabalho e os objetivos desta tese. Na sequência, descreve-se como o trabalho está organizado e o que será apresentado em seus capítulos.

\subsection{OBJETIVOS}

Uma das questões fundamentais em captura de energia (energy harvesting) utilizando materiais piezoelétricos está no fato de o sistema apresentar melhor desempenho quando é excitado em sua frequência natural. Quando a frequência de vibração difere ligeiramente desta, ocorrerá significante redução na potência capturada.

Muitas pesquisas têm sido realizadas num esforço para aumentar a faixa de frequência destes sistemas, com o objetivo de permitir sua operação de forma eficaz, em uma ampla faixa de frequências.

Uma possível maneira para atingir esse objetivo consiste na introdução de controles passivos que podem alterar o regime de vibração do sistema não ideal (NIS), por exemplo, pelo acoplamento de uma subestrutura com características de absorvedor de energia não linear, do inglês nonlinear energy sink (NES), ou um pêndulo.

A partir disso, o principal objetivo desta tese é propor e analisar as vibrações não lineares eletromecânicas de um modelo de sistema de captura de energia piezoelétrico não linear e não ideal, este deduzido a partir do modelo experimental construído por Garzeri (2001) utilizando uma estrutura aporticada do tipo shear building, como pode ser visto na Figura 1 . Onde, o sistema recebeu uma excitação externa do tipo não ideal, na qual um motor elétrico de corrente contínua (CC) com potência limitada foi acoplado à massa, com o objetivo de perturbar o sistema e promover oscilações. 
Figura 1 - Modelo Experimental Construído por Garzeri (2001)

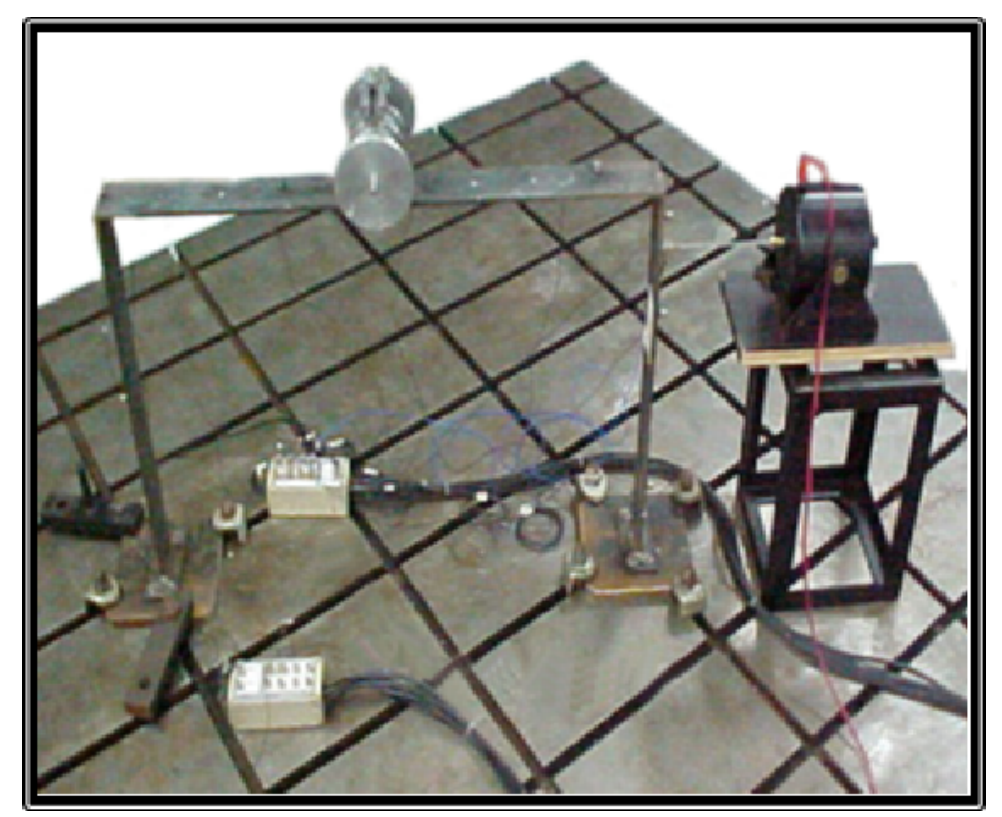

Fonte: (GARZERI, 2001)

A ilustração da Figura 2 representa um esquema para o sistema de captura de energia piezoelétrico, no qual em relação ao acoplamento do material piezoelétrico, o sistema leva em consideração as não linearidades inerentes ao material.

Figura 2 - Esquema de um Sistema Não Ideal (NIS) e Não Linear de Captura de Energia Piezoelétrico

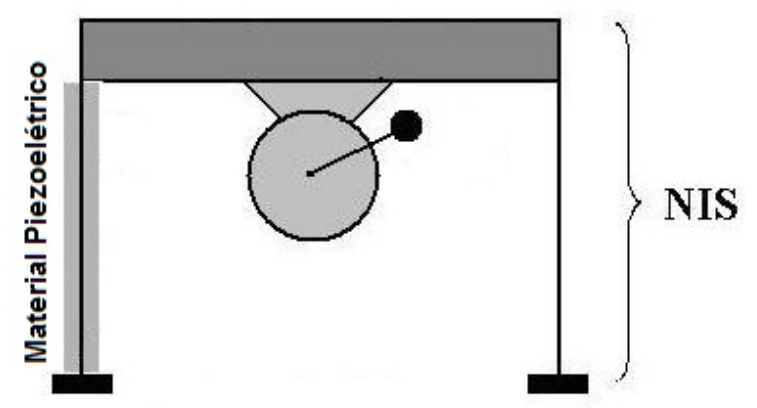

Fonte: Elaborada pelo próprio autor

Assim, os objetivos específicos desta tese resumem-se a:

- Por meio do uso de simulações numéricas, utilizando o Matlabß, determinar a eficiência do modelo proposto.

- Aplicar técnicas de controle passivo de vibrações para controlar o sistema e melhorar a sua eficiência na captura de energia, dentro de uma ampla faixa de vibrações. 
- Testar a estabilidade e controlabilidade do sistema, bem como apresentar a potência máxima e potência média de saída do sistema.

- Analisar a robustez do controlador por meio de uma análise de incertezas sobre os valores dos parâmetros.

- Analisar o fenômeno do bombeamento de energia (energy pumping) sobre o sistema não ideal (NIS) e o nonlinear energy sink (NES).

- Introduzir um pêndulo no modelo para verificar os efeitos do bombeamento de energia sobre o sistema de captura de energia.

- Analisar o fenômeno de saturação modal em um sistema do tipo pórtico com não linearidade geométrica e ressonância 2:1.

- Propor uma função matemática para melhorar a aproximação do coeficiente de acoplamento piezoelétrico não linear.

\subsection{ORGANIZAÇÃO DA TESE}

Esta tese está organizada em 10 capítulos, tendo como foco a modelagem e análise da resposta do sistema de captura de energia piezoelétrico não linear excitado por uma fonte não ideal.

No capítulo 1, apresentam-se os principais motivos, objetivos e a organização da tese.

O capítulo 2 apresenta a revisão bibliográfica, com uma introdução sobre piezoeletricidade, captura de energia de vibrações piezoelétricas, e os modelos que incluem as não linearidades na sua concepção.

No capítulo 3, é realizada a modelagem matemática do sistema não ideal NIS proposto, concebido com base em uma estrutura aporticada não ideal, em que, usando-se uma abordagem lagrangeana, são definidas as equações do movimento para o sistema. Também são apresentadas e modeladas duas possibilidades de estratégia de controle passivo para meIhorar a eficiência da captura de energia elétrica do sistema não ideal de captura de energia: a primeira, utilizando o absorvedor passivo (NES) e a segunda, utilizando um pêndulo. $\mathrm{Na}$ sequência, são adimensionalizadas as equações e reescritas em espaço de estados para facilitar as simulações numéricas.

As simulações numéricas para o (NIS) sem controle foram realizadas no software

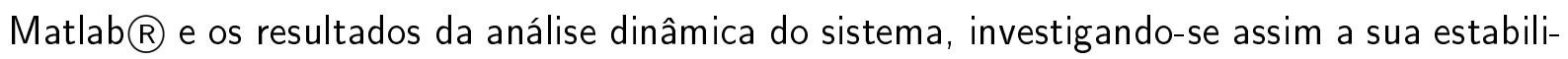
dade, foram obtidos por meio do gráfico de plano de fase, mapa de Poincaré, dos históricos de 
deslocamento no tempo e do cálculo da potência capturada. Esses resultados são apresentados no capítulo 4.

No capítulo 5, o processo irreversível de transferência de energia no sistema acoplado, consistindo do sistema não ideal (NIS) e do controle passivo (NES), é examinado na forma adimensional, considerando-se a troca de energia instantânea com respeito à energia total do sistema, para a escolha do parâmetro de controle passivo. É realizada uma análise de sensibilidade nos valores dos parâmetros de rigidez e amortecimento, a fim de verificar a influência destes na captura de energia. A verificação da estabilidade é feita por meio dos gráficos de planos de fase, mapas de Poincaré, dos históricos de deslocamento no tempo, diagramas de bifurcação e do cálculo da potência instantânea e potência média. Também o fenômeno de bombeamento de energia (energy pumping) é investigado, bem como seu efeito na melhora da captura de energia do sistema. Dois casos foram encolhidos para estudo. No primeiro, busca-se alcançar a maior potência média capturada e, no segundo caso, deseja-se o movimento periódico do sistema controlado.

No capítulo 6, seguindo a metodologia do capítulo anterior, são apresentados os resultados da simulação numérica do sistema não ideal (NIS) com controle passivo por pêndulo. Foram escolhidos três casos para estudo. Dois buscam manter o sistema em uma órbita periódica estável e um busca alcançar a maior potência média capturada, mesmo com o sistema operando em regime caótico.

Os resultados do uso da análise wavelet para identificação de comportamento regular e irregular em sistemas dinâmicos no domínio da frequência, por meio da aplicação da transformada wavelet contínua (CWT) nos modelos de sistema de captura de energia piezoelétricos não-ideais sem controle e com controle passivo acoplados, são apresentados no capítulo 7 .

O capítulo 8 apresenta um estudo de caso especial, considerando a aplicação de uma estrutura aporticada com comportamento geometricamente não linear, como um sistema de captura de energia. É apresentado o fenômeno de saturação modal, com troca de energia entre os modos de vibração acoplados em uma configuração de ressonância 2:1. Utilizou-se uma análise por elementos finitos (FEA) para obter as respostas do sistema.

No capítulo 9, é apresentada a proposta de uma função logística obtida pelo método dos mínimos quadrados para a aproximação do coeficiente de acoplamento piezoelétrico não linear.

Por fim, no capítulo 10, são apresentadas as considerações finais, conclusões e recomendações de futuros trabalhos. 


\section{REVISÃO BIBLIOGRÁFICA}

\subsection{CONSIDERAÇÕES INICIAIS}

Neste capítulo, apresentam-se a revisão bibliográfica, com uma introdução sobre piezoeletricidade e captura de energia, e alguns dos principais sistemas de captura de energia de vibrações piezoelétricos, destacando-se aqueles que consideram o efeito das não linearidades piezoelétricas em sua concepção.

\subsection{PIEZOELETRICIDADE}

Segundo Iliuk (2012), a piezoeletricidade é uma forma de acoplamento entre os comportamentos mecânico e elétrico de certos materiais com propriedades piezoelétricas, que possuem a capacidade de se tornarem eletricamente polarizados, se forem submetidos a algum tipo de tensão mecânica ou, ao inverso, apresentarem alguma deformação mecânica, quando experimentam uma carga elétrica.

O efeito piezoelétrico divide-se em: efeito piezoelétrico direto e efeito piezoelétrico inverso. O primeiro percebe-se quando uma deformação mecânica é aplicada ao material, sendo esta convertida em uma carga elétrica. O segundo é definido quando se aplica um potencial elétrico ao material e esse é convertido em deformação mecânica.

Segundo Jalili (2010), quando um material piezoelétrico é comprimido (ou seja, mecanicamente tensionado), recolhe uma carga elétrica nos eletrodos localizados em sua superfície. Isso é chamado de efeito piezoelétrico direto e foi demonstrado pela primeira vez pelos irmãos Curie, em 1880. Se o mesmo material é submetido a uma queda de tensão (ou seja, uma diferença de potencial elétrico aplicado em todos seus eletrodos), ele deforma mecanicamente. Isso é chamado de efeito piezoelétrico inverso e foi deduzido matematicamente (após a descoberta do efeito piezoelétrico direto), a partir dos princípios fundamentais da termodinâmica, por Gabriel Lippmann em 1881 e, em seguida, confirmado experimentalmente pelos irmãos Curie (ILIUK, 2012).

Silva et al. (2009) demonstram que os materiais piezoelétricos, ao serem submetidos a um esforço mecânico, apresentam um momento elétrico com intensidade proporcional ao esforço aplicado. Conforme o tipo de esforço mecânico, se de tração ou de compressão, aplicado ao material piezoelétrico, o sentido da polarização resultante é inverso ao da aplicação de um campo elétrico a um cristal. Dessa forma, o efeito piezoelétrico inverso apresenta uma deformação do cristal, que é tanto maior quanto o campo elétrico exercido e depende do sentido desse campo. 
Ainda segundo Silva et al. (2009), na direção em que ocorre uma extensão positiva do cristal, verifica-se uma extensão negativa, e vice-versa, quando se modifica o sentido do campo atuante.

Esses efeitos são representados na Figura 3.

Figura 3 - a) Efeito Piezoelétrico Direto; b) Efeito Piezoelétrico Inverso

Efeito Direto
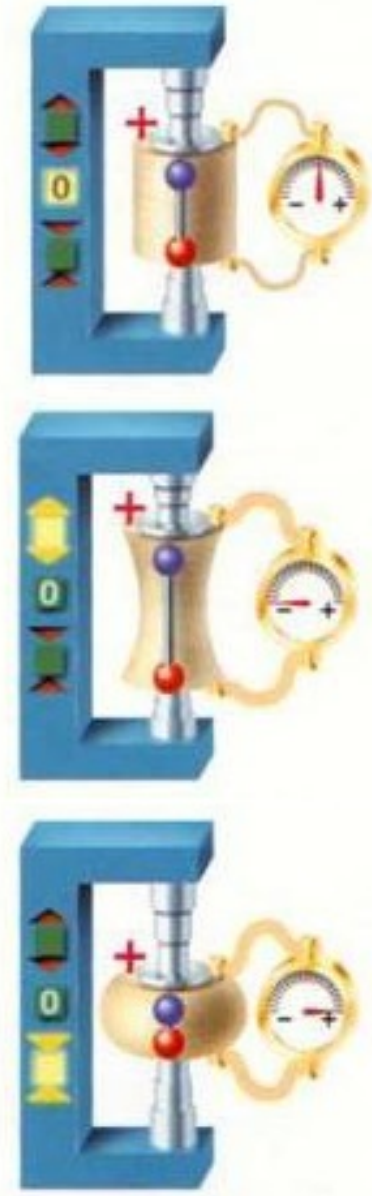

(a)

\section{Efeito Inverso}
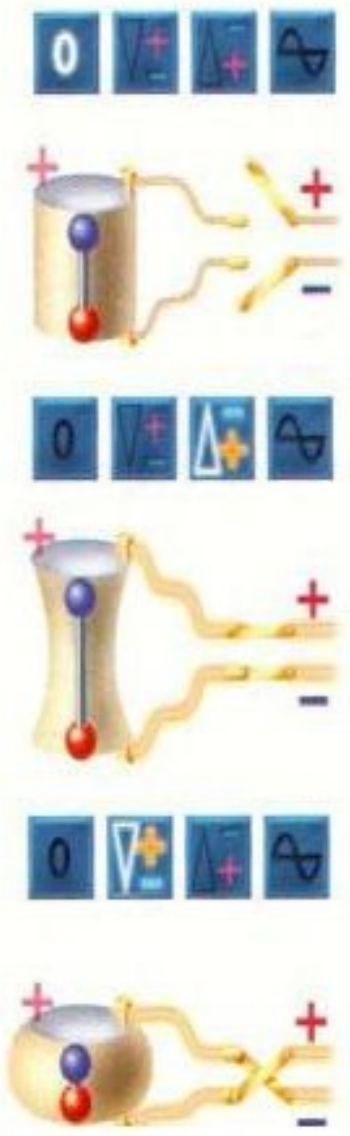

(b)

Fonte: (SILVA et al., 2009)

Conforme explicitam Erturk, Hoffmann e Inman (2009), é preciso notar que os dois efeitos coexistem normalmente em um mesmo material piezoelétrico. Sendo assim, mesmo para uma aplicação em que o efeito piezoelétrico direto é o foco (caso da captura de energia), ignorar a presença do efeito piezoelétrico inverso seria termodinamicamente inconsistente.

Segundo Cottone (2007), os materiais que apresentam propriedades piezoelétricas estão amplamente disponíveis em muitas formas, podendo ser naturais, como por exemplo: cristal de quartzo, cana-de-açúcar, sal de Rochelle. 
Ainda, podem ser artificialmente produzidos como os materiais sintéticos que demonstram as propriedades piezoelétricas, os quais surgiram em meados da década de 50 , podendo ser materiais compostos piezocerâmicos, como por exemplo o titanato zirconato de chumbo (PZT), titanato de chumbo (PbTiO3), zirconato de chumbo (PbZrO), compósitos como o titanato de bário (BaTiO3), as películas finas produzidas via um processo de pulverização de óxido de zinco $(\mathrm{ZnO})$ sobre uma tela para impressão de filmes finos baseados em talcos piezocerâmicos, assim como os polímeros, tais como fluoreto de polivinilideno (PVDF), material nanoestruturado como o grafeno piezoelétrico, resultante de pesquisas com parceria da Universidade de Aveiro, Universidade de Campinas e Universidade dos Urais (Rússia).

As vantagens dos PZTs para aplicação em engenharia se devem às suas características físicas e químicas, uma vez que são materiais que possuem dureza e densidade elevadas e podem ser produzidos em qualquer tamanho e formato. Ainda, são inertes quimicamente, apresentando resistência às condições atmosféricas e à umidade. Além disso, quando se aplica uma vibração ao material, uma tensão de saída pode ser obtida diretamente.

Uma descrição mais completa das propriedades dos materiais piezoelétricos pode ser obtida pela leitura dos trabalhos de Preumont (2006), Heywang, Lubitz e Wersing (2008). Priya e Inman (2009), Jalili (2010), sem desmerecer outros.

\subsection{CAPTURA DE ENERGIA}

O interesse por novas fontes limpas de energia aumentou nos últimos anos, porque a indústria de tecnologia e microeletrônica tem necessidade de uma fonte de energia menor e mais eficiente, para a concepção de modernos sistemas de tecnologia embarcada, redes de sensores remotos e novas tecnologias emergentes, como a internet das coisas ou, em inglês internet of things (loT) (PRIYA; INMAN, 2009).

Tendo por princípio que a eletricidade é fornecida por meio de uma usina ou de uma bateria, observa-se que esses fatores são limitantes para a expansão tecnológica, ora pela exigência de uma rede elétrica, ora por uma consequente necessidade de substituição das baterias, segundo Fujitsu Laboratories (2010). Assim, nos últimos anos, a ideia de utilizar energia ambiente nas formas de luz, calor, vibrações, ondas de rádio etc., tornou-se mais atraente, e muitos métodos para produzir eletricidade a partir desses diferentes tipos de fontes de energia têm sido desenvolvidos. Com isso, a substituição das baterias e instalação de cabos de alimentação pode ser eliminada com o uso de sistemas de captura de energia do ambiente (ILIUK, 2012). Um exemplo do processo de captura de energia e suas possíveis fontes e aplicações pode ser visto na Figura 4

Entre as possíveis fontes de energia do ambiente para captura, a energia cinética é uma 
Figura 4 - Processo de Captura de Energia do Ambiente

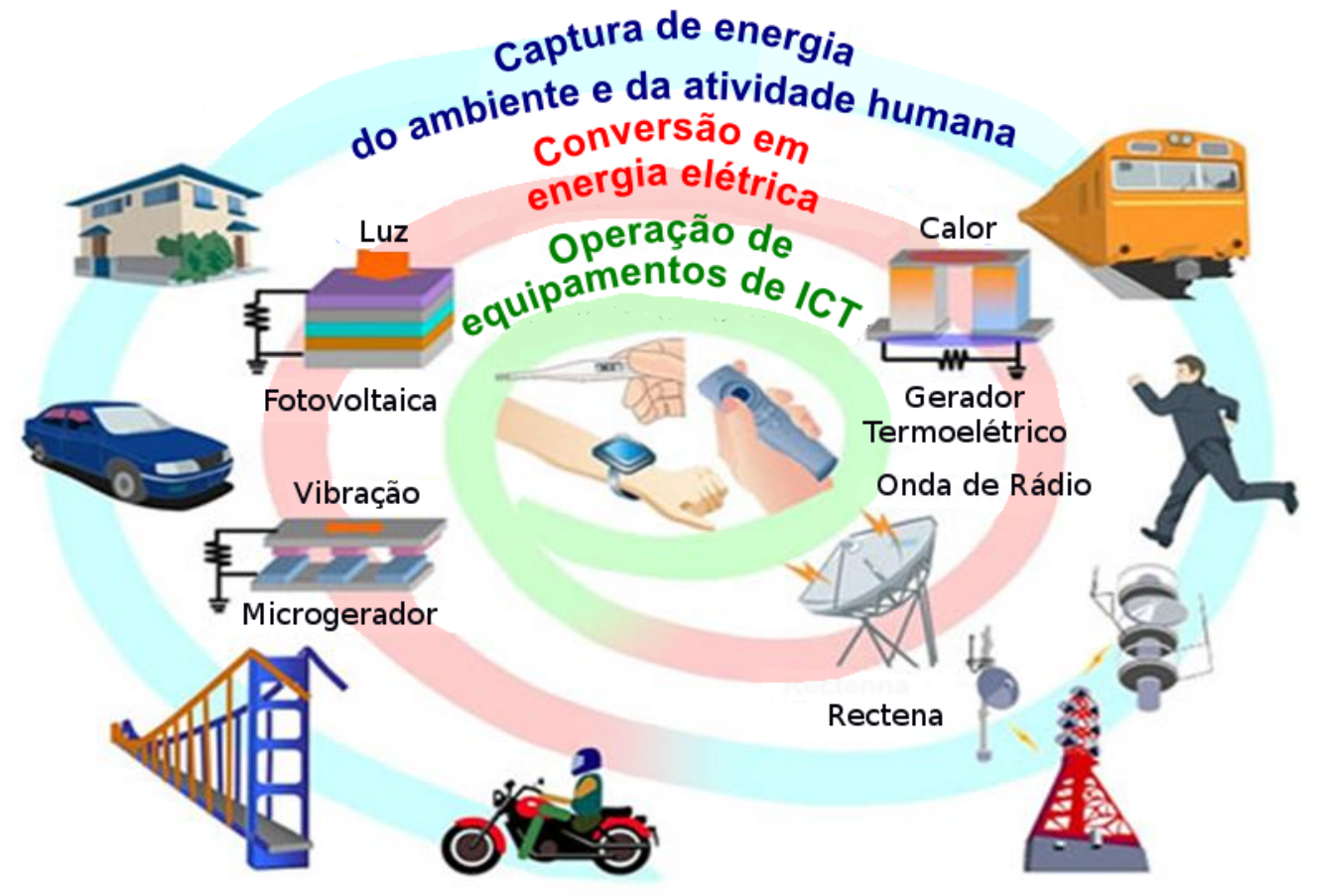

Fonte: (Fujitsu Laboratories, 2010)

das que se encontram mais prontamente disponíveis.

O princípio da captura da energia cinética é o movimento ou a deformação de uma estrutura contida dentro do sistema de captura de energia, e foi inicialmente proposto por Williams e Yates (1996). Nesse princípio, o deslocamento ou deformação pode ser convertido em energia elétrica por meio de métodos de transdução da energia de vibrações, como: piezoelétrico (PRIYA; INMAN, 2009), eletrostático (BEEBY et al., 2007), eletromagnético (MITCHESON et al., 2004), magnetoestritivo (COTTONE, 2007) ou polímeros electret (SUZUKI, 2008). Cada método alcança menor ou maior nível de eficiência, dependendo do tipo de escala de tamanho e frequência de vibração a que é submetido (PRIYA; INMAN, 2009).

Segundo Priya e Inman (2009), Erturk e Inman (2011b), Heywang, Lubitz e Wersing (2008), especial atenção tem sido dedicada a sistemas que utilizam elementos piezoelétricos como meio de transdução de energia. Chtiba et al. (2010) e De Marqui, Erturk e Inman (2009) também concluíram que o principal método de captura de energia é com a utilização de materiais piezoelétricos.

Dentre os modelos mais estudados para concepção de sistemas de captura de energia piezoelétricos, a viga em balanço (cantilever) é uma das estruturas preferidas para a conversão de energia cinética em energia elétrica. A viga tem uma ou as duas superfícies cobertas por uma película de material piezoelétrico. Esta última configuração é dita ser do tipo bimorph, 
uma das mais estudadas na literatura atual (DUTOIT; WARDLE, 2007).

Em um sistema de captura de energia piezoelétrico, a estrutura é planejada de forma a ser flexionada com a vibração do ambiente. Assim, a película de material piezoelétrico será comprimida e ocorrerá a conversão de energia, segundo Sodano, Park e Inman (2004), Anton e Sodano (2007). Cottone, Vocca e Gammaitoni (2009).

Conforme Erturk, Hoffmann e Inman (2009), a maior potência de saída ocorrerá quando a estrutura vibrar na sua frequência de ressonância, o que explica a escolha pela viga, uma vez que esta possui menores frequências de ressonância, as quais podem ser reduzidas ainda mais, pela adição de uma massa na sua extremidade livre.

Com isso, muitos esforços têm sido realizados por vários pesquisadores, com o intuito de encontrar a melhor configuração para esses sistemas e os materiais adequados, bem como otimizar seus projetos para produzir a potência máxima sob determinadas condições ambientais, de acordo com Chtiba et al. (2010), De Marqui, Erturk e Inman (2009).

De acordo com Triplett e Quinn (2009), uma série de diferentes mecanismos de acoplamento eletromecânico foi desenvolvida para sistemas de captura de energia piezoelétricos.

Devido às leis constitutivas dos materiais piezoelétricos, que apresentam uma forte dependência entre a tensão (esforço mecânico) aplicada e o campo elétrico desenvolvido, como demonstrado por DuToit e Wardle (2007), Twiefel et al. (2007), vários autores têm incorporado a seus modelos de sistema de captura de energia o papel das não linearidades piezolétricas no acoplamento eletromecânico, durante o processo de design (TRIPLETT; QUINN, 2009). Com isso, a previsão da potência elétrica de saída pode ser melhorada e o desempenho do sistema, de maneira geral, pode ser otimizado.

A principal vantagem da inclusão das não linearidades nos sistemas de captura de energia é a capacidade de conversão de energia sobre uma ampla faixa de frequência das vibrações. Como exemplo de imposição de não linearidades nos sistemas de captura do tipo viga engastada em balanço, tem-se os trabalhos de Stanton, McGehee e Mann (2010), Cottone, Vocca e Gammaitoni (2009), Mann e Sims (2009), Erturk, Hoffmann e Inman (2009), sem desmerecer outros, nos quais os autores utilizam a fixação de materiais magnéticos na extremidade livre.

Já as não linearidades inerentes aos materiais piezoelétricos foram consideradas nos trabalhos de Crawley e Anderson (1990), Wagner e Hagedorn (2002), Triplett e Quinn (2009). lliuk et al. (2011a), Karami e Inman (2011), Iliuk (2012), Iliuk et al. (2013a), sem desmerecer outros. 


\subsection{SISTEMAS DE CAPTURA DE ENERGIA NÃO LINEARES}

Dentre os trabalhos que incorporam as não linearidades nos sistemas de captura de energia, destacam-se alguns, citados a seguir.

No trabalho de Mann e Sims (2009), um sistema de captura de energia na forma de um oscilador com ressonância ajustável foi obtido por meio da inclusão de forças de levitação magnéticas restauradoras. Modelou-se matematicamente o sistema na forma de uma equação de Duffing, considerando-se uma excitação harmônica da base. As simulações numéricas do sistema não linear apresentaram como resposta oscilações consideravelmente grandes para uma ampla faixa de frequências, tendo forte dependência do fator de amortecimento, e efeito do tipo "mola dura" (THOMPSON; STEWART, 2002) foi utilizado para ampliar a faixa de frequências. Contudo, observou-se a limitação de que a resposta somente pode ampliar a banda de frequência em uma direção.

Stanton, McGehee e Mann (2009) revisaram o problema proposto por Mann e Sims (2009) e propuseram um sistema similar que superou a limitação do anterior, por meio da introdução das interações magnéticas não lineares, apresentando o efeito de "mola dura", bem como o efeito de "mola mole" (THOMPSON; STEWART, 2002), e com isso habilitando o sistema a obter uma ampliação da resposta em frequência, com sentido agora bidirecional. $O$ sistema demonstrou ser eficiente na captura de energia por meio de vibrações com variação lenta.

No trabalho de Mann e Owens (2009), um sistema de captura de energia não linear com potêncial duplo (biestável) por meio de interações magnéticas foi investigado a partir de testes teóricos e experimentais, demonstrando que o potencial duplo pode ser utilizado para ampliar a resposta do sistema. O mesmo oscilador com potencial duplo foi investigado por Stanton, McGehee e Mann (2010), que obtiveram um modelo não linear completo, por meio de uma formulação analítica magnética e realizando adequação das expressões modais relacionadas com descontinuidades nas camadas piezoelétricas. Experimentalmente, foram validados para uma ampla faixa de frequência os valores previstos numericamente pelo modelo. Também foi realizada uma análise sobre um parâmetro de bifurcação para verificar a sensibilidade à excitação do ambiente. Algumas melhorias foram aplicadas ao modelo posteriormente, por meio da inclusão de dissipações não lineares e a influência da não linearidade cúbica no sistema realizadas por Stanton, Owens e Mann (2012). Pela aplicação do método do balanço harmônico, pode-se prever de forma analítica a existência dessas não linearidades, bem como testar a estabilidade e influência da variação dos parâmetros do potencial não-harmônico (poços quárticos duplos) para o sistema de captura de energia piezoelétrico. Segundo os autores, os movimentos do sistema apresentam sensibilidade às variações do amortecimento não linear, 
cargas de impedância e do acoplamento eletromecânico, e os autores chegaram à conclusão de que existe uma carga de impedância e acoplamento ótimos que maximiza a extração de energia, tanto para oscilações dentro dos "poços" do potencial quanto entre eles.

A modelagem de um sistema microeletromecânico (MEMS) para captura de energia de vibrações mecânicas em forma de viga em balanço do tipo cantilever com potêncial duplo foi realizada por Andò et al. (2010). O sistema piezomagnetoelástico apresenta uma dinâmica não linear por meio da colocação de magnetos fixos na extremidade livre da viga, permitindo que o sistema salte entre dois estados estáveis, em resposta às oscilações externas. Como esperado, o estudo demonstrou que o sistema não linear exibe o comportamento de um filtro "passa-baixa", desejável para captura de energia do ambiente a baixas frequências.

Erturk, Hoffmann e Inman (2009) desenvolveram um sistema de captura piezomagnetoelástico baseado no modelo piezoelástico proposto por Moon (1987), com o objetivo de ampliar a captura de energia do sistema. As equações não lineares que regem o movimento do sistema eletromecânico são do tipo Duffing com potencial duplo. O sistema apresenta em suas simulações numéricas um movimento caótico demonstrando a possibilidade de capturar energia sobre as órbitas de alta energia que foram obtidas. Segundo os autores, um aumento de $200 \%$ na amplitude de tensão foi obtido para o sistema operando em circuito aberto.

Nguyen (2013), em sua tese, investiga um método para estender a largura de banda dos dispositivos de captura de energia, explorando não linearidades de suspensões, em especial, em sistemas com características de potencial duplo com "mola mole", para ampliar a largura de banda de captura. As características não lineares das molas foram obtidas exclusivamente por meio do seu desenho geométrico, sem depender de recursos extras, como ímãs permanentes, que podem interferir no ambiente. Dois modelos de sistemas de captura de energia eletrostática foram projetados, fabricados e caracterizados com base em sistemas MEMS. O primeiro utiliza uma mola em ângulo quádruplo, o qual exibe uma característica de "mola mole", com aumento de potência de saída média, com tolerância a variações tanto na frequência central como na largura de banda de vibração. Já o segundo modelo MEMS foi concebido utilizando-se molas curvas, as quais apresentam um comportamento assimétrico biestável, mediante um design geométrico. Os resultados experimentais demonstram que o sistema de captura se adapta de forma satisfatória para extrair energia a partir de um amplo espectro de vibrações ou a partir de fontes com uma vasta gama de variabilidade no espectro.

Uma revisão da conversão da energia vibracional em energia elétrica pelo uso de sistemas de captura de energia piezoelétricos com potencial duplo (biestáveis) é o foco de Harne e Wang (2013) em seu trabalho. Os autores destacam algumas características destes sistemas, como por exemplo uma ação snap-through, que poderia causar movimentos de grande amplitude na transição de um estado para outro do sistema biestável e com isso aumentar 
drasticamente a captura de energia. Devido às características não lineares, o sistema de captura pode ser eficaz dentro de uma ampla largura de banda de frequência. Por fim, são apresentados comentários, relatórios e um quadro analítico comum para a dinâmica dos sistemas eletromecânicos biestáveis, cujos principais resultados são fornecidos e uma vasta gama de sistemas de captura de energia com potencial duplo são descritos.

Daqaq et al. (2014) apresentam uma revisão sobre o conceito de captura de energia de vibrações. Os autores destacam que, enquanto o sistema de captura de energia de vibrações tem recebido a maior parte da atenção na literatura, um grupo significativo de pesquisadores tem se dedicado à investigação do conceito de inclusão intencional de não linearidades para a transdução em banda larga. Quando se comparam sistemas de captura lineares que operam em ressonância em relação a sistemas não lineares, verifica-se que esses últimos possuem largura de banda de frequência em estado estacionário mais ampla, o que leva a uma crença comum de que a inclusão das não linearidades pode ser utilizada para melhorar o desempenho da captura de energia do ambiente. Mediante uma revisão da literatura aberta, os autores destacam o papel das não linearidades na transdução de sistemas de captura de energia em diferentes tipos de excitações e investigam as condições, em termos da natureza da excitação e forma potencial, em que essas não linearidades podem ser benéficas para captura de energia.

No trabalho de Wagner e Hagedorn (2002), faz-se uma abordagem inicial sobre os efeitos das não linearidades inerentes ao material piezoelétrico, por meio de uma formulação não linear das equações constitutivas piezoelétricas. Os autores identificaram os efeitos da histerese piezoelétrica, utilizando um modelo de viga piezoelétrica excitada por uma tensão alternada no modo de operação do transdutor piezoelétrico $d_{31}$. Uma análise entre a relação do módulo de Young e o fator piezoelétrico $d_{31}$ como parâmetros não constantes foi realizada. Os parâmetros não lineares foram obtidos, e os resultados numéricos foram comparados com os dados experimentais. Como conclusão, os autores demonstram que os efeitos das não linearidades do material piezoelétrico podem ter influência significativa no desempenho dos sistemas de captura de energia.

Triplett e Quinn (2009) investigaram em seu trabalho analiticamente os efeitos das não linearidades no acoplamento eletromecânico, bem como sua influência sobre a captura de energia, em contraste com o sistema de captura linear de energia. O sistema de captura não linear foi modelado como um oscilador Duffing forçado. A não linearidade foi atribuída às leis constitutivas dos materiais piezoelétricos, especificamente sobre a relação não linear entre a tensão (esforço mecânico) e o campo elétrico no material piezocerâmico (ILIUK, 2012). Os resultados demonstram que os efeitos da não linearidade ocorrem no caso da variação da amplitude de excitação. Os autores então aproximaram os coeficientes de acoplamento piezoelétricos linear e não linear por meio de função matemática, com base nos resultados ex- 
perimentais de Crawley e Anderson (1990). Foram aproximados o coeficientes de acoplamento linear e não linear piezoelétrico. Essa função impõe uma não linearidade fraca no componente mecânico, e uma não linearidade forte no circuito elétrico. Conclui-se que a energia capturada pelo sistema pode ser melhorada por meio da inclusão das não linearidades no modelo.

Erturk e Inman (2011a) realizaram uma comparação entre dois sistemas de captura de energia, sendo um do tipo piezoelástico e outro do tipo piezomagnetoelástico. Análises teórica e experimental revelam que o segundo sistema citado apresenta uma amplitude com faixa mais larga para a resposta de tensão. Os diagramas de fase para ambos os sistemas eletromecânicos foram comparados, e observou-se uma relevante vantagem para o sistema piezomagnetoelástico. Também os autores compararam a resposta periódica e a resposta caótica dos dois sistemas, observando que a tensão de saída em ambos os casos apresentou comportamento similar.

Um sistema de captura de energia eletromagnético não linear foi modelado por meio da equação Duffing, e os resultados foram comparados com dados experimentais (BARTON; BURROW; CLARE, 2010). Os autores demonstraram que os sistemas de captura de energia não lineares, operando em uma ampla faixa de frequências de ressonância, podem superar certas limitações inerentes aos sistemas de captura lineares; e que, além disso, por meio de uma variação na carga resistiva, a faixa de frequência de excitação pode ser aumentada. Como conclusão, os autores demonstram que ressonâncias super-harmônicas presentes em frequências inferiores à frequência natural permitem que os sistemas de captura continuem sendo eficientes na captura de quantidades medianas de energia.

Daqaq et al. (2009) propuseram um modelo de sistema de captura de energia do tipo viga cantilever excitado parametricamente. Os autores consideram as não linearidades geométricas, de inércia e as não linearidades referentes à interação ar-estrutura. Utilizando o método das múltiplas escalas, uma solução analítica aproximada foi encontrada para a resposta da viga, tensão, resistência de carga e potência elétrica capturada. A solução foi obtida considerando-se a região próxima da primeira ressonância paramétrica. Utilizou-se a solução obtida para investigar os efeitos de acoplamento eletromecânico do sistema. Ainda, segundo os autores, existe um valor ótimo para o coeficiente de acoplamento e a carga resistiva que maximiza a potência de saída. Esses parâmetros podem afetar as características da faixa de frequência, ativando a ressonância paramétrica.

Mclnnes, Gorman e Cartmell (2008) investigaram os fenômenos de ressonância estocástica com o intuito de melhorar o desempenho de um sistema de captura de energia não linear com potencial duplo. Quando foi inclusa uma força periódica de excitação no sistema de vibrações, a potência média de saída foi superior em relação ao caso em que tal força não foi aplicada. 
Seguindo o mesmo raciocínio, Ferrari et al. (2010) desenvolveram um sistema de captura de energia semelhante, e acoplaram à viga um par de magnetos permanentes para criar um sistema com potêncial duplo (biestável) em resposta a excitações aleatórias. Por meio de simulações utilizando vibrações de ruído branco, verificaram-se as melhorias já esperadas na resposta do sistema. Os ensaios experimentais realizados pelos autores aferindo as deflexões sofridas pela viga, bem como a tensão obtida na saída pelo acréscimo de vários graus de não linearidade no sistema, demonstram que o desempenho é melhorado ao se considerar o sistema com potencial duplo.

Litak, Friswell e Adhikari (2010) investigaram um sistema de captura de energia não linear com características piezomagnetoelásticas com excitação de ruído branco em banda larga. Para uma excitação harmônica variada lentamente em frequência, o sistema de captura apresentou aumento na potência de saída. A potência máxima do sistema foi obtida via excitação aleatória.

Daqaq (2010) realizou uma comparação entre excitações aleatórias e harmônicas em um sistema de captura de energia modelado como um oscilador Duffing. Para excitações com ruído branco gaussiano, não se observou influência das não linearidades, como a rigidez sobre a potência capturada do sistema. Isso não aconteceu para excitações de ruídos coloridos. Já alterações na inércia e no amortecimento podem melhorar a resposta do sistema sob excitação gaussiana.

Uma análise sobre os benefícios do ruído e da não linearidade em sistemas de captura de energia piezoelétricos foi realizada por Gammaitoni, Neri e Vocca (2010), utilizando vibrações aleatórias, em que o sistema foi modelado por meio de equações diferenciais não lineares estocásticas. Segundo os autores, as não linearidades, bem como o ruído, podem trazer benefícios para o funcionamento do sistema, e, mediante a devida escolha da não linearidade, é possível maximizar a potência capturada.

Karami e Inman (2011) utilizaram sistemas de captura de energia híbridos que possuem acoplamento eletromecânico piezoelétrico e eletromagnético para estabelecer um método que aproxima de forma unificada as características dos sistemas de captura de energia lineares, fracamente não lineares e não lineares de potencial duplo. Foram empregadas técnicas de perturbação e integrações numéricas para verificar a precisão do método, e chegou-se à conclusão de que este reduziu o esforço computacional em uma ordem de magnitude na análise de alguns sistemas que apresentam biestabilidade. Os autores demonstram que, projetando-se o sistema de captura de energia para operar no ciclo limite, um aumento em uma ordem de magnitude na potência capturada pode ser obtido.

As respostas não lineares de um sistema de captura de energia piezoelétrico utilizando PZT-5A em uma configuração do tipo bimorph foram investigadas por Stanton, McGehee e 
Mann (2010). Os autores mostram que, mesmo com o movimento geometricamente linear, o sistema apresenta um comportamento intrinsecamente não linear próximo das frequências de ressonância. Observou-se também a presença de um mecanismo dissipativo não linear na resposta do sistema.

Um modelo piezoelétrico não linear para captura de energia foi proposto e validado experimentalmente por Stanton et al. (2010). O modelo destaca a importância das não linearidades inerentes ao material piezoelétrico serem incorporadas ao sistema, não se limitando a efeitos elásticos de ordem superior, como também ao acoplamento não linear do circuito. A amplitude e a banda da resposta em frequência são restringidas pelo mecanismo de amortecimento não linear. A partir de um algoritmo de otimização não linear de mínimos quadrados e utilizando-se uma solução analítica aproximada obtida por meio da aplicação do método do balanço harmônico, os coeficientes não lineares são identificados e otimizados.

Stanton et al. (2012) analisaram a influência das características não lineares do PZT5A e do PZT-5H em um sistema de captura de energia piezoelétrico. O sistema tipo viga foi excitado em altas e baixas frequências, com a inclusão de massas de provas sucessivamente maiores sendo adicionadas. Os autores identificaram, por meio das relações constitutivas dos materiais piezoelétricos, uma forma de explicar a criticalidade do amortecimento não linear. O sistema tem como principal fonte de não linearidade a elasticidade, e, na ausência da massa de prova, uma não linearidade cúbica representa de forma satisfatória o comportamento não linear.

A resposta da simulação numérica de um sistema de captura de energia piezoelétrico biestável atuando sobre vibrações ambientais reais medidas é apresentada por Vocca et al. (2012). Os autores investigaram um método que explora as características dinâmicas de osciladores estocásticos para captura de energia. Tanto para vibrações em casos reais como na presença de ruído branco, o método proposto mostra-se superior aos osciladores lineares. Os resultados das simulações confirmam os desempenhos superiores desta abordagem, e conclui-se que os resultados também podem ser aplicados a sistemas de captura indutivos e capacitivos.

Ali et al. (2011) investigaram a captura de energia piezomagnetoelástica não linear sob uma excitação aleatória de banda larga. Analisaram os efeitos e incertezas paramétricas no sistema eletromecânico e apresentaram uma formulação explícita como aproximação dos parâmetros elétricos ótimos para maximizar a potência capturada. A potência máxima se reduz com o aumento das incertezas, bem como a frequência ótima. Uma forte influência sobre a energia capturada é observada, devido ao coeficiente de acoplamento e da frequência.

Friswell et al. (2012) investigaram um sistema de captura de energia do tipo viga cantilever disposta verticalmente, com uma configuração piezoelástica não linear, sendo anexada uma massa de prova na extremidade livre. O sistema sofre excitações na direção transversal 
a sua base. Para grandes deformações, o sistema apresenta comportamento não linear. A massa é ajustada de tal modo que a viga apresenta um perfil de curvatura quase totalmente dobrado, com frequência de ressonância baixa. Essa configuração é a mais adequada na visão dos autores que simularam numericamente as equações do modelo e posteriormente validaram experimentalmente o sistema, apresentando a potência máxima capturada.

Segundo Mann, Barton e Owens (2012), sistemas de captura de energia de vibrações são frequentemente dispositivos do tipo massa-mola-amortecedor lineares, que possuem sua frequência de ressonância sintonizada para a frequência de vibração principal do ambiente onde estão inseridos. Sendo assim, esses sistemas podem ser altamente sensíveis a incertezas, que podem surgir a partir da caracterização imprecisa do ambiente ou mesmo por defeitos de fabricação e tolerâncias. Desse modo, a utilização de sistemas de captura de energia não lineares pode ser um modo para mitigar os problemas destas incertezas. Os autores apresentam um estudo de propagação de incertezas sistemáticas em um protótipo de sistema de captura de energia eletromagnética. Mais especificamente, a resposta de um sistema de captura de energia linear na presença de incertezas paramétricas é comparada com a resposta de outros sistemas que contêm algumas formas comuns de não linearidades, como "mola dura", "mola mole" ou potencial duplo. Soluções analíticas foram usadas em combinação com níveis presumidos de incertezas paramétricas para quantificar a incerteza resultante na potência de saída. Por fim, esses estudos visam a determinar as regiões do espaço de parâmetros onde uma estratégia não linear pode superar uma abordagem linear tradicional.

Vocca e Cottone (2014) discutiram as várias estratégias desenvolvidas para captura de energia de vibração. Uma referência específica ao papel da linearidade e não linearidade foi discutida. Os autores mostram que os sistemas lineares ressonantes ainda são claramente limitados nas suas aplicações práticas, mesmo quando várias técnicas têm sido desenvolvidas e aplicadas para aumentar a sua largura de banda. Eles demonstram em seu trabalho que sistemas de captura de energia de vibrações mais complexos baseados em osciladores mecânicos não lineares podem superar os sistemas lineares ressonantes em vários cenários reais de captura de energia. Também concluíram, a partir de uma comparação entre trabalhos publicados, que as estruturas não lineares monoestáveis e biestáveis são as melhores configurações para otimizar o desempenho global dos sistemas de captura de energia de vibrações com foco na alimentação de dispositivos eletrônicos.

Scruggs (2009) projetou um sistema de captura de energia utilizando uma viga engastada do tipo bimorph para contextualizar sua teoria, que é baseada na teoria de controle ótimo. Simulações numéricas foram realizadas com sistemas de vibração excitados estocasticamente para uma faixa ampla de frequências, o que permitiu a otimização da potência capturada pelo sistema. Segundo o autor, sua teoria pode ser aplicável a sistemas com um único transdutor 
ou a sistemas que possuam uma rede de transdutores acoplados.

Iliuk et al. (2011b) analisaram a influência da variação dos parâmetros de acoplamento piezoelétrico em um modelo de captura de energia de vibração não linear. Segundo os autores, o aumento no valor dos parâmetros de acoplamento lineares e não lineares influenciou a saída de potência máxima capturada. O efeito Sommerfeld ocorreu na passagem pela ressonância.

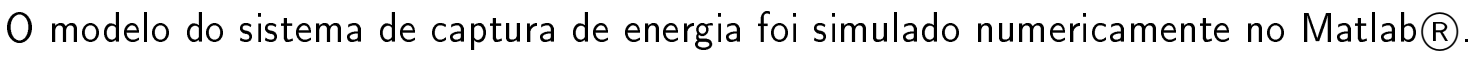

lliuk et al. (2012c) apresentaram um modelo matemático para um sistema de captura de energia que incluiu o papel das não linearidades no acoplamento piezoelétrico e uma fonte de energia não ideal (motor CC). Analisou-se a captura de energia para o caso do acoplamento linear piezoelétrico e, em seguida, para o acoplamento não linear piezoelétrico, demonstrandose a influência deste último na melhora da potência média capturada. Segundo os autores, com o aumento da tensão no motor (CC), o sistema produziu uma resposta de potência satisfatória, especialmente em órbitas de alta energia na região de ressonância, mas o efeito Sommerfeld ocorreu no sistema, e um comportamento caótico foi encontrado na região pós-ressonância. Assim, a potência capturada diminuiu, devido à interação entre fonte de energia de potência limitada e a estrutura. Uma técnica de controle foi aplicada com sucesso para estabilizar o sistema caótico em uma órbita periódica estável.

Iliuk et al. (2012b) propuseram um modelo para um sistema de captura de energia de vibrações incluindo as não linearidades do acoplamento piezoelétrico sob uma excitação não ideal. Por meio da análise das respostas dinâmicas, e realizando simulações numéricas, os autores verificaram que a energia capturada é influenciada por vibrações não lineares da estrutura. Também foi observado um comportamento caótico no sistema, causando perda de energia durante todo o tempo de simulação. Usando-se uma técnica de perturbação conhecida como "método da média", foi encontrada uma solução analítica aproximada para o sistema não ideal. Em seguida, aplicaram-se duas técnicas de controle para manter o sistema em uma órbita periódica estável. Tanto o controle baseado na equação de Riccati dependente do estado (SDRE) quanto o controle de feedback, que altera a energia do oscilador, foram eficientes para manter o sistema não ideal estável.

Iliuk et al. (2012a) analisaram as vibrações não lineares de um sistema de captura de energia piezoelétrica não ideal. Foram realizadas uma série de simulações numéricas, utilizando históricos de deslocamento, retratos de fase, expoentes de Lyapunov e espectro de frequências, nas quais um comportamento caótico no sistema de vibração foi encontrado. Devido a esse comportamento, a energia capturada não se manteve em um nível constante ao longo do tempo. Os autores então aplicaram uma técnica de controle do regulador linear quadrático $(\mathrm{LQR})$, que trouxe o sistema que estava em um comportamento caótico para uma órbita periódica estável determinada, mantendo a amplitude de oscilação do sistema em um nível 
desejado, bem como garantiu a integridade física do sistema, que atingiu uma captura de energia estável.

Iliuk et al. (2013a) propuseram um novo modelo de dispositvo para captura de energia com base em uma estrutura aporticada excitada por um motor CC. O sistema não ideal possui uma fonte de excitação com potência limitada, a qual tem seu comportamento influenciado pela resposta do sistema. O movimento horizontal da estrutura aporticada foi considerado sob a excitação não ideal, e o modelo matemático do tipo Duffing foi obtido, considerando-se os osciladores acoplados. Para modelar o acoplamento piezoelétrico, foram consideradas as não linearidades do material piezoelétrico, conforme Triplett e Quinn (2009). Uma estratégia de controle passivo foi obtida por meio da introdução do NES no sistema. Simulações numéricas foram realizadas, a fim de encontrar os melhores valores para os parâmetros de controle. Também, uma análise considerando as incertezas sobre a variação dos parâmetros do modelo foi realizada, para testar a robustez do controle passivo pelo bombeamento de energia (energy pumping) na supressão do comportamento caótico, bem como a sensibilidade do sistema de controle a erros paramétricos. Como resultado, o controle passivo levou o sistema a uma órbita periódica estável, permitindo uma colheita mais eficiente de energia, devido à amplitude de pico-a-pico mais elevada de oscilação do valor médio da potência capturada.

Iliuk et al. (2013c) analisaram um sistema de captura de energia piezoelétrico não linear com excitação não ideal, modelado como um oscilador Duffing de potencial duplo, que apresenta comportamento caótico. Os autores propuseram uma estratégia de controle passivo por meio da inclusão de um pêndulo no modelo. Analisando a variação da potência média e os diagramas de bifurcação, o valor da variável de controle que otimiza a potência capturada e estabiliza o sistema caótico em uma órbita periódica foi determinado. A sensibilidade a erros paramétricos sobre o amortecimento e a rigidez foi encontrada. A técnica de controle passivo proposto realizou um ajuste da vibração da estrutura e melhorou a energia média capturada.

Iliuk et al. (2014c) realizaram uma análise por elementos finitos (FEA), referente à troca de energia modal e uma configuração possível para um sistema de captura de energia concebido sobre uma estrutura aporticada. Foram consideradas ambas as excitações do suporte, horizontal e vertical, primeiro em ressonância com o primeiro modo, com movimento horizontal (sway mode), e depois com o segundo modo, com movimento vertical (first simmetrical mode). Como a ressonância interna 2:1 está presente entre esses dois modos, os fenômenos de saturação modal e troca de energia (acoplamento modal) podem ocorrer. Assim, a energia bombeada (energy pumping) dentro do sistema, por meio de um dos modos, é parcialmente transferida para o outro modo, não diretamente excitado. Os autores calcularam a energia disponível para captura em cada um dos modos considerados, demonstrando que é possível capturar a energia do sistema em um modo diferente do modo que está sendo excitado 
diretamente.

Iliuk et al. (2014b) descrevem o uso da análise wavelet para a identificação do comportamento regular e irregular de sistemas dinâmicos. Os autores focam suas análises sobre sistemas de captura de energia não lineares do tipo Duffing com potencial duplo, que podem apresentar comportamento periódico ou caótico. Aplicando a transformada wavelet contínua (CWT) com a utilização da wavelet de Morlet complexa, o tipo de movimento oscilatório de um conjunto de sistemas de captura de energia foi identificado com boa precisão, sendo ele periódico ou caótico. A análise wavelet é uma técnica que pode ser utilizada como ferramenta auxiliar para a validação da presença de caos em sistemas dinâmicos, em conjunto com as técnicas consolidadas como expoentes de Lyapunov e mapas de Poincaré.

lliuk et al. (2014a) propuseram uma função logística baseada no método dos mínimos quadrados para aproximar e modelar o comportamento da curva experimental da resposta piezoelétrica obtida por Crawley e Anderson (1990). Os autores realizaram então uma comparação da sua função proposta com uma função de referência disponível na literatura, com o objetivo de demonstrar a eficácia da proposta em melhorar a predição da quantidade de energia capturada pelo sistema piezoelétrico.

Remick et al. (2014) investigaram um sistema de captura de energia de vibração composto por dois osciladores acoplados com uma não linearidade essencial da rigidez e sujeito a uma carga impulsiva do componente mecânico. Os osciladores do sistema são fracamente amortecidos e estão acoplados por meio de um cabo piezoelástico. Os autores realizam simulações numéricas sob excitações impulsivas simples e repetitivas, para estudar as transições de frequência resultantes por meio da análise wavelet $(A W)$ e sobreposição de espectros wavelet nos gráficos de energia em frequência, do inglês frequency energy plot (FEP). Devido aos efeitos mecânicos, tanto geométricos quanto cinemáticos, o cabo piezoelástico gera uma não linearidade na rigidez cúbica. Sob entradas impulsivas simples e repetidas, o sistema exibe capturas de ressonância transientes (TRC) que causam "rajadas" de alta frequência ou instabilidades na resposta do sistema de captura. Por sua vez, essas instabilidades dinâmicas de alta frequência resultam em transferências de energia fortes e sustentadas do sistema primário diretamente excitado para o elemento transdutor, por meio do cabo piezoelástico. Essa abordagem demonstra a eficácia de empregar esse tipo de instabilidade dinâmica de alta frequência para alcançar uma captura de energia de vibração não linear, melhorada sob excitações impulsivas.

Remick et al. (2016) propuseram um sistema de captura de energia de vibração utilizando não linearidades essenciais e elementos de acoplamento eletromagnéticos. O sistema principal, sujeito a uma carga impulsiva, consiste em um oscilador linear fracamente amortecido, acoplado ao dissipador de energia não linear (NES) como sistema secundário por meio de um magneto de neodímio e uma bobina de indutância, e um fio de piano, o que gera uma não 
linearidade cúbica essencial da rigidez. Sob uma entrada impulsiva, o sistema apresenta TRC, causando intencionalmente instabilidades na resposta do NES com grande amplitude e de alta-frequência, resultando na forte transferência de energia do sistema primário diretamente excitado para o sistema secundário. A energia então é capturada pelos elementos eletromagnéticos no acoplamento. Os autores demonstram, numericamente, analiticamente e experimentalmente, a eficácia de empregar esse tipo de instabilidade dinâmica de alta frequência intencional para alcançar melhora na captura de energia de vibração sob excitação impulsiva.

Pode-se verificar, mediante a revisão bibliográfica, que uma série de trabalhos tem sido realizada para otimizar a captura de energia em sistemas não lineares. Vários autores têm proposto seus modelos, bem como técnicas para otimizar a sua eficiência. Devido à ampla faixa de frequência que a configuração dos sistemas não lineares pode alcançar, conclui-se que esta é a mais promissora para captura de energia do ambiente. 


\section{MODELAGEM MATEMÁTICA DO SISTEMA}

\subsection{CARACTERÍSTICAS}

O sistema não ideal proposto neste trabalho para captura de energia (energy harvesting), conforme modelo apresentado na Figura 5 , foi concebido com base na estrutura aporticada não linear estudada por Brasil (1990) e Felix (2002).

O movimento horizontal da estrutura aporticada é considerado sob uma excitação não ideal devido a um motor elétrico de corrente contínua (CC) com uma massa desbalanceada que fornece potência limitada. Uma extensa análise sobre a teoria dos sistemas não-ideais foi realizada por Kononenko (1969), Balthazar et al. (2003) e Balthazar, Felix e Brasil (2003). sem desmerecer outros.

Considerou-se a aplicação, em ambos os lados de uma das colunas da estrutura, das camadas de material piezoelétrico (piezocerâmico) em uma configuração conhecida na literatura como bimorph (DUTOIT; WARDLE, 2007). Os elementos piezoelétricos são conectados, por meio de eletrodos, a uma carga elétrica, como um resistor, por exemplo.

Utilizou-se o método das equações de Lagrange para obtenção das equações do movimento do sistema eletromecânico não linear, e o termo de acoplamento para o material piezoelétrico no conjunto de equações foi o mesmo definido por Triplett e Quinn (2009).

Em seguida, adimensionalizaram-se as equações, para que fosse possível trabalhar com números puros. Na forma de espaço de estados, as equações foram simuladas numericamente, permitindo a avaliação dos resultados.

Figura 5 - Modelo Esquemático do Sistema NIS

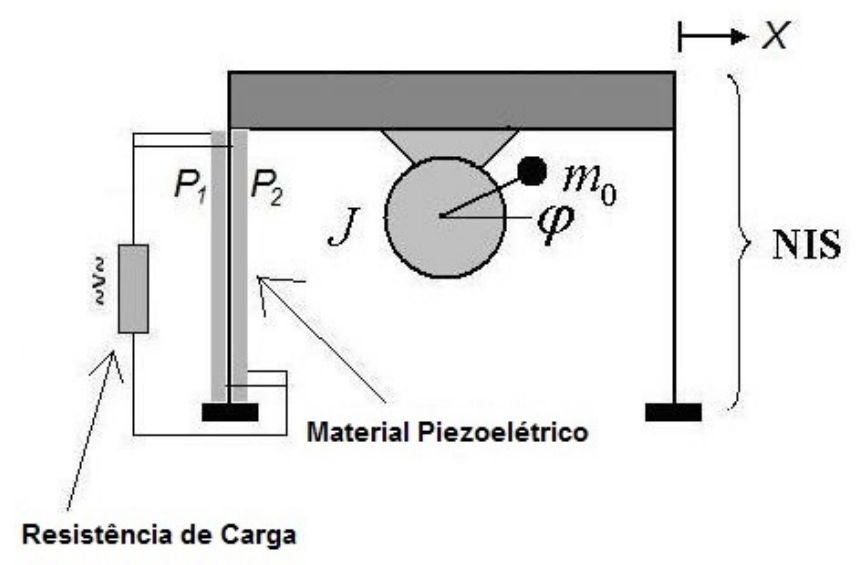

Fonte: Elaborada pelo próprio autor 


\subsection{EQUAÇÕES DO MOVIMENTO}

O modelo físico de um sistema de captura de energia não ideal no presente trabalho encontra-se na Figura 6

Figura 6 - Modelo Físico do Sistema (NIS)

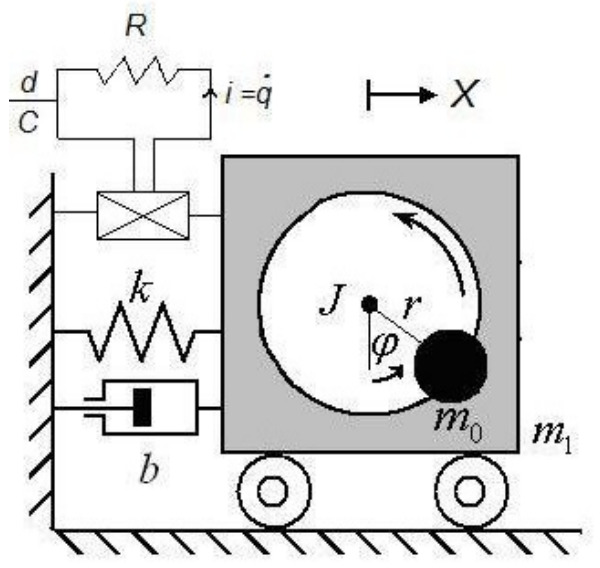

Fonte: Elaborada pelo próprio autor

O sistema não ideal (NIS) consiste em uma massa desbalanceada $m_{0}$, a massa da estrutura $m_{1}$, da rigidez da mola $k$, do amortecimento linear $b$, do deslocamento horizontal do sistema $X(t)$, do deslocamento angular do rotor $\varphi(t)$, do momento de inércia $J$, da excentricidade $r$, onde $k=-k_{l} X+k_{n l} X^{3}$ representa a rigidez do sistema, tendo $k_{l}$ como o coeficiente da mola linear e $k_{n l}$ o coeficiente da mola não linear (mola cúbica).

Nesse caso, a coluna da estrutura do pórtico é um tipo de oscilador Duffing (TUSSET; BALTHAZAR; FELIX, 2013). A não linearidade cúbica também foi considerada nos modelos propostos por Karami e Inman (2011), Erturk, Hoffmann e Inman (2009), Ferrari et al. (2010) e validada experimentalmente nas obras de Erturk, Hoffmann e Inman (2009) e Ferrari et al. (2010).

O torque resistivo aplicado ao motor é representado pela função $H(\dot{\varphi})$ e o torque de acionamento da fonte de energia (motor) é representado por $L(\dot{\varphi})$, segundo Felix (2002). Balthazar et al. (2003), Tusset et al. (2012) e Tusset, Balthazar e Felix (2013).

As camadas de material piezoelétrico aplicadas são representados por $P_{1}$ e $P_{2}$. De acordo com Triplett e Quinn (2009), a carga elétrica desenvolvida no circuito acoplado é dada por $q$ e o termo $\frac{d(X)}{C} q$ representa o acoplamento piezoelétrico do componente mecânico, com um coeficiente de acoplamento dependente da tensão mecânica aplicada $d(X)$.

A tensão elétrica $V$, através do material piezoelétrico, tem a forma da Eq. 1, em que $C$ representa a capacitância do material piezoelétrico em Farads $(F)$. Pode-se definir a tensão 
elétrica como $V=-R \dot{q}$, em Volts $(\mathrm{V})$, sendo $R$ a resistência elétrica da carga em Ohms $(\Omega)$ e $\dot{q}$ a corrente elétrica em Ampéres (A).

$$
V=-\frac{d(X)}{C} X+\frac{q}{C}
$$

Para facilitar o equacionamento sem a perda das características dinâmicas principais do sistema estudado, faz-se necessária a utilização da representação dos sistemas dinâmicos na forma de modelos matemáticos de equações diferenciais. Para se obterem essas equações, consideram-se as energias do sistema e aplicam-se as equações de Lagrange.

A energia cinética do sistema é:

$$
T=\frac{1}{2}\left(m_{0}+m_{1}\right) \dot{X}^{2}+\frac{1}{2} J \dot{\varphi}^{2} \frac{1}{2} m_{0}(\dot{X}-r \dot{\varphi} \operatorname{sen} \varphi)^{2}+\frac{1}{2} m_{0}(r \dot{\varphi} \cos \varphi)^{2}
$$

A energia potencial do sistema é:

$$
V=\frac{1}{2} k_{l} X^{2}+\frac{1}{4} k_{n l} X^{4}+m_{0} g r \operatorname{sen} \varphi
$$

onde $g$ é a aceleração da gravidade.

A equação de Lagrange é:

$$
\frac{d}{d t}\left(\frac{\partial L}{\partial \dot{q}_{i}}\right)+\frac{\partial L}{\partial q_{i}}=N_{i}
$$

onde a função lagrangeana é $L=T-V$ e $i=1,2$ são os graus de liberdade.

Assim tem-se 2 graus de liberdade: $i=1$, relacionado com o movimento horizontal da estrutura, e $i=2$, relacionado com a rotação angular do motor.

Para $i=1$ :

$$
\begin{aligned}
& \frac{\partial L}{\partial \dot{X}}=\left(m_{0}+m_{1}\right) \dot{X}+m_{0} r \dot{\varphi} \cos \varphi \\
& \frac{d}{d t}\left(\frac{\partial L}{\partial \dot{X}}\right)=\left(m_{0}+m_{1}\right) \ddot{X}-m_{0} r\left(\dot{\varphi}^{2} \operatorname{sen} \varphi-\ddot{\varphi} \cos \varphi\right) \\
& \frac{\partial L}{\partial X}=-k_{l} X-k_{n l} X^{3} \\
& N_{1}=-b \dot{X}+\frac{d(X)}{C} q
\end{aligned}
$$


Para $i=2$ :

$$
\begin{aligned}
& \frac{\partial L}{\partial \dot{\varphi}}=J \varphi+m_{0} r^{2} \dot{\varphi}+m_{0} r \dot{X} \cos \varphi \\
& \frac{d}{d t}\left(\frac{\partial L}{\dot{\varphi}}\right)=\left(J+m_{0} r^{2}\right) \ddot{\varphi}-m_{0} r(-\ddot{X} \cos \varphi+\dot{X} \dot{\varphi} \operatorname{sen} \varphi) \\
& \frac{\partial L}{\partial \varphi}=m_{0} r \dot{X} \dot{\varphi} \operatorname{sen} \varphi \\
& N_{2}=L(\dot{\varphi})-H(\dot{\varphi})
\end{aligned}
$$

Utilizando-se as equações de Lagrange, Eq.5 e Eq.6, obtêm-se as equações do movimento para o NIS:

$$
\begin{gathered}
\left(m_{0}+m_{1}\right) \ddot{X}+b \dot{X}+k_{l} X+k_{n l} X^{3}=m_{0} r\left(\ddot{\varphi} \cos \varphi-\dot{\varphi}^{2} \operatorname{sen} \varphi\right)+\frac{d(X)}{C} q \\
\left(J+m_{0} r^{2}\right) \ddot{\varphi} m_{0} r \ddot{X} \cos \varphi=L(\dot{\varphi})-H(\dot{\varphi}) \\
R \dot{q}-\frac{d(X)}{C} X+\frac{q}{C}=0
\end{gathered}
$$

A função que define a fonte de energia não ideal pode ser definida como uma função exponencial ou como uma função linear, as quais representam as curvas características da relação entre o torque versus velocidade do motor de corrente contínua, conforme Felix (2002). Balthazar et al. (2003), Rafikova (2006) e (ILIUK, 2012).

Então, pode-se considerar a função exponencial como apresentada na Eq. 8 ;

$$
L(\dot{\varphi})-H(\dot{\varphi})=V_{1} e^{-V_{2} \dot{\varphi}}
$$

A função que define a fonte de energia na forma linear é representada pela Eq. 9

$$
L(\dot{\varphi})-H(\dot{\varphi})=V_{1}-V_{2} \dot{\varphi}
$$

onde $V_{1}$ está relacionado com a tensão aplicada à armadura do motor de corrente contínua, ou seja, um possível parâmetro de controle do problema, e $V_{2}$ é uma constante para cada modelo de motor CC considerado. A função linear foi utilizada nesta tese.

É possível tornar a Eq. 7 uma forma adimensional, introduzindo os seguintes parâmetros adimensionais, normalizando convenientemente as coordenadas e o tempo de acordo com Tusset e Balthazar (2012), Tusset et al. (2012) e Tusset, Balthazar e Felix (2013).

$$
\tau=\omega_{1} t, \quad x=\frac{r X}{\omega_{1}^{2}}, \quad \omega_{1}=\sqrt{\frac{k_{l}}{\left(m_{0}+m_{1}\right)}}, \quad \alpha_{1}=\frac{b}{\left(m_{0}+m_{1}\right) \omega_{1}},
$$




$$
\begin{gathered}
\beta_{1}=\frac{k_{l}}{\left(m_{0}+m_{1}\right) \omega_{1}^{2}}, \quad \beta_{3}=\frac{k_{n l} r^{2}}{\left(m_{0}+m_{1}\right) \omega_{1}^{6}}, \quad \delta_{1}=\frac{m_{0} \omega_{1}^{2}}{\left(m_{0}+m_{1}\right)}, \\
\rho_{1}=\frac{m_{0} r^{2}}{\left(J+r^{2} m_{0}\right) \omega_{1}^{2}}, \quad \rho_{2}=\frac{V_{1}}{\left(J+r^{2} m_{0}\right) \omega_{1}^{2}}, \quad \rho_{3}=\frac{V_{2}}{\left(J+r^{2} m_{0}\right) \omega_{1}}, \\
v=\frac{q}{q_{0}}, \quad \rho=R C \sqrt{\frac{k_{l}}{\left(m_{0}+m_{1}\right)}}, \quad \hat{d}(x)=\left(\frac{r}{q_{0}}\right) d(r), \\
\theta\left(\frac{r}{q_{0}}\right) d_{l i n}, \quad \Theta r d_{\text {nlin }}, \quad \hat{d}(x)=\theta(1+\Theta|x|),
\end{gathered}
$$

A função proposta por Triplett e Quinn (2009), $\hat{d}(x)=\theta(1+\Theta|x|)$, representa o coeficiente piezoelétrico de acoplamento não linear adimensional, sendo dividido em uma parte linear (representada por $\theta$ ) e uma parte não linear (representada por $\Theta$ ).

Com isso, é possível reduzir as equações que regem o movimento, levando em consideração uma função linear para a fonte de excitação como a Eq. 9, obtendo-se assim a Eq. 10 .

$$
\begin{gathered}
x^{\prime \prime}+\alpha_{1} x^{\prime}-\beta_{1} x+\beta_{3} x^{3}-\theta(1+\Theta|x|) v=\delta_{1} \varphi^{\prime \prime} \operatorname{sen} \varphi+\delta_{1} \varphi^{\prime 2} \cos \varphi \\
\varphi^{\prime \prime}=\rho_{1} \cos \varphi x^{\prime \prime}+\rho_{2}-\rho_{3} \varphi^{\prime} \\
\rho v^{\prime}=\theta(1+\Theta|x|) x+v
\end{gathered}
$$

Usando-se novas variáveis, definidas como: $x_{1}=x, x_{2}=x^{\prime}, x_{3}=\varphi, x_{4}=\varphi^{\prime}, x_{5}=v$, as equações podem ser reescritas na representação em forma de espaço de estados na Eq. 11 .

$$
\begin{aligned}
x_{1}^{\prime} & =x_{2} \\
x_{2}^{\prime} & =-\alpha_{1} x_{2}+\beta_{1} x_{1}-\beta_{3} x_{1}^{3}+\theta\left(1+\Theta\left|x_{1}\right|\right) x_{5}+\delta_{1} \operatorname{sen}\left(x_{3}\right) x_{4}^{\prime}+\delta_{1} \cos \left(x_{3}\right) x_{4}^{2} \\
x_{3}^{\prime} & =x_{4} \\
x_{4}^{\prime} & =\rho_{1} \operatorname{sen}\left(x_{3}\right) x_{2}^{\prime}+\rho_{2}-\rho_{3} x_{4} \\
x_{5}^{\prime} & =\frac{\theta\left(1+\Theta\left|x_{1}\right|\right) x_{1}}{\rho}-\frac{x_{5}}{\rho}
\end{aligned}
$$

Com a tensão elétrica previamente definida como $V=-R \dot{q}$, a energia capturada a partir do componente mecânico é $\frac{V^{2}}{R}$, fazendo com que a energia elétrica adimensional 
capturada a partir do sistema, conforme Priya e Inman (2009), Triplett e Quinn (2009). Erturk e Inman (2011b), seja dada pela Eq. 12 .

$$
P=\rho v^{\prime 2}
$$

Para o cálculo da potência média, faz-se uso da integração da potência total obtida sobre o período, como demonstrado na Eq. 13

$$
P_{\text {med }}=\frac{1}{T} \int P(\tau) d \tau
$$

\subsection{CONTROLE PASSIVO DE VIBRAÇÕES}

Nesta seção, serão apresentadas duas possibilidades de estratégia de controle passivo para melhorar a eficiência da captura de energia elétrica do sistema não ideal (NIS).

\subsubsection{Pórtico com Controle Passivo (NES)}

A captura de energia mantida de forma constante é essencial para o uso destes sistemas como fonte de energia em aplicações reais, tais como alimentação de microssensores, biossensores implantáveis, entre outros. Sendo assim, uma estratégia de controle faz-se necessária para obter os resultados desejados.

Como possível solução para esse problema, a utilização de controles passivos pode melhorar a energia capturada, removendo o movimento caótico do sistema e mantendo a oscilação em uma órbita periódica estável. A principal vantagem da técnica de controle passivo é que esta elimina a necessidade de se utilizar qualquer componente eletrônico para controlar o sistema, havendo apenas um componente mecânico "massa" acoplado à estrutura principal.

Nesta seção, o controle passivo é obtido por meio de uma subestrutura fortemente não linear, totalmente passiva, com propriedades de dissipador não linear de energia, do inglês nonlinear energy sink (NES). Segundo Vakakis et al. (2009), a transferência de energia, do inglês targeted energy transfer (TET), ou fenômeno do bombeamento de energia, do inglês energy pumping, que ocorre entre o oscilador principal e o NES, é empregada para alterar drasticamente a dinâmica do sistema primário ao qual o NES está acoplado.

O NES possui a capacidade intrínseca de rápida localização da vibração ou choque aplicado ao sistema, e assim pode capturar ou dissipar essa energia. Isso permite utilizar o NES como uma poderosa estratégia de controle para um grande número de aplicações, 
como: isolação de choque e vibrações, energy harvesting passivo, supressão de instabilidades aeroelásticas, entre outros.

Considerando que o NES não requer qualquer injeção de energia no sistema para controlar a estrutura, Vakakis et al. (2009), Tusset et al. (2012), Tusset, Balthazar e Felix (2013). Felix et al. (2013), lliuk et al. (2013c) demonstraram que o NES é uma estratégia eficaz de controle passivo.

O movimento horizontal da estrutura aporticada é considerado sob uma excitação não ideal, tendo acoplado ao oscilador principal um dissipador de energia não linear (NES) na forma de um controlador passivo, como demonstrado na Figura 7.

Figura 7 - Pórtico com Controle Passivo (NES) Acoplado

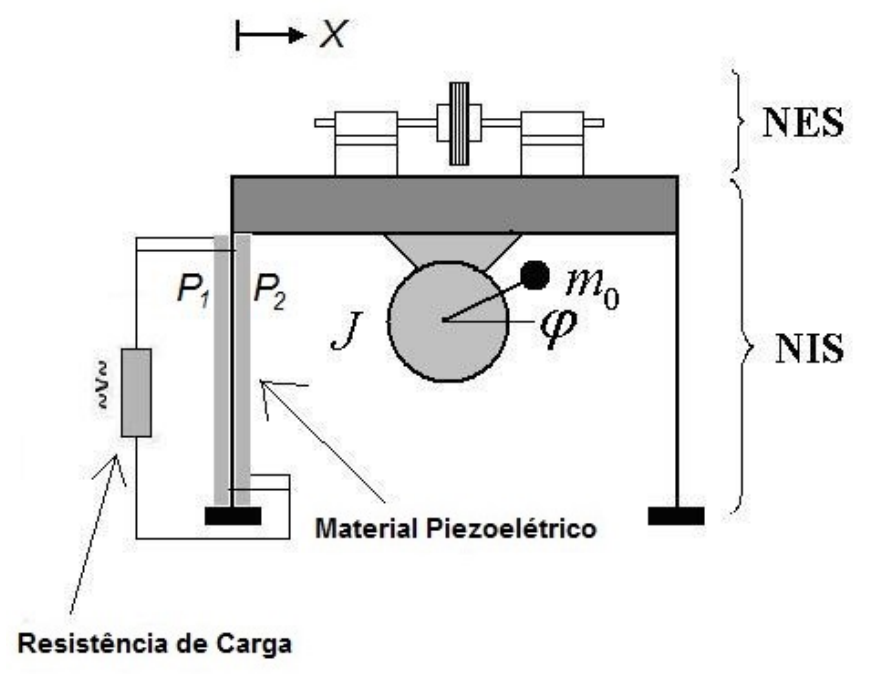

Fonte: Elaborada pelo próprio autor

O modelo físico do sistema com o controle passivo na Figura8 é representado pelo sistema não ideal (NIS), com o oscilador NES acoplado.

O modelo matemático do sistema com controle é obtido a partir da Eq. 10, com a inclusão da massa do NES $m_{2}$, da rigidez não linear $k_{1}$, do amortecimento linear $b_{1}$. Considerase o deslocamento $X_{1}(t)$ do NIS e o deslocamento do oscilador NES $X_{2}(t)$. Assim, as equações acopladas que regem o movimento do sistema são dadas pela Eq. 14 . 
Figura 8 - Modelo Físico do Oscilador com o Controle Passivo (NES) Acoplado

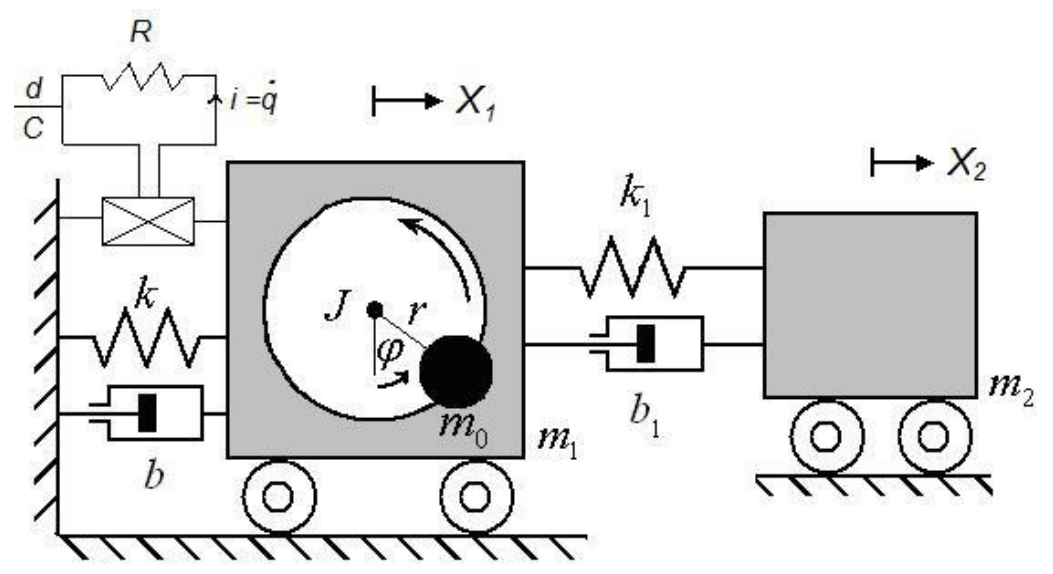

Fonte: Elaborada pelo próprio autor

$$
\begin{gathered}
\left(m_{0}+m_{1}\right) \ddot{X}_{1}+b \dot{X}_{1}+b_{1}\left(\dot{X}_{1}-\dot{X}_{2}\right)-k_{l} X_{1}+k_{n} l X_{1}^{3}+k_{1}\left(X_{1}-X_{2}\right)^{3} \\
=m_{0} r\left(\ddot{\varphi} \operatorname{sen}(\varphi)+\dot{\varphi}^{2} \cos (\varphi)+\frac{d\left(X_{1}\right)}{C} q\right. \\
m_{2} \ddot{X}_{2}-b_{1}\left(\dot{X}_{1}-\dot{X}_{2}\right)-k_{1}\left(X_{1}-X_{3}\right)^{3}=0 \\
\left(J+r^{2} m_{0}\right) \ddot{\varphi}-r m_{0} \ddot{X}_{1} \operatorname{sen}(\varphi)=V_{1}-V_{2} \dot{\varphi} \\
R \dot{q}-\frac{d\left(X_{1}\right)}{C} X_{1}+\frac{q}{C}=0
\end{gathered}
$$

Introduzindo-se os seguintes parâmetros adimensionais e normalizando-se convenientemente as coordenadas e o tempo de acordo com Tusset e Balthazar (2012), Tusset et al. (2012), Tusset, Balthazar e Felix (2013), obtem-se:

$$
\alpha_{2}=\frac{b_{1}}{m_{2} \omega_{1}}, \quad \alpha_{3}=\frac{k_{1} r^{2}}{m_{1}}, \quad \epsilon_{1}=\frac{m_{1} b_{1}}{m_{2} \omega_{1}}, \quad \epsilon_{2}=k_{1} r^{2}, \quad e=\frac{1}{m_{2}}
$$

onde a variável de controle $(e)$ depende diretamente da massa $m_{2}$ do NES.

Reduzindo-se as equações que regem o movimento para a forma adimensional, obtémse a Eq. 15 .

$$
\begin{gathered}
x^{\prime \prime}-\beta_{1} x+\alpha_{1} x^{\prime}+\alpha_{2}\left(x^{\prime}-z^{\prime}\right)+\beta_{3} x^{3}+\alpha_{3}(x-z)^{3}-\theta(1+\Theta|x|) v \\
=\delta_{1} \varphi^{\prime \prime} \operatorname{sen} \varphi+\delta_{1} \varphi^{2} \cos \varphi \\
z^{\prime \prime}-e \epsilon_{1}\left(x^{\prime}-z^{\prime}\right)-e \epsilon_{2}(x-z)^{3}=0 \\
\varphi^{\prime \prime}=\rho_{1} \cos \varphi x^{\prime \prime}-\rho_{3} \varphi^{\prime}+\rho_{2} \\
\rho v^{\prime}=\theta(1+\Theta|x|) x+v
\end{gathered}
$$


Usando-se as novas variáveis definidas como: $x_{1}=x, x_{2}=x^{\prime}, x_{3}=z, x_{4}=z^{\prime}$, $x_{5}=\varphi, x_{6}=\varphi^{\prime}, x_{7}=v$, as equações podem ser reescritas na representação em forma de espaço de estados:

$$
\begin{aligned}
& x_{1}^{\prime}=x_{2} \\
& x_{2}^{\prime}=\beta_{1} x_{1}-\alpha_{1} x_{2}-\alpha_{2}\left(x_{2}-x_{4}\right)-\beta_{3} x_{1}^{3}-\alpha_{3}\left(x_{1}-x_{3}\right)^{3}+\theta\left(1+\Theta\left|x_{1}\right|\right) x_{7} \\
& +\delta_{1} \operatorname{sen}\left(x_{5}\right) x_{6}^{\prime}+\delta_{1} \cos \left(x_{5}\right) x_{6}^{2} \\
& x_{3}^{\prime}=x_{4} \\
& x_{4}^{\prime}=e \epsilon_{1}\left(x_{2}-x_{4}\right)+e \epsilon_{2}\left(x_{1}-x_{3}\right)^{3} \\
& x_{5}^{\prime}=x_{6} \\
& x_{6}^{\prime}=\rho_{1} \operatorname{sen}\left(x_{5}\right) x_{2}^{\prime}+\rho_{2}-\rho_{3} x_{6} \\
& x_{7}^{\prime}=\frac{\theta\left(1+\Theta\left|x_{1}\right|\right) x_{1}}{\rho}-\frac{x_{7}}{\rho}
\end{aligned}
$$

\subsubsection{Pórtico com Controle Passivo por Pêndulo}

Nesta seção, para controlar o sistema de captura de energia, uma técnica de controle passivo é proposta por meio da introdução, no sistema, de um pêndulo, como nos trabalhos de Belato et al. (1999) e de Sado e Kot (2007). Analisando-se a variação média da potência e os diagramas de bifurcação, o valor da variável de controle que otimiza a potência de saída do sistema de captura de energia ou o valor médio que estabiliza o sistema caótico em uma órbita periódica pode ser determinado. A sensibilidade do controle é determinada por meio da análise de erros paramétricos, conforme Tusset et al. (2012), sobre os valores dos parâmetros de amortecimento e rigidez não lineares da estrutura aporticada.

Considerando-se o movimento horizontal do pórtico não ideal e acoplando-se a este um pêndulo a meio vão da viga da estrutura aporticada como um controlador passivo, tem-se a representação da Fig. 9 
Figura 9 - Pórtico com Controle Passivo do Tipo Pêndulo Acoplado

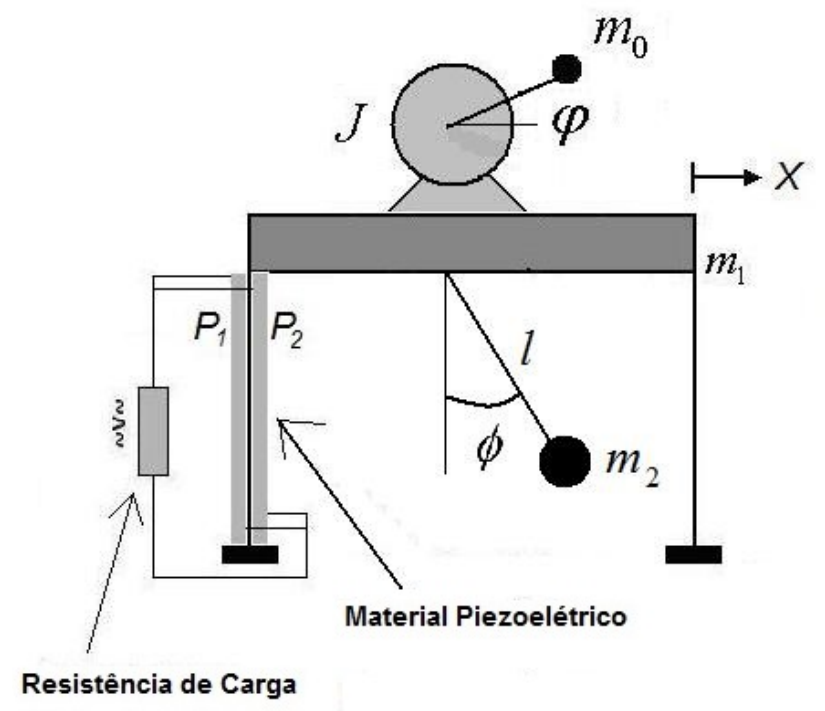

Fonte: Elaborada pelo próprio autor

Na Figura 10, é apresentado o modelo físico do sistema com controle, representado pelo sistema não ideal (NIS) com o pêndulo conectado.

Figura 10 - Modelo Físico do Oscilador com o Controle Passivo do Tipo Pêndulo Acoplado

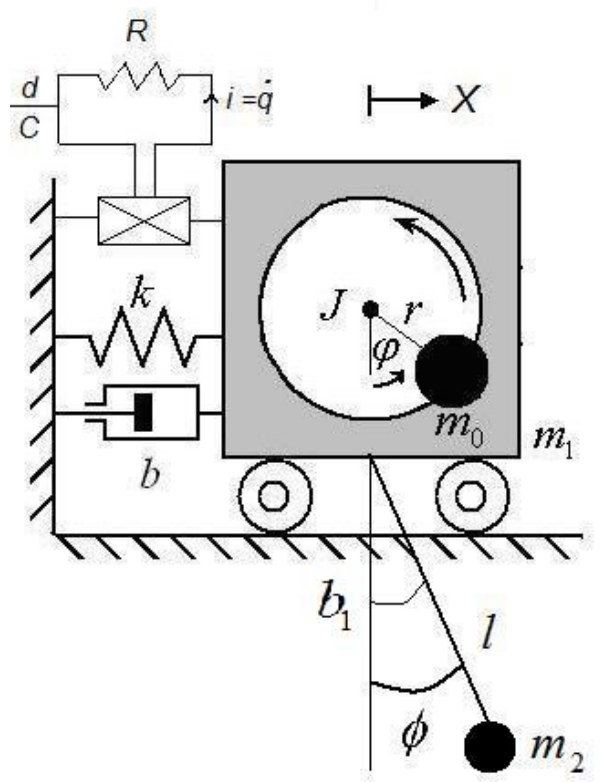

Fonte: Elaborada pelo próprio autor

O modelo matemático do sistema com controle é obtido a partir da Eq. 10, com a 
inclusão de um pêndulo com massa $m_{2}$, comprimento $l$, amortecimento linear $b_{1}$ e deslocamento angular do pêndulo $\phi(t)$. Assim, as equações acopladas que regem o movimento do sistema são dadas pela Eq. 17 .

$$
\begin{gathered}
\left(m_{0}+m_{1}+m_{2}\right) \ddot{X}+b \dot{X}-k_{l} X+k_{n} l X^{3}=m_{0} r \ddot{\varphi} \operatorname{sen} \varphi+m_{0} r \dot{\varphi}^{2} \cos \varphi \\
+m_{2} l \dot{\phi}^{2} \operatorname{sen} \phi-m_{2} l \ddot{\phi} \cos \phi+\frac{d(X)}{C} q \\
\left(J+r^{2} m_{0}\right) \ddot{\varphi}-r m_{0} \ddot{X} \operatorname{sen} \varphi=V_{1}-V_{2} \dot{\varphi} \\
m_{2} l^{2} \ddot{\varphi}+m_{2} \ddot{X} l \cos \phi+m_{2} g l \operatorname{sen} \phi=-b_{1} \dot{\phi} \\
R \dot{q}-\frac{d(X)}{C} X+\frac{q}{C}=0
\end{gathered}
$$

Introduzindo-se os seguintes parâmetros adimensionais e normalizando-se convenientemente as coordenadas e o tempo de acordo com Tusset e Balthazar (2012), Tusset et al. (2012), Tusset, Balthazar e Felix (2013), tem-se:

$$
\begin{gathered}
\omega_{1}=\sqrt{\frac{k_{l}}{\left(m_{0}+m_{1}+m_{2}\right)}}, \quad \alpha_{1}=\frac{b}{\left(m_{0}+m_{1}+m_{2}\right) \omega_{1}}, \\
\beta_{1}=\frac{k_{l}}{\left(m_{0}+m_{1}+m_{2}\right) \omega_{1}^{2}}, \quad \beta_{3}=\frac{k_{n l} r^{2}}{\left(m_{0}+m_{1}+m_{2}\right) \omega_{1}^{6}}, \quad \delta_{1}=\frac{m_{0} \omega_{1}^{2}}{\left(m_{0}+m_{1}+m_{2}\right)}, \\
\delta_{2}=\frac{m_{2} l \omega_{1}^{2}}{\left(m_{0}+m_{1}+m 2\right)}, \quad \rho_{4}=\frac{m_{2} \omega_{1}^{2}}{r}, \quad \rho_{5}=\frac{m_{2} g}{\omega^{2}}, \quad \rho_{6}=\frac{b_{1}}{l \omega}, \quad e=\frac{1}{m_{2} l} .
\end{gathered}
$$

onde e é a variável de controle e depende diretamente da massa e do comprimento do pêndulo.

$\mathrm{Na}$ Eq. 18 apresenta-se o modelo reduzido das equações que regem o movimento:

$$
\begin{gathered}
x^{\prime \prime}=-\alpha_{1} x^{\prime}+\beta_{1} x-\beta_{3} x^{3}+\theta(1+\Theta|x|) v+\delta_{1} \varphi^{\prime \prime} \operatorname{sen} \varphi+\delta_{1} \varphi^{2} \cos \varphi \\
+\delta_{2} \phi^{\prime 2} \operatorname{sen} \phi-\delta_{2} \phi^{\prime \prime} \cos \phi \\
\varphi^{\prime \prime}=\rho_{1} x^{\prime \prime} \operatorname{sen} \varphi+\rho_{2}-\rho_{3} \varphi^{\prime} \\
\phi^{\prime \prime}=-e \rho_{4} x^{\prime \prime} \cos \phi-e \rho_{5} \operatorname{sen} \phi-e \rho_{6} \phi^{\prime} \\
v^{\prime}=\frac{\theta(1+\Theta|x|) x_{1}}{\rho}-\frac{v}{\rho}
\end{gathered}
$$

Usando-se as novas variáveis definidas como: $x_{1}=x, x_{2}=x^{\prime}, x_{3}=\varphi, x_{4}=\varphi^{\prime}$, $x_{5}=\phi, x_{6}=\phi^{\prime}, x_{7}=v$, as equações podem ser reescritas na representação em forma de espaço de estados. 


$$
\begin{aligned}
& x_{1}^{\prime}=x_{2} \\
& x_{2}^{\prime}=-\alpha_{1} x_{2}+\beta_{1} x_{1}-\beta_{3} x_{1}^{3}+\theta\left(1+\Theta\left|x_{1}\right|\right) x_{7}+\delta_{1} x_{4}^{\prime} \operatorname{sen} x_{3}+\delta_{1} x_{4}^{2} \cos x_{3} \\
& +\delta_{2} x_{6}^{2} \operatorname{sen} x_{5}-\delta_{2} x_{6}^{\prime} \cos x_{5} \\
& x_{3}^{\prime}=x_{4} \\
& x_{4}^{\prime}=\rho_{1} x_{2}^{\prime} \operatorname{sen} x_{3}+\rho_{2}-\rho_{3} x_{4} \\
& x_{5}^{\prime}=x_{6} \\
& x_{6}^{\prime}=-e \rho_{4} x_{2}^{\prime} \cos x_{5}-e \rho_{5} \operatorname{sen} x_{5}-e \rho_{6} x_{6}^{\prime} \\
& x_{7}^{\prime}=\frac{\theta\left(1+\Theta\left|x_{1}\right|\right) x_{1}}{\rho}-\frac{x_{7}}{\rho}
\end{aligned}
$$




\section{PÓRTICO SEM CONTROLE PASSIVO}

\subsection{TRATAMENTOS PRELIMINARES}

Neste capítulo, são apresentados os resultados obtidos via simulações numéricas, bem como são realizados alguns comentários sobre o comportamento dinâmico do sistema de captura de energia piezoelétrico na ausência do controle passivo.

\subsection{RESULTADOS NUMÉRICOS}

As simulações numéricas das equações diferenciais foram realizadas com o software Matlab®, tendo como integrador numérico o algoritmo Runge-Kutta de quarta ordem "ode45".

Os resultados das simulações no domínio do tempo apresentados na Figura 11 foram obtidos por meio da Eq. 11. na forma de espaço de estados, considerando-se os parâmetros da Tabela 1, os quais foram adaptados e estão em conformidade com Triplett e Quinn (2009). Tusset e Balthazar (2012) Tusset et al. (2012), Tusset, Balthazar e Felix (2013), lliuk et al. (2013a)

Tabela 1 - Parâmetros da Simulação - Sistema de Captura sem
\begin{tabular}{cccc} 
Parâmetro & Valor & Parâmetro & Valor \\
\hline$\alpha_{1}$ & 0.10 & $\beta_{1}$ & 1.00 \\
$\beta_{3}$ & 0.20 & $\delta_{1}$ & 8.373 \\
$\rho_{1}$ & 0.05 & $\rho_{2}$ & 100 \\
$\rho_{3}$ & 200 & $\theta$ & 0.20 \\
$\Theta$ & 0.60 & $\rho$ & 1.00 \\
\hline
\end{tabular}

Nas simulações numéricas, a resposta do sistema foi considerada para as condições iniciais nulas, levando-se em consideração o intervalo de tempo adimensional $0 \leq \tau \leq 1000$.

O movimento vibratório resultante foi um atrator estranho caótico, que produziu o retrato fase caótico mostrado na Figura 11 a.

Pela observação do mapa de Poincaré, visto na Figura 11b tem-se a confirmação do comportamento caótico do sistema considerado, para os parâmetros utilizados.

O histórico de deslocamento no tempo para a tensão elétrica é mostrado na Figura $11 \mathrm{c}$

A Figura 11d mostra a potência adimensional máxima capturada obtida por meio da Eq. 12 para o sistema sem controle passivo. Como se pode notar, a potência capturada 
para o sistema sem controle é instável ao longo do tempo de simulação, e esse não é um comportamento desejával para sistemas de captura.

Figura 11 - Respostas do Sistema de Captura de Energia sem a Aplicação de Controle Passivo

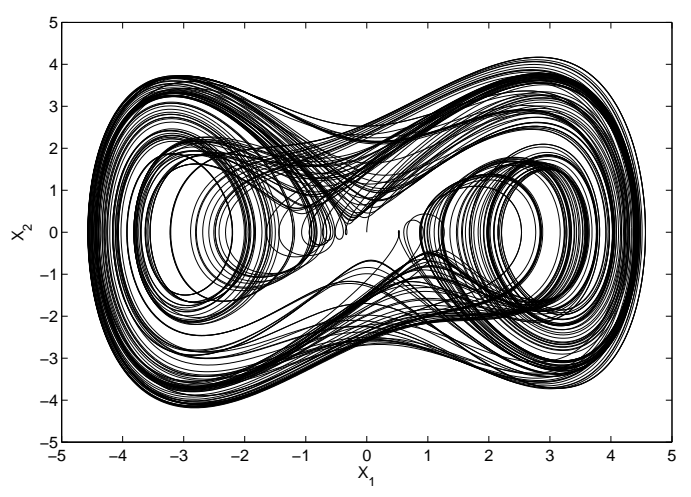

(a) Retrato de Fase

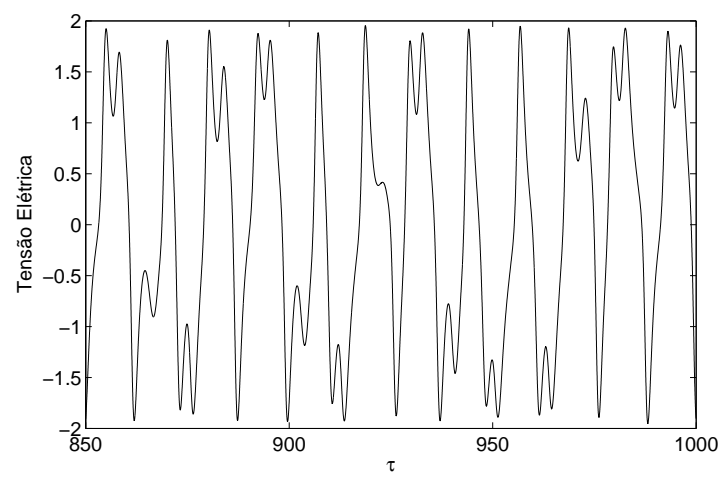

(c) Tensão Elétrica

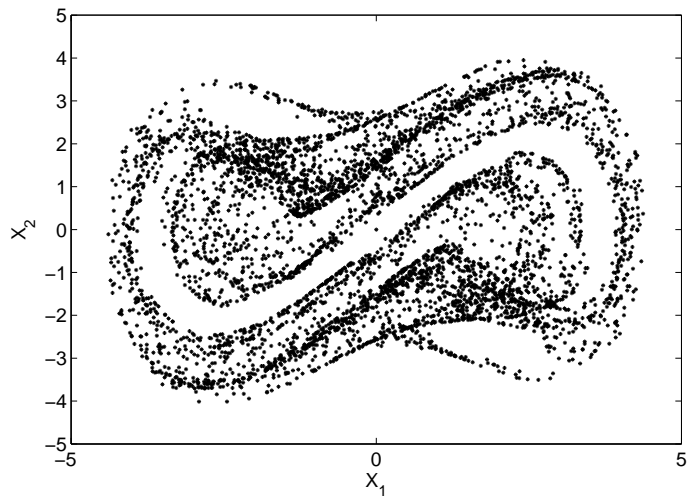

(b) Mapa de Poincaré

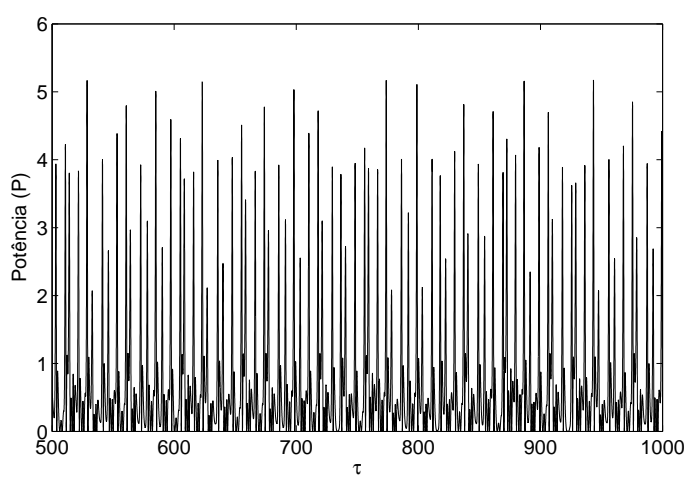

(d) Potência Adimensional

Fonte: Elaborada pelo próprio autor

A aplicação de uma estratégia de controle para o modelo faz-se necessária para se obter uma energia mais estável. 


\section{PÓRTICO COM CONTROLE PASSIVO NES}

\subsection{TRATAMENTOS PRELIMINARES}

Pretende-se estudar, por meio das simulações numéricas, as respostas do sistema de captura de energia com a inclusão do controle passivo NES, e assim verificar a sua influência no movimento vibratório do sistema e a possível melhora da eficiência da captura de energia, buscando os parâmetros do controlador que obtenham maior potência.

Os resultados das simulações no domínio do tempo apresentados nesta seção foram obtidos utilizando-se a Eq. 16, considerando-se os parâmetros da Tabela 2, em conformidade com Triplett e Quinn (2009), Iliuk et al. (2012c), Tusset e Balthazar (2012), Tusset et al. (2012), Tusset, Balthazar e Felix (2013).

Tabela 2 - Parâmetros da Simulação - Sistema com Controle NES

\begin{tabular}{cccc}
\hline Parâmetro & Valor & Parâmetro & Valor \\
\hline$\alpha_{1}$ & 0.10 & $\beta_{1}$ & 1.00 \\
$\beta_{3}$ & 0.20 & $\delta_{1}$ & 8.373 \\
$\rho_{1}$ & 0.05 & $\rho_{2}$ & 100 \\
$\rho_{3}$ & 200 & $\alpha_{2}$ & 0.10 \\
$\alpha_{3}$ & 0.50 & $\epsilon_{1}$ & 1.00 \\
$\epsilon_{2}$ & 5.00 & $\theta$ & 0.20 \\
$\Theta$ & 0.60 & $\rho$ & 1.00 \\
\hline
\end{tabular}

Nas simulações numéricas, a resposta do sistema também considerou as condições iniciais nulas para o intervalo de tempo adimensional $0 \leq \tau \leq 1000$.

\subsection{CONTROLE PASSIVO DAS OSCILAÇÕES UTILIZANDO O (NES)}

Para determinar os parâmetros a ser utilizados no controle passivo, a troca de energia entre as massas $m_{1}$ e $m_{2}$ e a variável de controle $e$ são consideradas.

Na Figura 12 o diagrama de bifurcação para a Eq. 16 é utilizado com o objetivo de definir o valor do parâmetro de controle $e$ a ser simulado. Pode-se identificar uma possível região de interesse próxima do valor $e=5.0$, onde o sistema apresenta um comportamento periódico. 
Figura 12 - Diagrama de Bifurcação para o Parâmetro de Controle $e$

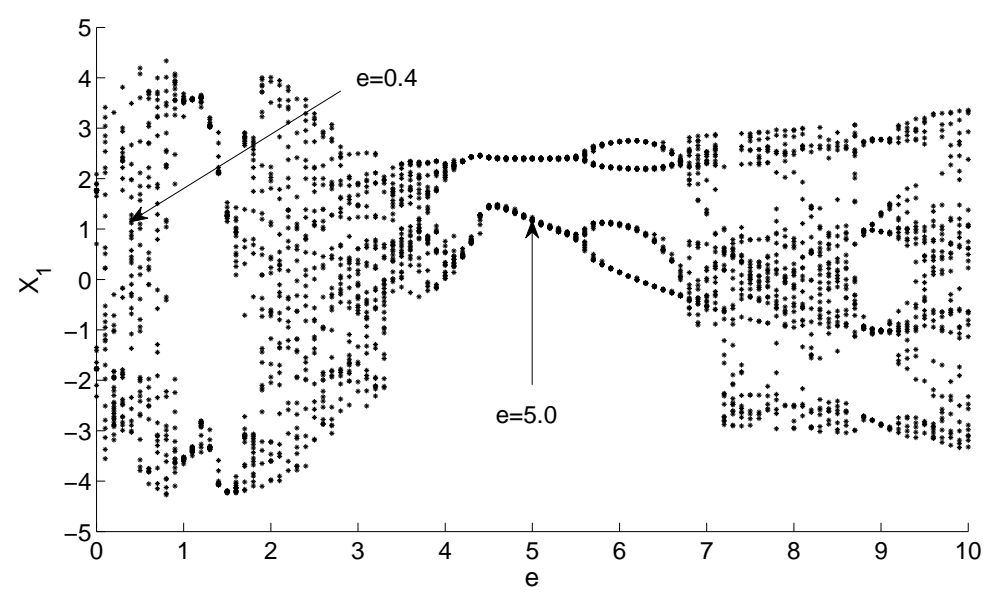

Fonte: Elaborada pelo próprio autor

Para uma comparação mais precisa entre o sistema controlado e sem controle, bem como para auxiliar na escolha do parâmetro de controle, a potência média capturada foi calculada. A potência média é obtida pela Eq. 13, de acordo com Triplett e Quinn (2009). A potência média foi calculada após a eliminação da resposta transiente.

A Figura 13 mostra a potência média capturada para incrementos no valor do parâmetro de controle $e$. Os resultados demonstram que, para alguns valores de $e$, o absorvedor passivo NES amplificou a energia capturada quando o sistema apresentou um comportamento caótico $e=0.4$, possivelmente devido às órbitas elevadas de energia. Quando o valor do parâmetro de controle foi $e=5.0$, o sistema demonstrou um comportamento periódico estável, o que é desejável, porém alcançou uma potência média capturada ligeiramente menor do que a obtida a partir do sistema sem controle. Esses dois valores do parâmetro de controle $e=0.4 \mathrm{e}$ $e=5.0$ foram escolhidos para ser analisados. 
Figura 13 - Potência Média Capturada para Incrementos do Parâmetro de Controle $e$

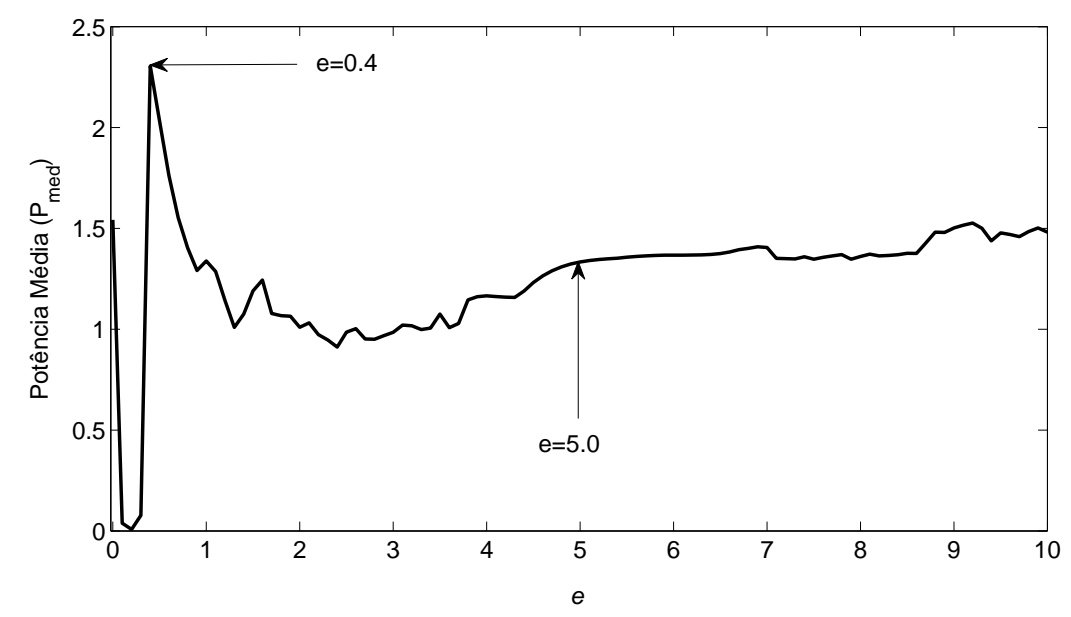

Fonte: Elaborada pelo próprio autor

\subsubsection{Aplicação da Estratégia de Controle Passivo (NES): Caso $e=0.4$}

A Figura 14a mostra o retrato de fase para o pórtico com o controle NES ativo. O sistema controlado apresenta uma órbita irregular, considerando-se o valor do parâmetro de controle $e=0.4$.

O mapa de Poincaré, mostrado na Figura 14b, confirma o comportamento caótico do sistema considerado para o parâmetro $e=0.4$ utilizado.

A tensão elétrica teórica é apresentada na Figura $14 c$ que mostra um comportamento também irregular.

A Figura $14 \mathrm{~d}$ mostra a potência adimensional máxima capturada, obtida por meio do sistema controlado.

Como se pode notar, o sistema teve significativo aumento da potência capturada em relação ao sistema sem controle. Isso confirma que o NES pode ser utilizado para amplificar a vibração do sistema, melhorando a quantidade de energia capturada, porém o sistema, nesta condição, permaneceu em um regime caótico, o que pode não ser desejável ou mesmo ser prejudicial à integridade da estrutura. 
Figura 14 - Aplicação do Controle Passivo (NES) Utilizando o Valor do Parâmetro de Controle $e=0.4$

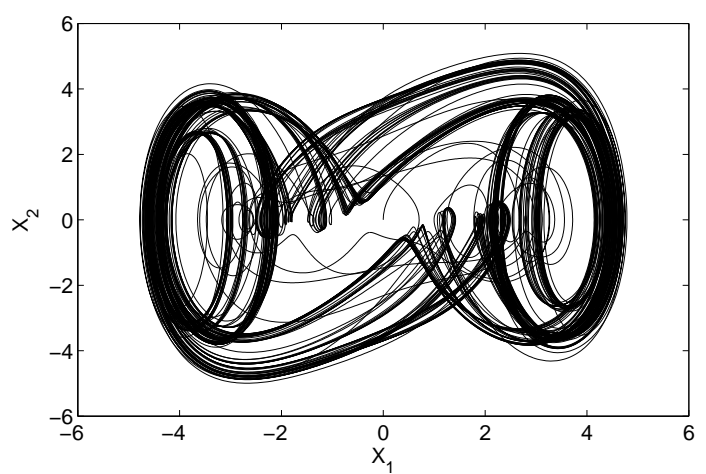

(a) Retrato de Fase

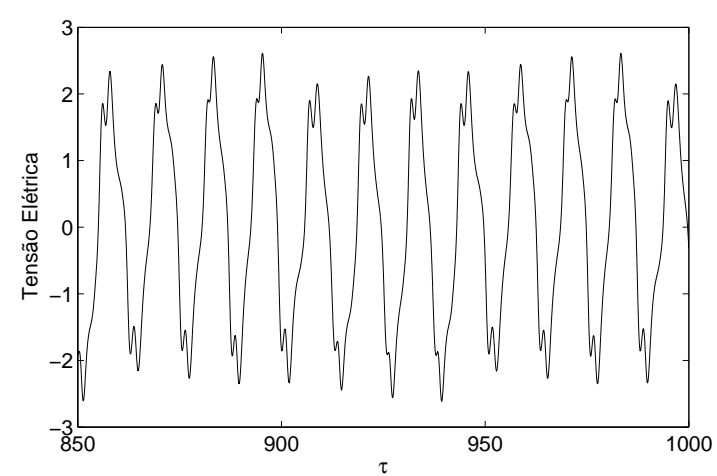

(c) Tensão Elétrica

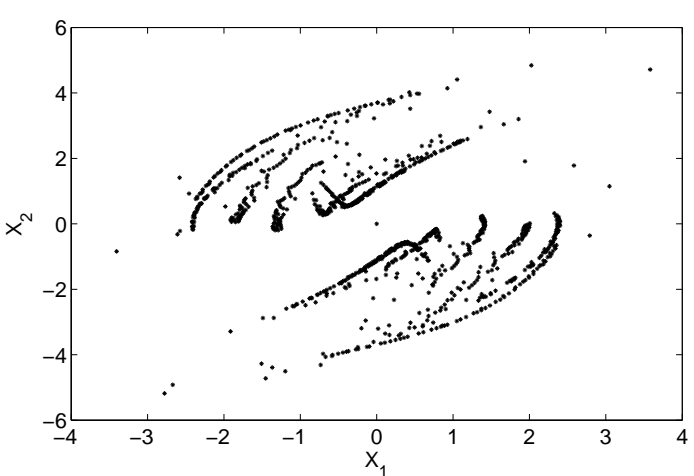

(b) Mapa de Poincaré

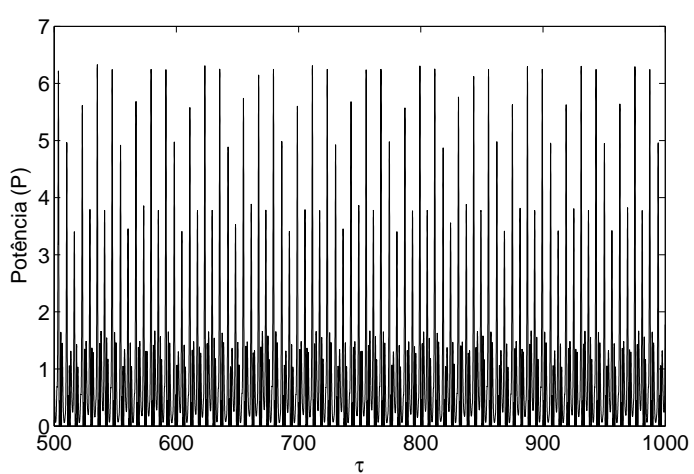

(d) Potência Adimensional

Fonte: Elaborada pelo próprio autor

\subsubsection{Aplicação da Estratégia de Controle Passivo (NES): Caso $e=5.0$}

A Figura 15 a mostra o retrato de fase para o pórtico com o controle NES ativo. O sistema controlado apresenta uma órbita periódica, considerando-se o valor do parâmetro de controle $e=5.0$.

O mapa de Poincaré, mostrado na Figura $15 \mathrm{~b}$ confirma o comportamento periódico do sistema considerado para o parâmetro $e=5.0$ utilizado.

A tensão elétrica teórica é mostrada na Figura $15 \mathrm{c}$ que mostra um comportamento periódico e estável.

A Figura $15 \mathrm{~d}$ mostra a potência adimensional máxima capturada, obtida por meio do sistema controlado. 
Figura 15 - Aplicação do Controle Passivo (NES) Utilizando o Valor do Parâmetro de Controle $e=5.0$

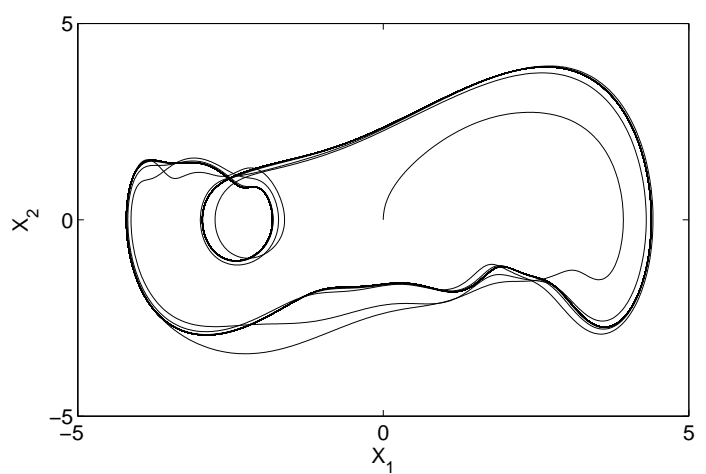

(a) Retrato de Fase

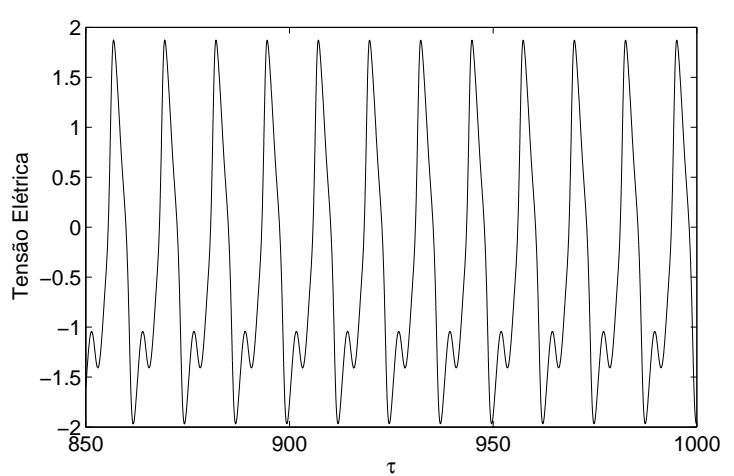

(c) Tensão Elétrica

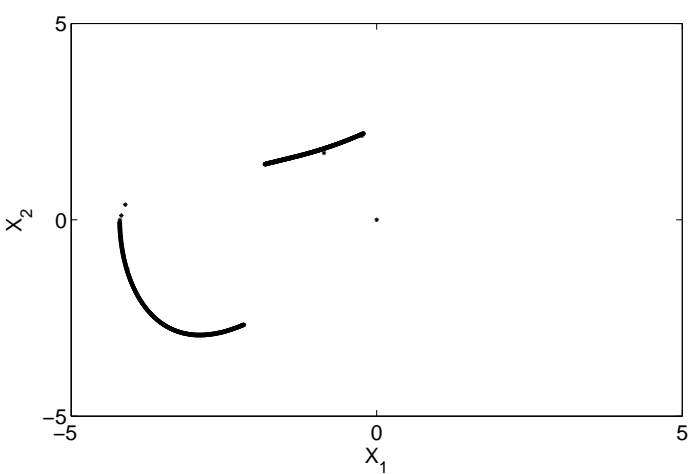

(b) Mapa de Poincaré

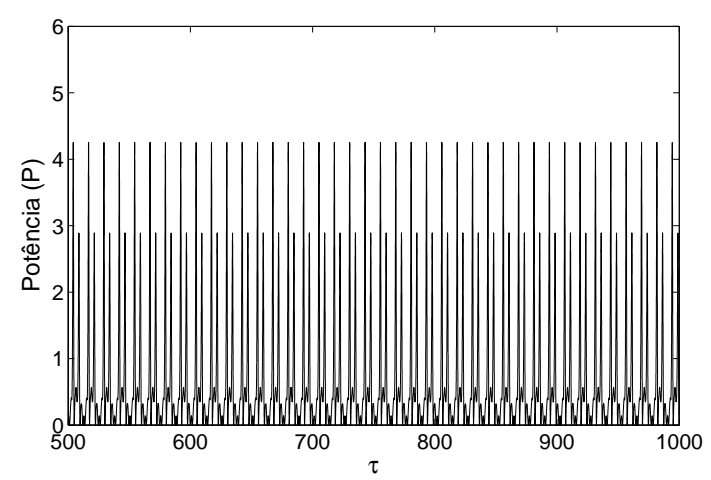

(d) Potência Adimensional

Fonte: Elaborada pelo próprio autor

O sistema apresentou pequena redução na potência capturada em relação ao sistema sem controle. Essa redução pode ser aceitável para o caso em que o comportamento periódico é desejável e necessário.

\subsubsection{Transferência de Energia}

O processo irreversível de transferência de energia no sistema acoplado, consistindo no sistema não ideal (NIS) e no controle passivo (NES), é examinado na forma adimensional, em que a energia instantânea com respeito à energia total do sistema é dada pela Eq. 20, de acordo com Tusset et al. (2012) e Tusset, Balthazar e Felix (2013). 


$$
\begin{aligned}
E_{N I S_{i}} & =\frac{E_{N I S}}{\left(E_{N I S}+E_{N E S}\right)} \\
E_{N E S_{i}} & =\frac{E_{N E S}}{\left(E_{N I S}+E_{N E S}\right)}
\end{aligned}
$$

onde:

$$
E_{N I S}=\left|-\beta_{1} \frac{x_{1}^{2}}{2}+\beta_{3} \frac{x_{1}^{4}}{4}+\frac{x_{2}^{2}}{2}+\frac{x_{6}^{2}}{2}\right| ; \quad E_{N E S}=\left|\frac{x_{4}^{2}}{2}+e \epsilon_{2} \frac{\left(x_{1}-x_{3}\right)^{4}}{4}\right|
$$

Na Figura 16, os fenômenos de bombeamento de energia (energy pumping) entre o sistema não ideal (NIS) e NES são apresentados, concomitantemente à captura de energia piezoelétrica, para o caso em que o parâmetro de controle assume o valor $e=0.4$.

Figura 16 - Deslocamento no Tempo da Transferência de Energia e da Potência Instantânea Capturada $e=0.4$

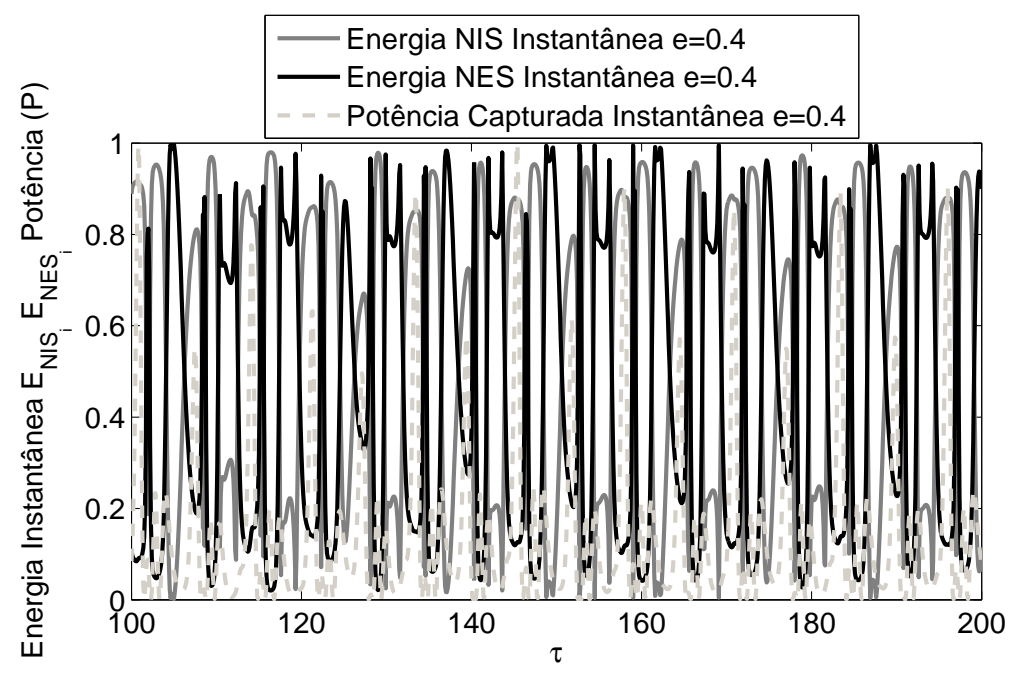

Fonte: Elaborada pelo próprio autor

Um zoom nos fenômenos de bombeamento de energia e captura de energia instantânea é apresentado na Figura 17 em que o aumento evidente na potência capturada pode ser visto exatamente quando ocorre a troca de energia entre o sistema não ideal (NIS) e o NES. 
Figura 17 - Zoom do Deslocamento no Tempo da Transferência de Energia e da Potência Instantânea Capturada $e=0.4$

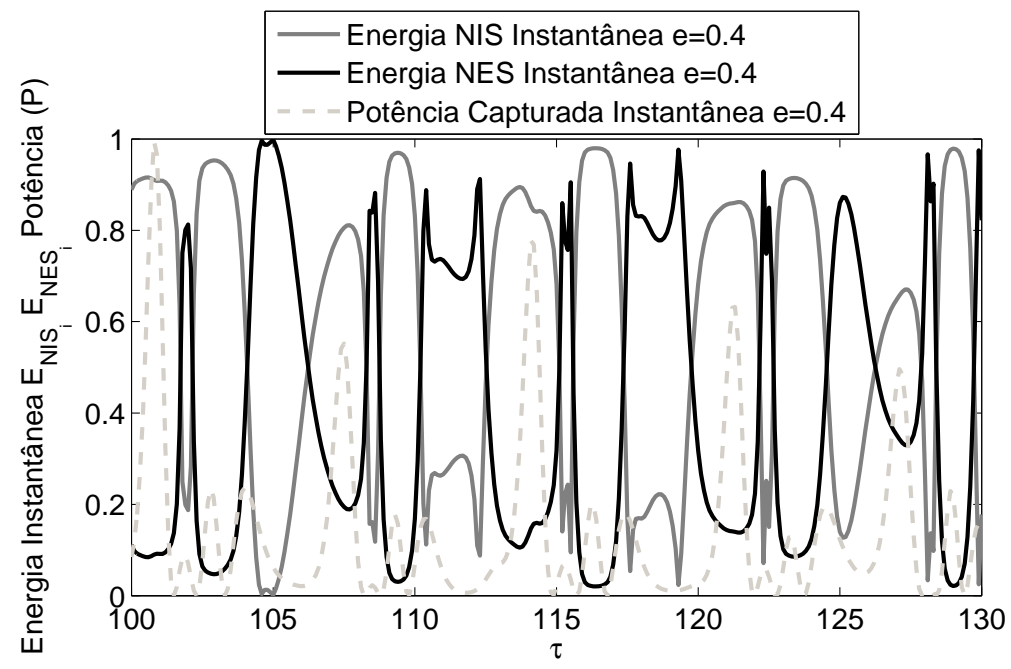

Fonte: Elaborada pelo próprio autor

Na Figura 18, são apresentados os fenômenos de bombeamento de energia (energy pumping) entre o sistema não ideal (NIS) e o NES, para o parâmetro de controle $e=5.0$. Também é apresentada a captura de energia piezoelétrica instantânea.

Figura 18 - Deslocamento no Tempo da Transferência de Energia e da Potência Instantânea Capturada $e=5.0$

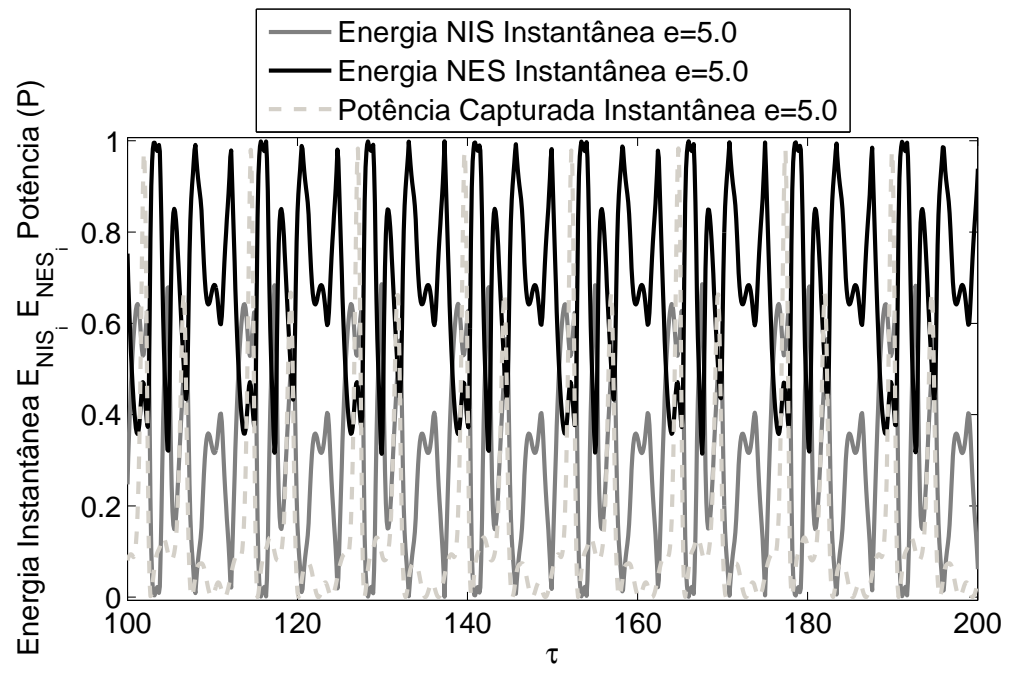

Fonte: Elaborada pelo próprio autor

Um zoom nos fenômenos de bombeamento de energia e captura de energia instantânea é apresentado na Figura 19 em que o aumento evidente na potência capturada pode ser visto exatamente quando ocorre a troca de energia entre o sistema não ideal (NIS) e o NES. 
Figura 19 - Zoom do Deslocamento no Tempo da Transferência de Energia e da Potência Instantânea Capturada $e=5.0$

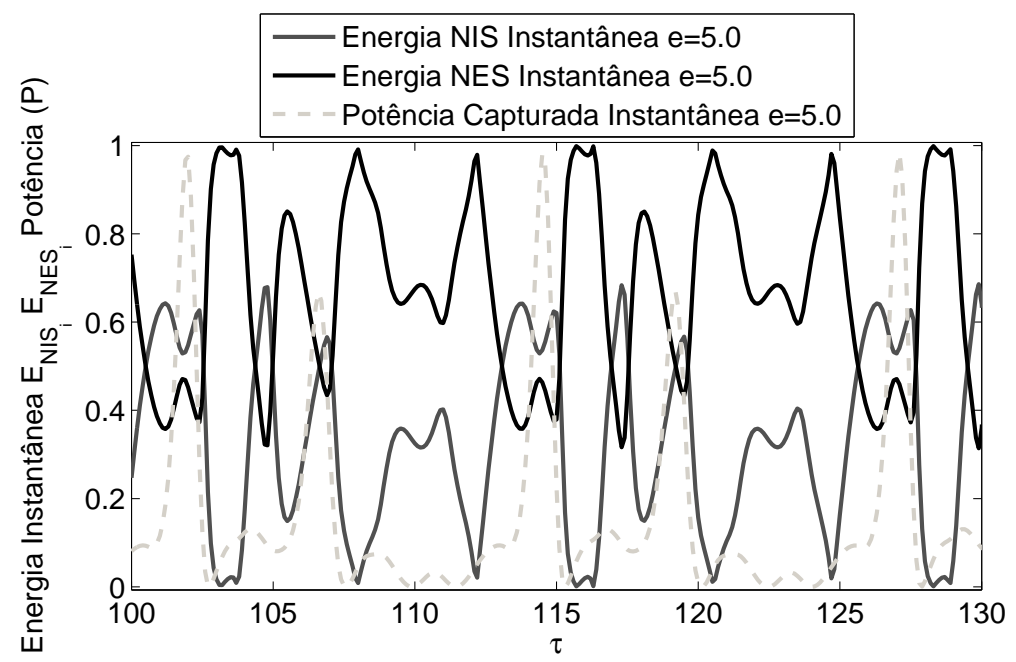

Fonte: Elaborada pelo próprio autor

Nas Figuras 16 a 19, um importante resultado confirma a eficiência da introdução do controle passivo (NES) no sistema. Como se pode notar, o aumento da potência capturada é obtido exatamente quando ocorre a transferência de energia entre o oscilador principal (NIS) e o sistema passivo (NES). Isso valida a implementação do NES como estratégia para melhorar a potência do sistema.

Na Figura 20, a potência máxima capturada sem controle e com o controle (NES) ativo é apresentada, a fim de comparar a eficácia da estratégia de controle.

Figura 20 - Potência Máxima Capturada para o Sistema Controlado e sem Controle

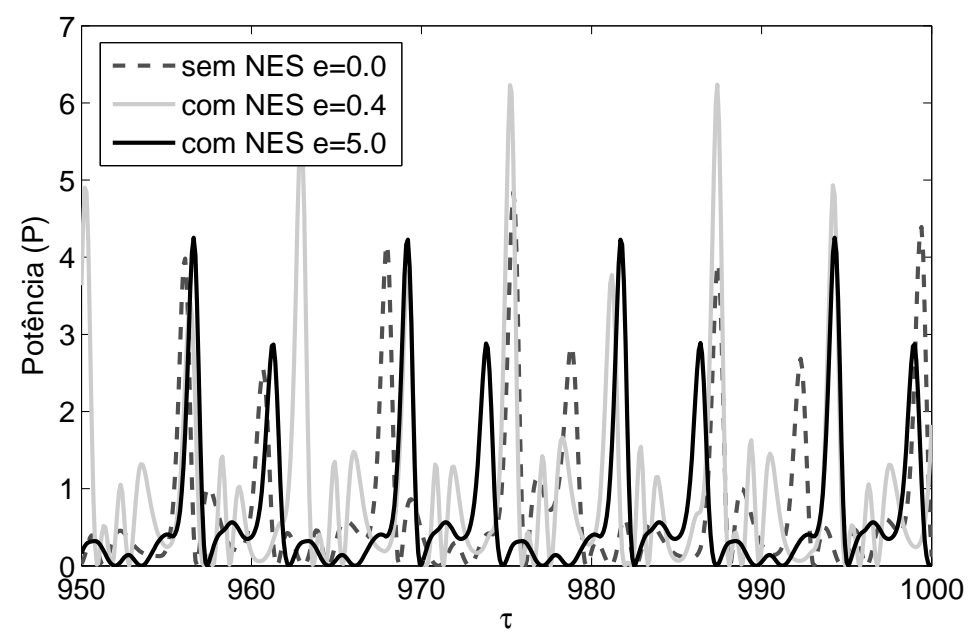

Fonte: Elaborada pelo próprio autor

Calculando-se a potência média, por meio da Eq.13 sobre o intervalo de tempo $0 \leq$ 
$\tau \leq 1000$, obtêm-se os resultados da Tabela 3 .

Tabela 3 - Potência Média Capturada - Sistema com Controle (NES)

\begin{tabular}{cc}
\hline Parâmetro de Controle & Potência Média \\
\hline$e=0$ & 1.542 \\
$e=0.4$ & 2.305 \\
$e=5.0$ & 1.334 \\
\hline
\end{tabular}

A diferença de aproximadamente $-10 \%$ na potência do sistema com NES $e=5.0$ justifica a sua implementação no pórtico não ideal, para o caso em que o comportamento periódico é necessário ou desejado. A diferença de aproximadamente $+30 \%$, no sistema com NES $e=0.4$, demonstra que o sistema com comportamento caótico apresenta aumento na potência média capturada.

\subsection{EFEITO DA VARIAÇÃO DOS PARÂMETROS}

Normalmente, os parâmetros utilizados no controle são obtidos a partir de um conjunto de dados. O conjunto de dados fornecido pode introduzir erros paramétricos, como erros de medição ou incertezas ao modelo. Para verificar a robustez do sinal de controle $e$, uma análise dos efeitos das incertezas sobre os parâmetros do sistema foi realizada.

A fim de avaliar a robustez do controle passivo proposto, de modo semelhante à metodologia aplicada ao controle ativo estudado por Tusset e Balthazar (2012), Shirazi et al. (2012), Balthazar et al. (2013), os parâmetros $\alpha_{1}=0.1, \alpha_{2}=0.1, \alpha_{3}=0.5, \beta_{2}=0.2$, $\delta_{1}=8.373$ foram analisados individualmente, tendo em vista a variação de $\pm 20 \%$ em relação ao valor nominal de cada um dos parâmetros com um passo de $5 \%$.

\subsubsection{Variação do Paramâtro de Amortecimento $\alpha_{1}$}

A partir de simulações numéricas e pela análise dos diagramas de bifurcação obtidos, foi possível verificar que o controle proposto usando o parâmetro $e=5.0$ foi robusto a erros no parâmetro $\alpha_{1}$.

Na Figura 21, a sequência de diagramas de bifurcação do parâmetro $\alpha_{1}$ é retratada para destacar a região de interesse, onde o parâmetro de controle tem o valor $e=5.0$. 
Figura 21 - Diagramas de Bifurcação do Parâmetro e para a Variação do Amortecimento $\alpha_{1}$

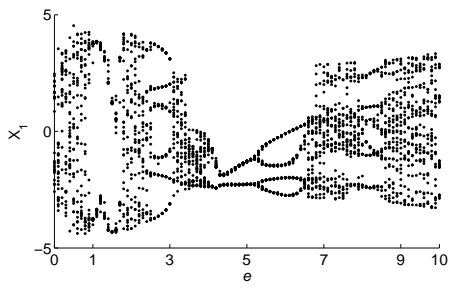

(a) $\alpha_{1}=0.080$

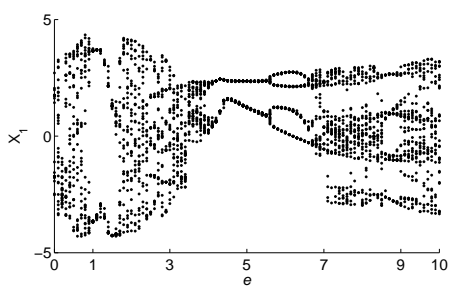

(d) $\alpha_{1}=0.095$

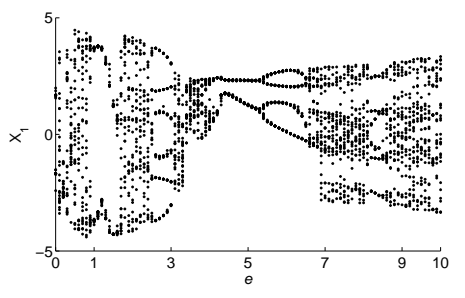

(b) $\alpha_{1}=0.085$

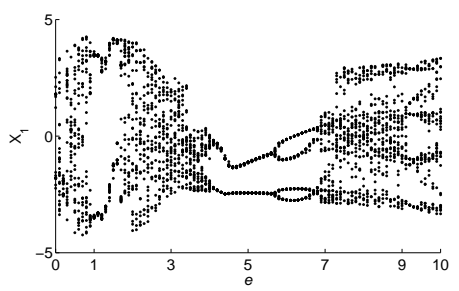

(e) $\alpha_{1}=0.105$

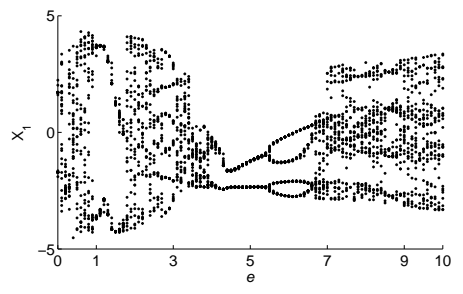

(c) $\alpha_{1}=0.090$

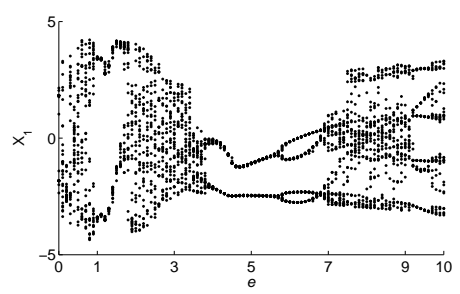

(f) $\alpha_{1}=0.110$

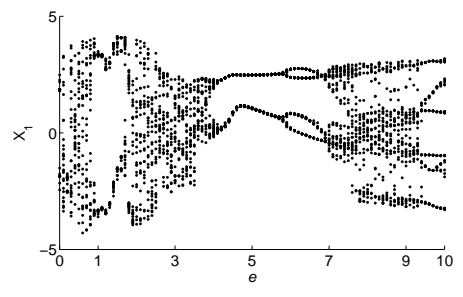

(g) $\alpha_{1}=0.115$

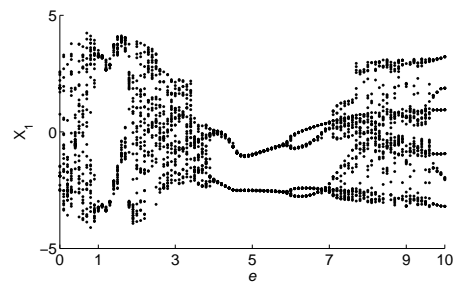

(h) $\alpha_{1}=0.120$

Fonte: Elaborada pelo próprio autor

Na Figura 22, a influência das incertezas na variação do valor do coeficiente de amortecimento $\alpha_{1}$ sobre a potência média capturada pela Eq. 13 . considerando-se uma variação de $\pm 20 \%$ sobre o valor nominal do parâmetro, é apresentada. O parâmetro de controle foi considerado sobre o intervalo $0 \leq e \leq 10$.

Como se pode notar, com o aumento do amortecimento, a potência média capturada sofre redução constante. 
Figura 22 - Diagrama de Potência Média para o Parâmetro $\alpha_{1}$

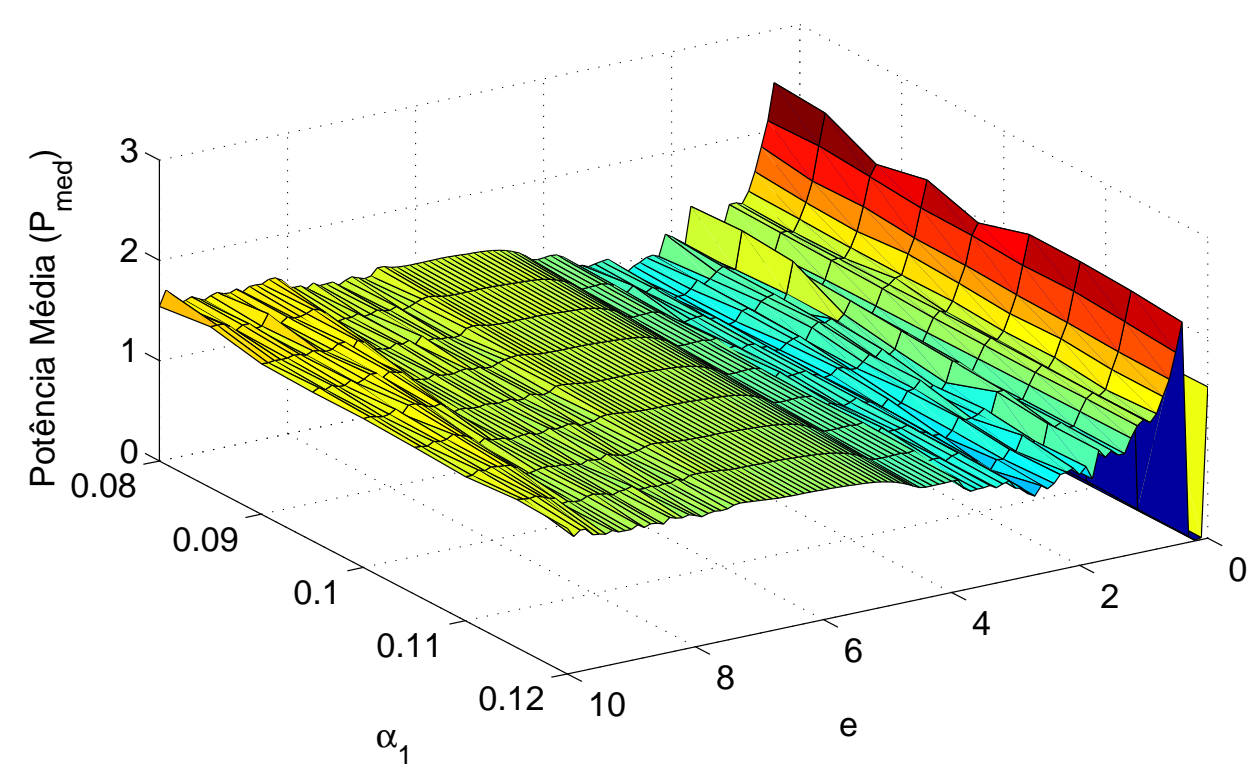

Fonte: Elaborada pelo próprio autor

Na Figura 23, a potência média capturada para o parâmetro $\alpha_{1}$ é apresentada, mostrando a potência média capturada iniciando a partir de $-20 \%$ do valor nominal e demonstrando uma constante redução da potência média capturada para cada aumento de $5 \%$ no valor do parâmetro $\alpha_{1}$.

Figura 23 - Potência Média para o Parâmetro $\alpha_{1}$

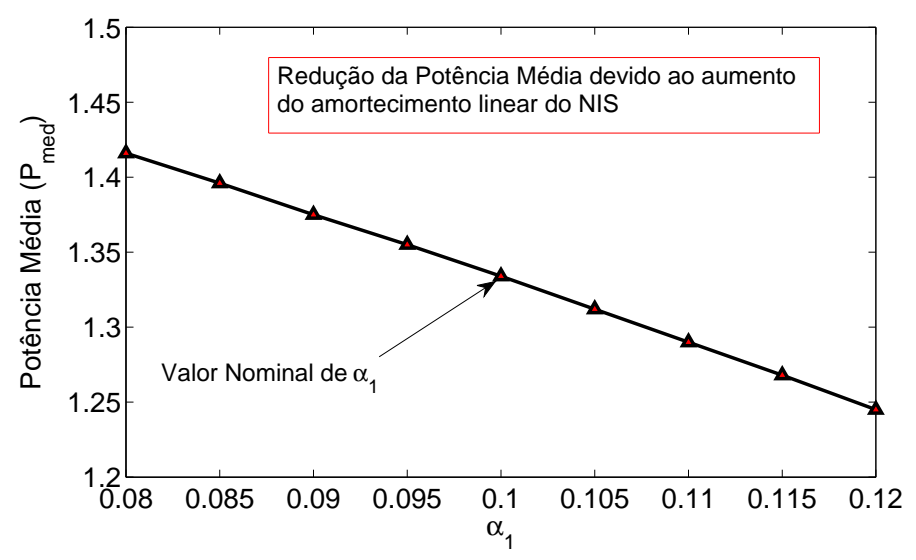

Fonte: Elaborada pelo próprio autor 


\subsubsection{Variação do Paramâtro de Amortecimento $\alpha_{2}$}

Através de simulações numéricas e pela análise dos diagramas de bifurcação obtidos, foi possível verificar que o controle proposto, usando-se o parâmetro $e=5.0$, foi robusto a erros no parâmetro $\alpha_{2}$.

Os diagramas de bifurcação do parâmetro $\alpha_{2}$ são representados na sequência da Figura 24 e são utilizados para destacar a região de interesse, onde o parâmetro de controle tem o valor $e=5.0$.

O controle mostrou-se, novamente, robusto à variação neste parâmetro.

Figura 24 - Diagramas de Bifurcação do Parâmetro $e$ para a Variação do Amortecimento $\alpha_{2}$

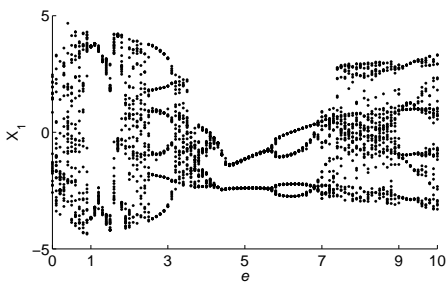

(a) $\alpha_{2}=0.080$

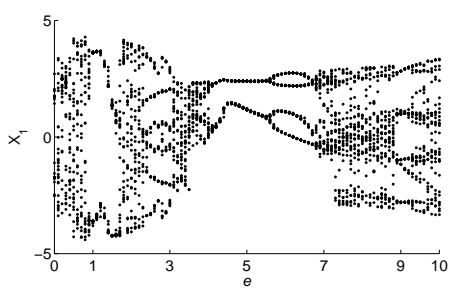

(d) $\alpha_{2}=0.095$

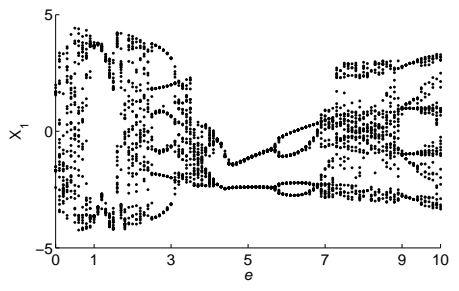

(b) $\alpha_{2}=0.085$

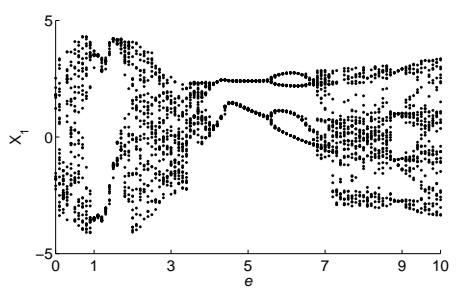

(e) $\alpha_{2}=0.105$

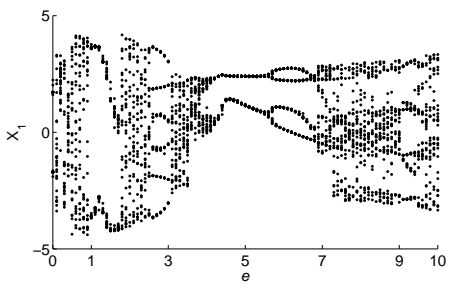

(c) $\alpha_{2}=0.090$

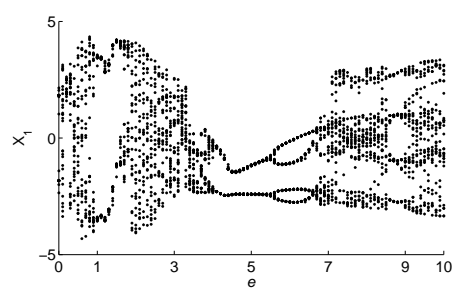

(f) $\alpha_{2}=0.110$

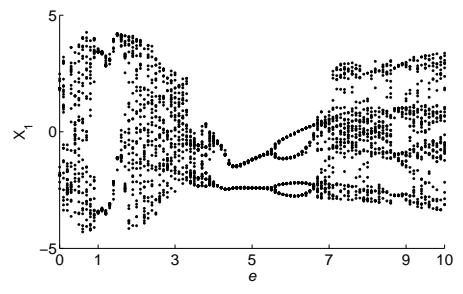

(g) $\alpha_{2}=0.115$

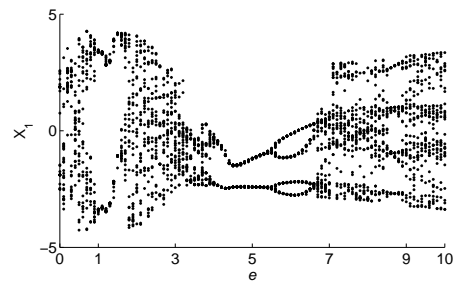

(h) $\alpha_{2}=0.120$

Fonte: Elaborada pelo próprio autor

Na Figura 25, a influência do coeficiente $\alpha_{2}$ na potência média foi considerada sobre o parâmetro de controle $0 \leq e \leq 10$, e pode ser observado o aumento da potência média capturada para incrementos no valor nominal do parâmetro $\alpha_{2}=0.1$. 
Figura 25 - Diagrama de Potência Média para o Parâmetro $\alpha_{2}$

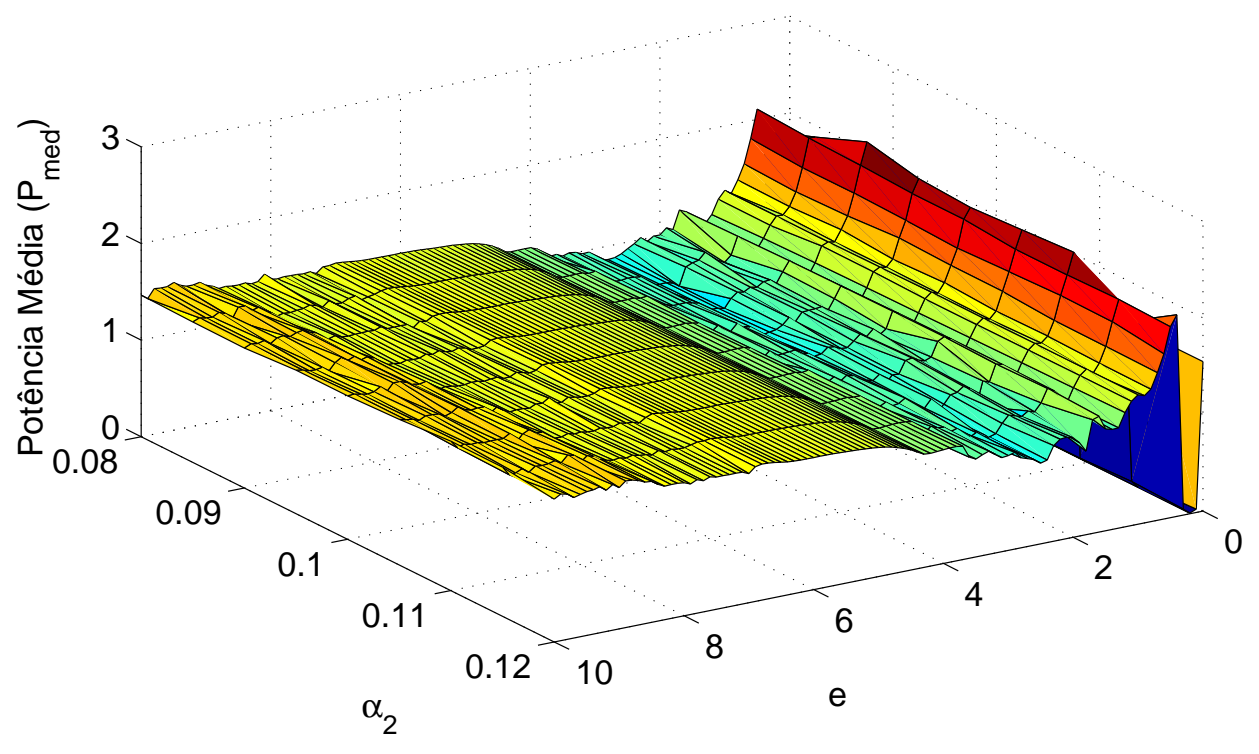

Fonte: Elaborada pelo próprio autor

Na Figura 26, a potência média capturada no parâmetro $\alpha_{2}$ é mostrada. A energia capturada aumenta a cada incremento de $5 \%$ do valor do parâmetro e atinge o maior valor quando $\alpha_{2}$ tem um acréscimo de $+20 \%$ em relação a seu valor nominal.

Figura 26 - Potência Média para o Parâmetro $\alpha_{2}$

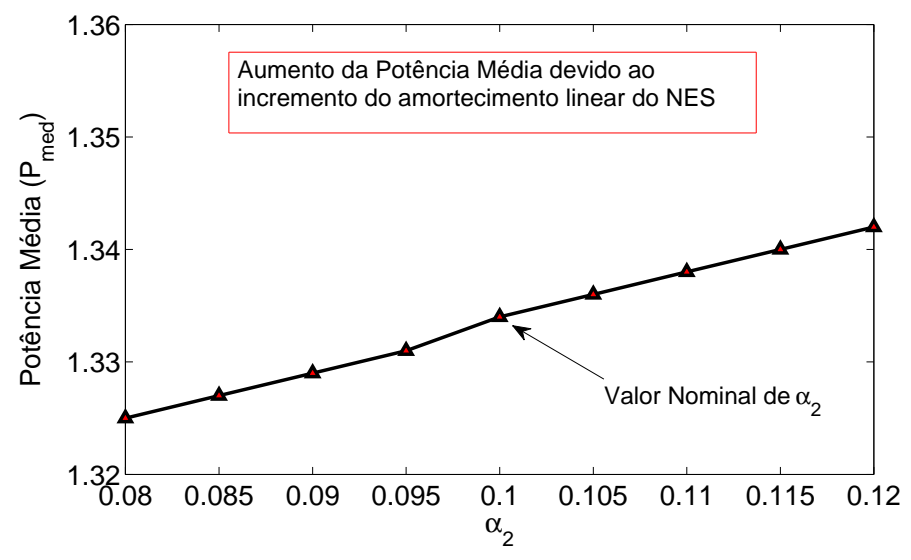

Fonte: Elaborada pelo próprio autor

\subsubsection{Variação do Paramâtro de Rigidez $\alpha_{3}$}

O comportamento do sistema, levando-se em consideração a variação no parâmetro $\alpha_{3}$, é mostrado na sequência. 
O controle apresentou algum tipo de sensibilidade à variação dos valores do parâmetro, e uma duplicação do período ocorreu.

A sequência dos diagramas de bifurcação é apresentada para o parâmetro $\alpha_{3}$ na Figura 27. que facilita a visualização da alteração no comportamento do sistema em função da variação do valor do parâmetro. Os maiores erros devido ao parâmetro $\alpha_{3}$ ocorreram com a variação de $-20 \%$ e $-15 \%$. Isso pode ser observado na Figura $27 a$ e Figura $27 b$ respectivamente.

Figura 27 - Diagramas de Bifurcação do Parâmetro e para a Variação de Rigidez $\alpha_{3}$

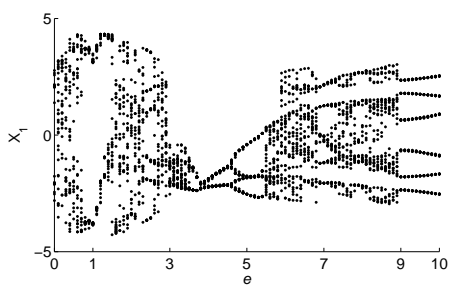

(a) $\alpha_{3}=0.400$

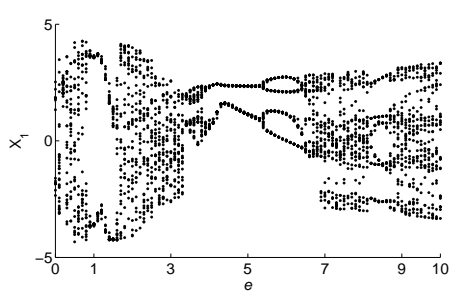

(d) $\alpha_{3}=0.475$

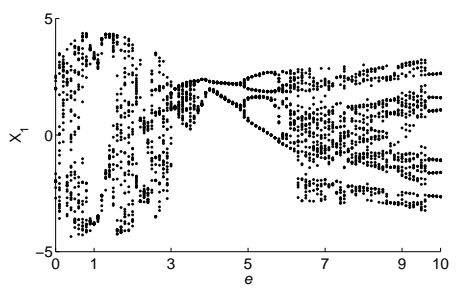

(b) $\alpha_{3}=0.425$

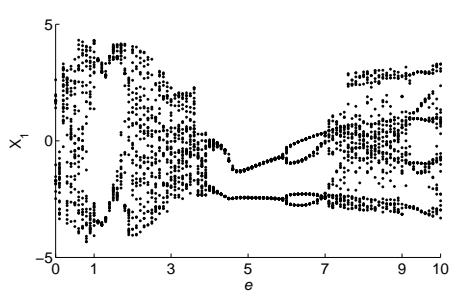

(e) $\alpha_{3}=0.525$

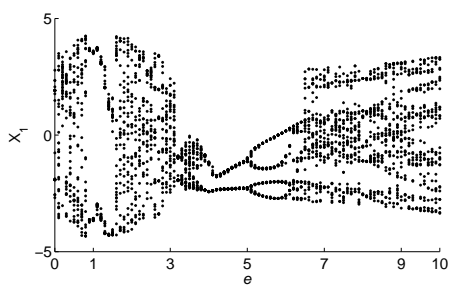

(c) $\alpha_{3}=0.450$

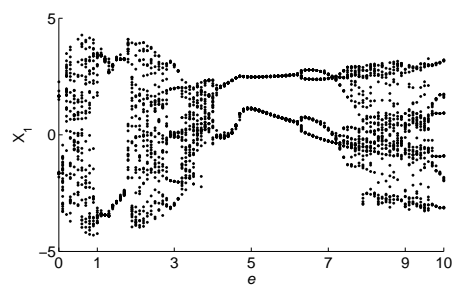

(f) $\alpha_{3}=0.550$

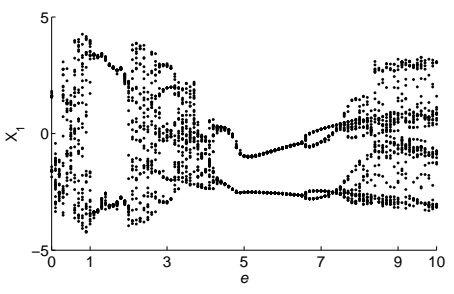

(g) $\alpha_{3}=0.575$

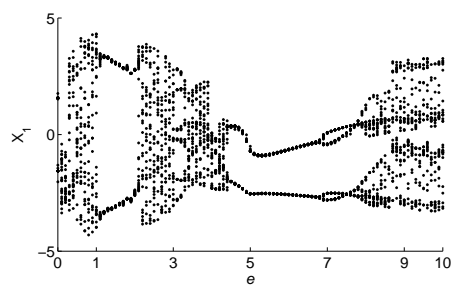

(h) $\alpha_{3}=0.600$

Fonte: Elaborada pelo próprio autor

Pode-se verificar na Figura 28 a influência da variação do coeficiente $\alpha_{3}$ na potência média capturada, considerando-se $0 \leq e \leq 10$ e o valor nominal de $\alpha_{3}=0.5$. 
Figura 28 - Diagrama de Potência Média para o Parâmetro $\alpha_{3}$

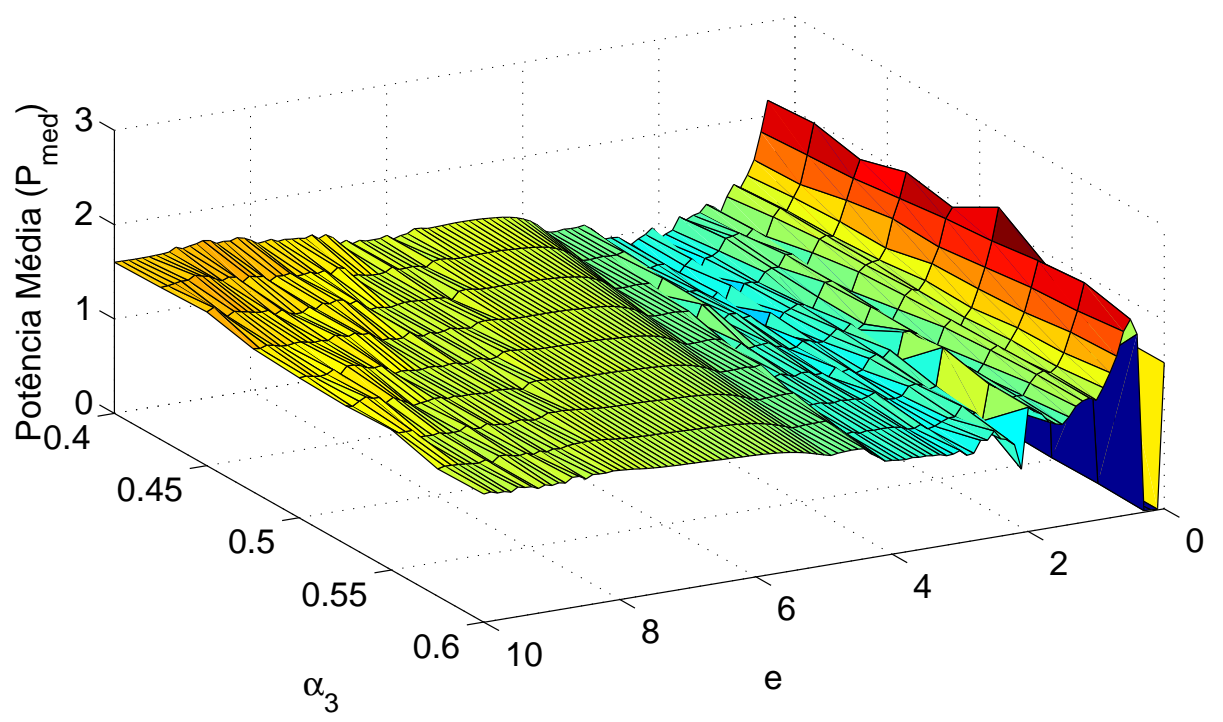

Fonte: Elaborada pelo próprio autor

Na Figura 29. é apresentada a potência média capturada para o parâmetro $\alpha_{3}$, na qual pode ser visto que a energia capturada é maior, quando o valor do parâmetro $\alpha_{3}$ tem um valor de $-20 \%$ em relação ao seu valor nominal.

Figura 29 - Potência Média para o Parâmetro $\alpha_{3}$

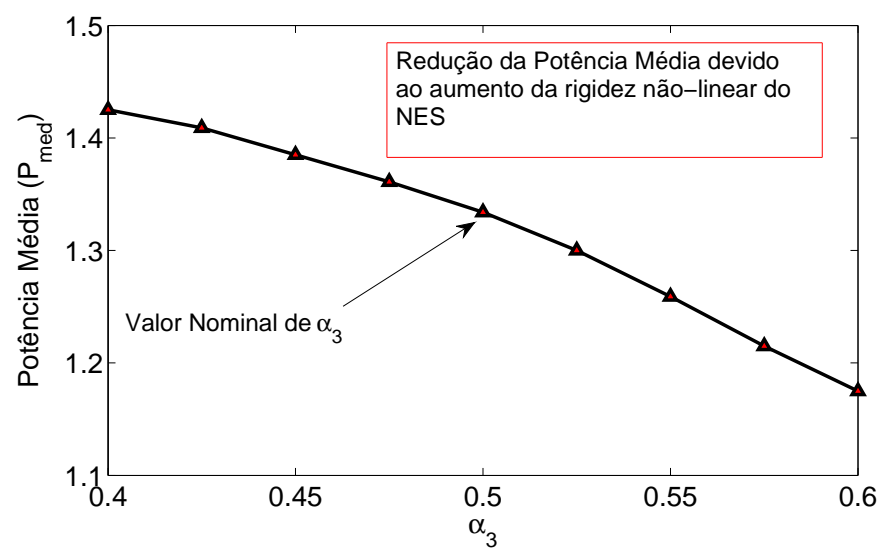

Fonte: Elaborada pelo próprio autor

Essa condição ocorre por causa da sensibilidade na variação do parâmetro, que causa duplicação do período de oscilação no sistema. A estratégia de controle manteve o sistema em uma órbita periódica estável para outros valores de parâmetro $\alpha_{3}$, mas uma diminuição constante na potência média capturada foi observada. 


\subsubsection{Variação do Parâmetro de Rigidez Não Linear $\beta_{3}$}

O comportamento do sistema, levando em consideração a variação no parâmetro $\beta_{3}$, é mostrado na sequência.

O controle apresentou algum tipo de sensibilidade à variação dos valores do parâmetro, e uma duplicação do período ocorreu.

A Figura 30 permite observar que os maiores erros no parâmetro $\beta_{3}$ ocorrem quando a variação do valor do parâmetro é de $+15 \%$ e $+20 \%$ em relação ao seu valor nominal. Nessa condição, o sistema apresenta uma potência média capturada inferior, em relação à alcançada pelo sistema com o valor nominal. Os resultados presentes nas figuras demonstram que a variação no valor do parâmetro $\beta_{3}$ altera o comportamento do sistema e o período de duplicação ocorre, mudando a quantidade de energia capturada.

Figura 30 - Diagramas de Bifurcação do Parâmetro $e$ para a Variação da Rigidez Não Linear $\beta_{3}$

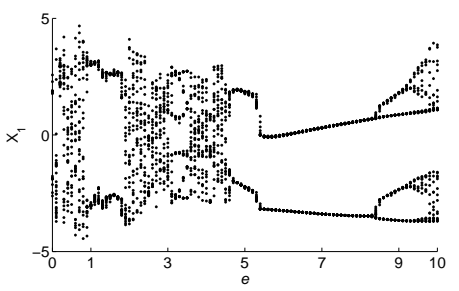

(a) $\beta_{3}=0.16$

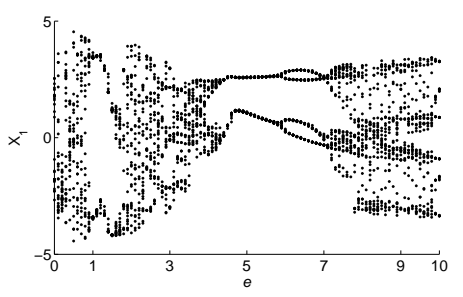

(d) $\beta_{3}=0.19$

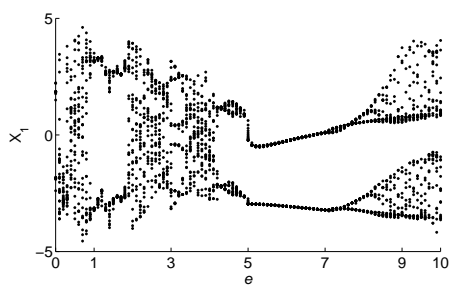

(b) $\beta_{3}=0.17$

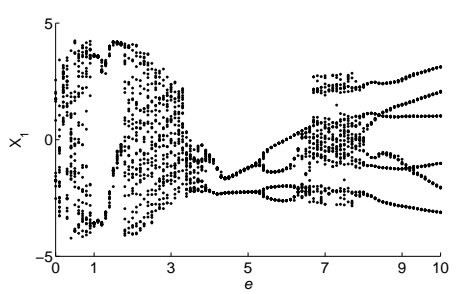

(e) $\beta_{3}=0.21$

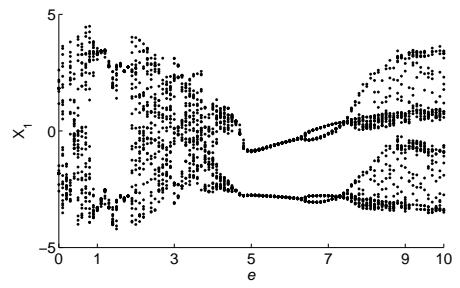

(c) $\beta_{3}=0.18$

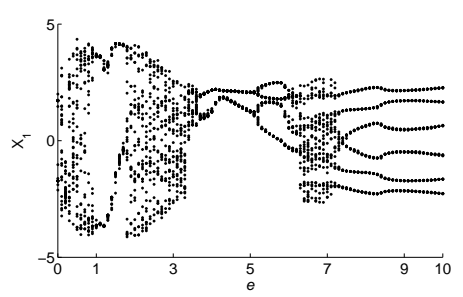

(f) $\beta_{3}=0.22$

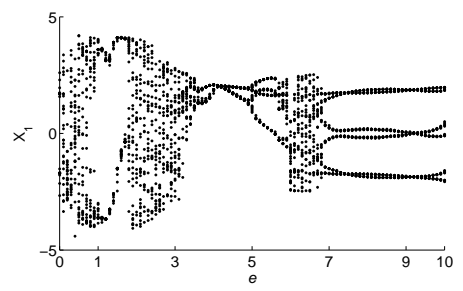

(g) $\beta_{3}=0.23$

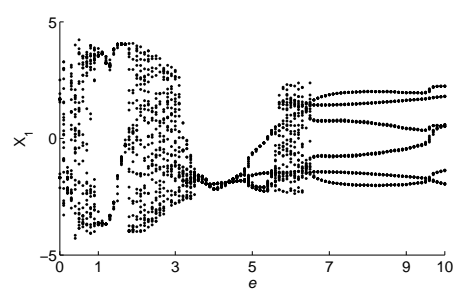

(h) $\beta_{3}=0.24$

Fonte: Elaborada pelo próprio autor

A influência do coeficiente $\beta_{3}$ sobre a potência média capturada foi considerada sobre 
o intervalo do parâmetro de controle $0 \leq e \leq 10$ e foi mostrada na Figura 31 em que o valor nominal de $\beta_{2}=0.2$.

Figura 31 - Diagrama de Potência Média para o Parâmetro $\beta_{3}$

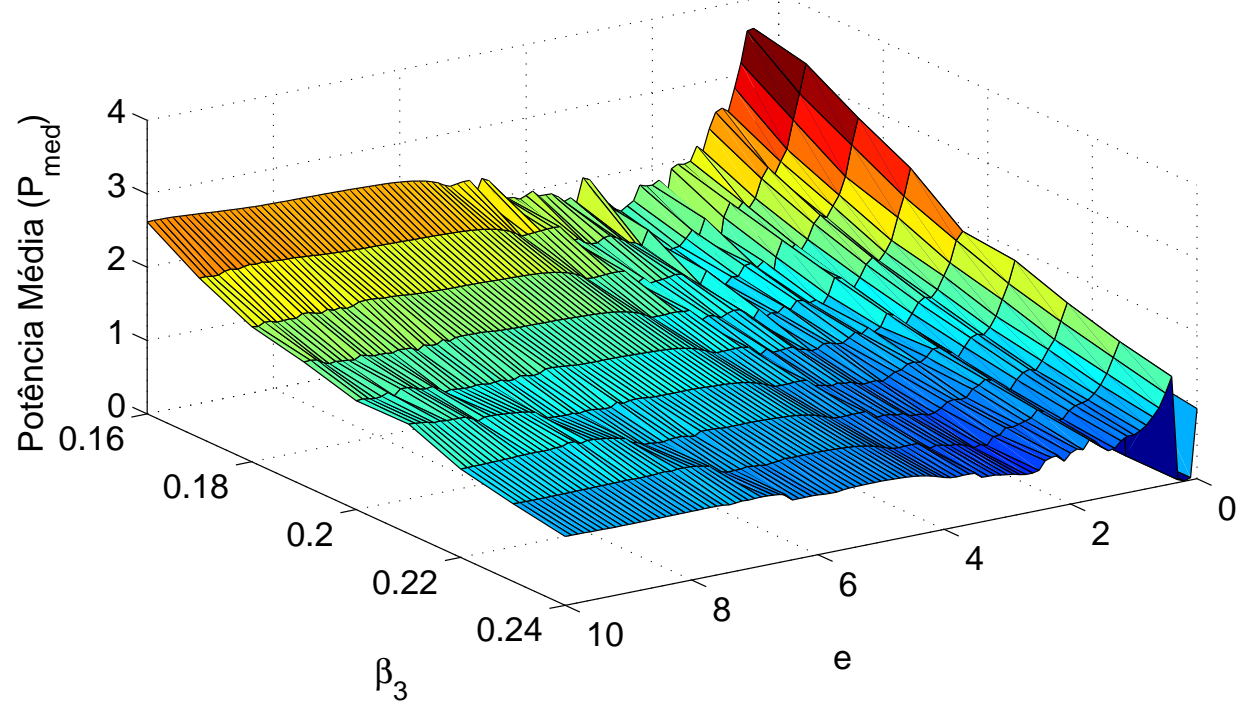

Fonte: Elaborada pelo próprio autor

A Figura 32 apresenta a potência média capturada devido a mudanças no parâmetro $\beta_{3}$. Aqui, novamente foi verificado que a potência capturada é superior, quando o valor do parâmetro $\beta_{3}$ é menor. Quando o valor do parâmetro é acrescido, a potência média capturada sofre redução.

Figura 32 - Potência Média para o Parâmetro $\beta_{3}$

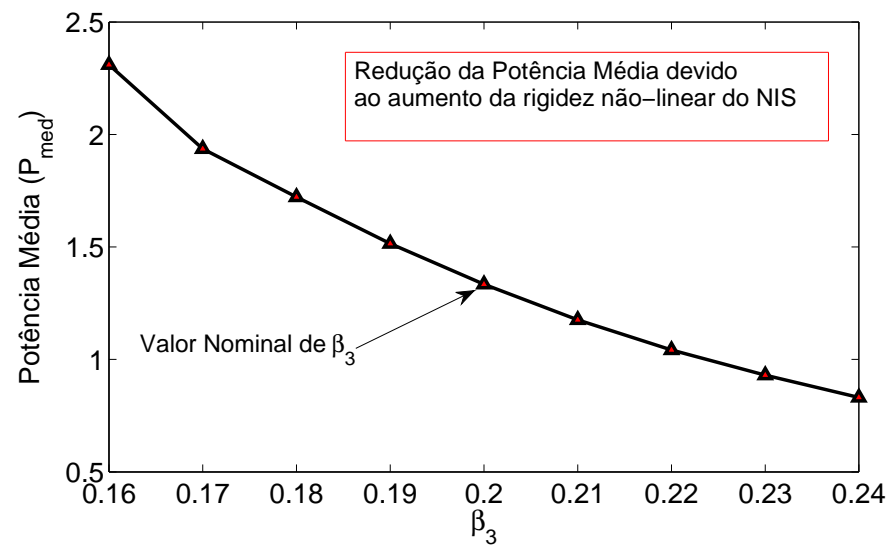

Fonte: Elaborada pelo próprio autor 


\subsubsection{Variação do Paramâtro $\delta_{1}$}

Analisando-se os diagramas de bifurcação na Figura 33 , pode-se ver que constantes erros do parâmetro $\delta_{1}$ ocorreram com a variação do seu valor nominal, em passos de $5 \%$. Com $-20 \%,-15 \%,+15 \%,+20 \%$, o comportamento do sistema deixa de ser periódico. Depois de uma análise dos resultados da variação de $\delta_{1}$ para esse parâmetro, conclui-se que este é o parâmetro mais sensível às incertezas. Sua variação fez com que ocorresse a perda de estabilidade e levou o sistema a um comportamento caótico. Essa condição provoca uma alteração na captura de energia, em que a resposta final poderia ser imprevisível.

Figura 33 - Diagramas de Bifurcação do Parâmetro $e$ para a Variação de $\delta_{1}$

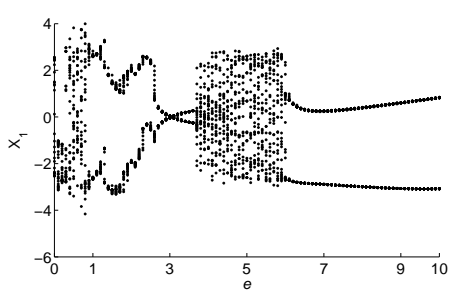

(a) $\delta_{1}=6.6984$

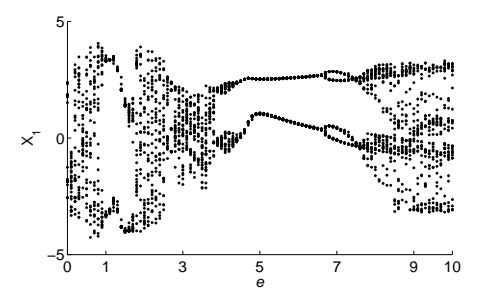

(d) $\delta_{1}=7.95435$

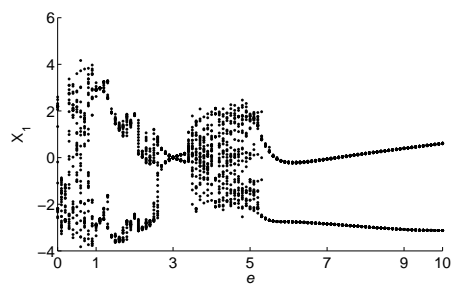

(b) $\delta_{1}=7.11705$

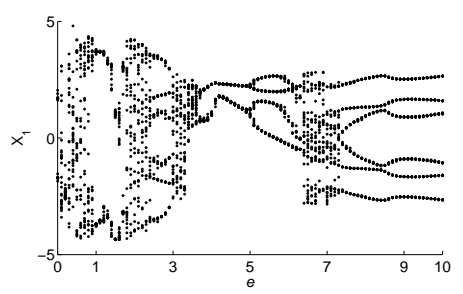

(e) $\delta_{1}=8.79165$

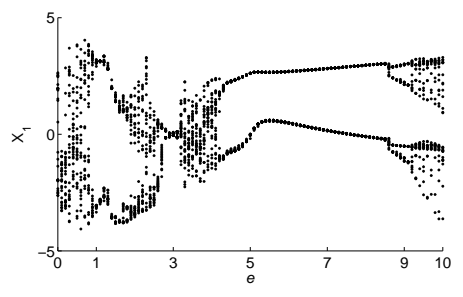

(c) $\delta_{1}=7.5357$

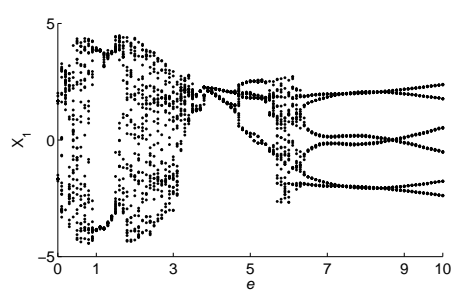

(f) $\delta_{1}=9.2103$

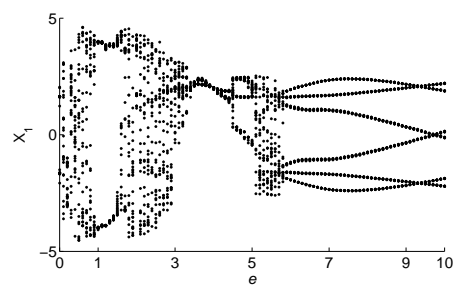

(g) $\delta_{1}=9.62895$

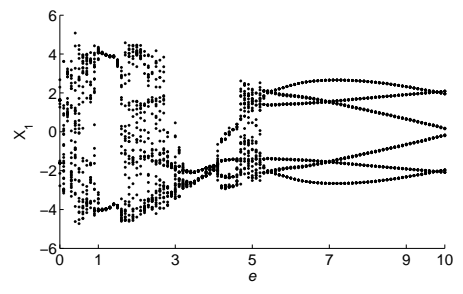

(h) $\delta_{1}=10.0476$

Fonte: Elaborada pelo próprio autor

Na Figura 34 é apresentada a influência da variação no coeficiente $\delta_{1}$ sobre a potência média capturada, considerando-se $0 \leq e \leq 10$. 
Figura 34 - Diagrama de Potência Média para o Parâmetro $\delta_{1}$

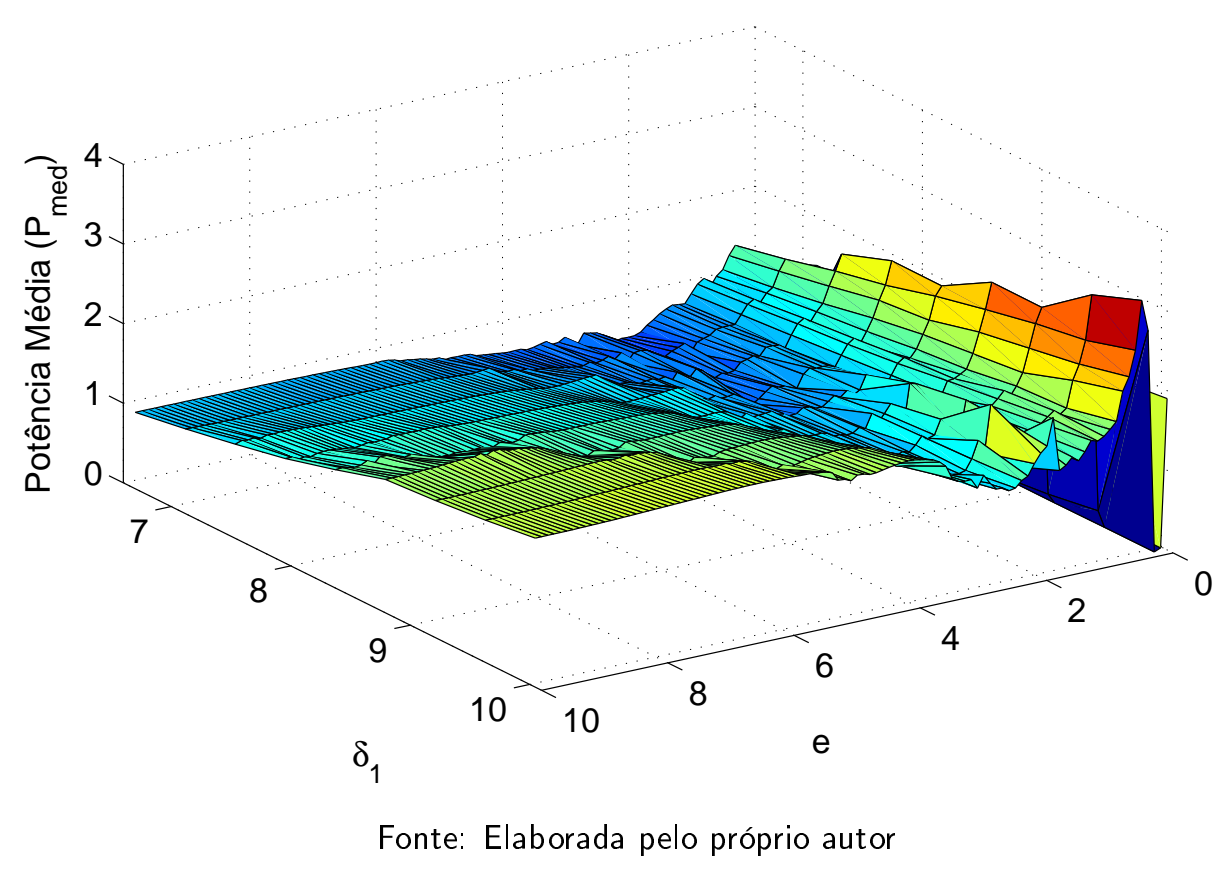

Na Figura 35, a potência média capturada no parâmetro $\delta_{1}$ é apresentada. Os resultados mostram que a potência média capturada foi fortemente influenciada por incertezas, e o parâmetro de controle $e$, em alguns casos, levou o sistema a um comportamento caótico, mas, em outros casos, o controle foi robusto. Olhando para os diagramas de bifurcação, pode concluir-se que, no comportamento caótico, existem órbitas interessantes para ser consideradas, a fim de alcançar uma captura de energia satisfatória.

Figura 35 - Potência Média para o Parâmetro $\delta_{1}$

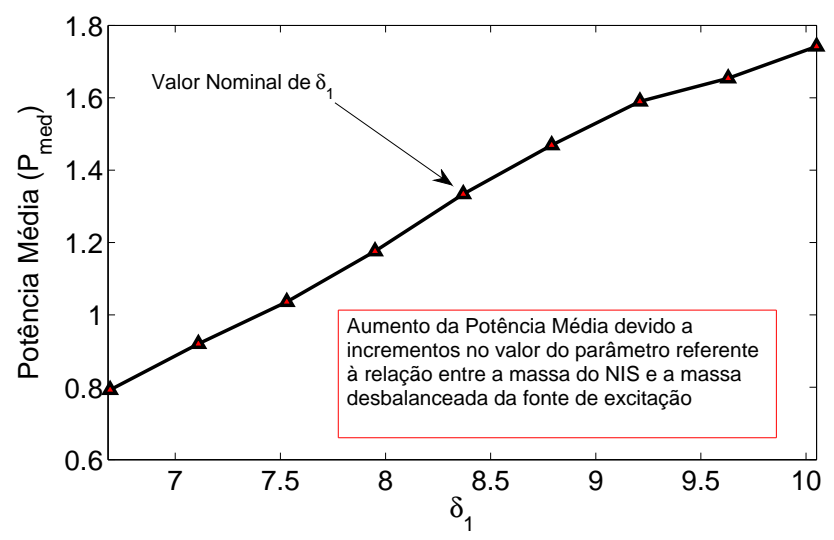

Fonte: Elaborada pelo próprio autor 


\subsection{RESUMO DOS RESULTADOS PARA O CONTROLE (NES)}

Os resultados das simulações para as potências médias capturadas, considerando-se o parâmetro de controle $e=5.0$, são apresentados de forma resumida nas tabelas a seguir (Tabela 4 à Tabela 8):

Tabela 4 - Potência Média $\alpha_{1}$

\begin{tabular}{ccc}
\hline Parâmetro $\alpha_{1}$ & Valor & Potência Média $\left(P_{\text {med }}\right)$ \\
\hline$-20 \%$ & 0.080 & 1.416 \\
$-15 \%$ & 0.085 & 1.396 \\
$-10 \%$ & 0.090 & 1.375 \\
$-5 \%$ & 0.095 & 1.355 \\
Valor Nominal & 0.100 & 1.334 \\
$+5 \%$ & 0.105 & 1.312 \\
$+10 \%$ & 0.110 & 1.290 \\
$+15 \%$ & 0.115 & 1.268 \\
$+20 \%$ & 0.120 & 1.245 \\
\hline
\end{tabular}

Tabela 5 - Potência Média $\alpha_{2}$

\begin{tabular}{ccc}
\hline Parâmetro $\alpha_{2}$ & Valor & Potência Média $\left(P_{\text {med }}\right)$ \\
\hline$-20 \%$ & 0.080 & 1.325 \\
$-15 \%$ & 0.085 & 1.327 \\
$-10 \%$ & 0.090 & 1.329 \\
$-5 \%$ & 0.095 & 1.331 \\
Valor Nominal & 0.100 & 1.334 \\
$+5 \%$ & 0.105 & 1.336 \\
$+10 \%$ & 0.110 & 1.338 \\
$+15 \%$ & 0.115 & 1.340 \\
$+20 \%$ & 0.120 & 1.342 \\
\hline
\end{tabular}


Tabela 6 - Potência Média $\alpha_{3}$

\begin{tabular}{ccc}
\hline Parâmetro $\alpha_{3}$ & Valor & Potência Média $\left(P_{\text {med }}\right)$ \\
\hline$-20 \%$ & 0.400 & 1.425 \\
$-15 \%$ & 0.425 & 1.409 \\
$-10 \%$ & 0.450 & 1.385 \\
$-5 \%$ & 0.475 & 1.361 \\
Valor Nominal & 0.500 & 1.334 \\
$+5 \%$ & 0.525 & 1.300 \\
$+10 \%$ & 0.550 & 1.259 \\
$+15 \%$ & 0.575 & 1.215 \\
$+20 \%$ & 0.600 & 1.175 \\
\hline
\end{tabular}

Tabela 7 - Potência Média $\beta_{3}$

\begin{tabular}{ccc}
\hline Parâmetro $\beta_{3}$ & Valor & Potência Média $\left(P_{\text {med }}\right)$ \\
\hline$-20 \%$ & 0.160 & 2.310 \\
$-15 \%$ & 0.170 & 1.936 \\
$-10 \%$ & 0.180 & 1.722 \\
$-5 \%$ & 0.190 & 1.515 \\
Valor Nominal & 0.200 & 1.334 \\
$+5 \%$ & 0.210 & 1.176 \\
$+10 \%$ & 0.220 & 1.042 \\
$+15 \%$ & 0.230 & 0.930 \\
$+20 \%$ & 0.240 & 0.831 \\
\hline
\end{tabular}


Tabela 8 - Potência Média $\delta_{1}$

\begin{tabular}{ccc}
\hline Parâmetro $\delta_{1}$ & Valor & Potência Média $\left(P_{m e d}\right)$ \\
\hline$-20 \%$ & 6.6984 & 0.793 \\
$-15 \%$ & 7.11705 & 0.920 \\
$-10 \%$ & 7.5357 & 1.036 \\
$-5 \%$ & 7.95435 & 1.176 \\
Valor Nominal & $\mathbf{8 . 3 7 3}$ & $\mathbf{1 . 3 3 4}$ \\
$+5 \%$ & 8.79165 & 1.469 \\
$+10 \%$ & 9.2103 & 1.590 \\
$+15 \%$ & 9.62895 & 1.654 \\
$+20 \%$ & 10.0476 & 1.742 \\
\hline
\end{tabular}




\section{PÓRTICO COM CONTROLE PASSIVO POR PÊNDULO}

\subsection{TRATAMENTOS PRELIMINARES}

Por meio de simulações numéricas, a influência no movimento vibratório do NIS com a inclusão do controle passivo por pêndulo são verificadas. A melhora na eficiência da captura de energia é obtida buscando-se os parâmetros do controlador que obtenham maior potência. As

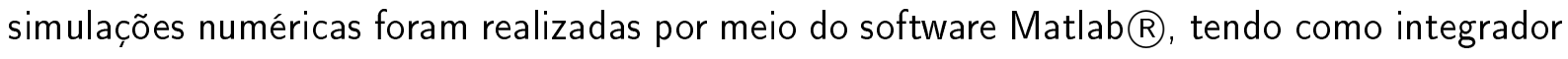
numérico o algoritmo Runge-Kutta de quarta ordem "ode45". Os resultados das simulações no domínio do tempo foram obtidos pela Eq. 19 considerando-se os parâmetros da Tabela 9 obtidos e adaptados de Triplett e Quinn (2009), Tusset, Balthazar e Felix (2013), lliuk et al. (2013c).

\begin{tabular}{|c|c|c|c|}
\hline Parâmetro & Valor & Parâmetro & Valor \\
\hline$\alpha_{1}$ & 0.10 & $\beta_{1}$ & 1.00 \\
\hline$\beta_{3}$ & 0.20 & $\delta_{1}$ & 8.373 \\
\hline$\delta_{2}$ & 8.373 & $\rho_{1}$ & 0.05 \\
\hline$\rho_{2}$ & 100 & $\rho_{3}$ & 200 \\
\hline$\rho_{4}$ & 2.254 & $\rho_{5}$ & 0.23 \\
\hline$\rho_{6}$ & 0.40 & $\theta$ & 0.20 \\
\hline$\Theta$ & 0.60 & $\rho$ & 1.00 \\
\hline
\end{tabular}

As simulações numéricas para a obtenção da resposta do NIS foram realizadas mantendose as condições iniciais iguais a zero e levando-se em conta o intervalo de tempo adimensional $0 \leq \tau \leq 500$. Considerou-se o parâmetro de controle válido no intervalo $0 \leq e \leq 1$.

\subsection{CONTROLE PASSIVO DE OSCILAÇÕES USANDO UM PÊNDULO}

Para determinar o valor da variável de controle $e$, analisou-se o diagrama de bifurcação da Figura 36 em conjunto com a mudança na potência média apresentada na Figura 37. Com isso, obteve-se os valores de $e$ que geram um comportamento periódico, assim como, os valores de $e$ que otimizam a potência média capturada, considerando-se $0 \leq e \leq 1$. Para o caso de $e=0$, temos o sistema da Eq. 19 sem o controle passivo acoplado. 
Figura 36 - Diagrama de Bifurcação do Parâmetro de Controle $e$

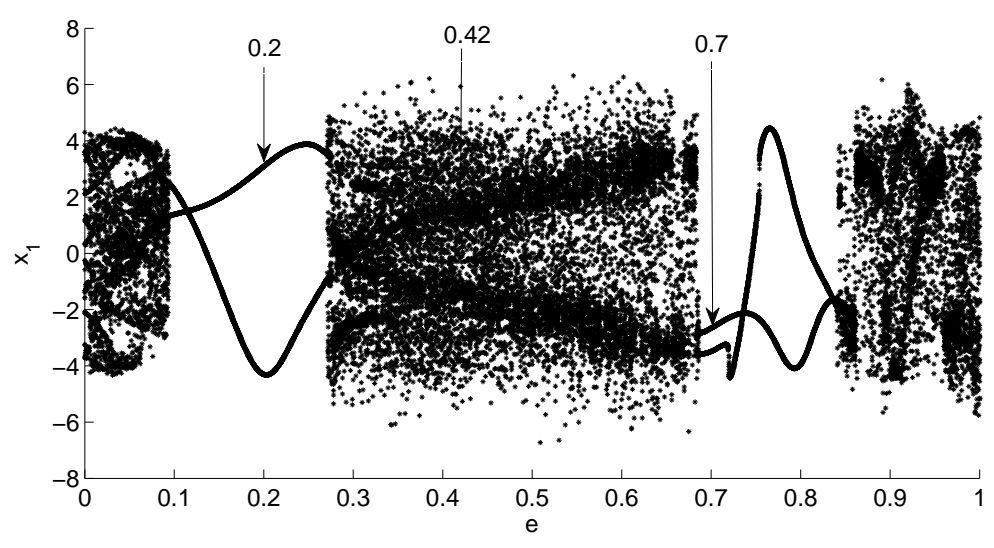

Fonte: Elaborada pelo próprio autor

Figura 37 - Potência Média Capturada para a Variação do Parâmetro $e$

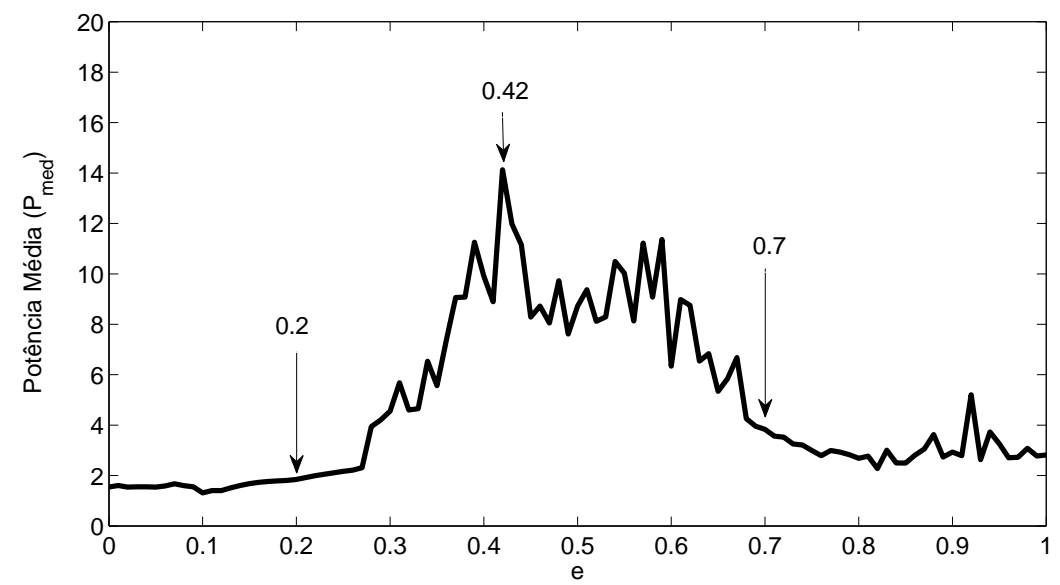

Fonte: Elaborada pelo próprio autor

Como pode ser visto na Figura 36 , é possível determinar os intervalos em que o sistema apresenta um comportamento periódico ou caótico, e na Figura 37 analisa-se a mudança na potência média capturada. Relacionando-se os dois resultados, é possível definir estratégias de controle para o sistema de captura de energia.

Foram realizadas simulações para os casos em que o parâmetro de controle $e$ assumiu os valores apontados nas figuras 36 e 37 . em que o objetivo foi capturar uma potência média máxima: caso $e=0.42$, e a observação de dois casos em que se desejava o comportamento periódico com maior estabilidade: caso $e=0.2$ e caso $e=0.7$.

Os resultados para os casos são demonstrados nas subseções a seguir: 


\subsubsection{Aplicação da Estratégia de Controle Passivo: Caso $e=0.2$}

A Figura 38 apresenta a aplicação da estratégia de controle passivo para o caso em que o parâmetro de controle assume o valor de $e=0.2$. Na Figura 38a, tem-se o retrato de fase para o modelo que apresenta um comportamento periódico, que pode ser verificado na Figura 38b, a qual apresenta o mapa de Poincaré. A tensão elétrica adimensional capturada é apresentada na Figura 38c e na Figura 38d a potência adimensional capturada para o sistema periódico é apresentada.

Pode-se notar que o sistema apresenta um comportamento periódico desejável e com um pequeno aumento na potência capturada.

Figura 38 - Aplicação do Controle Passivo Utilizando os Valores do Parâmetro $e=0.2$

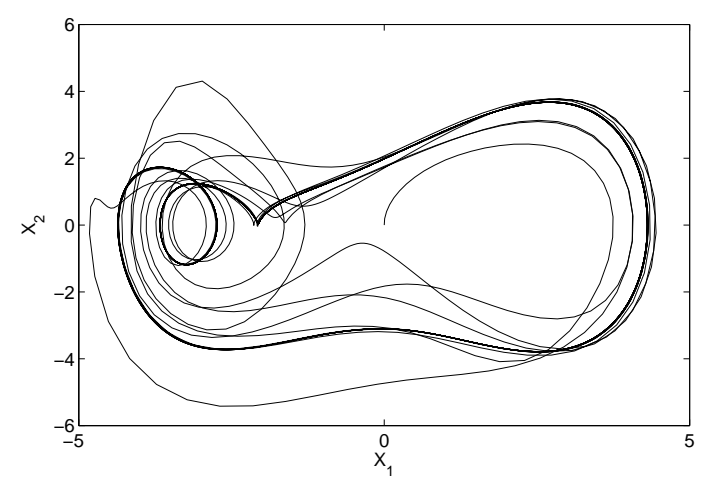

(a) Retrato de Fase

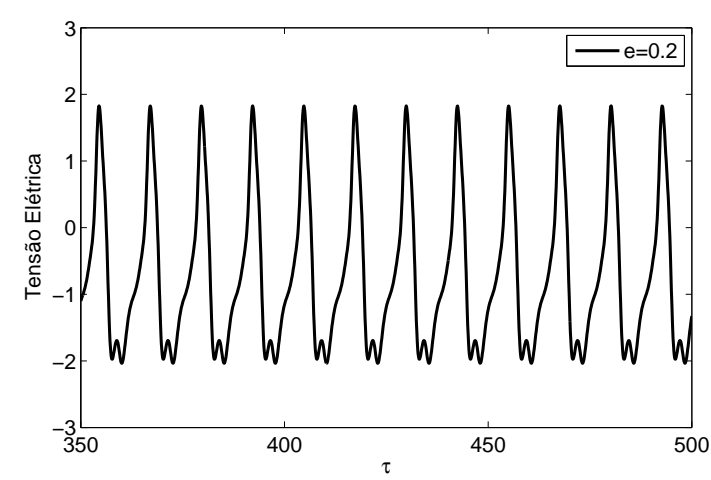

(c) Tensão Elétrica

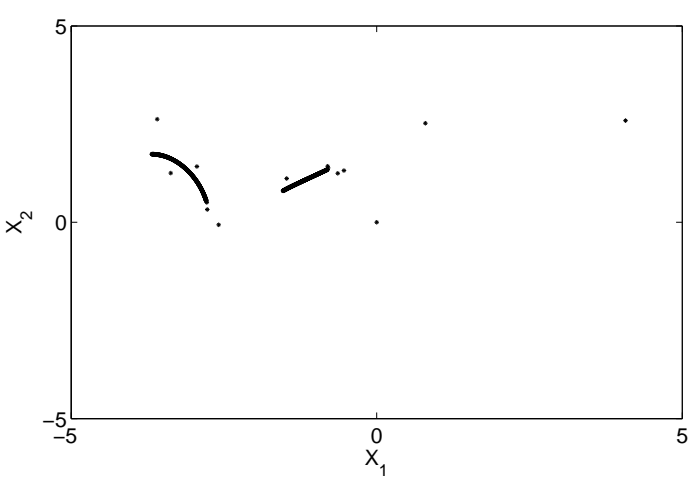

(b) Mapa de Poincaré

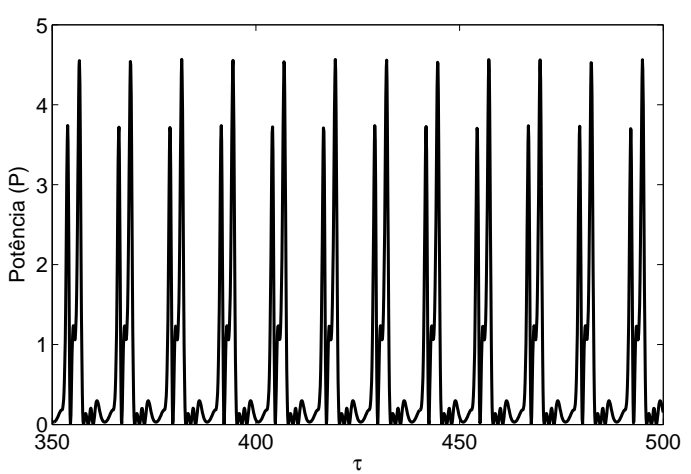

(d) Potência Capturada

Fonte: Elaborada pelo próprio autor 


\subsubsection{Aplicação da Estratégia de Controle Passivo: Caso $e=0.42$}

A Figura 39 apresenta a aplicação da estratégia de controle passivo para o caso em que o parâmetro de controle assume o valor de $e=0.42$. Na Figura 39a tem-se o retrato de fase para o modelo que apresenta um comportamento caótico com característica de potencial duplo, semelhante a um oscilador Duffing forçado. Tal comportamento pode ser verificado por meio da análise do atrator estranho, presente no mapa de Poincaré da Figura $39 \mathrm{~b}$. A tensão elétrica adimensional capturada é apresentada na Figura 39c. A potência adimensional para o oscilador pode ser vista na Figura 39d, e apresenta um comportamento caótico.

O sistema apresenta aumento significativo na potência capturada em regime caótico, o que é um bom resultado, porém seria necessário avaliar também a integridade da estrutura nesse caso.

Figura 39 - Aplicação do Controle Passivo Utilizando os Valores do Parâmetro $e=0.42$

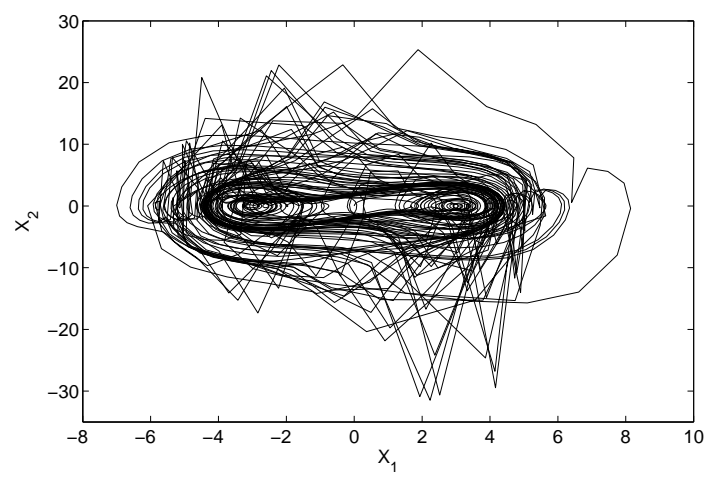

(a) Retrato de Fase

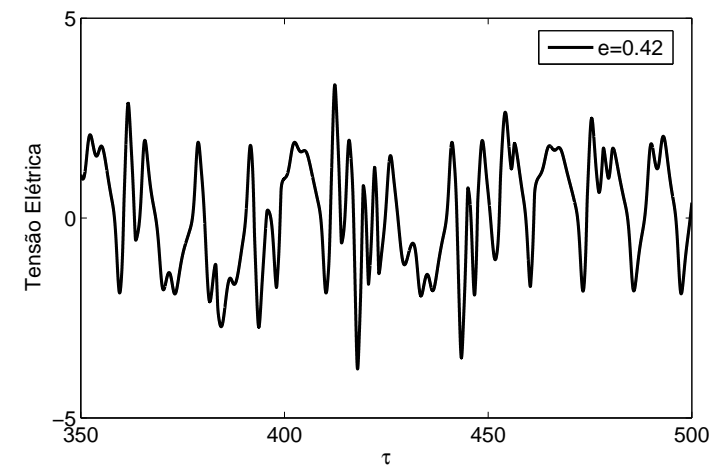

(c) Tensão Elétrica

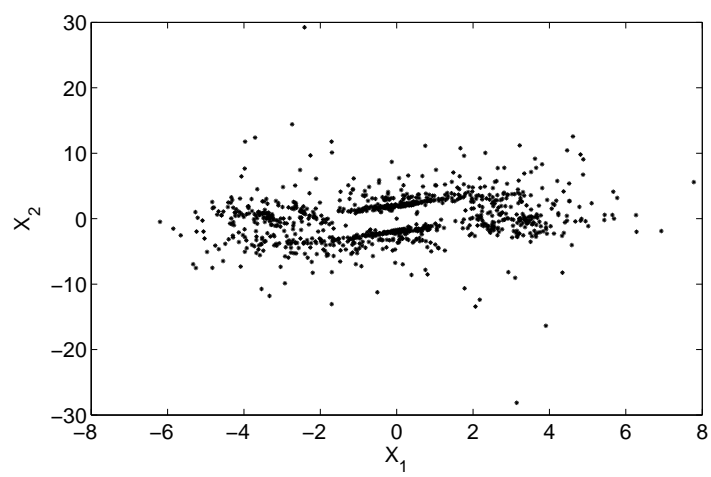

(b) Mapa de Poincaré

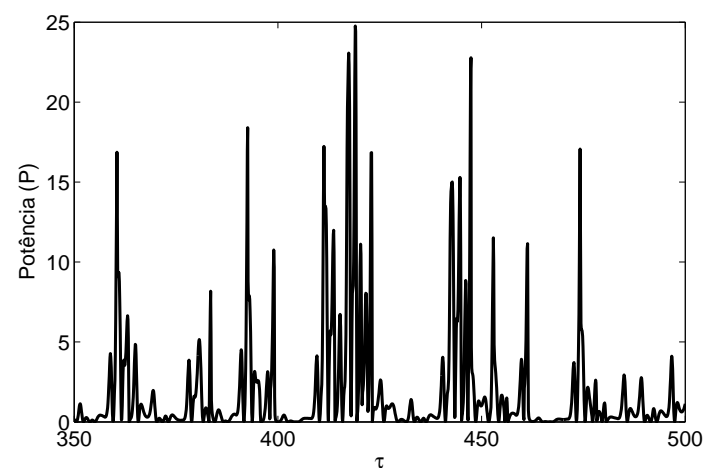

(d) Potência Capturada

Fonte: Elaborada pelo próprio autor 


\subsubsection{Aplicação da Estratégia de Controle Passivo: Caso $e=0.7$}

A Figura 40 apresenta a aplicação da estratégia de controle passivo para o caso em que o parâmetro de controle assume o valor de $e=0.7$. Na Figura 40a, tem-se o retrato de fase para o modelo que apresenta um comportamento periódico, o que pode ser verificado na Figura 40b, a qual apresenta o mapa de Poincaré. A tensão elétrica adimensional capturada é apresentada na Figura 40d. Na Figura 40c, a potência adimensional capturada apresenta um comportamento periódico.

Nesse caso, o sistema apresentou um comportamento periódico, bem como sensível melhora na captura de energia.

Figura 40 - Aplicação do Controle Passivo Utilizando os Valores do Parâmetro $e=0.7$

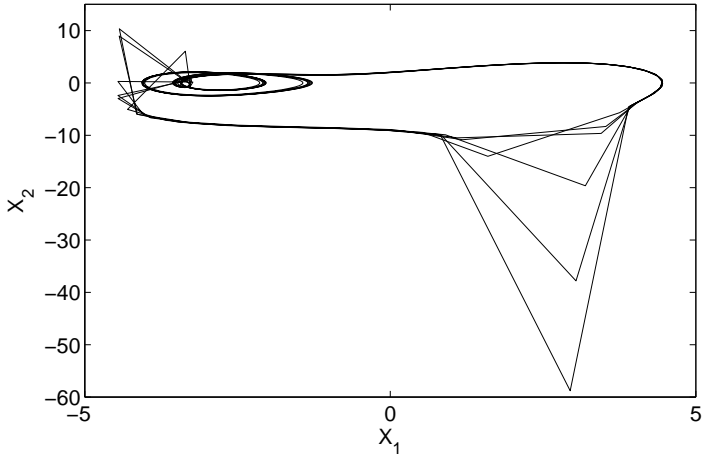

(a) Retrato de Fase

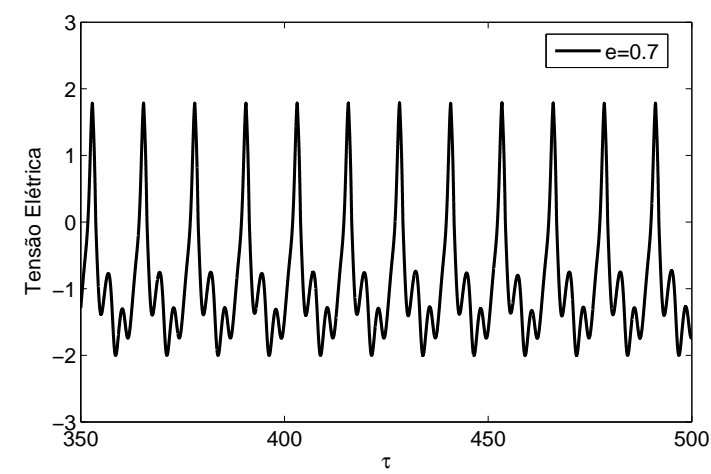

(c) Tensão Elétrica

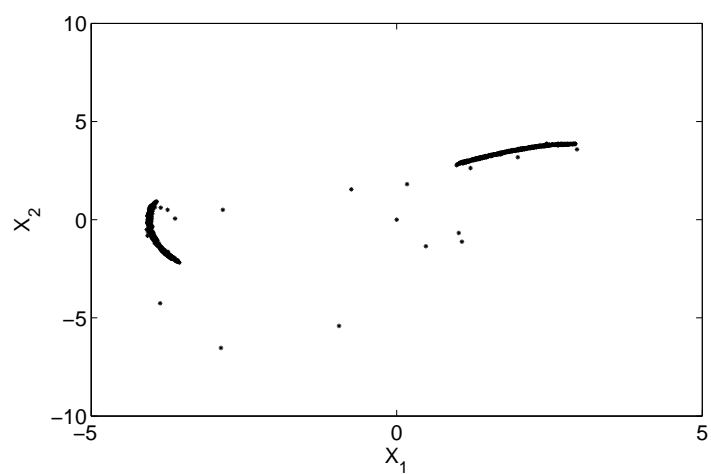

(b) Mapa de Poincaré

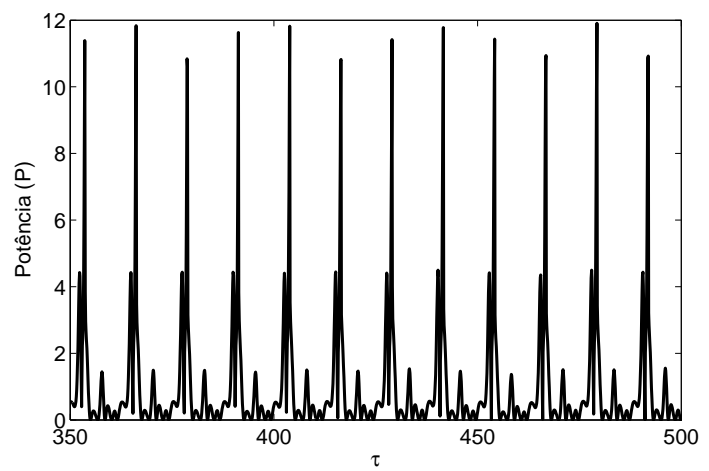

(d) Potência Capturada

Fonte: Elaborada pelo próprio autor 


\subsubsection{Transferência da Energia}

Como em Tusset et al. (2012) e Tusset, Balthazar e Felix (2013), o controle ocorre devido à troca de energia entre o sistema não ideal (NIS) e o pêndulo sendo utilizado como um controlador passivo. Considerando-se apenas a energia cinética do modelo proposto por Tusset, Balthazar e Felix (2013), tem-se as seguintes equações de troca de energia instantânea entre o NIS e o pêndulo:

$$
\begin{aligned}
E_{N I S_{i}} & =\frac{E_{N I S}}{\left(E_{N I S}+E_{p}\right)} \\
E_{P_{i}} & =\frac{E_{P}}{\left(E_{N I S}+E_{p}\right)}
\end{aligned}
$$

onde:

$$
E_{N I S}=\frac{x_{2}^{2}}{2}+\frac{x_{4}^{2}}{2} ; \quad E_{p}=\frac{x_{6}^{2}}{2}
$$

Na Figura 41, é apresentado o histórico de deslocamento no tempo da energia instantânea para o fenômeno de bombeamento de energia (energy pumping) entre o sistema não ideal (NIS) e o pêndulo, para o parâmetro de controle $e=0.2$. Também é apresentada a captura de energia piezoelétrica instantânea.

Figura 41 - Deslocamento no Tempo da Transferência de Energia e da Potência Instantânea Capturada $e=0.2$

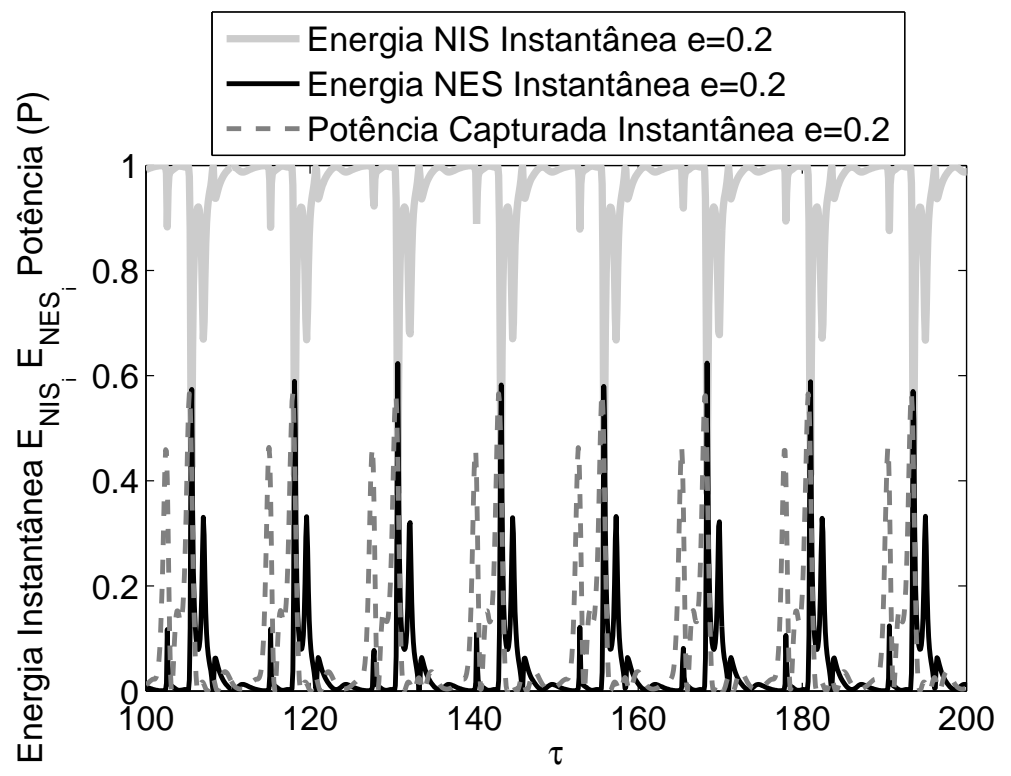

Fonte: Elaborada pelo próprio autor 
Um zoom nos fenômenos de bombeamento de energia e captura de energia é apresentado na Figura 42 em que o aumento evidente na potência capturada pode ser visto exatamente quando ocorre a troca de energia entre o sistema não ideal (NIS) e o pêndulo.

Figura 42 - Zoom do Deslocamento no Tempo da Transferência de Energia e da Potência Instantânea Capturada $e=0.2$

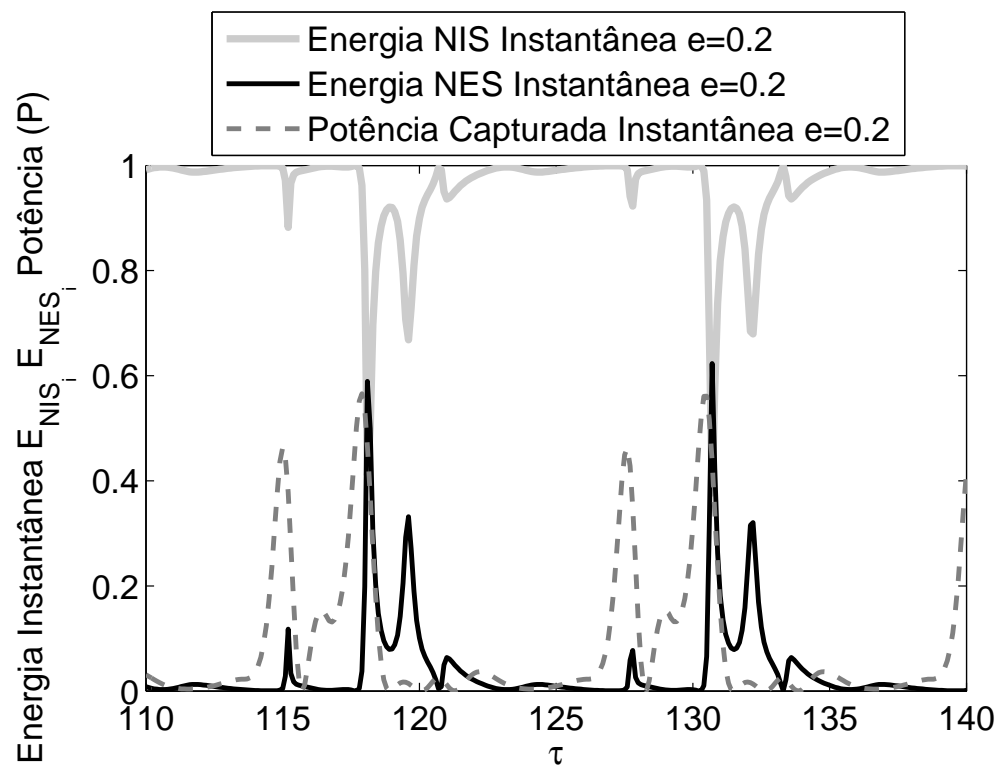

Fonte: Elaborada pelo próprio autor

Na Figura 43, é apresentado o histórico de deslocamento no tempo para o fenômeno de bombeamento (energy pumping) e a captura de energia piezoelétrica instantânea entre o NIS e o pêndulo, para o parâmetro de controle $e=0.42$. 
Figura 43 - Deslocamento no Tempo da Transferência de Energia e da Potência Instantânea Capturada $e=0.42$

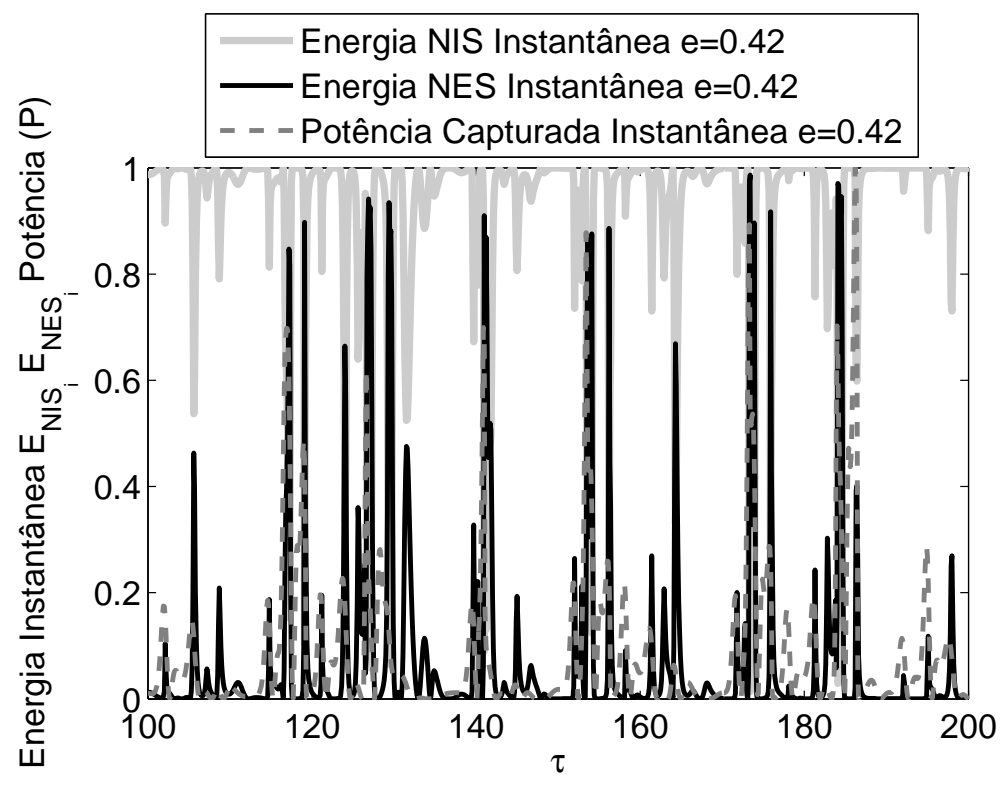

Fonte: Elaborada pelo próprio autor

Um zoom nos fenômenos de bombeamento de energia e captura de energia é mostrado na Figura 44, em que o aumento evidente na potência capturada pode ser visto exatamente quando ocorre a troca de energia entre o sistema não ideal (NIS) e o pêndulo.

Figura 44 - Zoom do Deslocamento no Tempo da Transferência de Energia e da Potência Instantânea Capturada $e=0.42$

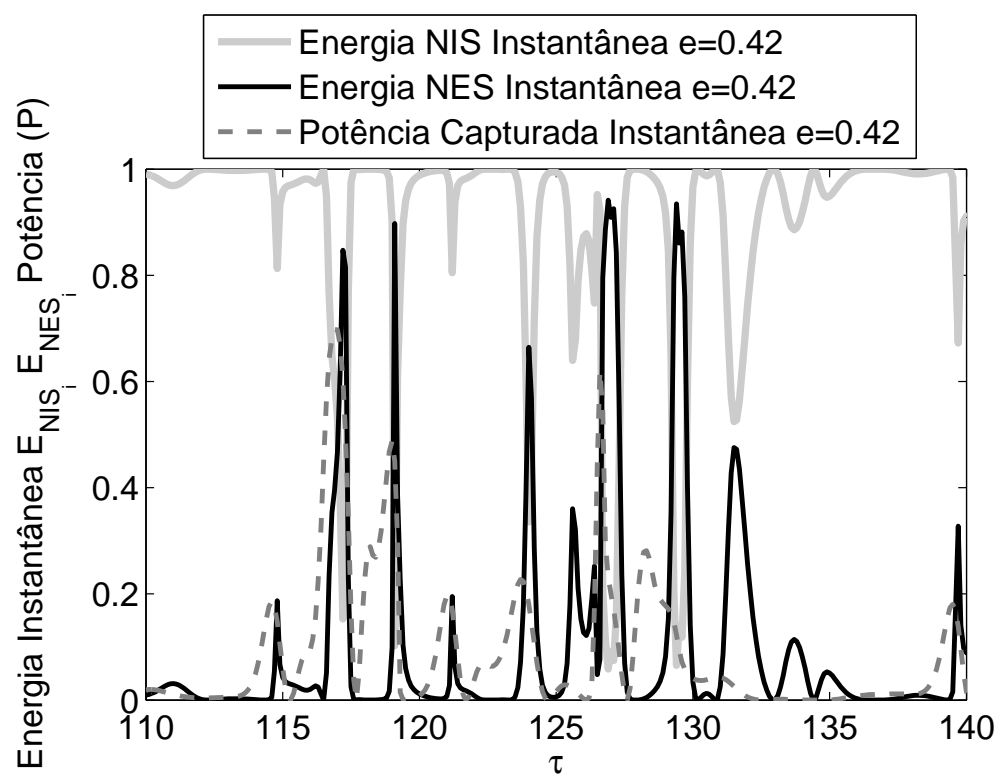

Fonte: Elaborada pelo próprio autor

Na Figura 45, é apresentado o histórico de deslocamento no tempo para o fenômeno 
de bombeamento (energy pumping) e a captura de energia piezoelétrica instantânea entre o NIS e o pêndulo, para o parâmetro de controle $e=0.7$.

Figura 45 - Deslocamento no Tempo da Transferência de Energia e da Potência Instantânea Capturada $e=0.7$

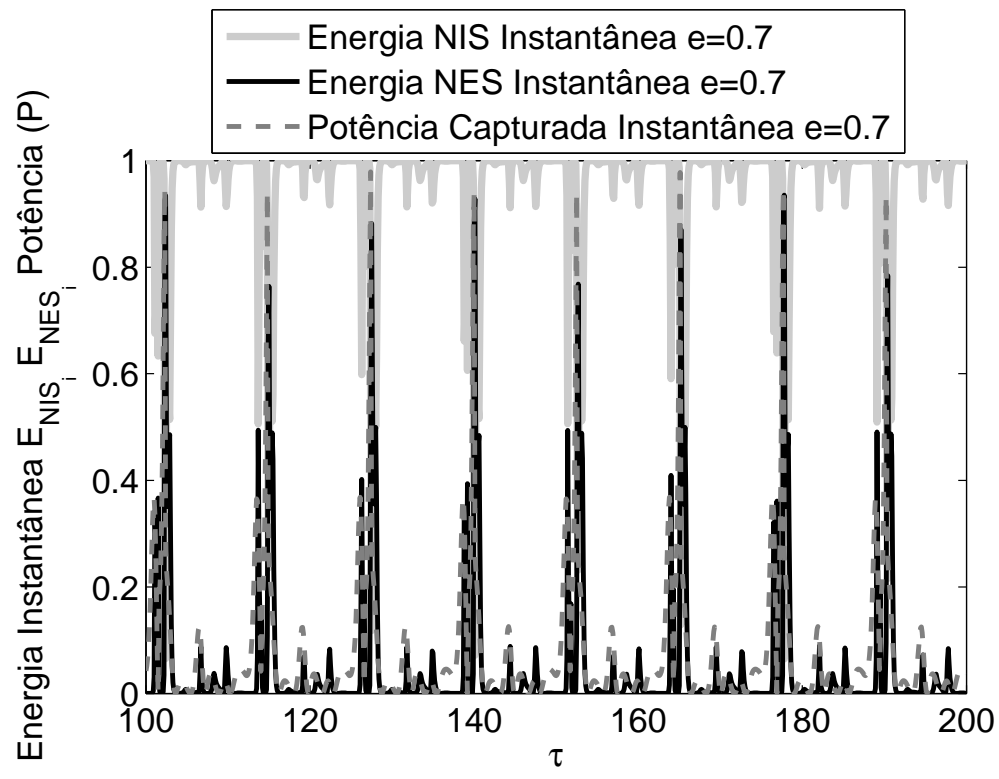

Fonte: Elaborada pelo próprio autor

Um zoom nos fenômenos de bombeamento de energia e captura de energia é apresentado na Figura 46 em que o aumento evidente na potência capturada pode ser visto exatamente quando ocorre a troca de energia entre o sistema não ideal (NIS) e o pêndulo.

Figura 46 - Zoom do Deslocamento no Tempo da Transferência de Energia e da Potência Instantânea Capturada $e=0.7$

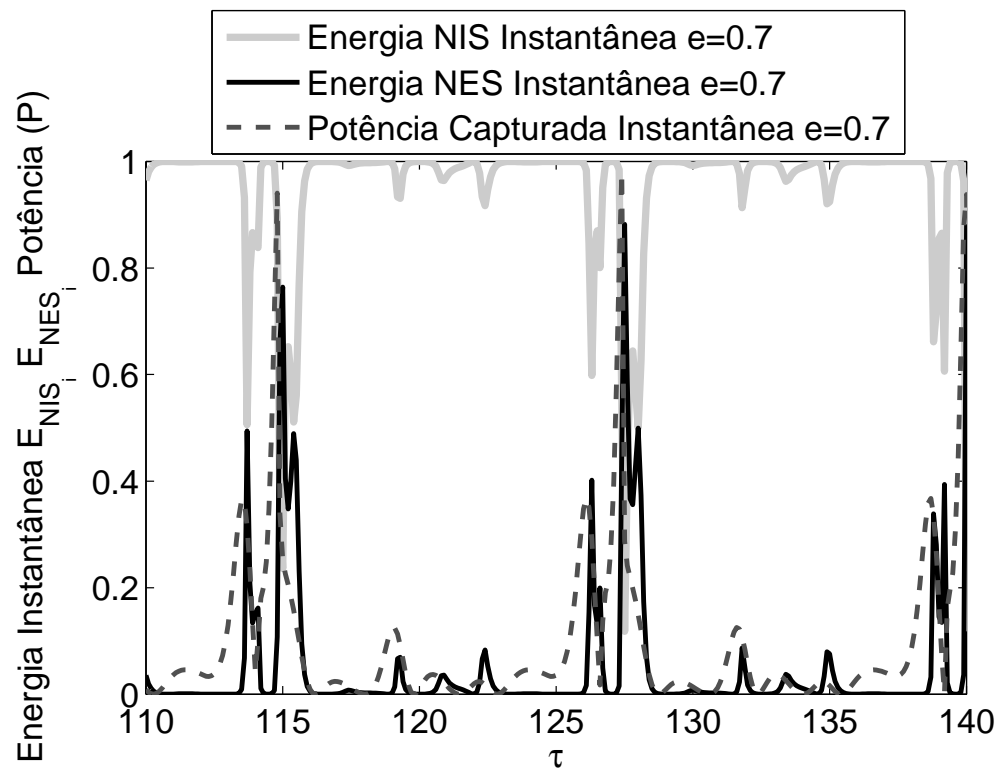

Fonte: Elaborada pelo próprio autor 
Novamente, pode-se verificar que, quando o sistema principal trocou energia com o sistema passivo de controle (pêndulo), ocorreu o aumento da potência capturada. Isso demonstra a eficiência da técnica de controle passivo.

As potências máximas capturadas são apresentadas na Figura 47. a fim de comparar a eficácia da estratégia de controle para o sistema sem controle e com o controle por pêndulo acoplado.

Figura 47 - Potência Máxima para o Sistema Controlado e sem Controle

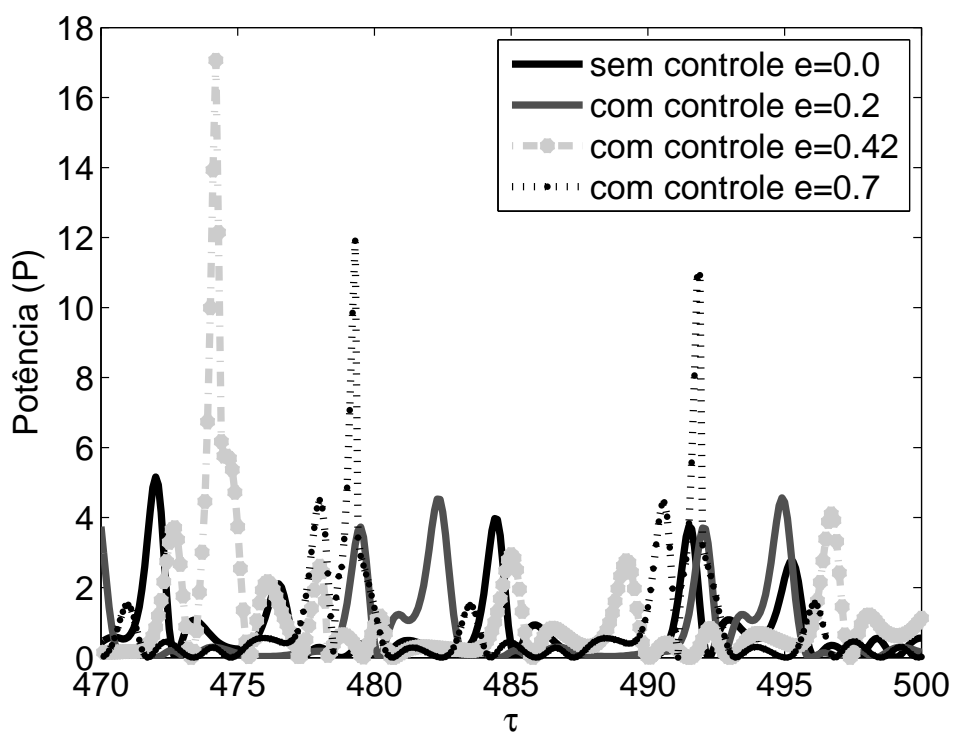

Fonte: Elaborada pelo próprio autor

Calculando-se a potência média capturada por meio da Eq. 13 sobre o intervalo de tempo $0 \leq \tau \leq 500$, obtêm-se os resultados da Tabela 10

Tabela 10 - Potência Média Capturada - Sistema com Controle por Pêndulo

\begin{tabular}{cc}
\hline Parâmetro de Controle & Potência Média \\
\hline$e=0$ & 1.542 \\
$e=0.2$ & 1.844 \\
$e=0.42$ & 15.7 \\
$e=0.7$ & 3.662 \\
\hline
\end{tabular}

Como pode ser visto, mediante a escolha apropriada da variável de controle, foi possível controlar o sistema em uma órbita periódica, com ganho na potência média capturada de $19.20 \%$ para o caso $e=0.2$, e com o ganho de $136.71 \%$ para o caso $e=0.7$. Também foi possível alcançar a potência máxima capturada com ganho de $914.86 \%$ para o caso $e=0.42$. 


\subsection{EFEITO DA VARIAÇÃO DOS PARÂMETROS DE RIGIDEZ E AMORTECIMENTO}

Nos trabalhos de Karami e Inman (2011) e Ferrari et al. (2010), foi analisada e demonstrada a influência do coeficiente de amortecimento e do coeficiente de rigidez não linear em sistemas de captura de energia vibracional. Com o objetivo de analisar o comportamento do sistema proposto com controle passivo, foram analisados individualmente os parâmetros $\alpha_{1}$ e $\beta_{3}$, considerando-se a variação de $\pm 20 \%$ em relação ao valor nominal destes parâmetros, com um passo de $10 \%$.

\subsubsection{Variação do Parâmetro de Amortecimento $\alpha_{1}$}

Na Figura 48 , pode-se verificar a influência da variação do coeficiente de amortecimento $\alpha_{1}$ sobre a potência média capturada. A linha em preto representa o valor nominal do parâmetro $\alpha_{1}=0.1$.

Figura 48 - Potência Média Capturada para a Variação do Parâmetro de Amortecimento $\alpha_{1}$

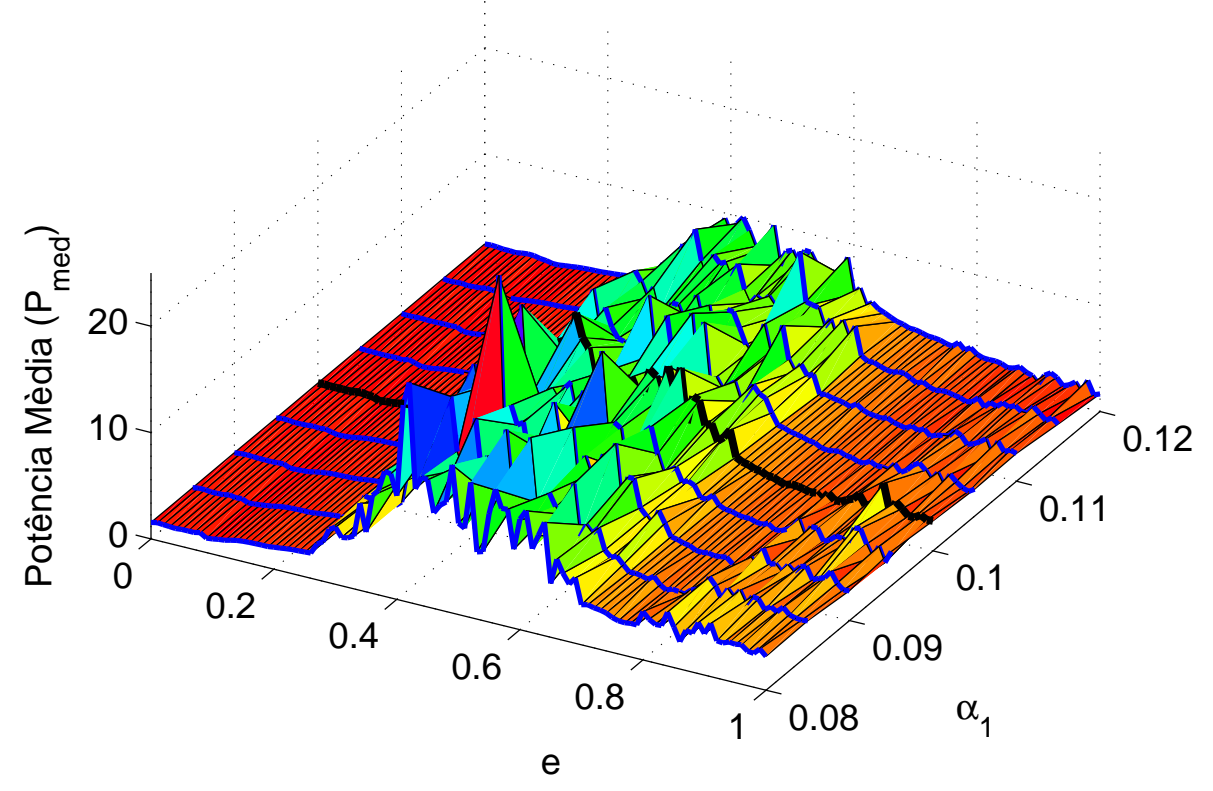

Fonte: Elaborada pelo próprio autor

Como se pode ver na Figura 49, a variação de potência média capturada é sensível para a variação do coeficiente de amortecimento $\alpha_{1}$, no entanto, a potência máxima é alcançada para valores próximos de $e=0.42$. 
Figura 49 - Potência Média Capturada para os Casos do Parâmetro de Controle $e$ com Variação de $\alpha_{1}$

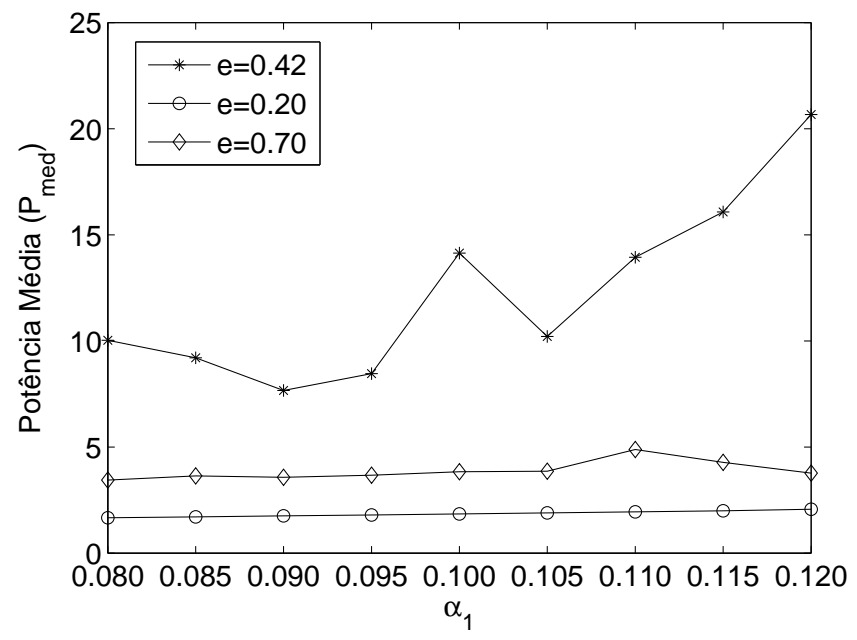

Fonte: Elaborada pelo próprio autor

Na Figura 50 , podem-se ver os diagramas de bifurcação, nos quais se identificam os intervalos em que o sistema possui movimento caótico ou periódico.

Figura 50 - Diagramas de Bifurcação para o Paramêtro de Amortecimento $\alpha_{1}$

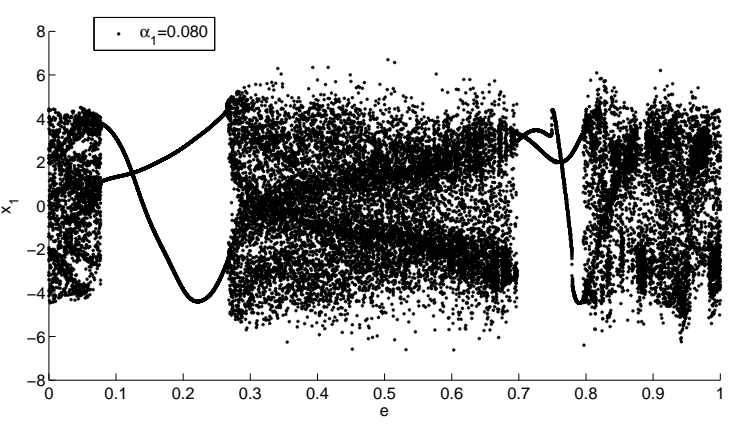

(a) $\alpha_{1}=0.080$

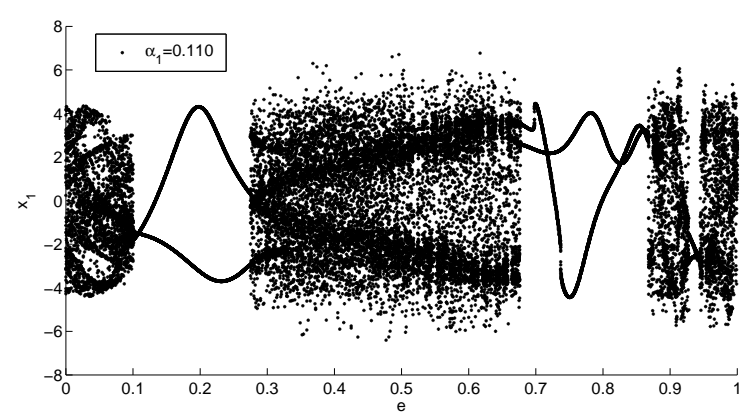

(c) $\alpha_{1}=0.110$

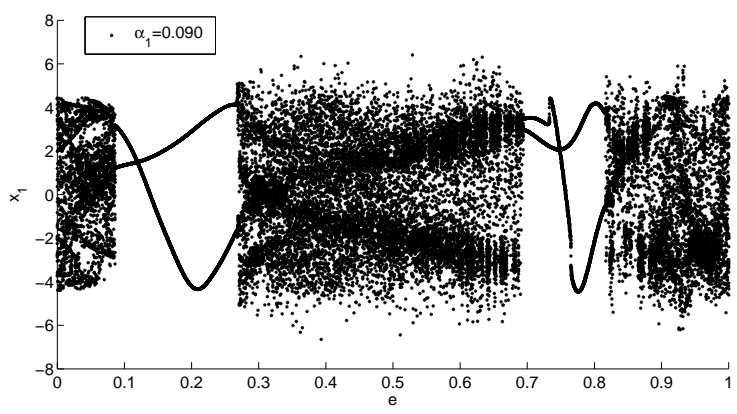

(b) $\alpha_{1}=0.090$

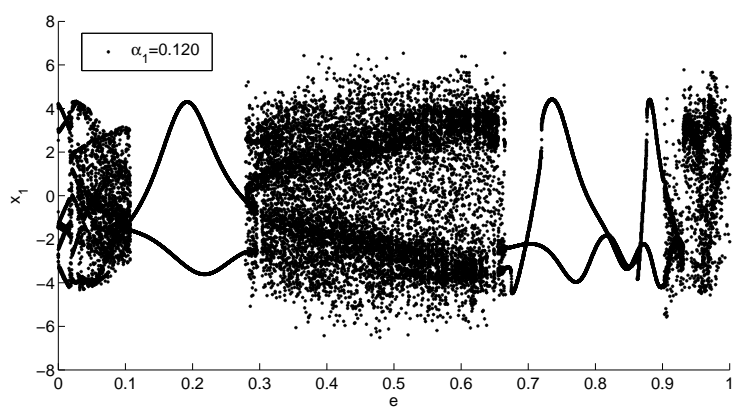

(d) $\alpha_{1}=0.120$

Fonte: Elaborada pelo próprio autor 
Percebe-se que o sistema é sensível às variações nos intervalos entre periódico e caótico, mas as variáveis de controle ( $e=0.2, e=0.42$ e $e=0.7$ ) permanecem no range escolhido para a concepção do controle planejado inicialmente (caótico, periódico).

Pode concluir-se que o controle proposto $(e)$ é robusto para variações no parâmetro de amortecimento $\alpha_{1}$.

\subsubsection{Variação no Parâmetro de Rigidez Não Linear $\beta_{3}$}

Na Figura 51, pode-se ver a influência do parâmetro de rigidez não linear $\beta_{3}$ na potência média capturada pelo sistema, em que a linha em preto representa o valor nominal do parâmetro $\beta_{3}=0.20$.

Figura 51 - Potência Média Capturada para a Variação do Parâmetro de Rigidez Não Linear $\beta_{3}$

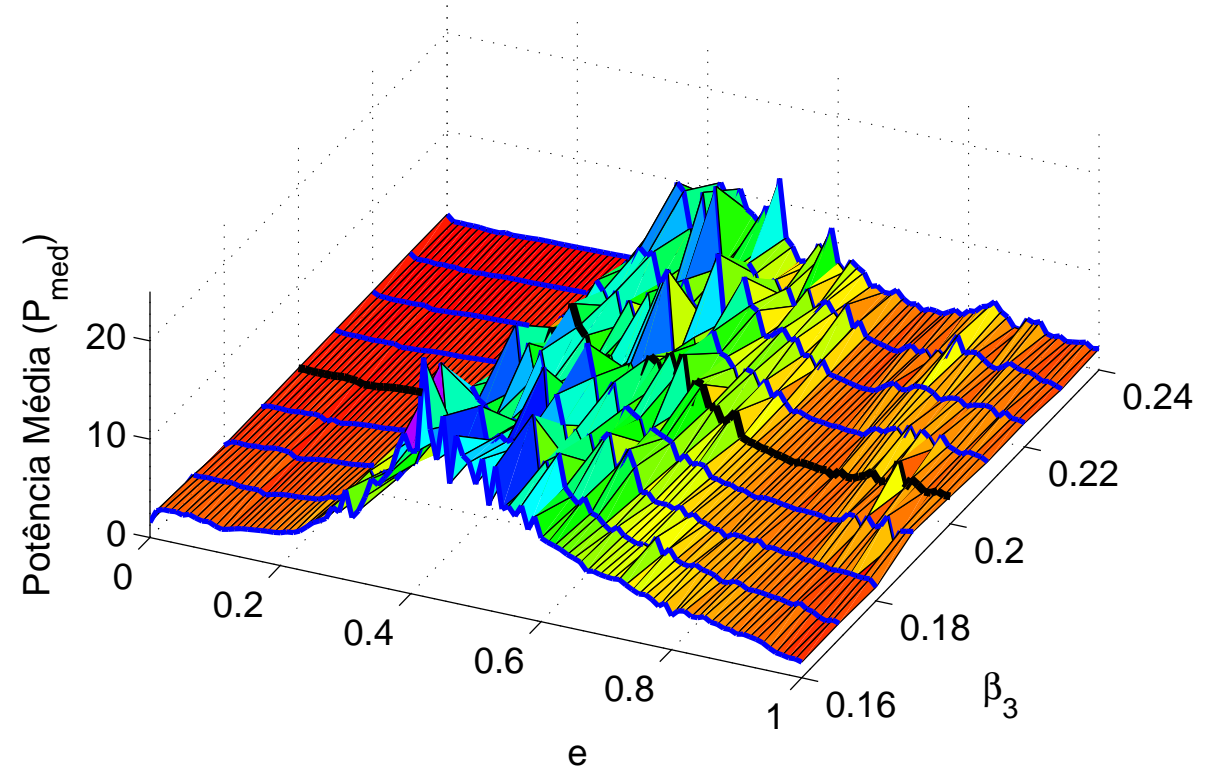

Fonte: Elaborada pelo próprio autor

A Figura 52 apresenta a variação da potência média capturada, sendo esta sensível à variação do coeficiente de rigidez não linear $\beta_{3}$, com a potência máxima capturada, que é ainda alcançada para valores próximos de $e=0.42$, no caso em que ocorre a redução do valor de $\beta_{3}$. 
Figura 52 - Potência Média Capturada para os Casos do Parâmetro de Controle e com Variação de $\beta_{3}$

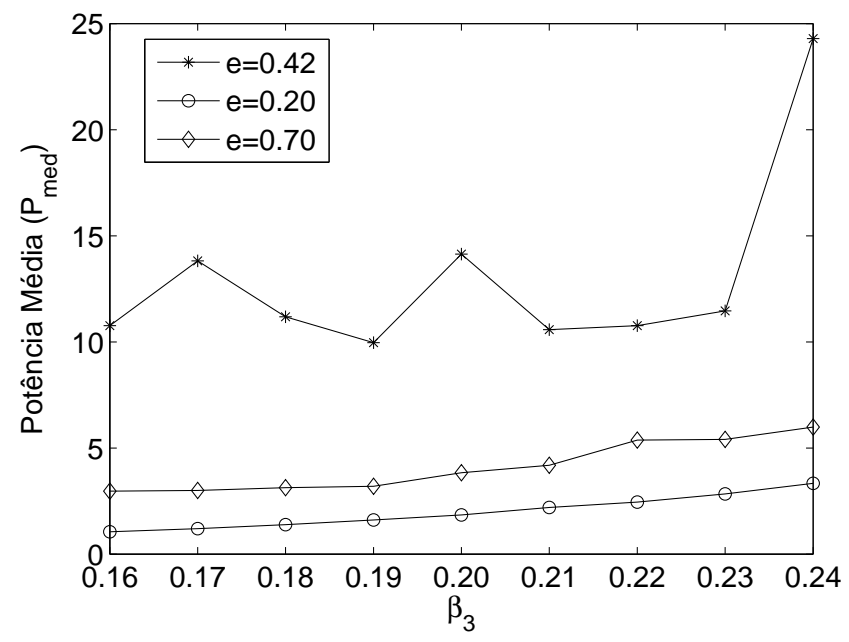

Fonte: Elaborada pelo próprio autor

Na Figura 53, podem-se verificar os diagramas de bifurcação para o parâmetro de controle $e$ com a variação do valor de $\beta_{3}$.

Figura 53 - Diagramas de Bifurcação para o Paramêtro de Rigidez Não Linear $\beta_{3}$

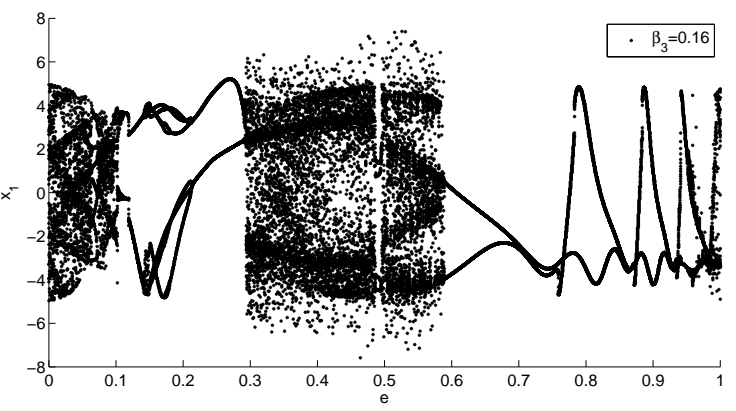

(a) $\beta_{3}=0.16$

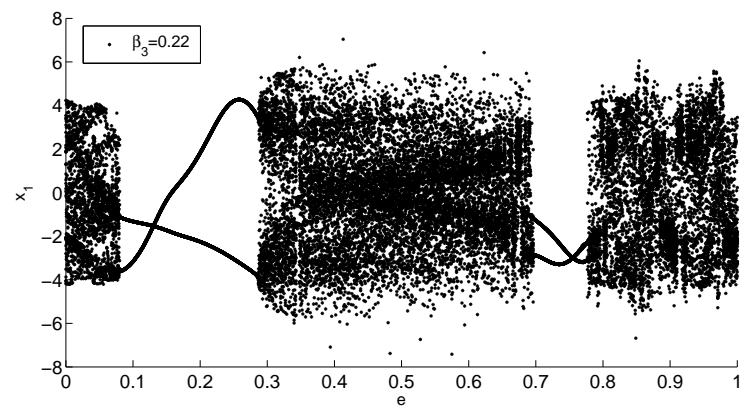

(c) $\beta_{3}=0.22$

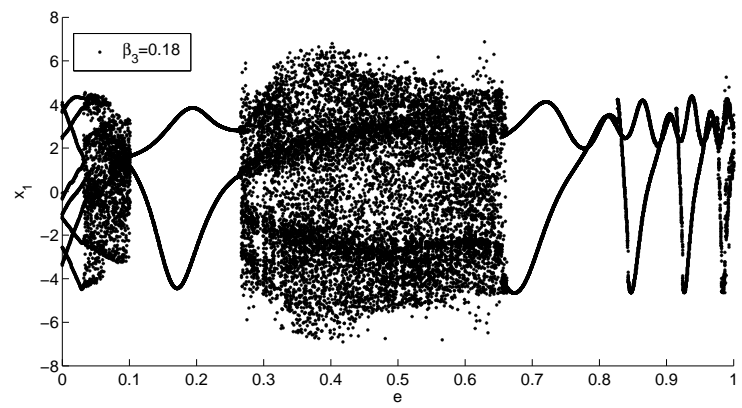

(b) $\beta_{3}=0.18$

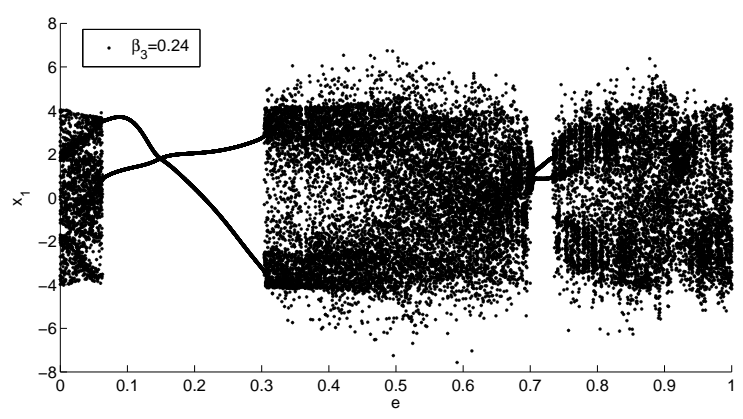

(d) $\beta_{3}=0.24$

Fonte: Elaborada pelo próprio autor 
Verifica-se que o sistema é sensível a variações nos intervalos entre movimento periódico e caótico, e que as variáveis de controle $(e=0.2$, $e=0.42$ e $e=0.7)$ permanecem no range escolhido na concepção inicial do controle (caótico, periódico), mas com redução significativa do intervalo, com os aumentos periódicos no parâmetro de rigidez não linear $\beta_{3}$.

Pode concluir-se que o controle proposto ( $e=0.2$, $e=0.42$ e $e=0.7$ ) não é robusto para variações que aumentam o valor de $\beta_{3}$. 


\section{ANÁLISE DINÂMICA POR WAVELETS}

\subsection{CONSIDERAÇÕES INICIAIS}

O presente capítulo demonstra o uso da análise wavelet para identificação de comportamento regular e irregular em sistemas dinâmicos no domínio da frequência, por meio da aplicação da transformada wavelet contínua (CWT) nos modelos de sistemas de captura de energia não-ideais sem controle e com controle passivo acoplados.

Conforme descrito anteriormente, os modelos apresentam uma configuração semelhante a um oscilador Duffing forçado com potencial duplo, demonstrando movimentos periódicos ou caóticos. Atualmente, muitos dispositivos de captura de energia não lineares têm sido modelados, como osciladores Duffing forçados. Dentre os diferentes modelos desse tipo, podem-se mencionar os de Erturk e Inman (2011a), Triplett e Quinn (2009), lliuk et al. (2012c), lliuk et al. (2013a), lliuk et al. (2013c), entre outros.

A correta identificação do comportamento dinâmico de sistemas de captura de energia é de grande importância para auxiliar na predição de seu potencial energético de saída.

A fim de obter uma visão rápida sobre o comportamento de um sistema dinâmico, uma análise utilizando-se a CWT pode ser realizada, como alternativa aos métodos clássicos utilizados na teoria dos sistemas dinâmicos. De acordo com Addison (2002), a análise wavelet tem sido aplicada a uma variedade de problemas pertinentes nas áreas da ciência, engenharia, medicina, economia, entre outras.

A Wavelet Toolbox ${ }^{T M}$ do MatLabß é uma ferramenta poderosa para análise de sinais. O software inclui um grande número de wavelets que podem ser utilizadas para efetuar uma análise, tanto discreta quanto contínua (MISITI et al., 2013).

Alternativamente, uma wavelet toolbox para análise de séries temporais no domínio tempo-frequência foi desenvolvida por Torrence e Compo (1998), para analisar uma série temporal de dados do fenômeno meteorológico El Niño, com a inclusão de um teste de significância estatístico. Reboita (2004) aplicou esta wavelet toolbox sobre dois conjuntos de dados com o objetivo de determinar os sistemas atmosféricos que causam maior variabilidade do clima no sul do Brasil, e assim fornecer informações para o desenvolvimento futuro de um modelo climático regional.

Uma análise da dinâmica de um oscilador Duffing foi realizada, utilizando-se o espectro wavelet cruzado (XWT) por Kyprianou e Stazewski (1999), como uma alternativa à análise clássica de entrada e saída. O trabalho de Permann e Hamilton (1992) enfatiza a robustez da análise wavelet, mesmo quando o sistema apresenta comportamento caótico, como um oscilador Duffing, em séries de tempo curto. O comportamento dinâmico das oscilações 
mecânicas de um sistema não ideal, que descreve um modelo físico que trata do movimento de um bloco excitado por um motor elétrico de corrente contínua com potência limitada, foi estudado por Chierice Júnior (2007). A análise foi realizada utilizando a wavelet toolbox desenvolvida por Torrence e Compo (1998).

Neste capítulo, são apresentados os resultados da aplicação da CWT utilizando-se a wavelet de Morlet complexa, contida na wavelet toolbox desenvolvida por Torrence e Compo (1998), para identificação, e uma análise qualitativa do comportamento dos modelos de captura de energia propostos nesta tese, em concordância com lliuk et al. (2013b), lliuk et al. (2014b) Também, uma análise de frequência desses sistemas foi realizada, utilizando-se a transformada rápida de Fourier (FFT) e a Wavelet Toolbox ${ }^{T M}$ do MatLab $R$. Os resultados da aplicação da transformada wavelet permitiram a identificação dos movimentos dos sistemas oscilatórios com boa precisão, para o conjunto particular de parâmetros estudados. A visualização dos espectros de energia wavelet (escalogramas) e dos espectros wavelet global são ferramentas muito úteis para identificar o tipo de movimento encontrado: periódico ou caótico. A análise wavelet pode ser considerada uma ferramenta alternativa ou complementar na detecção e validação de caos em sistemas dinâmicos, em conjunto com técnicas bem consolidadas, como expoentes de Lyapunov, mapas de Poincaré, bacias de atração e teste 0-1.

\subsection{APLICAÇÃO DA CWT}

As figuras obtidas por meio da aplicação da wavelet toolbox desenvolvida por Torrence e Compo (1998) sobre a séries temporais de dados representam a variação no domínio tempofrequência do conteúdo dos sinais. Para representar um certo fenômeno no domínio do tempofrequência, o espectro de energia wavelet (escalograma) é retratado usando-se o comando

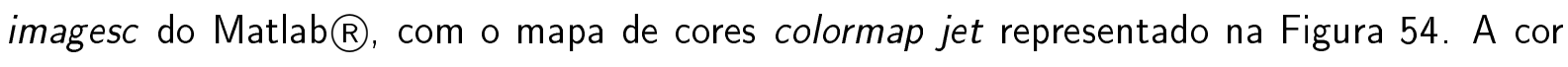
azul representa os menores valores dos coeficientes wavelet, e a cor vermelha, os maiores valores dos coeficientes wavelet.

Figura 54 - Matlab colormap jet

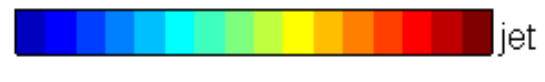

Fonte: (MATLAB 7.14., 2012)

A análise dos escalogramas fornecidos pela wavelet toolbox de Torrence e Compo (1998) permite a observação de o quanto um pico é estatisticamente diferente do outro pico. O contorno em preto ao redor das células na Figura 55 representa as regiões fechadas com intervalo de confiança superior a 95\%, para um processo de ruído vermelho com um coeficiente 
de lag-1 de 0,72, de acordo com Torrence e Compo (1998).

Em muitos casos, erros de análise espectral poderão ocorrer no início e no fim do espectro, devido à série possuir tempo limitado. Para minimizar tais efeitos, a wavelet toolbox preencherá o sinal com zeros suficientes para que o comprimento do sinal aproxime-se da próxima potência superior de dois (2). Isso limita os efeitos de borda e acelera os cálculos da FFT. Contudo, o preenchimento com zeros introduz descontinuidades nos extremos e, à medida que se utilizam escalas maiores, ocorre a redução da amplitude próximo da borda, quanto mais zeros são adicionados. Assim, o cone de influência apresentado na Figura 55 é a região do espectro wavelet em que esses efeitos se tornam importantes, e é definido como um fator de tempo (e-folding time) para a autocorrelação da energia wavelet em cada escala. Este cone é escolhido para garantir que a energia de uma descontinuidade caia por um fator de $e^{-2}$, e desta forma, os efeitos de borda sejam insignificantes para além deste ponto.

Figura 55 - Limites de Confiança

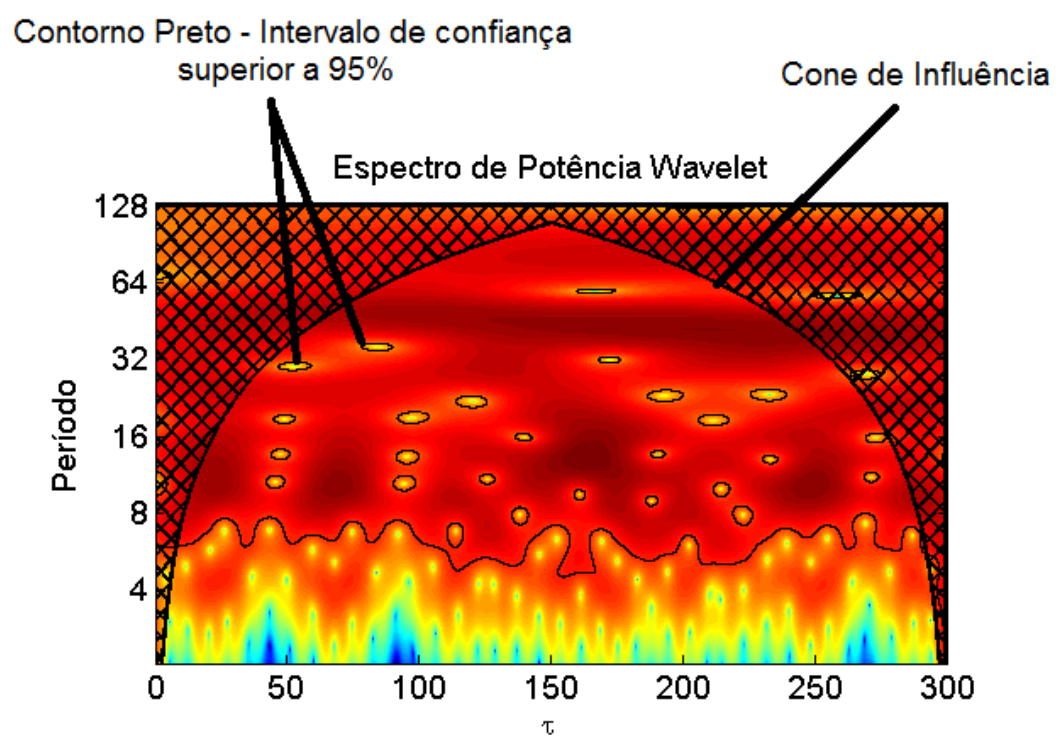

Fonte: Elaborada pelo próprio autor

Conforme relatado por Torrence e Compo (1998), o espectro wavelet global fornece uma estimativa imparcial e coerente do espectro de energia real de uma série temporal, ou seja, representa o espectro de energia equivalente ao espectro de Fourier do sinal. Por exemplo, um sistema periódico apresenta apenas um pico na FFT e apenas um pico no espectro wavelet global, como pode ser visto na Figura 56. 
Figura 56 - Comparação entre a FFT e o Espectro Wavelet Global de um Sistema Periódico
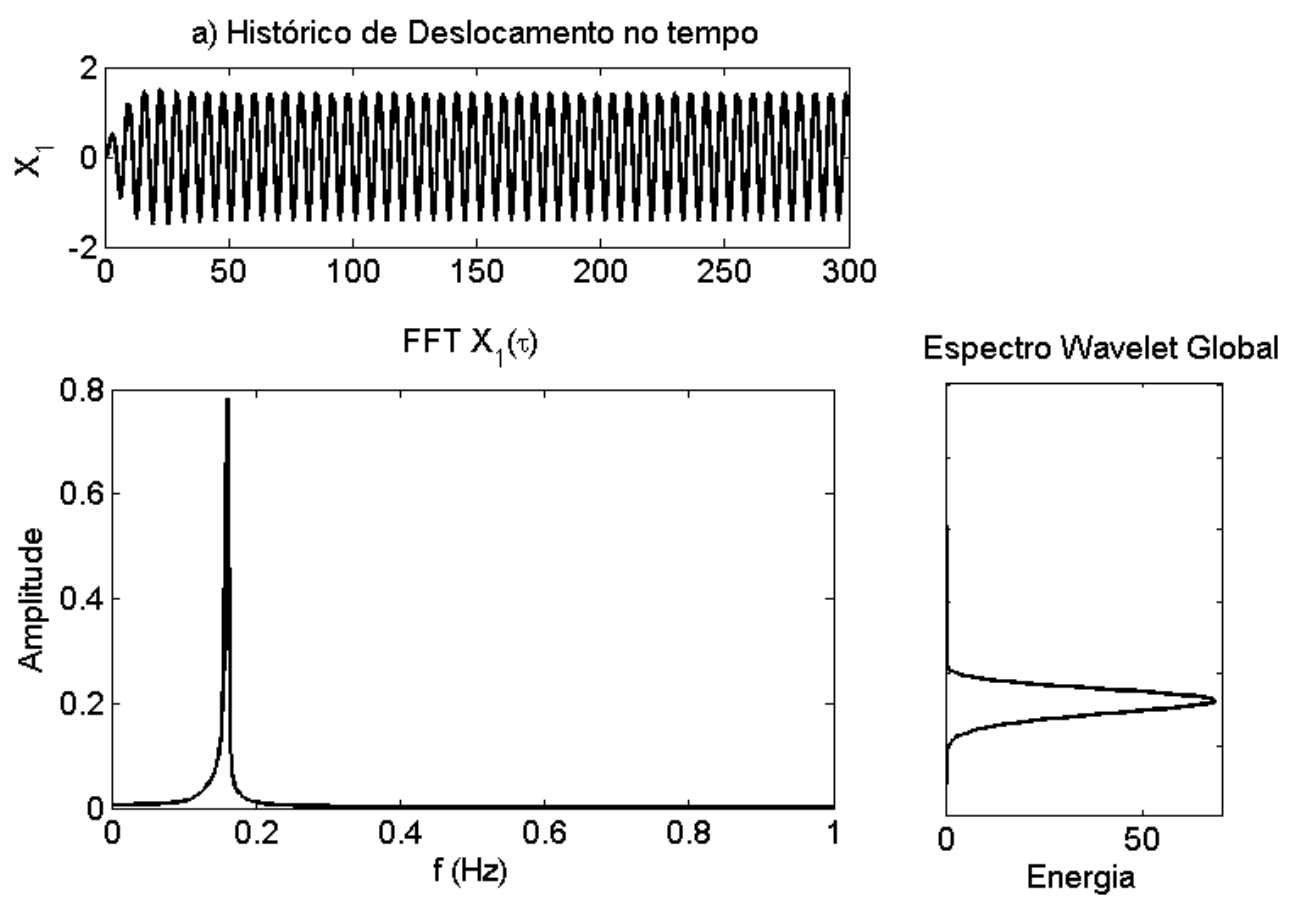

Fonte: Elaborada pelo próprio autor

Os resultados qualitativos dos escalogramas podem ser comparados com os resultados apresentados por Wong e Chen (2001), nos quais os contornos do módulo da wavelet são representados por uma série de células de turbulência semelhantes, no domínio tempo-frequência. Isso indica que as respostas ao impulso consistem em um conjunto de modos harmônicos com diferentes frequências, mas muito próximas.

As amplitudes desses modos harmônicos são constantes para o caso linear, uma vez que as células de turbulência são regularmente dispostas ao longo do eixo do tempo, como mostrado na Figura 57 Essa declaração é usada para classificar o comportamento de um sistema como periódico. 
Figura 57 - Sistema Periódico: Padrão Regular das Células de Turbulência

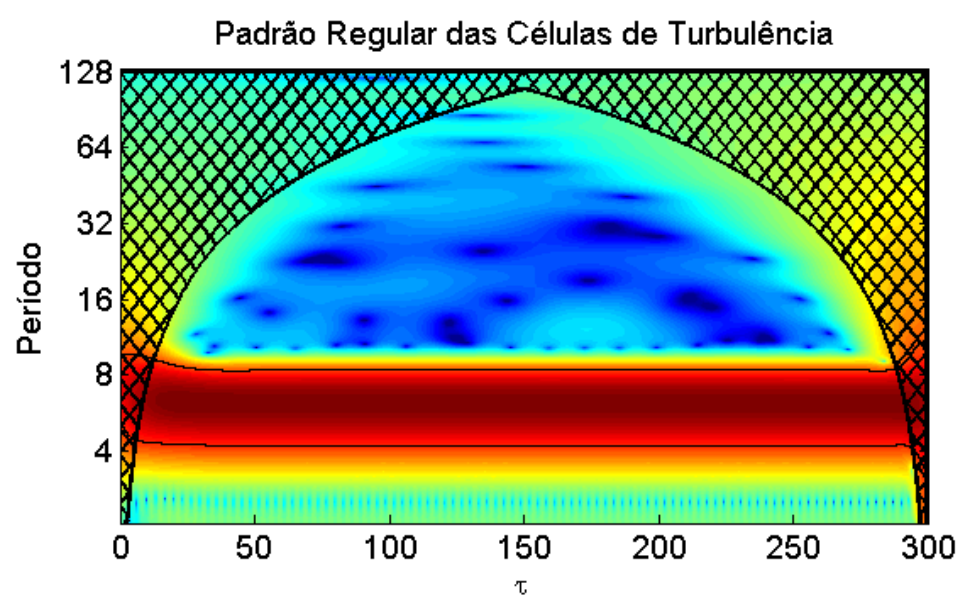

Fonte: Elaborada pelo próprio autor

Para sistemas não lineares, por outro lado, as amplitudes desses modos harmônicos não são constantes, como mostrado por uma distribuição aleatória de células de turbulência, tal como representado na Figura 58, Essa declaração é usada para classificar o comportamento de um sistema como caótico.

Figura 58 - Sistema Caótico: Padrão Aleatório na Distribuição das Células de Turbulência

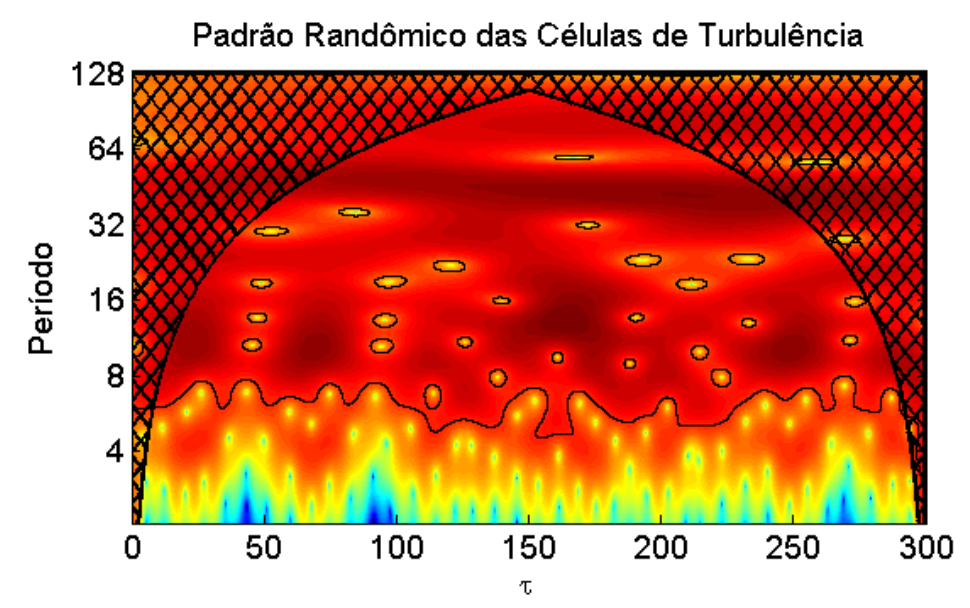

Fonte: Elaborada pelo próprio autor

Outra forma de classificar o movimento do sistema é analisando o ângulo de fase da wavelet complexa. O ângulo de fase da wavelet em um sistema com comportamento caótico apresenta similaridade com o ângulo de fase de um ruído gaussiano, como pode ser visto na Figura 59 Essa declaração foi utilizada por Addison (2002), para classificar o comportamento dos sistemas por ele estudados. 
Figura 59 - (a)Ângulo de Fase da Wavelet para um Ruído Gaussiano; (b)Ângulo de Fase da Wavelet para um Oscilador Duffing Caótico
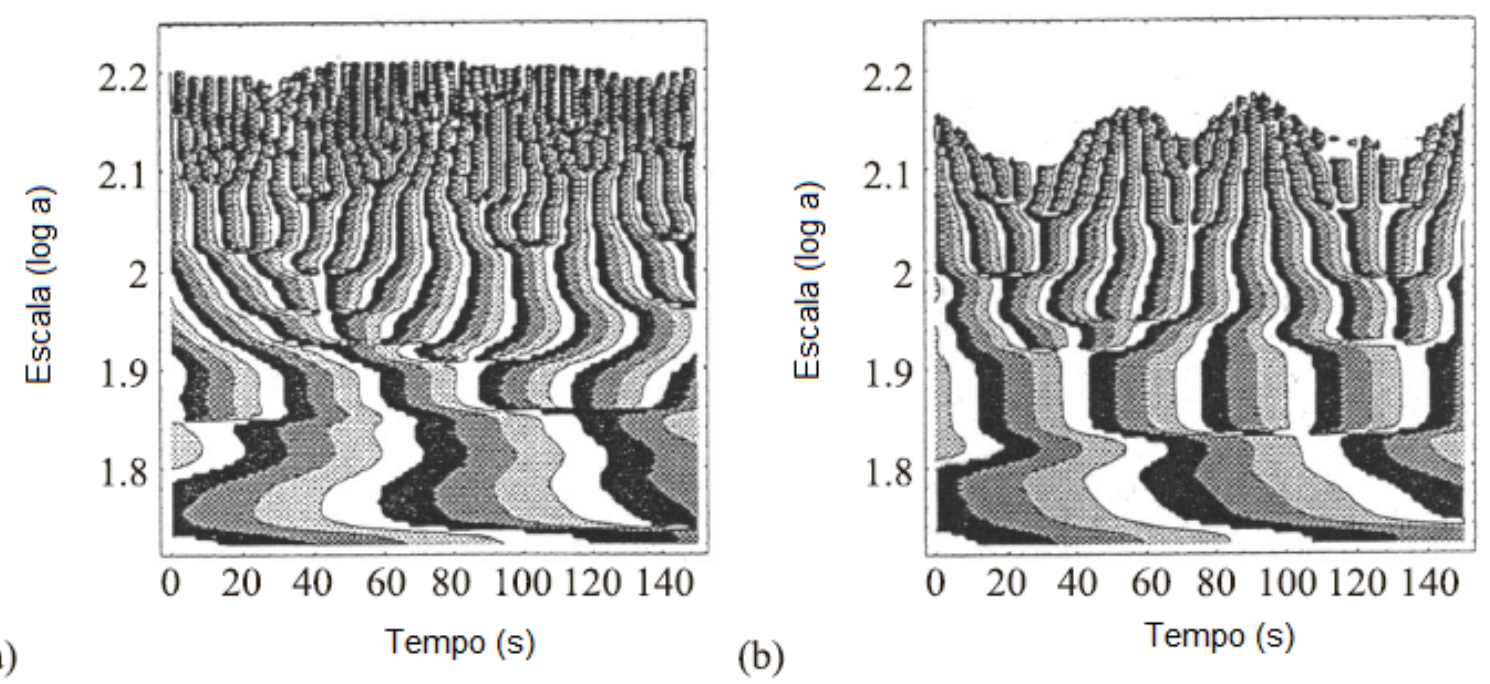

Fonte: (ADDISON, 2002)

As figuras obtidas com a aplicação da Wavelet Toolbox ${ }^{T M}$ do Matlabß em uma série temporal mostra, na coluna da esquerda, uma representação do deslocamento no tempo do sistema, o módulo de todos os coeficientes da wavelet na forma de um escalograma e o módulo da escala escolhida, com a pseudofrequência calculada pela relação da Eq. 22 (MATLAB 7.14., 2012):

$$
F_{a}=\frac{F_{C}}{a \cdot \Delta}
$$

onde $F_{C}$ é a frequência central da wavelet em $\mathrm{Hz}, F_{a}$ é a pseudofrequência da escala $a$ em $\mathrm{Hz}, a$ é a escala e $\Delta$ é o período de amostragem.

De acordo com Misiti et al. (2013), uma forma fácil de capturar os valores das pseudofrequências é colocar o cursor do mouse sobre o gráfico dos coeficientes e então clicar com o botão direito sobre uma região, por exemplo sobre as células vermelhas mais largas; em seguida, verificar o valor da pseudofrequência para a escala escolhida, já calculada pela Wavelet Toolbox $^{T M}$ do Matlabß. Esse mecanismo foi utilizado ao longo do trabalho, a fim de preencher as tabelas com os valores das pseudofrequências.

Na coluna da direita, é fornecida uma representação do deslocamento no tempo do sistema, do ângulo de fase da wavelet para todos os coeficientes e do ângulo de fase para a 
escala escolhida.

A Eq 23 representa a wavelet de Morlet complexa implementada na Wavelet Toolbox ${ }^{T M}$ do software Matlabß:

$$
\Psi(X)=\left(\pi F_{B}\right)^{-0.5} e^{2 i \pi F_{C} X} e^{-\frac{X^{2}}{F_{B}}}
$$

onde $\Psi(X)$ é a wavelet mãe, $X$ é o deslocamento, $\pi$ é uma constante matemática, $F_{B}$ é um parâmetro de largura de banda positivo, $F_{C}$ é a frequência central da wavelet em $\mathrm{Hz}$.

A fim de obter melhor resolução da análise wavelet contínua, os parâmetros $F_{B}$ e $F_{C}$ devem ser ajustados em conformidade com as características do sinal a ser analisado (MATLAB 7.14., 2012).

Outros parâmetros importantes a ser considerados são: $F_{s}$ é a frequência de amostragem, $N$ é o comprimento da série temporal e $\tau$, o tempo.

Numericamente, neste capítulo, tem-se: $F_{s}=100, \Delta=0.01, N=30000, \tau=300$.

\subsubsection{Modelo de Pórtico sem Controle Passivo}

Na Figura 60, são apresentados os resultados obtidos pela aplicação da wavelet de Morlet complexa implementada na wavelet toolbox de Torrence e Compo (1998), sobre o sinal de deslocamento do modelo do pórtico sem controle passivo.

Esse sistema modelado como um oscilador Duffing forçado apresenta movimentos caóticos, como pode ser verificado na análise realizada no capítulo 4.

Visualmente, pode-se notar que o espectro de energia wavelet apresenta as células de turbulência com distribuição aleatória, assim caracterizando o movimento caótico do sistema. O espectro wavelet global mostra uma frequência principal como um pico de maior amplitude, e uma série de outras frequências presentes na resposta do sistema. 
Figura 60 - Aplicação da Wavelet Toolbox de Torrence e Compo (1998) - Pórtico sem Controle

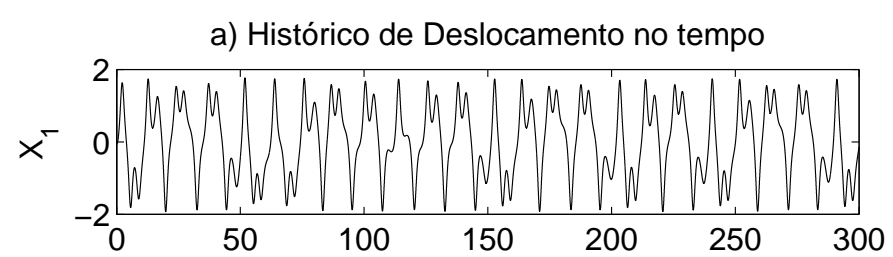

b) Espectro de Energia Wavelet

c) Espectro Wavelet Global
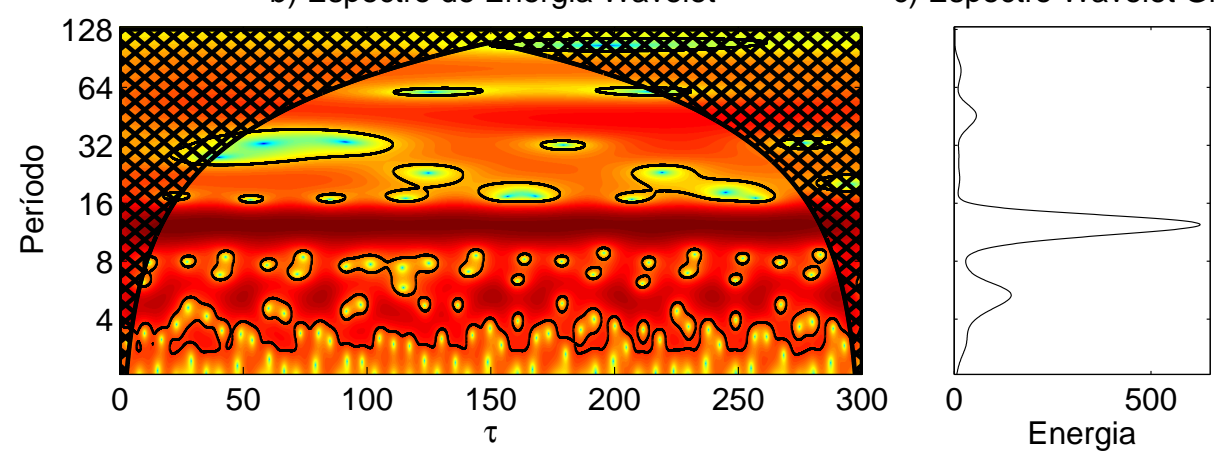

Fonte: Elaborada pelo próprio autor

Inspecionando a Figura 61. pode-se verificar a semelhença ente a FFT apresentada e o espectro wavelet global da Figura 60k. Como o espectro se espalha para o sistema sem o controlador passivo, pode-se deduzir que este apresenta comportamento caótico.

Figura 61 - FFT - Pórtico sem Controle

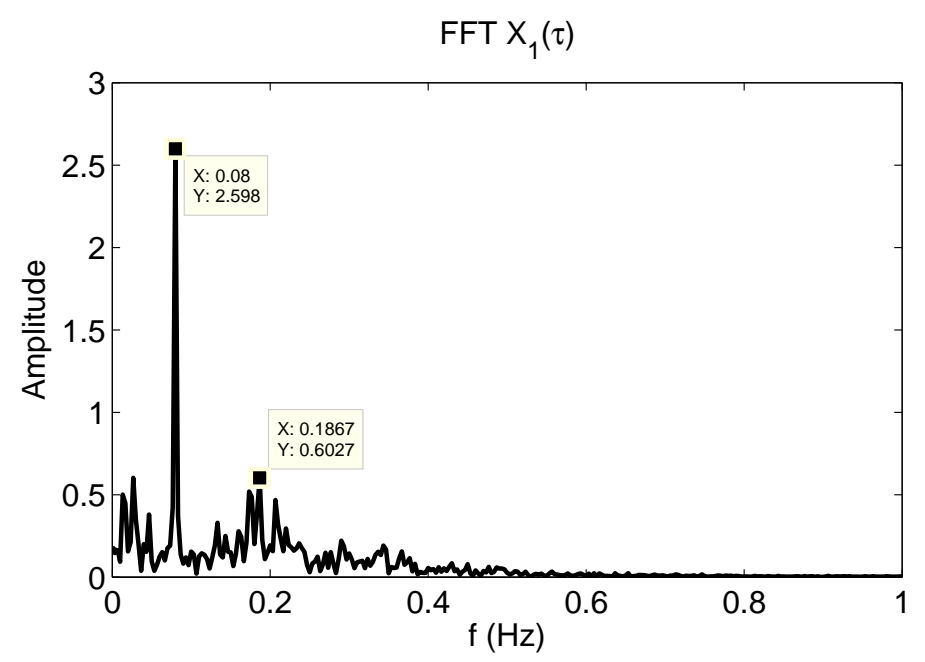

Fonte: Elaborada pelo próprio autor

Na Figura 62, o cálculo dos coeficientes da wavelet foi realizado utilizando-se a wavelet de Morlet complexa implementada na Wavelet Toolbox ${ }^{T M}$ do Matlabß, Eq. 23 com parâmetros $F_{B}=10$ e $F_{C}=1$, com as escalas $a=100: 2: 1500$.

$\mathrm{Na}$ coluna da esquerda da Figura 62, tem-se o escalograma que também apresenta 
várias células de turbulência. A propagação do espectro de energia indica um comportamento caótico.

O principal pico no espectro de Fourier e o outro ponto apontado na Figura 61 foram escolhidos para uma comparação entre as pseudofrequências calculadas pela wavelet toolbox, por meio da Eq. 22, e as frequências obtidas pela FFT, em Hz. Os dois valores de escala encontrados foram 1246 (para o pico principal) e 538 (outro ponto escolhido), os quais apresentam ótima concordância, quando convertidos para frequência em $\mathrm{Hz}$ por meio da Eq. 22 Para melhor visualização, os resultados estão na Tabela 11 .

Inspecionando o ângulo de fase na coluna da direita na Figura 62 identifica-se uma distribuição irregular nas linhas verticais, indicando a presença de um comportamento caótico do sistema.

Figura 62 - Aplicação da Wavelet Toolbox ${ }^{\mathrm{TM}}$ do Matlab® - Pórtico sem Controle
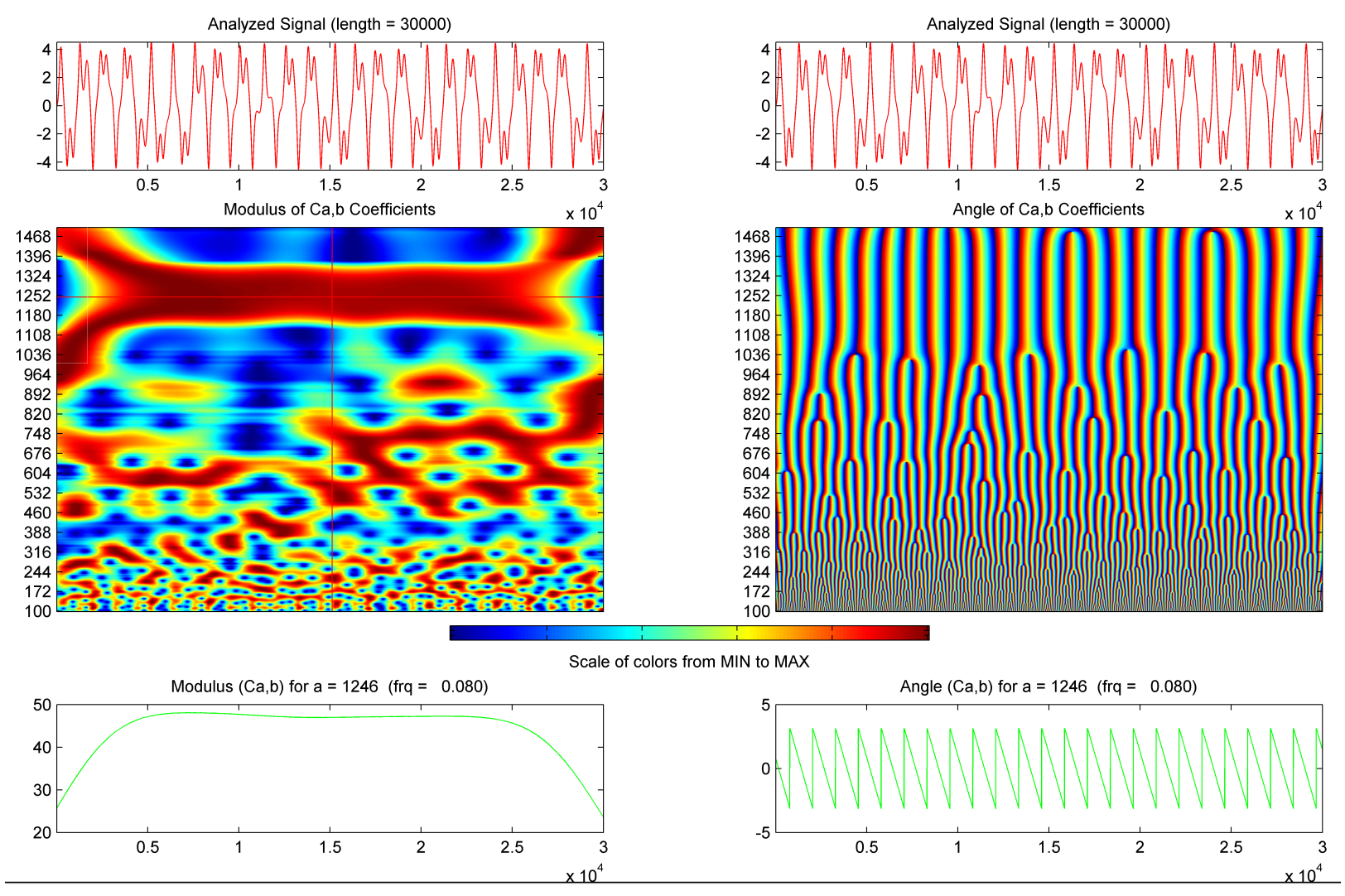

Fonte: Elaborada pelo próprio autor 
Tabela 11 - Pseudofrequência da Wavelet em Hz x Frequência da FFT em Hz - Pórtico sem Controle

\begin{tabular}{ccc}
\hline Escala & Pseudofrequência da Wavelet & Frequência da FFT \\
\hline 538 & 0.186 & 0.1867 \\
1246 & 0.080 & 0.080 \\
\hline
\end{tabular}

\subsubsection{Modelo de Pórtico com Controle Passivo (NES) $e=0.4$}

Na Figura 63, são apresentados os resultados obtidos pela aplicação da wavelet de Morlet complexa implementada na wavelet toolbox de Torrence e Compo (1998), sobre o sinal de deslocamento do modelo do pórtico com o controle passivo NES $e=0.4$.

Visualmente, pode-se notar que o espectro de energia wavelet apresenta as células de turbulência com distribuição aleatória, tanto abaixo do período 8 quanto acima do período 16. Assim, pode-se relacionar esse comportamento com o movimento caótico do sistema. No espectro wavelet global, tem-se também representada uma frequência principal como um pico de maior amplitude e uma série de outras frequências, presentes na resposta do sistema.

Figura 63 - Aplicação da Wavelet Toolbox de Torrence e Compo (1998) - Pórtico com Controle NES $e=0.4$

a) Histórico de Deslocamento no tempo

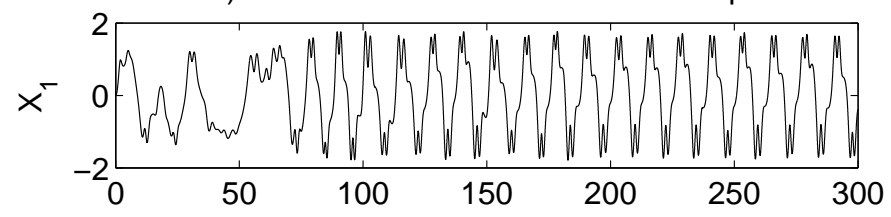

b) Espectro de Energia Wavelet

c) Espectro Wavelet Global
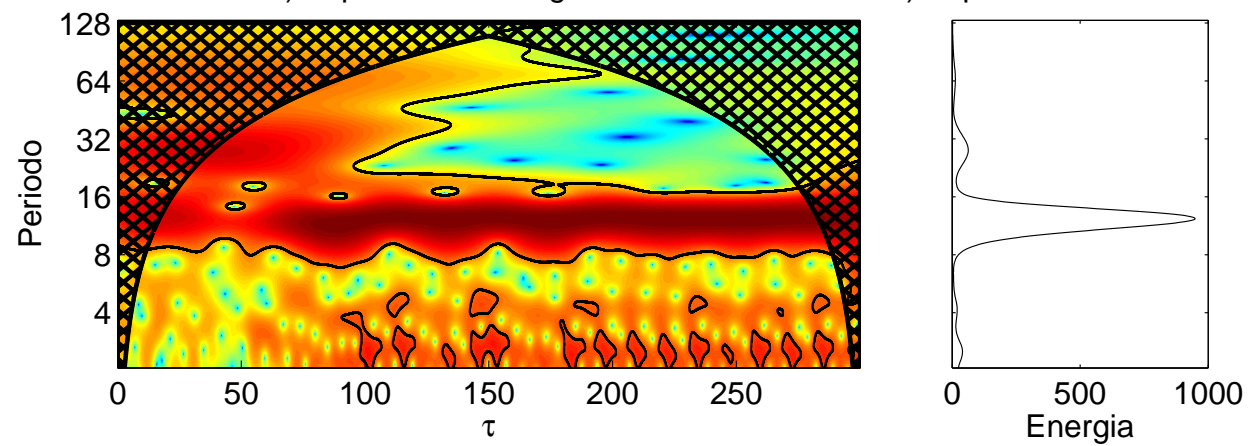

Fonte: Elaborada pelo próprio autor

Na Figura 64, pode-se comparar a FFT apresentada e o espectro wavelet global da Figura 63k. O espectro da FFT apresenta o pico principal equivalente ao pico principal do sistema sem controle visto na Figura 61. Somente a inspeção visual dessa figura não permite a conclusão do movimento do sistema, fazendo-se necessária a visualização conjunta do diagrama de bifurcação e do mapa de Poincaré. 
Figura 64 - FFT - Pórtico com Controle NES $e=0.4$

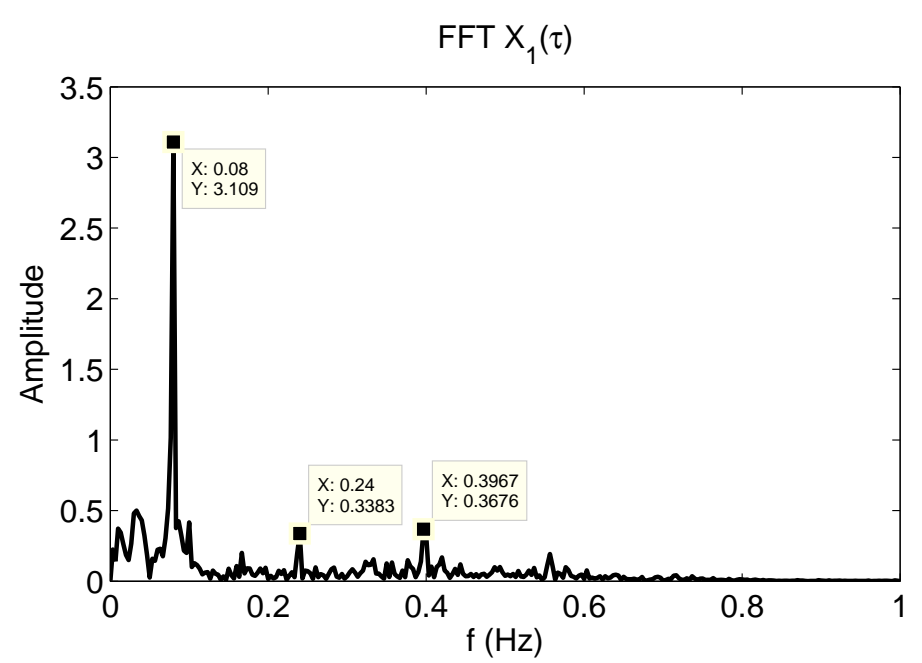

Fonte: Elaborada pelo próprio autor

Na Figura 65 o cálculo dos coeficientes da wavelet foi realizado utilizando-se a wavelet de Morlet complexa implementada na Wavelet Toolbox ${ }^{T M}$ do Matlabß, Eq. 23 , com parâmetros $F_{B}=10$ e $F_{C}=1$, com as escalas $a=100: 2: 1500$.

Na coluna da esquerda da Figura 65, tem-se o escalograma, que também apresenta várias células de turbulência. A propagação do espectro de energia é um indicativo da ocorrência de um comportamento caótico.

O principal pico no espectro de Fourier e dois outros pontos apontados na Figura 64 foram escolhidos para uma comparação entre as pseudofrequências calculadas pela wavelet toolbox, por meio da Eq. 22, e as frequências obtidas pela FFT em Hz. Os três valores de escala encontrados foram 1246 (para o pico principal), 416 e 252, os quais apresentam ótima concordância, quando convertidos para frequência em Hz via Eq. 22. Para melhor visualização, os resultados estão na Tabela 12 .

Por meio da inspeção do ângulo de fase, na coluna da direita da Figura 65, identifica-se uma distribuição irregular nas linhas verticais, indicando comportamento caótico do sistema. 
Figura 65 - Aplicação da Wavelet Toolbox ${ }^{T M}$ do Matlabß - Pórtico com Controle NES $e=0.4$

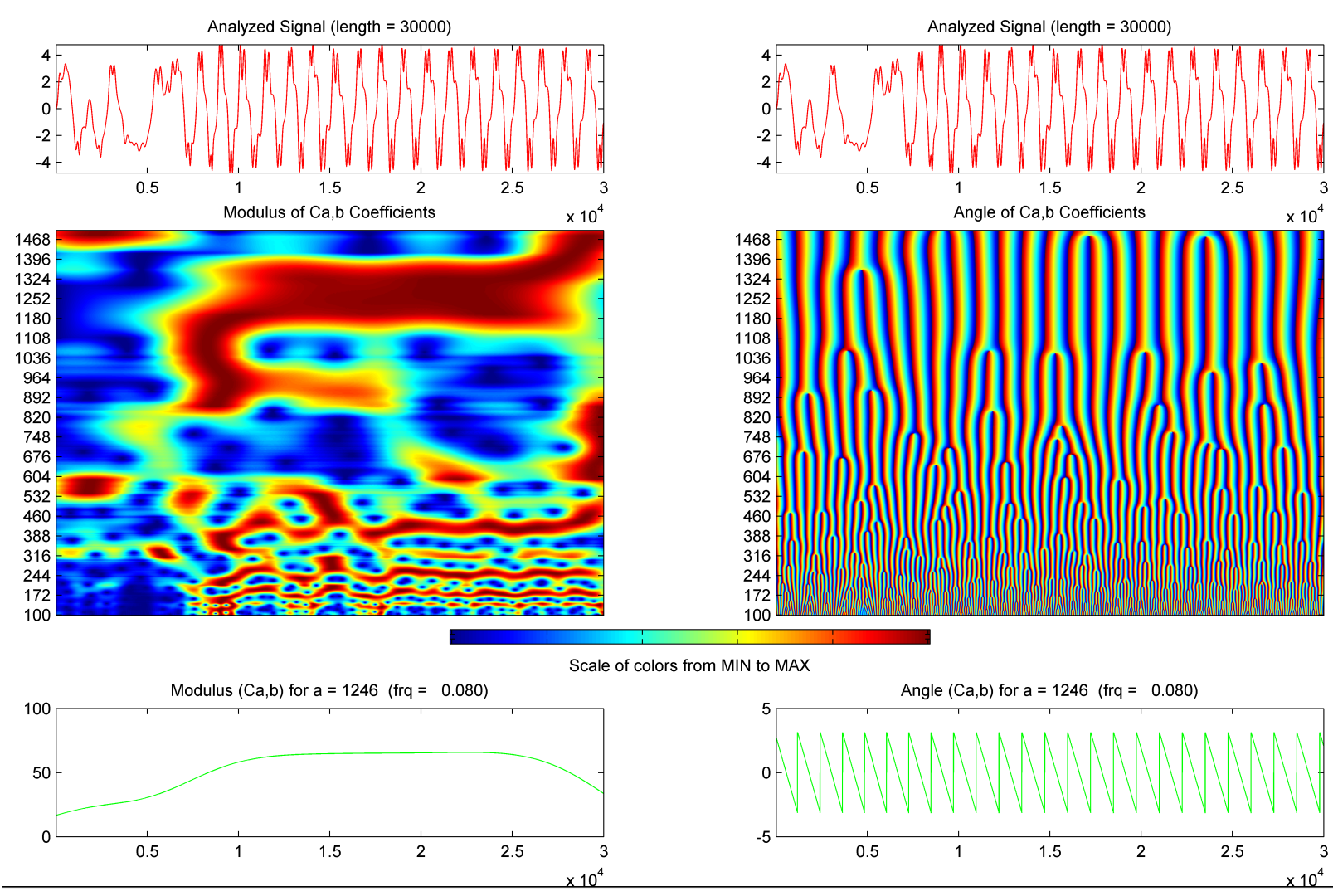

Fonte: Elaborada pelo próprio autor

Tabela 12 - Pseudofrequência da Wavelet em Hz x Frequência da FFT em Hz - Pórtico com Controle NES $e=0.4$

\begin{tabular}{ccc}
\hline Escala & Pseudofrequência da Wavelet & Frequência da FFT \\
\hline 252 & 0.397 & 0.3967 \\
416 & 0.240 & 0.240 \\
1246 & 0.080 & 0.080 \\
\hline
\end{tabular}

\subsubsection{Modelo de Pórtico com Controle Passivo (NES) $e=5.0$}

Na Figura 66, o sistema não ideal (NIS), excitado por um motor de corrente contínua, foi simulado com um controle passivo (NES) acoplado $e=5.0$. Como era de se esperar, para o valor do parâmetro de controle $e=5.0$, determinado no capítulo 5 por meio do diagrama de bifurcação, um comportamento periódico foi alcançado. Isso demonstra a eficácia do controle passivo, e pode ser visto no histórico de deslocamento no tempo. O espectro de energia 
wavelet mostra as células de turbulência com uma distribuição regular ao longo do eixo do tempo, caracterizando comportamento periódico. O espectro wavelet global perfeitamente caracteriza os dois períodos de oscilação do modelo.

Figura 66 - Aplicação da Wavelet Toolbox de Torrence e Compo (1998) - Pórtico com Controle NES $e=5.0$

a) Histórico de Deslocamento no tempo

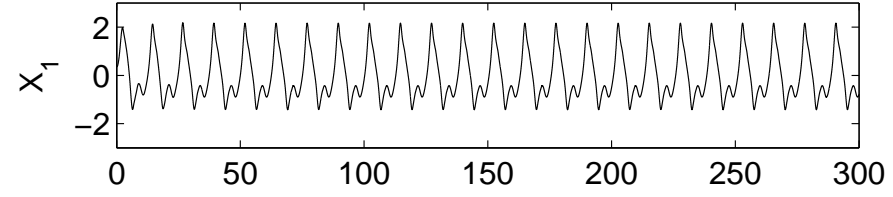

b) Espectro de Energia Wavelet

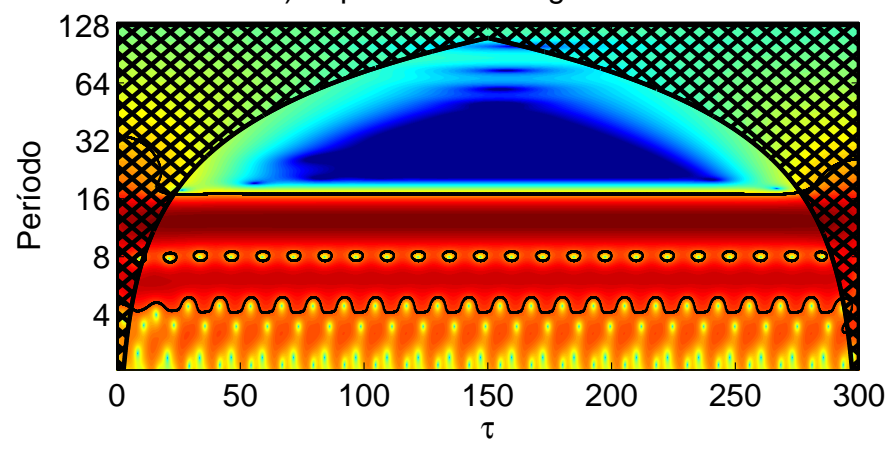

c) Espectro Wavelet Global

Fonte: Elaborada pelo próprio autor

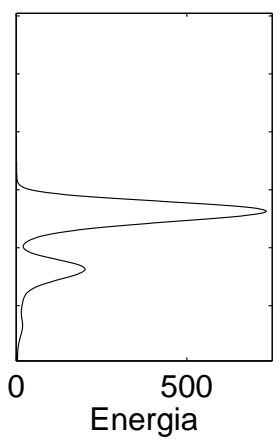

A Figura 67 representa a FFT para a resposta do sistema com o controle passivo (NES) acoplado $e=5.0$. O espectro de Fourier apresenta comportamento periódico, com as duas frequência principais bem caracterizadas, e também se notam outras frequências de ressonância.

Figura 67 - FFT - Pórtico com Controle NES $e=5.0$

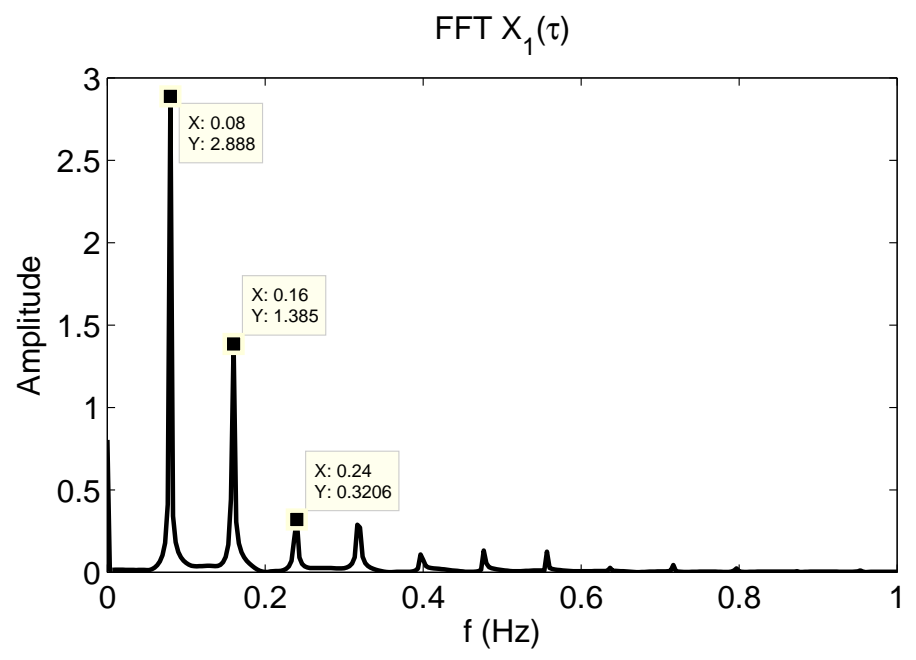

Fonte: Elaborada pelo próprio autor 
Na Figura 68 , o cálculo dos coeficientes da wavelet foi realizado utilizando-se a wavelet de Morlet complexa implementada na Wavelet Toolbox ${ }^{T M}$ do Matlabß, Eq. 23 , com parâmetros $F_{B}=10$ e $F_{C}=1$, com as escalas $a=100: 2: 1500$.

$\mathrm{Na}$ coluna da esquerda do escalograma, tem-se uma concentração do espectro de energia do módulo dos coeficientes para a wavelet de Morlet, os quais representam as frequências principais. O comportamento periódico do sistema controlado pode ser identificado pela distribuição das escalas, que apresentam comportamento regular.

O valor da escala 1246 está em conformidade com o pico principal representado na Figura 61 e Figura 67. O mesmo valor é obtido para o sistema caótico e para o sistema controlado. Os outros valores de escalas escolhidos para inspeção foram 626 e 416, que representam as frequências de ressonância. A pseudofrequência wavelet calculada foi equivalente à frequência em $\mathrm{Hz}$ obtida pela FFT do Matlab $\AA$ com ótima precisão. Os resultados estão na Tabela 13. O comportamento periódico do sistema pode ser provado pela inspeção do ângulo de fase na coluna da direita, que apresenta uma distribuição regular no padrão vertical para todas as frequências de ressonância.

Figura 68 - Aplicação da Wavelet Toolbox ${ }^{\mathrm{TM}}$ do Matlab ${ }^{\circledR}$ - Pórtico com Controle NES $e=5.0$
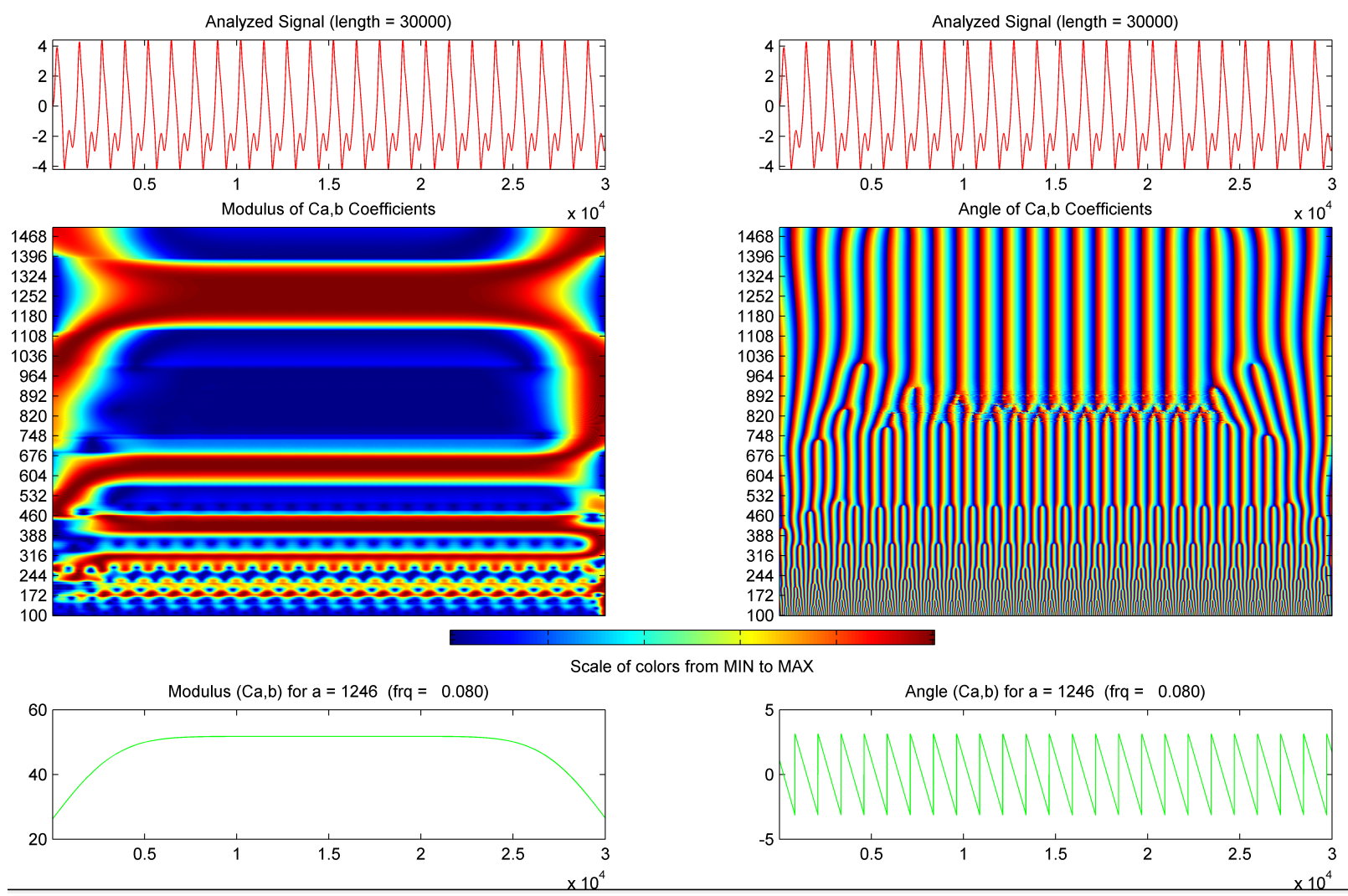
Tabela 13 - Pseudofrequência da Wavelet em Hz x Frequência da FFT em Hz - Pórtico com Controle NES $e=5.0$

\begin{tabular}{ccc}
\hline Escala & Pseudofrequência da Wavelet & Frequência da FFT \\
\hline 416 & 0.240 & 0.240 \\
626 & 0.160 & 0.160 \\
1246 & 0.080 & 0.080 \\
\hline
\end{tabular}

\subsubsection{Modelo de Pórtico com Controle por Pêndulo $e=0.2$}

Na Figura 69, são apresentados os resultados obtidos pela aplicação da wavelet de Morlet complexa implementada na wavelet toolbox de Torrence e Compo (1998), sobre o sinal de deslocamento do sistema não ideal (NIS) com o controle por pêndulo $e=0.2$.

Visualmente, pode-se notar que o espectro de energia wavelet apresenta as células de turbulência com distribuição seguindo um padrão regular. Sendo assim, pode-se relacionar esse comportamento com o movimento periódico do sistema. O espectro wavelet global apresenta uma frequência principal com um pico de maior amplitude, e a segunda frequência de ressonância também é bem caracterizada na figura.

Figura 69 - Aplicação da Wavelet Toolbox de Torrence e Compo, (1998) - Pórtico com Controle por Pêndulo $e=0.2$

a) Histórico de Deslocamento no tempo

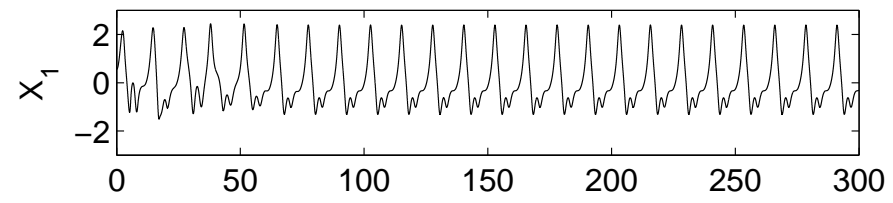

b) Espectro de Energia Wavelet

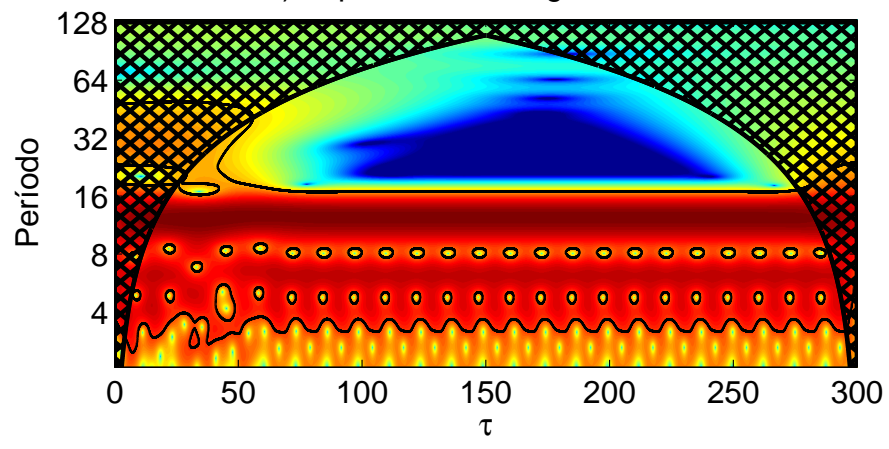

c) Espectro Wavelet Global

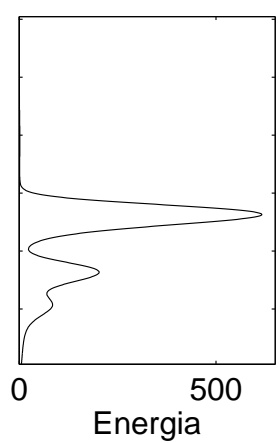

Fonte: Elaborada pelo próprio autor

A Figura 70 representa a FFT para a resposta do sistema com o controle por pêndulo $e=0.2$. O espectro de Fourier apresenta um comportamento periódico semelhante ao do modelo com controle passivo NES da Figura 67. com todas as frequência principais 
caracterizadas.

Figura 70 - FFT - Pórtico com Controle por Pêndulo $e=0.2$

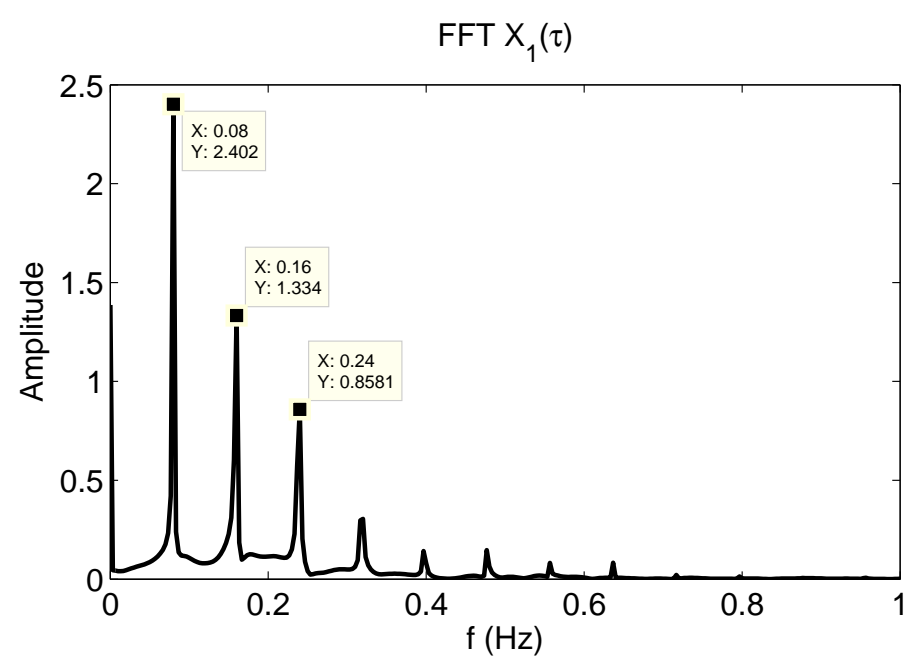

Fonte: Elaborada pelo próprio autor

Na Figura 71. o cálculo dos coeficientes da wavelet foi realizado utilizando-se a wavelet de Morlet complexa implementada na Wavelet Toolbox ${ }^{T M}$ do Matlabß, Eq. 23 , com parâmetros $F_{B}=10$ e $F_{C}=1$, com as escalas $a=100: 2: 1500$.

$\mathrm{Na}$ coluna da esquerda da Figura 71 . o escalograma demonstra a concentração do espectro de energia do módulo dos coeficientes wavelet que representam as frequências principais. O comportamento periódico do sistema controlado pode ser identificado pelo padrão regular da distribuição da energia pelas escalas.

Novamente, levando-se em consideração o pico principal no espectro de Fourier e dois outros pontos que foram escolhidos na Figura 70 para uma comparação entre as pseudofrequências calculadas pela wavelet toolbox, por meio da Eq. 22, e as frequências obtidas pela $\mathrm{FFT}$ em $\mathrm{Hz}$, os três valores de escala encontrados foram os mesmos obtidos pelo sistema controlado pelo absorvedor passivo NES, na Figura 68. São eles 1246 (para o pico principal), 416 e 252, os quais apresentam ótima concordância quando convertidos para frequência em $\mathrm{Hz}$, via Eq. 22. Para melhor visualização, os resultados estão na Tabela 14.

Por meio da inspeção do ângulo de fase na coluna da direita da Figura 71, identifica-se uma distribuição regular nas linhas verticais, indicando comportamento periódico do sistema. 
Figura 71 - Aplicação da Wavelet Toolbox ${ }^{T M}$ do Matlab® - Pórtico com Controle por Pêndulo $e=0.2$
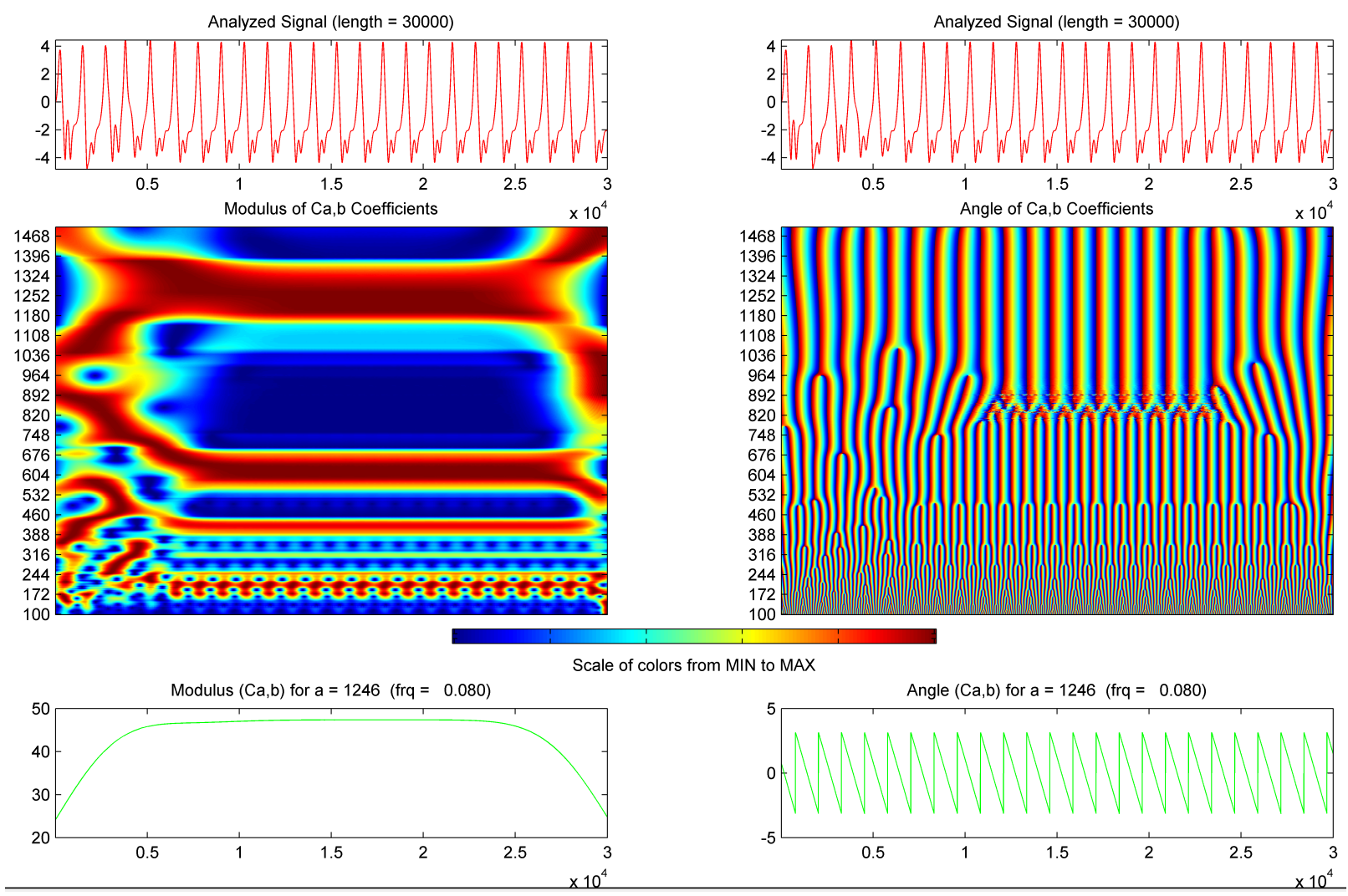

Fonte: Elaborada pelo próprio autor

Tabela 14 - Pseudofrequência da Wavelet em Hz x Frequência da FFT em Hz - Pórtico com Controle por Pêndulo $e=0.2$

\begin{tabular}{ccc}
\hline Escala & Pseudofrequência da Wavelet & Frequência da FFT \\
\hline 416 & 0.240 & 0.240 \\
626 & 0.160 & 0.160 \\
1246 & 0.080 & 0.080 \\
\hline
\end{tabular}

\subsubsection{Modelo de Pórtico com Controle por Pêndulo $e=0.42$}

Na Figura 72, são apresentados os resultados obtidos pela aplicação da wavelet de Morlet complexa implementada na wavelet toolbox de Torrence e Compo (1998), sobre o sinal de deslocamento do NIS com o controle por pêndulo $e=0.42$.

Visualmente, pode-se notar que o espectro de energia wavelet apresenta as células de turbulência com distribuição seguindo um padrão irregular. Sendo assim, pode-se relacionar 
esse comportamento com o movimento caótico do sistema. O espectro wavelet global na Figura $72 \mathrm{k}$, apresenta uma frequência principal com um pico de maior amplitude, e outras frequências de ressonância que também apresentam amplitude considerável.

Figura 72 - Aplicação da Wavelet Toolbox de Torrence e Compo (1998) - Pórtico com Controle por Pêndulo $e=0.42$

a) Histórico de Deslocamento no tempo

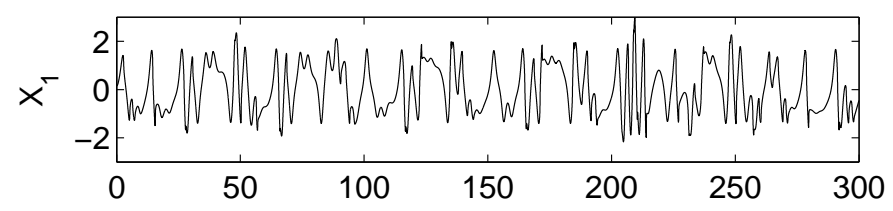

b) Espectro de Energia Wavelet

c) Espectro Wavelet Global
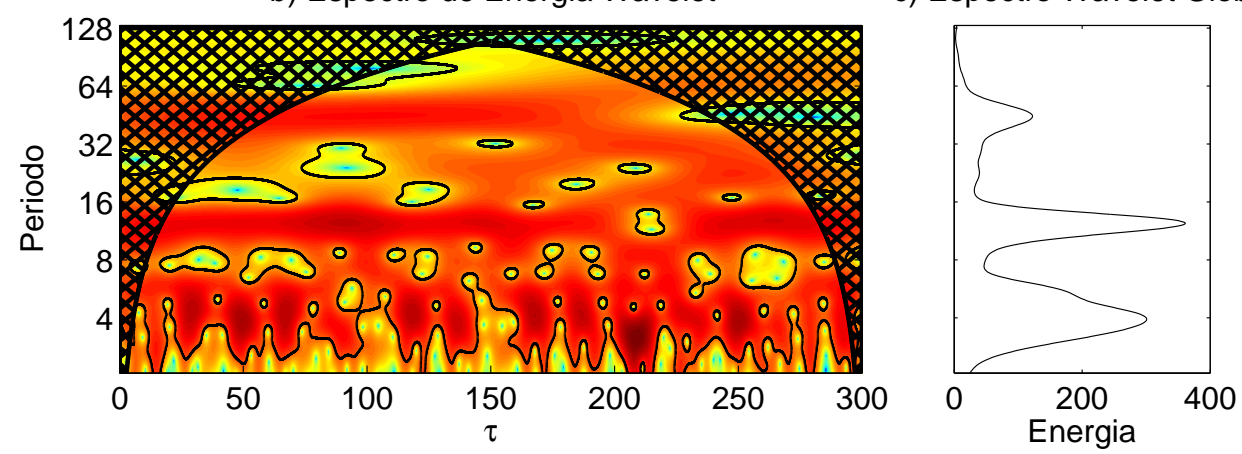

Fonte: Elaborada pelo próprio autor

A Figura 73 representa a FFT para a resposta do sistema com o controle por pêndulo $e=0.42$. O espectro de Fourier apresenta um comportamento caótico.

Figura 73 - FFT - Pórtico com Controle por Pêndulo $e=0.42$

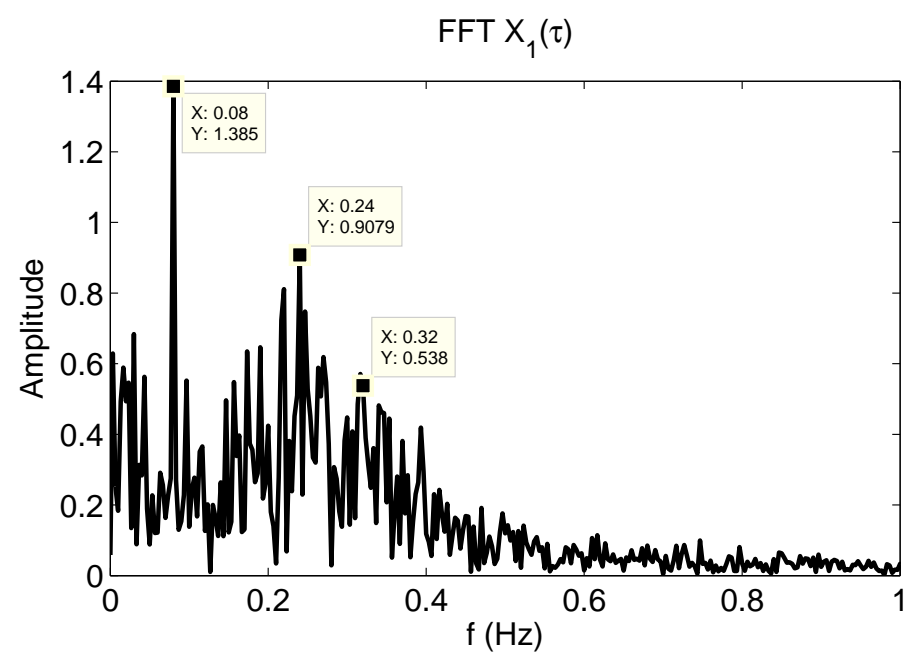

Fonte: Elaborada pelo próprio autor

Na Figura 74, o cálculo dos coeficientes da wavelet foi realizado utilizando-se a wavelet de Morlet complexa implementada na Wavelet Toolbox ${ }^{T M}$ do MatlabßR, Eq. 23 com 
parâmetros $F_{B}=10$ e $F_{C}=1$, com as escalas $a=100: 2: 1500$.

$\mathrm{Na}$ coluna da esquerda da Figura 74 tem-se o escalograma que também apresenta várias células de turbulência. A propagação do espectro de energia é um indicativo da ocorrência de um comportamento caótico.

Novamente, levando-se em consideração o pico principal no espectro de Fourier, dois outros pontos apontados na Figura 73 foram escolhidos para uma comparação entre as pseudofrequências calculadas pela wavelet toolbox, por meio da Eq. 22, e as frequências obtidas pela $\mathrm{FFT}$, em $\mathrm{Hz}$.

Os três valores de escala encontrados para o sistema controlado pelo pêndulo foram 1246 (para o pico principal), 416 e 310. Os dois primeiros apresentam ótima concordância, quando convertidos para frequência em $\mathrm{Hz}$, por meio da Eq. 22. e o último, uma diferença sutil entre a pseudofrequência e a FFT. Para melhor visualização, os resultados estão na Tabela 15.

Mediante a inspeção do ângulo de fase na coluna da direita da Figura 71 , identifica-se uma distribuição irregular nas linhas verticais, indicando comportamento caótico do sistema.

Figura 74 - Aplicação da Wavelet Toolbox ${ }^{\mathrm{TM}}$ do Matlab® - Pórtico com Controle por Pêndulo $e=0.42$
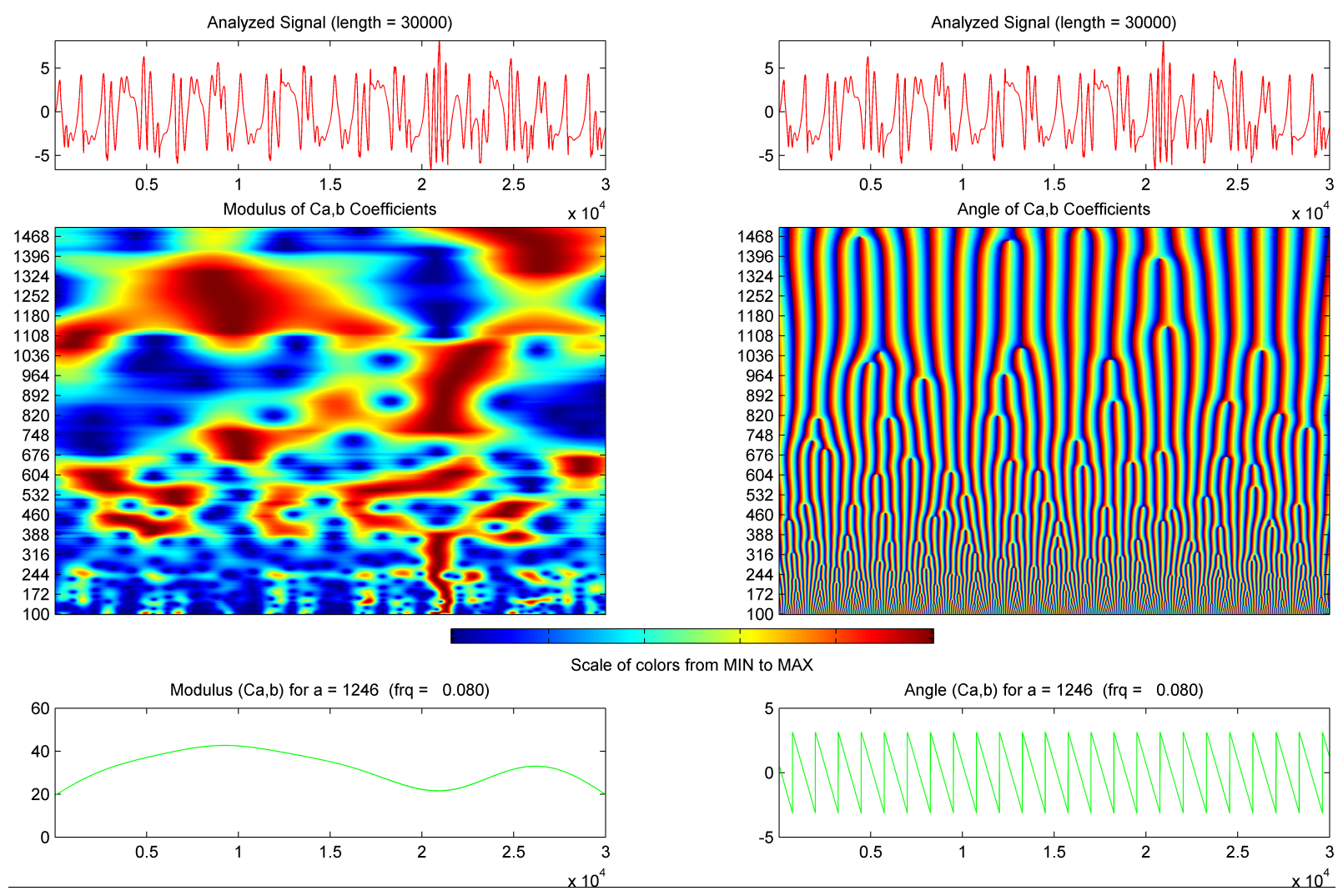

Fonte: Elaborada pelo próprio autor 
Tabela 15 - Pseudofrequência da Wavelet em Hz x Frequência da FFT em Hz - Pórtico com Controle por Pêndulo $e=0.42$

\begin{tabular}{ccc}
\hline Escala & Pseudofrequência da Wavelet & Frequência da FFT \\
\hline 310 & 0.323 & 0.320 \\
416 & 0.240 & 0.240 \\
1246 & 0.080 & 0.080 \\
\hline
\end{tabular}

\subsubsection{Modelo de Pórtico com Controle por Pêndulo $e=0.7$}

Na Figura 75, são apresentados os resultados obtidos pela aplicação da wavelet de Morlet complexa implementada na wavelet toolbox de Torrence e Compo (1998), sobre o sinal de deslocamento do NIS com o controle por pêndulo $e=0.7$.

Visualmente, pode-se notar que o espectro de energia wavelet apresenta as células de turbulência com distribuição seguindo um padrão regular. Sendo assim, pode-se relacionar esse comportamento com o movimento periódico do sistema. O espectro wavelet global apresenta uma frequência principal com um pico de maior amplitude, e a segunda frequência de ressonância também é bem caracterizada na figura.

Figura 75 - Aplicação da Wavelet Toolbox de Torrence e Compo (1998) - Pórtico com Controle por Pêndulo $e=0.7$

a) Histórico de Deslocamento no tempo

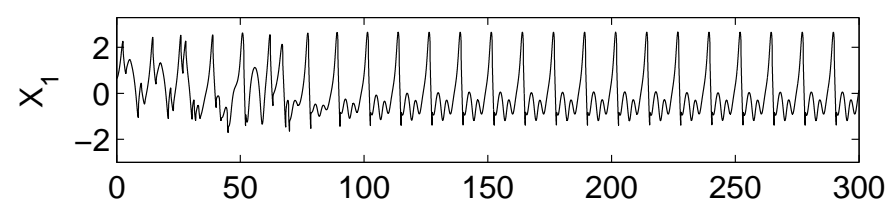

b) Espectro de Energia Wavelet

c) Espectro Wavelet Global
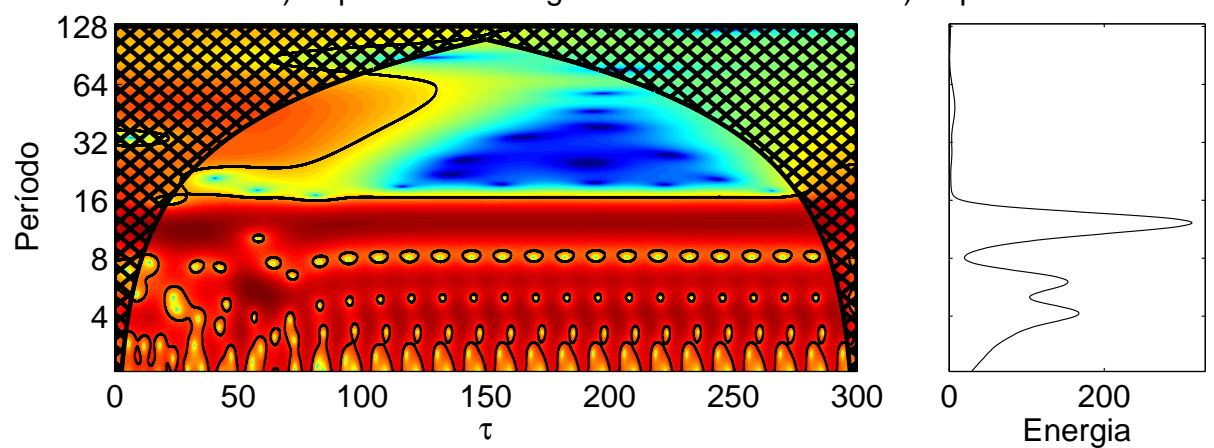

Fonte: Elaborada pelo próprio autor

A Figura 76 representa a FFT para a resposta do sistema com o controle por pêndulo $e=0.7$. O espectro de Fourier apresenta um comportamento periódico semelhante ao do NIS com controle passivo NES da Figura 67. com todas as frequências principais caracterizadas. 
Figura 76 - FFT - Pórtico com Controle por Pêndulo $e=0.7$

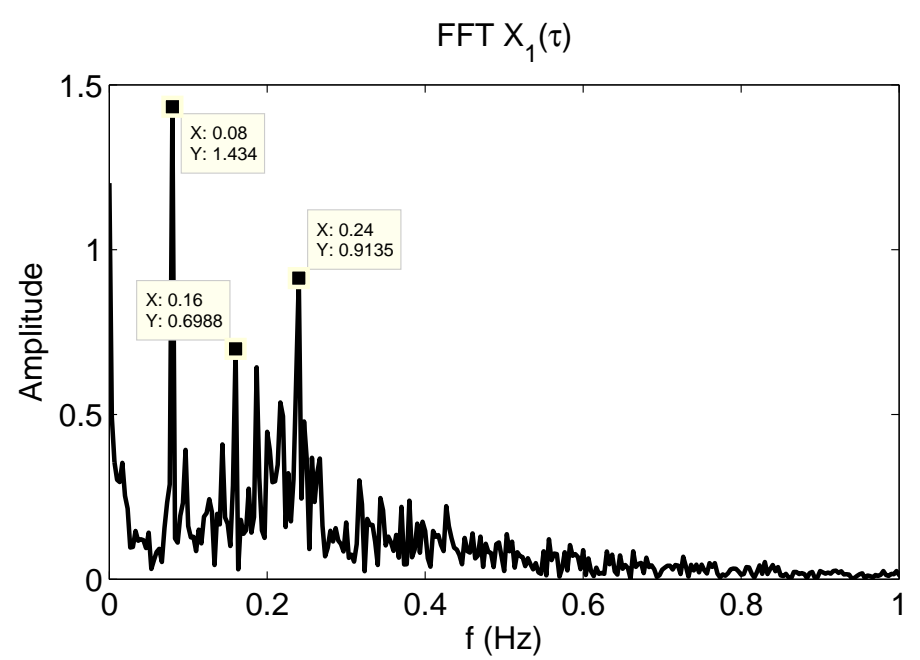

Fonte: Elaborada pelo próprio autor

Na Figura 77, o cálculo dos coeficientes da wavelet foi realizado, utilizando-se a wavelet de Morlet complexa implementada na Wavelet Toolbox ${ }^{T M}$ do Matlabß, Eq. 23 , com parâmetros $F_{B}=10$ e $F_{C}=1$, com as escalas $a=100: 2: 1500$.

Na coluna da esquerda da Figura 77. o escalograma demonstra a concentração do espectro de energia do módulo dos coeficientes wavelet que representam as frequências principais. O comportamento periódico do sistema controlado pode ser identificado pelo padrão regular da distribuição da energia pelas escalas.

Considerando-se o pico principal no espectro de Fourier, dois outros pontos indicados na Figura 76 foram escolhidos para uma comparação entre as pseudofrequências calculadas pela wavelet toolbox, por meio da Eq. 22, e as frequências obtidas pela FFT em Hz.

Os três valores de escala encontrados foram 1246 (para o pico principal), 626 e 416, os quais apresentam ótima concordância, quando convertidos para frequência em $\mathrm{Hz}$, via Eq. 22. Para melhor visualização, os resultados estão na Tabela 16.

Por meio da inspeção do ângulo de fase na coluna da direita da Figura 77, identifica-se uma distribuição regular nas linhas verticais, indicando comportamento periódico do sistema. 
Figura 77 - Aplicação da Wavelet Toolbox ${ }^{\mathrm{TM}}$ do Matlab $®$ - Pórtico com Controle por Pêndulo $e=0.7$
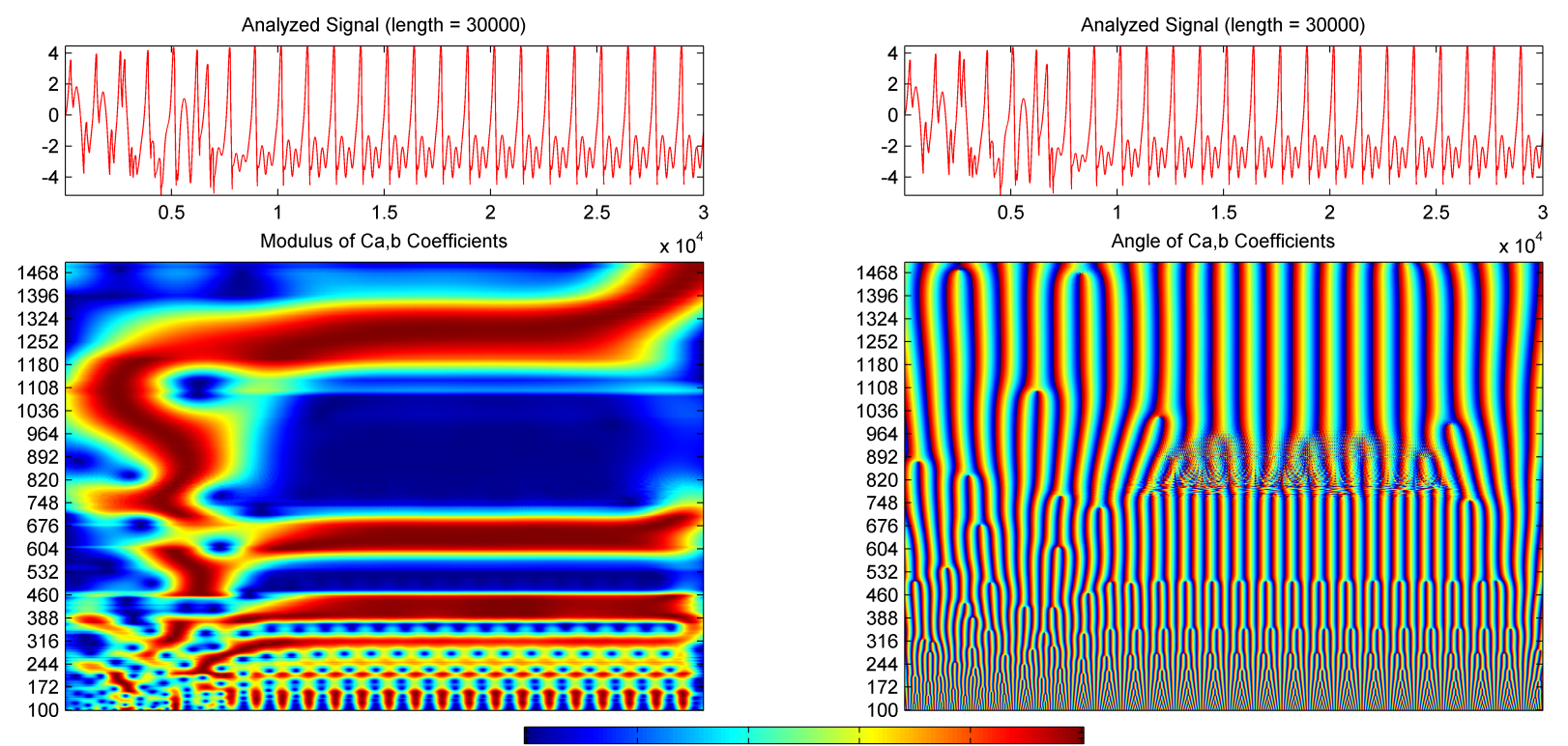

Scale of colors from MIN to MAX
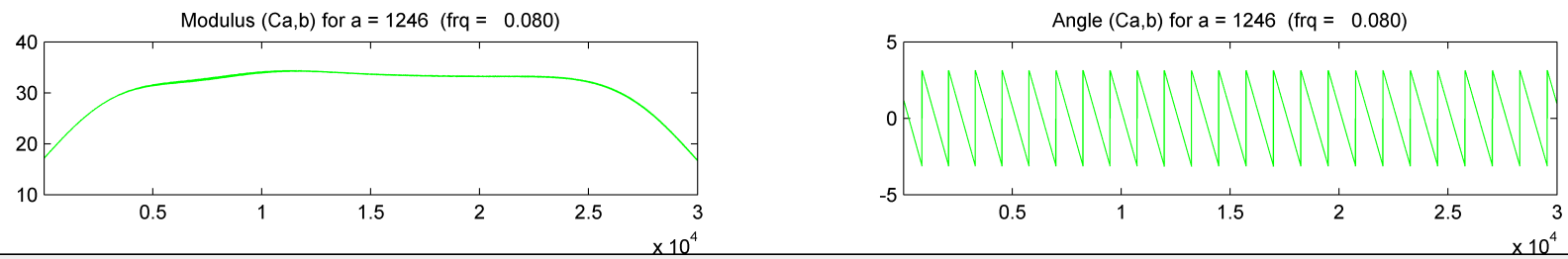

Fonte: Elaborada pelo próprio autor

Tabela 16 - Pseudofrequência da Wavelet em $\mathrm{Hz}$ x Frequência da FFT em Hz - Pórtico com Controle por Pêndulo $e=0.7$

\begin{tabular}{ccc}
\hline Escala & Pseudofrequência da Wavelet & Frequência da FFT \\
\hline 416 & 0.240 & 0.240 \\
626 & 0.160 & 0.160 \\
1246 & 0.080 & 0.080 \\
\hline
\end{tabular}

Por meio da análise wavelet, foi possível comparar as duas estratégias de controle propostas para o sistema de captura de energia não ideal.

Pode-se concluir que ambas as estratégias são eficientes na melhora da energia capturada, com destaque para o controle utilizando o pêndulo, que apresentou comportamento semelhante ao do NES para levar o sistema a uma órbita periódica estável, sem causar perdas de energia no sistema de captura. 


\section{PÓRTICO COM SATURAÇÃO MODAL}

\subsection{CONSIDERAÇÕES INICIAIS}

Nos últimos anos, o interesse por saturação e fenômenos de acoplamento modal tem aumentado na área de pesquisa de vibrações e controle. Neste capítulo, é apresentado um estudo de caso especial, considerando a aplicação de uma estrutura aporticada com comportamento geometricamente não linear, como um sistema de captura de energia. É apresentado o fenômeno de saturação modal, com a troca de energia entre os modos de vibração acoplados em uma configuração de ressonância 2:1. Utilizou-se uma análise por elementos finitos (FEA) para obter as respostas do sistema, como em lliuk et al. (2014c).

\subsection{FENÔMENO DE SATURAÇÃO MODAL}

O fenômeno denominado saturação modal, apresentado nas obras de Nayfeh e Mook (1979), Mook, Plaut e HaQuang (1985), Brasil (1990), Nayfeh (2000), Felix (2002), referese à ocorrência de não linearidades no movimento de estruturas aporticadas (apoiadas sobre colunas), nas quais a vibração do componente vertical da estrutura (viga) pode ser transferida para as colunas que servem de sustentação para a estrutura, causando danos ao conjunto. Alguns exemplos de estruturas aporticadas podem ser vistos na Figura 78 .

Figura 78 - Exemplos de Estruturas Aporticadas

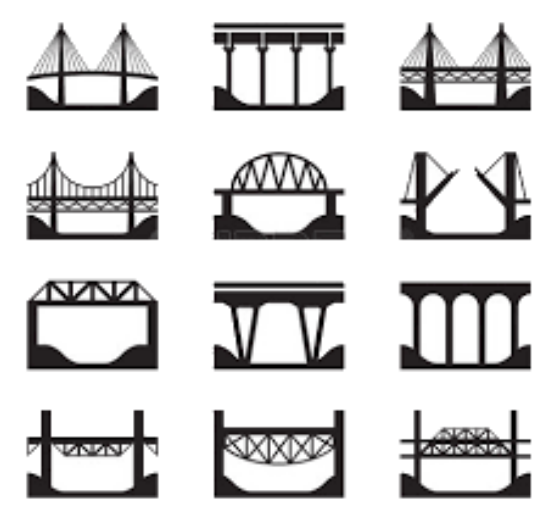

Fonte: (123RF, 2016)

Estruturas que possuem dois graus de liberdade podem apresentar a ocorrência do fenômeno de saturação modal, com a transferência de energia entre os modos de vibração, devido à presença de uma não linearidade quadrática que envolve os deslocamentos do conjunto estrutural, bem como a configuração de ressonância interna em uma razão de 2:1 entre o 
segundo modo, que apresenta movimento vertical (First Symmetrical Mode) e o primeiro modo, com movimento horizontal (Sway Mode), respectivamente.

A Eq. 24 e Eq. 25 demonstram a presença da não linearidade quadrática e a probabilidade de ocorrência de ressonância interna de 2:1 (NAYFEH; MOOK, 1979):

$$
\begin{gathered}
\ddot{u}_{1}+2 \mu_{1} \dot{u}_{1}+\omega_{1}^{2} u_{1}=u_{1} u_{2} \\
\ddot{u_{2}}+2 \mu_{2} \dot{u_{2}}+\omega_{2}^{2} u_{2}=u_{1}^{2}+f \cos (\Omega t)
\end{gathered}
$$

onde $u_{1}$ e $u_{2}$ são os deslocamentos da estrutura, e os fatores de amortecimento são dados por $\mu_{1}$ e $\mu_{2}$. As frequências naturais do sistema são $\omega_{1}$ e $\omega_{2}$, respectivamente. O sistema sofre a ação de uma força externa aplicada com amplitude $f$ e com frequência de excitação $\Omega$. $O$ tempo $t$ é dado em segundos.

Para que ocorra a troca de energia entre os modos e por fim o fenômeno de saturação modal, faz-se necessário que o sistema possua pouco amortecimento e sejam satisfeitas as relações $\omega_{2}=2 \omega_{1}+\sigma_{1}$ e $\omega_{2}=\Omega+\sigma_{2}$, para as quais $\sigma_{1} \ll 1$ e $\sigma_{2} \ll 1$ são parâmetros de sintonia.

A ocorrência do fenômeno de saturação no problema de um transdutor constituído por uma barra piezocerâmica e alimentado por uma válvula para geração de vácuo, excitado por uma fonte não ideal de energia, é uma inspiração para a utilização do controle por saturação em um problema de vibração não ideal (BALTHAZAR et al., 2008).

A análise do método de controle não linear com base no fenômeno de saturação em sistemas acoplados que apresentam uma não linearidade quadrática é detalhado nos trabalhos de Nayfeh e Mook (1979), Mook, Plaut e HaQuang (1985) e Nayfeh (2000). Já a implementação do controle de saturação ativa foi proposta por Nayfeh (2000), Golnaraghi (1991). Oueini, Nayfeh e Golnaraghi (1997), Pai e Schulz (2000).

O chamado método de controle de saturação original proposto por Pai et al. (1998) utiliza a ressonância interna 2:1 entre os modos de vibrar da estrutura e o fenômeno de saturação modal para suprimir vibrações no estado de equilíbrio do sistema, por meio da ligação do controlador de segunda ordem, usando termos de acoplamento quadrático.

Pode-se verificar que alguns autores têm mostrado que o método de controle não linear baseado na saturação para um problema não linear requer um mecanismo de ajuste adaptativo da frequência, uma vez que a frequência do sistema não linear muda com a amplitude. Assim, o controlador ficará fora de sintonia em relação ao sistema controlado, de acordo com Hall et al. (2000), Pratt, Oueini e Nayfeh (1999), Ashour e Nayfeh (2002), Balthazar, Felix e Brasil (2003). 
Levam-se em conta ambas as excitações da estrutura (horizontal e vertical) em ressonância inicialmente com o primeiro modo (Sway Mode), e na sequência com o segundo modo (First Symmetrical Mode). Com a ressonância interna 2:1 presente entre esses modos, os fenômenos de saturação modal e de troca de energia (acoplamento modal) podem ocorrer. Assim, a energia bombeada internamente no sistema, por meio de um dos modos, é parcialmente transferida para o outro modo, não diretamente excitado.

\subsection{MODELO ESTRUTURAL}

Considera-se a estrutura aporticada da Figura 79 com duas colunas verticais engastadas na base, onde: $E I_{1}$ é a rigidez das colunas e $h$ é a altura, e uma viga biarticulada horizontal, onde: $E I_{2}$ é a rigidez, com o comprimento dado por $L$, com uma massa $M$ fixa a meio vão da viga e as concentrações $m$, na extremidade superior das colunas.

Figura 79 - Modelo Estrutural do Pórtico

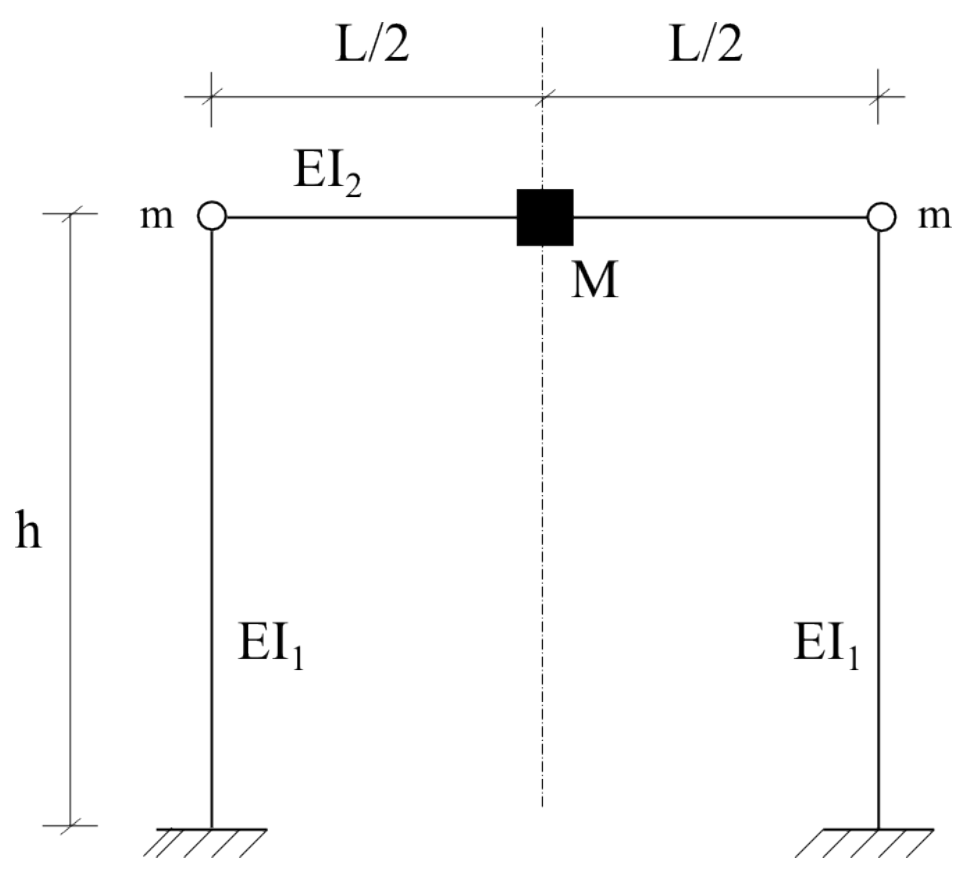

Fonte: Elaborada pelo próprio autor

Ajustam-se as frequências do primeiro modo com oscilação horizontal (Sway Mode) e do segundo modo com oscilação vertical (First Symmetrical Mode), em um relacionamento $\omega_{1} \approx 2 \omega_{2}$, a fim de obter o acoplamento modal no modelo formulado por meio do método dos elementos finitos (MEF) não linear. Em seguida, como mostrado na Figura 80 , a excitação harmônica da base é aplicada, com a primeira frequência em um relacionamento $\Omega \approx \omega_{1}$, próximo da ressonância com o primeiro modo de oscilação com movimento horizontal. 
Figura 80 - Excitações da Estrutura

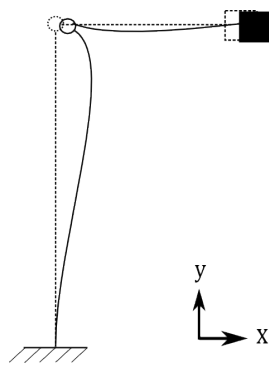

(a) Excitação Horizontal

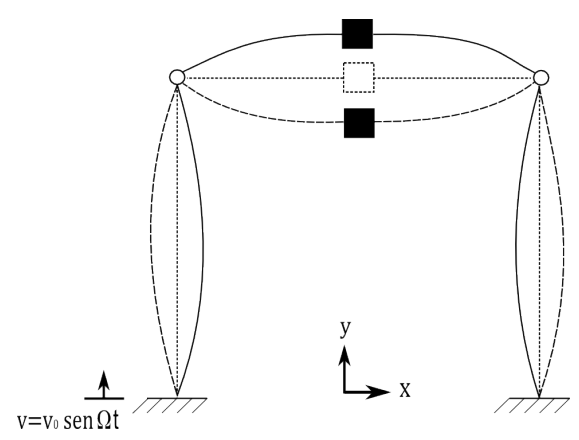

(b) Excitação Vertical

Fonte: Elaborada pelo próprio autor

A troca de energia entre os modos é observada nos resultados apresentados nas simulações numéricas, mas sem a saturação modal para esse caso.

Na sequência, um relacionamento de excitação com a forma $\Omega \approx \omega_{2}$ é aplicado. Como a amplitude da excitação aumenta, a saturação do segundo modo ocorre, e o excedente de energia é bombeado (transferido) dentro do sistema através desse modo para o primeiro modo, não excitado diretamente. A configuração final da vibração em estado estacionário, em ambos os casos, é mostrada na Figura 81 .

Figura 81 - Configuração Final para a Resposta em Estado Estacionário

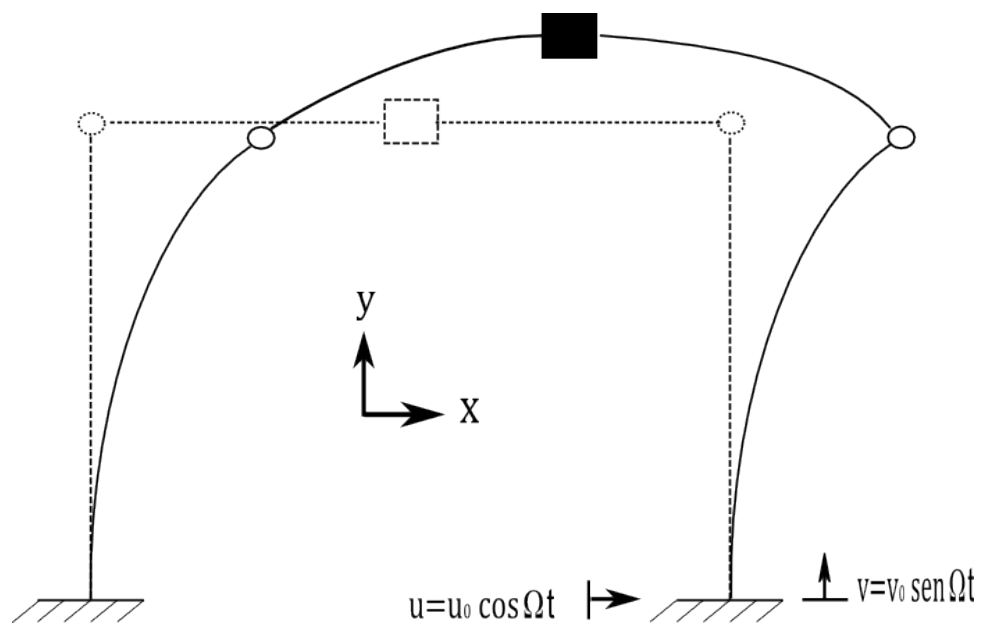

Fonte: Elaborada pelo próprio autor 


\subsection{PROGRAMA DE ELEMENTOS FINITOS}

Utilizou-se um código de elementos finitos descrito por Brasil (1990) e Mazzilli e Brasil (1995) nomeado Andros, que é um programa de MEF escrito em linguagem de programação Fortran, para realizar a análise dinâmica não linear da estrutura. Na sua versão atual, o código é capaz de realizar tanto a integração passo-a-passo da resposta do sistema no tempo quanto a determinação das frequências naturais dos pórticos de comportamento não linear geométrico.

A equação do movimento de uma estrutura discreta pode ser escrita em termos de coordenadas generalizadas $q_{s}$ e suas derivadas temporais, em que:

$$
m^{r s} \ddot{q}_{s}+d^{r s} \dot{q}_{s}+U_{, r}=f^{r},
$$

onde é usada a convenção de índice de Einstein, e na qual $m^{r s}$ são os coeficientes da matriz de massa $\mathbf{M}$; $d^{r s}$ são os coeficientes da matriz de amortecimento equivalente $\mathbf{D}$; e $f^{r s}$ são os componentes do vetor de carga $\mathbf{f}$.

Os componentes da força elástica de restauração $U_{, r}$ são derivados da energia de deformação $U$, e podem ser colocados sob a forma $U_{, r}=p^{r}$, onde $p^{r}$ o são os coeficientes do vetor de força de restauração elástica p. Assim, a Eq. 26 pode ser reformulada em notação matricial como:

$$
\mathrm{M} \ddot{\mathbf{q}}+\mathrm{D} \dot{\mathrm{q}}+\mathbf{p}=\mathbf{f}
$$

Os coeficientes dessas matrizes podem ser de funções generalizadas, e as coordenadas para as estruturas geometricamente não lineares são tais como a estrutura aqui analisada. A formulação lagrangeana não linear para um elemento de estrutura do tipo Euler-Bernoulli, como utilizado no programa Andros, é resumida aqui.

Adotando $q_{r}$ com $r=1$ a $\quad 6$, para os deslocamentos na extremidade de um elemento planar de comprimento $L$ com coordenadas generalizadas, podem-se obter os deslocamentos transversais do eixo $\bar{v}$, por meio das funções de interpolação hermitianas cúbicas $\psi_{r}$, como $\bar{v}=q_{r} \psi_{r}$. Em relação aos deslocamentos longitudinais, $\bar{u}$, a hipótese de que a força axial na viga deve ser constante leva a:

$$
\bar{u}=\left[\frac{q_{4}-q_{1}}{L}+\frac{1}{2 L} q_{i} q_{j} \alpha_{i j}(L)\right] x-\frac{q_{i} q_{j}}{2} \alpha_{i j}(x)=q_{1}
$$

com:

$$
\alpha_{i j}(x)=\int_{0}^{x} \psi_{i}{ }^{\prime} \psi_{j}{ }^{\prime} d \xi
$$

onde os apóstrofos denotam derivação em relação a $x$ ou $\xi$. 
O campo de tensão para o elemento pode ser aproximado por:

$$
\epsilon=\bar{u}^{\prime}+\frac{1}{2}\left(\bar{v}^{\prime}\right)^{2}-y \bar{v}^{\prime \prime}
$$

Assim os coeficientes do vetor $\mathbf{p}$ e da matriz de rigidez tangente:

$$
\begin{array}{r}
p^{r}=q_{i} E I \int_{0}^{L} \psi_{r}{ }^{\prime \prime} \psi_{s}{ }^{\prime \prime} d x+\frac{E A}{L}\left[L q_{i} \phi_{i}{ }^{\prime}+\frac{1}{2} \alpha_{i j}(L) q_{i} q_{j}\right]\left[L \phi_{r}{ }^{\prime}+q_{k} \alpha_{k r}(L)\right], \\
k_{T}^{r s}=E I \int_{0}^{L} \psi_{r}{ }^{\prime \prime} \psi_{s}{ }^{\prime \prime} d x \\
+\frac{E A}{L}\left\{L^{2} \phi_{r}{ }^{\prime} \phi_{s}{ }^{\prime}+L\left[\frac{q_{4}-q_{1}}{L} \alpha_{r s}(L)+\phi_{r}{ }^{\prime} \alpha_{i s}(L)+\phi_{s}{ }^{\prime} \alpha_{i r}(L)\right] q_{i}\right. \\
\left.+\left[\alpha_{i r}(L) \alpha_{j s}(L)+\frac{1}{2} \alpha_{i j}(L) \alpha_{r s}(L)\right] q_{i} q_{j}\right\}
\end{array}
$$

$A$ e $I$ são a área e o momento de inércia da seção transversal, e $E$, o módulo de elasticidade. As duas únicas funções de interpolação auxiliares lineares $\phi_{i}(x)$ diferentes de zero são:

$$
\phi_{1}=1-\frac{x}{L} \quad \phi_{1}=\frac{x}{L} \quad \beta_{r s}=\frac{x}{L} \alpha_{r s}(L)-\alpha_{r s}(x) .
$$

Os coeficientes resultantes (não lineares) das matrizes de massa e de amortecimento equivalentes, com $\rho$ sendo a massa específica, são:

$$
\begin{gathered}
m^{r s}=\rho A \int_{0}^{L}\left[\phi_{r} \phi_{s}+\psi_{r} \psi_{s}+q_{i}\left(\phi_{r} \beta_{i} s+\phi_{s} \beta_{i} r\right)+q_{i} q_{j} \beta_{i s} \beta_{j r}\right] d x \\
+\rho I\left[\int_{0}^{L}\left(\psi_{r}^{\prime} \psi_{s}^{\prime}\right) d x+q_{i} q_{j} \int_{0}^{L}\left(\psi_{r}^{\prime} \psi_{s}^{\prime} \psi_{i}^{\prime} \psi_{s}^{\prime}\right) d x\right], \\
d^{r s}=\rho A \dot{q}_{t} \int_{0}^{L}\left[\left(\phi_{r} \beta_{s t}+\frac{1}{2} \phi_{s} \beta_{s r}-\frac{1}{2} \phi_{t} \beta_{s r}\right)+\left(\beta_{s t} \beta_{i r}+\frac{1}{2} \beta_{r t} \beta_{i s}-\frac{1}{2} \beta_{s r} \beta_{i t}\right) q_{i}\right] d x \\
+\rho I \dot{q}_{t} q_{i} \int_{0}^{L}\left(\psi_{r}^{\prime} \psi_{s}^{\prime} \psi_{t}^{\prime} \psi_{i}^{\prime}\right) d x+\mu^{r s},
\end{gathered}
$$

onde $\mu^{r s}$ são os coeficientes de amortecimento linear viscoso.

O algoritmo básico para a integração passo-a-passo no tempo é o método de Newmark, com iteração de Newton-Raphson dentro de cada passo. O problema é reduzido para:

$$
\hat{\mathbf{K}}^{\tau} \Delta \mathbf{q}_{(i)}=\mathbf{r}_{(i-1)}
$$


onde $\hat{\mathbf{K}}^{\tau}$ é a matriz de gradiente do processo, com tempo $\tau$ (inicial de um passo), dada por:

$$
\hat{\mathbf{K}}^{\tau}=\hat{\mathbf{K}}_{T}^{\tau}=b_{0} \mathbf{M}_{T}+b_{1} \mathbf{D}^{\tau}
$$

$\Delta \mathbf{q}_{(i)}$ é a estimativa do ith, passo de incremento de deslocamento, e $\mathbf{r}_{(i-1)}$ é o resíduo das forças computado em termos dos deslocamentos estimados na iteração anterior, dada por:

$$
\mathbf{r}_{(i-1)}=\mathbf{f}^{\tau+\Delta \tau}-\mathbf{p}_{(i-1)}-\mathbf{D}_{(i-1)} \dot{\mathbf{q}}_{(i-1)}-\mathbf{M}_{(i-1)} \ddot{\mathbf{q}}_{(i-1)}
$$

onde os coeficientes $b_{0}$ e $b_{1}$ são a estimativa dos campos de velocidade e aceleração na Eq. 37 e são dados pelo método de aceleração média constante, de Newmark.

\subsection{RESULTADOS NUMÉRICOS}

Para o modelo da Figura 79, as barras são constituídas de perfis de aço de seção I de $8^{\prime \prime}$ (polegadas), $1^{a}$ alma, dispostos em uma configuração de modo a fletir no plano de sua menor inércia.

$\mathrm{Na}$ Tabela 17, apresentam-se os valores para as características geométricas e físicas da estrutura aporticada.

Tabela 17 - Características Geométricas e Físicas do Pórtico Analisado

\begin{tabular}{cc}
\hline Característica & Valor \\
\hline Altura das colunas & $\mathrm{h}=2,0 \mathrm{~m}$ \\
Vão da viga & $\mathrm{L}=2,575 \mathrm{~m}$ \\
Área da seção & $\mathrm{A}=3,484 \times 10^{-3} \mathrm{~m}^{2}$ \\
Momento de inércia da seção & $I_{1}=I_{2}=1,553 \times 10^{-6} \mathrm{~m}^{4}$ \\
Módulo de Young & $\mathrm{E}=210 \mathrm{GPa}$ \\
Massa específica & $\rho=7.860 \mathrm{~kg} / \mathrm{m}^{3}$ \\
Massa da máquina & $\mathrm{M}=900 \mathrm{~kg}$ \\
Frequência do primeiro modo & $\omega_{1}=15,6667 \mathrm{rad} / \mathrm{s}$ \\
Frequência do segundo modo & $\omega_{2}=31,3063 \mathrm{rad} / \mathrm{s}$ \\
Amplitude da força & $P_{0}=1 \mathrm{kN}$ \\
Frequência cíclica & $5 \mathrm{~Hz}$ \\
Frequência angular & $\Omega=10 \pi \mathrm{rad} / \mathrm{s}$ \\
Passo de integração & $\mathrm{dt}=0.0025 \mathrm{~s}$ \\
\hline
\end{tabular}


A discretização espacial do modelo com doze elementos é apresentada na Figura 82.

Figura 82 - Discretização do MEF Adotada

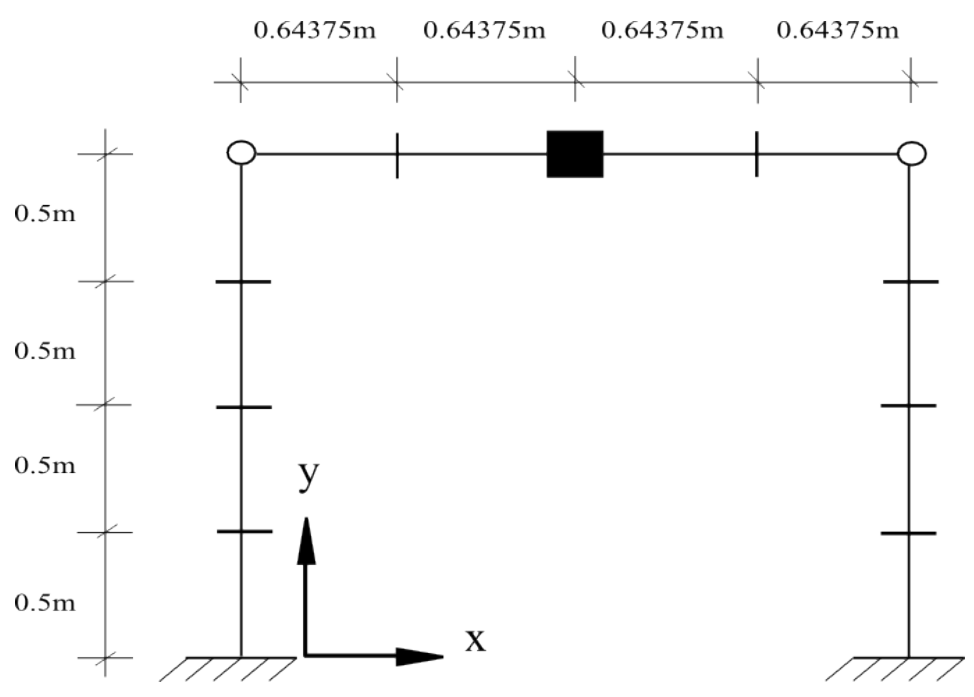

Fonte: Elaborada pelo próprio autor

A seguir, obtiveram-se, por meio de simulação numérica, os históricos de deslocamento no tempo para o modelo proposto.

- Para o caso $\Omega \approx \omega_{1}$, a Figura 83 mostra o acoplamento modal e grandes deslocamentos de ambos os modos, mas não há saturação do primeiro modo (modo de oscilação horizontal) diretamente excitado.

Figura 83 - Deslocamento no Tempo para o Caso $\Omega \approx \omega_{1}$

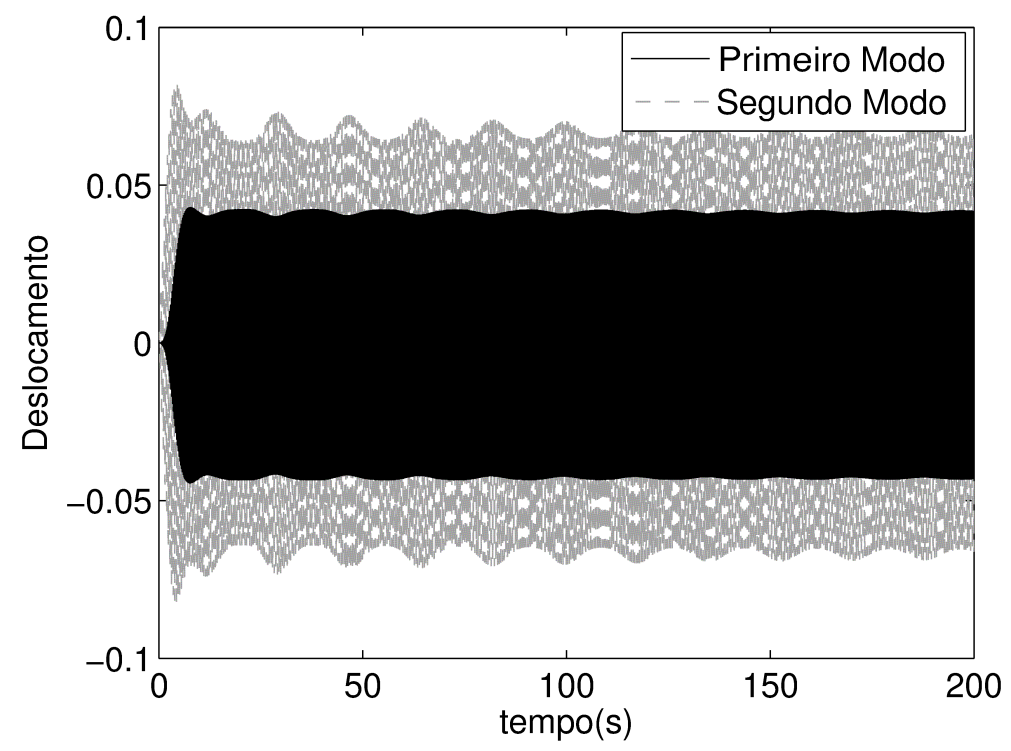

Fonte: Elaborada pelo próprio autor 
- Para o caso $\Omega \approx \omega_{2}$, a Figura 84 mostra a saturação do segundo modo e grandes movimentos horizontais no modo de oscilação, não diretamente excitado.

Figura 84 - Deslocamento no Tempo para o Caso $\Omega \approx \omega_{2}$

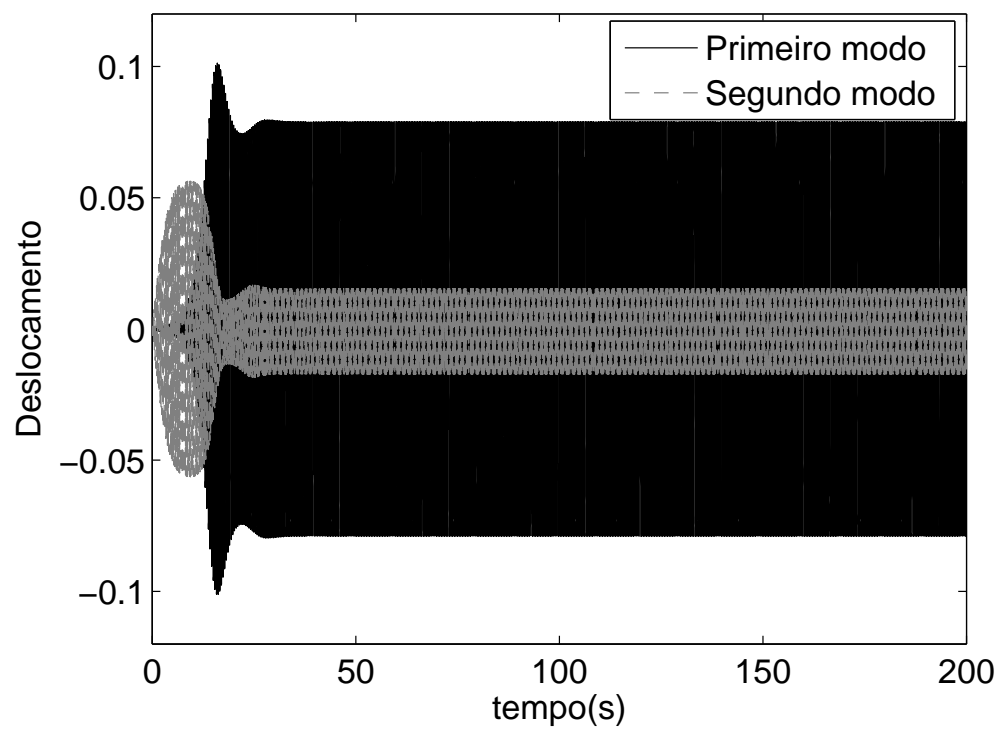

Fonte: Elaborada pelo próprio autor

Uma observação por meio de um zoom na Figura 85 revela a troca de energia durante o regime transiente.

Figura 85 - Aplicação de um Zoom no Transiente do Deslocamento no Tempo para o Caso $\Omega \approx \omega_{2}$

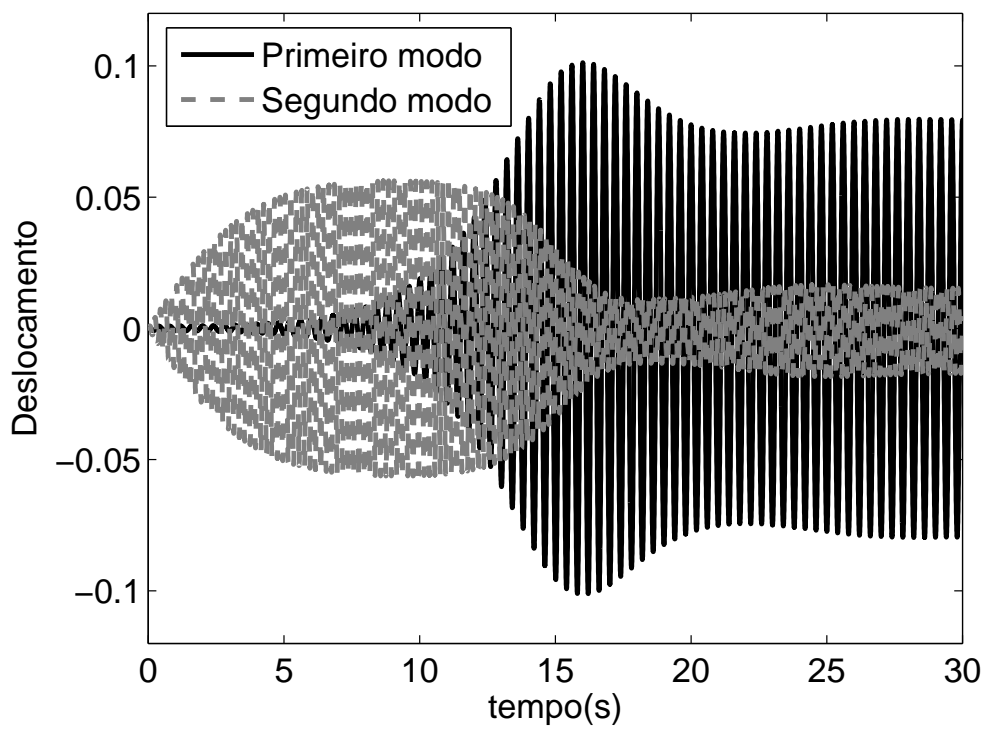

Fonte: Elaborada pelo próprio autor 


\subsection{PROPOSTA DE CAPTURA DE ENERGIA}

Supondo-se que havendo alguns sistemas de captura de energia, tais como os descritos nas referências lliuk et al. (2013a) e lliuk et al. (2013c), ligados às colunas ou à viga da estrutura aporticada, tal como sugerido na Figura 86 propõe-se a ligação de duas camadas piezoelétricas, em ambos os lados da coluna ou da viga, como ilustrado na Figura 86 . Essa configuração é descrita como bimorph. Ambas as regiões da estrutura poderiam ser utilizadas para deformar o material piezoelétrico, ocorrendo a captura da energia cinética e sua conversão em energia elétrica.

Figura 86 - Proposta de um Sistema de Captura de Energia

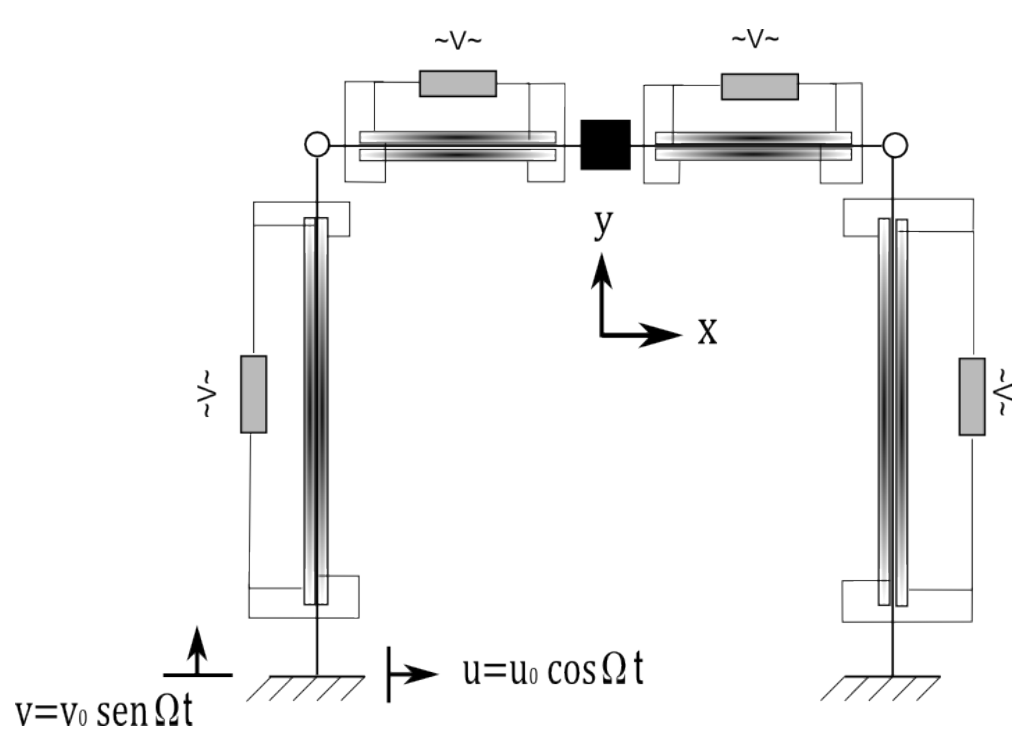

Fonte: Elaborada pelo próprio autor

A Figura 87 apresenta os registros temporais dos valores proporcionais à energia, para o caso em que o acoplamento modal ocorre, mas a saturação não está presente. 
Figura 87 - Histórico de Deslocamento no Tempo da Potência Proporcional para o Caso $\Omega \approx \omega_{1}$

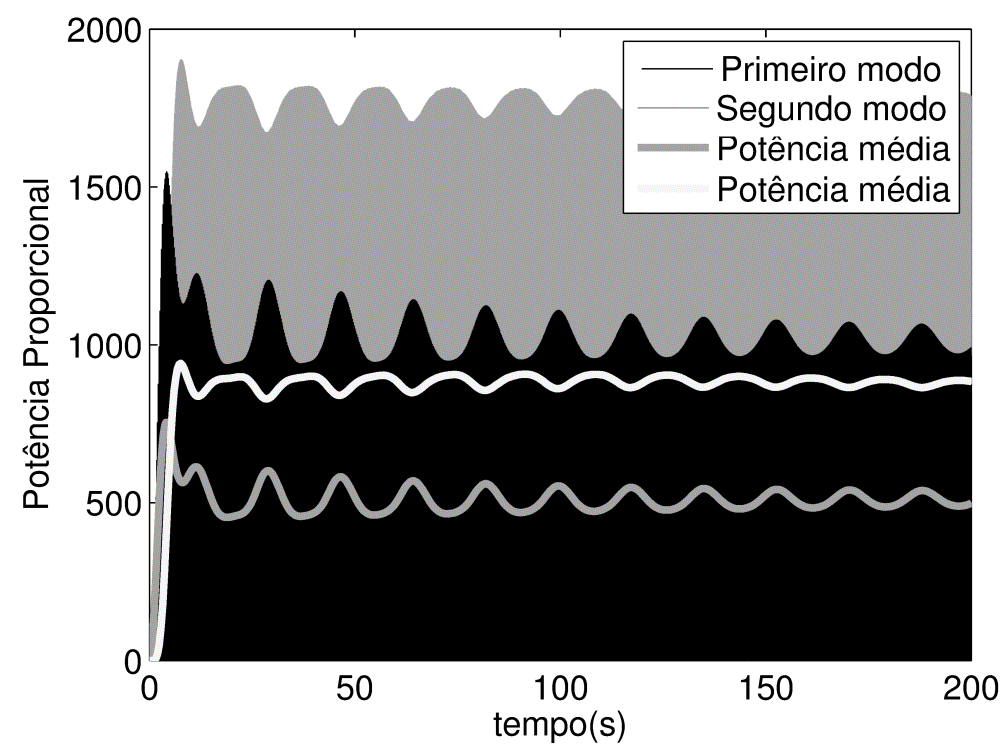

Fonte: Elaborada pelo próprio autor

Na Figura 88, pode-se ver um zoom nas potências médias calculadas.

Figura 88 - Zoom no Histórico de Deslocamento no Tempo da Potência Proporcional para o Caso $\Omega \approx \omega_{1}$

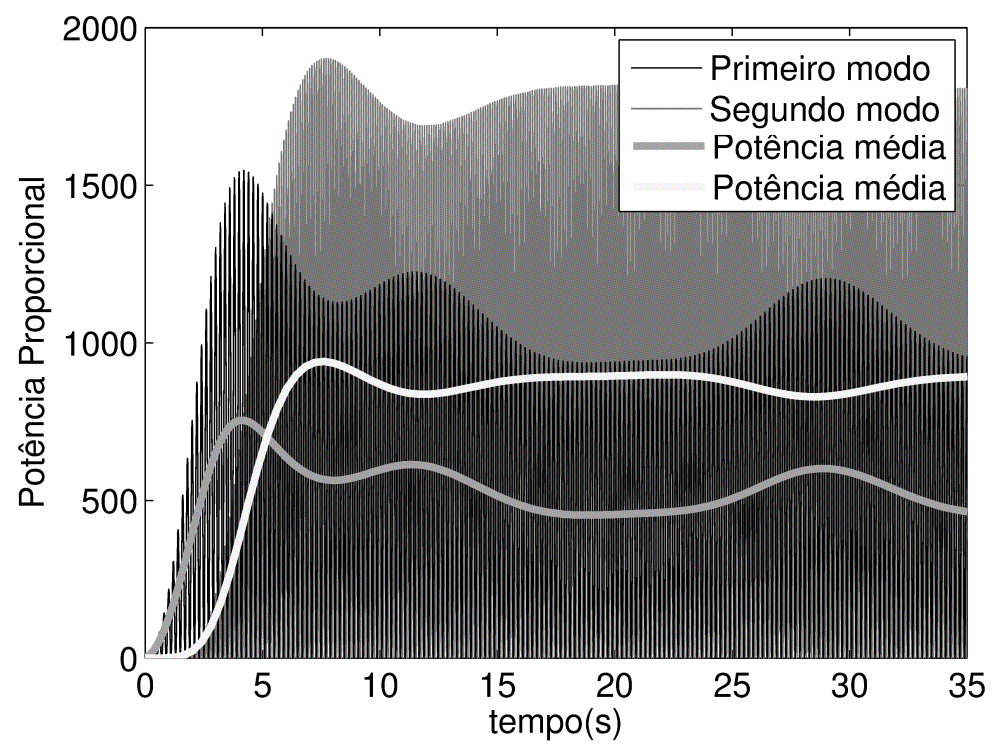

Fonte: Elaborada pelo próprio autor

As Figuras 89 e 90 apresentam os registos temporais dos valores proporcionais à quantidade de energia disponível para a captura em cada um dos modos, para o caso $\Omega \approx \omega_{2}$. 
Figura 89 - Histórico de Deslocamento no Tempo da Potência Proporcional Disponível para Captura em Cada Modo para o Caso $\Omega \approx \omega_{2}$

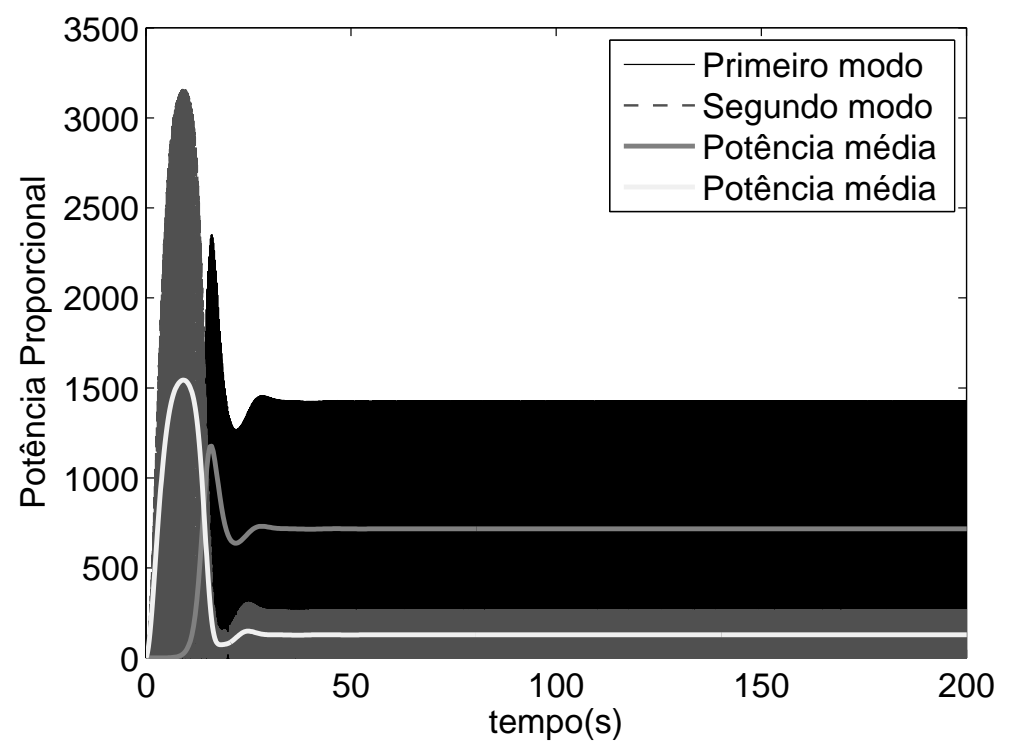

Fonte: Elaborada pelo próprio autor

Na Figura 90, pode-se ver um zoom nas potências médias calculadas.

Figura 90 - Zoom na Potência Proporcional Disponível para Captura para o Caso $\Omega \approx \omega_{2}$

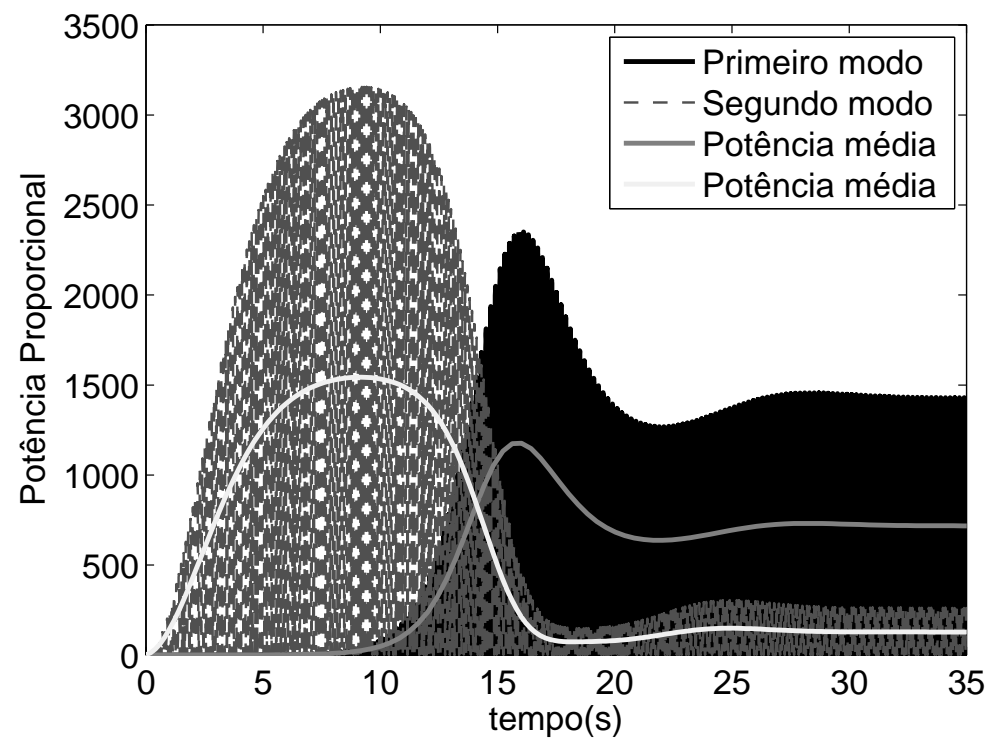

Fonte: Elaborada pelo próprio autor

A Tabela 18 mostra que esses valores sugerem que a quantidade total de energia é mais ou menos conservada, quando a saturação modal e a transferência de energia entre os modos ocorrem. 
Tabela 18 - Valores Proporcionais Disponíveis de Potência para Captura em Cada Modo ao Longo do Tempo

\begin{tabular}{ccc}
\hline Tempo & First Symmetrical Mode & Sway mode \\
\hline 9 & 1543.0 & 25.19 \\
16 & 212.5 & 1177.0 \\
30 & 128.7 & 723.4 \\
\hline
\end{tabular}

\subsection{CONSIDERAÇÕES E CONCLUSÕES}

Neste capítulo, analisou-se um modelo de MEF para uma estrutura aporticada, exibindo transferência de energia entre os modos, em que a estrutura foi excitada por intermédio do primeiro modo de oscilação. Mostrou-se também a saturação do segundo modo (primeiro modo simétrico vertical), quando a estrutura esteve excitada por movimento do suporte em ressonância com esse modo, e a transferência de energia para o primeiro modo de oscilação horizontal acoplado.

Valores proporcionais à potência disponível para a captura de energia em cada um dos modos foram calculados.

Evidencia-se, como uma nova contribuição obtida neste capítulo, a situação em que a energia introduzida em um sistema estrutural, por meio de uma determinada configuração, fez-se disponível para captura em outro modo totalmente diferente. 


\section{PROPOSTA DE UMA FUNÇÃO PARA O ACOPLAMENTO PIEZOELÉTRICO}

\subsection{CONSIDERAÇÕES INICIAIS}

Hoje em dia, tem sido proposta uma grande variedade de sistemas de captura de energia piezoelétricos. Em todos esses sistemas, os autores consideram o acoplamento piezoelétrico como sendo linear por um lado, e por outro lado, não linear. $O$ acoplamento não linear incorpora os efeitos mais realistas dos elementos piezoelétricos - por causa das leis constitutivas desses materiais -, especificamente a relação não linear entre a tensão e o campo elétrico no material piezocerâmico, de acordo com DuToit e Wardle (2007), Twiefel et al. (2007)

Alguns modelos de referência de captura de energia piezoelétricos que utilizaram a abordagem de acoplamento não linear podem ser vistos nas obras de Wagner e Hagedorn (2002), Triplett e Quinn (2009), Karami e Inman (2011), lliuk et al. (2011a), lliuk et al. (2012c), lliuk et al. (2013a) e lliuk et al. (2013c), sem desmerecer outros.

O comportamento não linear do elemento piezoelétrico foi verificado experimentalmente por Crawley e Anderson (1990), e pode ser visto na Figura 91a. Assim, o papel das não linearidades no acoplamento eletromecânico deve ser tomado em consideração na concepção do sistema de captura de energia (ILIUK et al., 2012).

Podem-se encontrar na literatura algumas funções propostas para o acoplamento piezoelétrico, e, em grande parte dos casos, essas funções matemáticas podem apresentar erros de aproximação contra a curva experimental da resposta piezoelétrica que apresenta saturação. Assim, ao longo do tempo de simulação numérica, o erro cumulativo pode ser propagado, causando uma previsão incorreta da energia capturada.

Nesta seção, é apresentada a proposta de uma função para o acoplamento piezoelétrico, utilizando-se o método dos mínimos quadrados.

Usando o modelo teórico de captura de energia piezoelétrico estudado por lliuk et al. (2012c), é proposta uma aproximação da curva experimental de resposta piezoelétrica por uma equação logística para modelar seu comportamento (ILIUK et al., 2014).

Utilizou-se a função para o coeficiente de acoplamento piezoelétrico adimensional sugerida por Triplett e Quinn (2009), a partir de agora referida como função de referência (FR), que tem a forma da Figura $91 \mathrm{~b}$ na qual foram aproximados o coeficiente piezoelétrico dimensional $d(x)$ como: $d(x)=d_{\text {linear }}\left(1+d_{\text {nonlinear }}|x|\right)$, tendo sua contraparte adimensional definida como: $\hat{d}(x)=\theta(1+\Theta|x|)$, cujo coeficiente piezoelétrico é constituído por uma parte linear, representada por $\theta$, e uma parte não linear, representada por $\Theta$. 
Figura 91 - Função de Referência (FR) para o Acoplamento Piezoelétrico Proposto por Triplett e Quinn (2009)

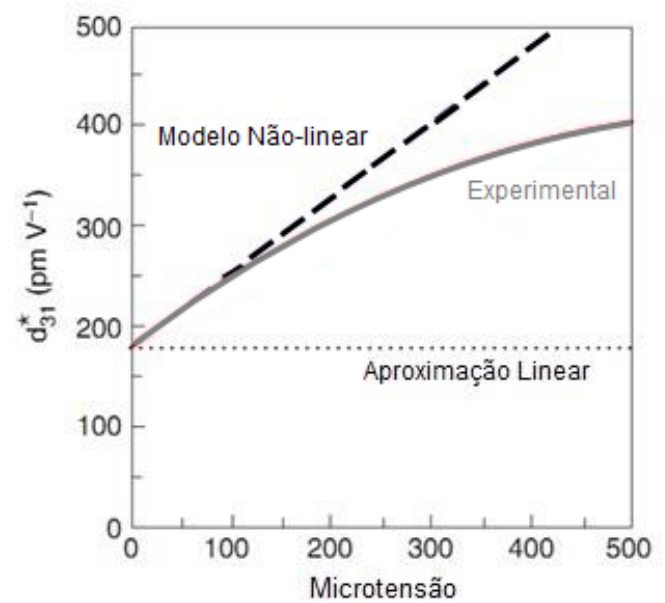

(a) Comparação com a Curva Experimental Obtida Utilizando PZT G-1195

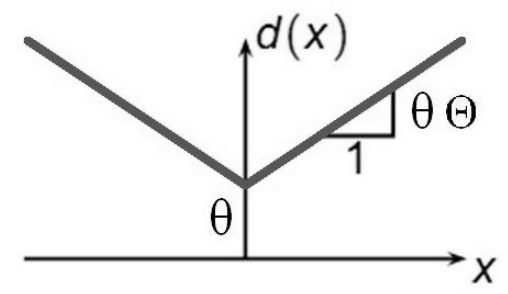

(b) Modelo Não Linear Proposto

Fonte: (TRIPLETT; QUINN, 2009)

\subsection{MODELO DE SISTEMA DE CAPTURA DE ENERGIA NÃO IDEAL}

$$
\begin{gathered}
x^{\prime \prime}+\epsilon \alpha_{1} x^{\prime}+\beta_{1} x+\epsilon \beta_{3} x^{3}+\epsilon \Phi v=\epsilon \delta_{1} \varphi^{\prime \prime} \operatorname{sen} \varphi-\epsilon \delta_{1} \varphi^{\prime 2} \cos \varphi \\
\varphi^{\prime \prime}=\epsilon \rho_{1} x^{\prime \prime} \cos \varphi+\epsilon \rho_{2}-\epsilon \rho_{3} \varphi^{\prime} \\
\rho v^{\prime}-\Phi x+v=0
\end{gathered}
$$

O parâmetro $\Phi$ nas equações representa a função de acoplamento piezoelétrico, e $\epsilon$ é um parâmetro adimensional.

A tensão elétrica adimensional capturada a partir do sistema tem a forma da Eq. 12. e a potência media é calculada pela aplicação da Eq; 13

\subsection{FUNCÃO DE APROXIMAÇÃO PROPOSTA}

Aqui é proposta uma função logística para se obter uma aproximação da curva experimental da Figura 91a a partir de agora referida como função proposta (FP), e que pode ser vista na Eq. 39 .

$$
y=\frac{0.0610646 e^{(5.6668 x)}}{1.01+0.0610646 e^{(5.6668 x)}}+E(x)
$$


onde:

$$
\left\{\begin{array}{l}
E(x)=-3.6552 x^{6}+7.7977 x^{5}-4.8763 x^{4}+2.2849 x^{3}-2.8365 x^{2}+0.9615 x+0.3672 \\
\text { para } \quad x \leq 1 \\
E(x)=0 \\
\text { para } \quad x>1
\end{array}\right.
$$

O termo $E(x)$ é requerido para corrigir os valores iniciais da função logística.

A Figura 92 apresenta a função de aproximação da não linearidade piezoelétrica proposta em escala adimensional.

Figura 92 - Função Proposta (FP) para o Acoplamento Piezoelétrico

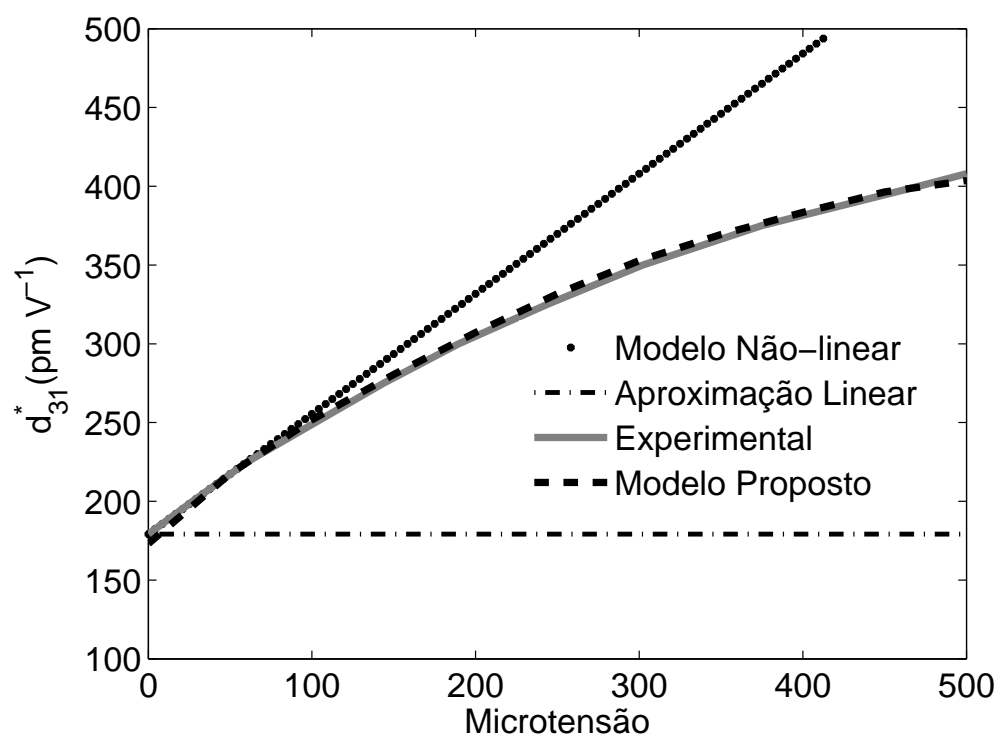

Fonte: Elaborada pelo próprio autor

\subsection{SIMULAÇÕES NUMÉRICAS}

As simulações numéricas foram realizadas no software Matlab $R$, e foram utilizados os valores para os parâmetros adimensionais da Tabela 19 , definidos nos trabalhos anteriores de lliuk et al. (2012c) e Triplett e Quinn (2009). 
Tabela 19 - Parâmetros da Simulação - Função de Acoplamento Piezoelétrico

\begin{tabular}{cccc}
\hline Parâmetro & Valor & Parâmetro & Valor \\
\hline$\alpha_{1}$ & 0.01 & $\beta_{1}$ & 1.00 \\
$\beta_{3}$ & 0.25 & $\delta_{1}$ & 0.40 \\
$\rho_{1}$ & 0.60 & $\rho$ & 1.00 \\
$\epsilon$ & 0.10 & $\rho_{3}$ & 1.50 \\
$\theta$ & 1.00 & $\Theta$ & 1.00 \\
\hline
\end{tabular}

O parâmetro $\rho_{2}$ teve de ser ajustado, de modo que a potência da fonte de excitação pudesse chegar próximo à frequência de ressonância do modelo para cada uma das funções testadas. Para atingir esse objetivo, uma simulação foi realizada, a fim de obter os gráficos do efeito Sommerfeld, como realizado por lliuk et al. (2012b).

Na Figura 93 , está representada a curva de ressonância do sistema, usando-se a função de referência, com o valor do parâmetro $\rho_{2}=1.55$.

Figura 93 - Efeito Sommerfeld para o Sistema Utilizando a Função de Referência

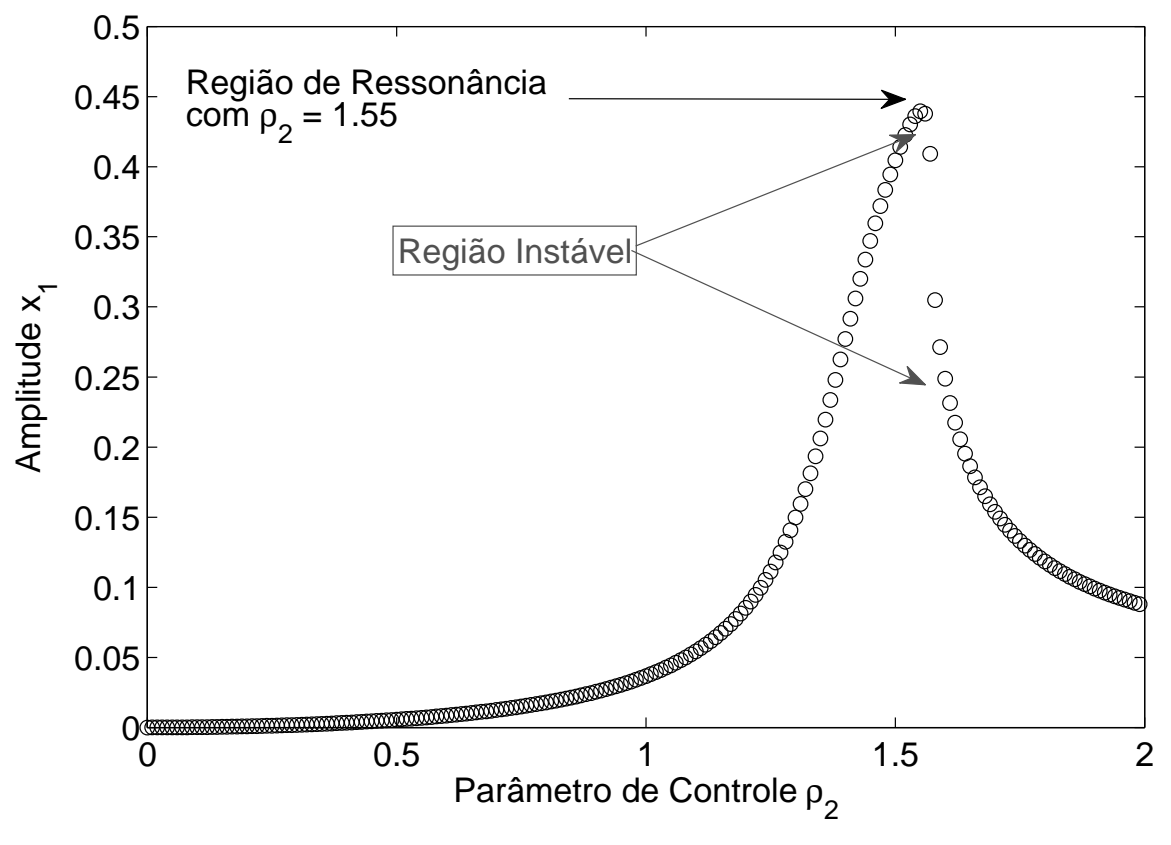

Fonte: Elaborada pelo próprio autor

Na Figura 94 é descrita a curva de ressonância do sistema, usando-se a função proposta, com o valor do parâmetro $\rho_{2}=1.52$. 
Figura 94 - Efeito Sommerfeld para o Sistema Utilizando a Função Proposta

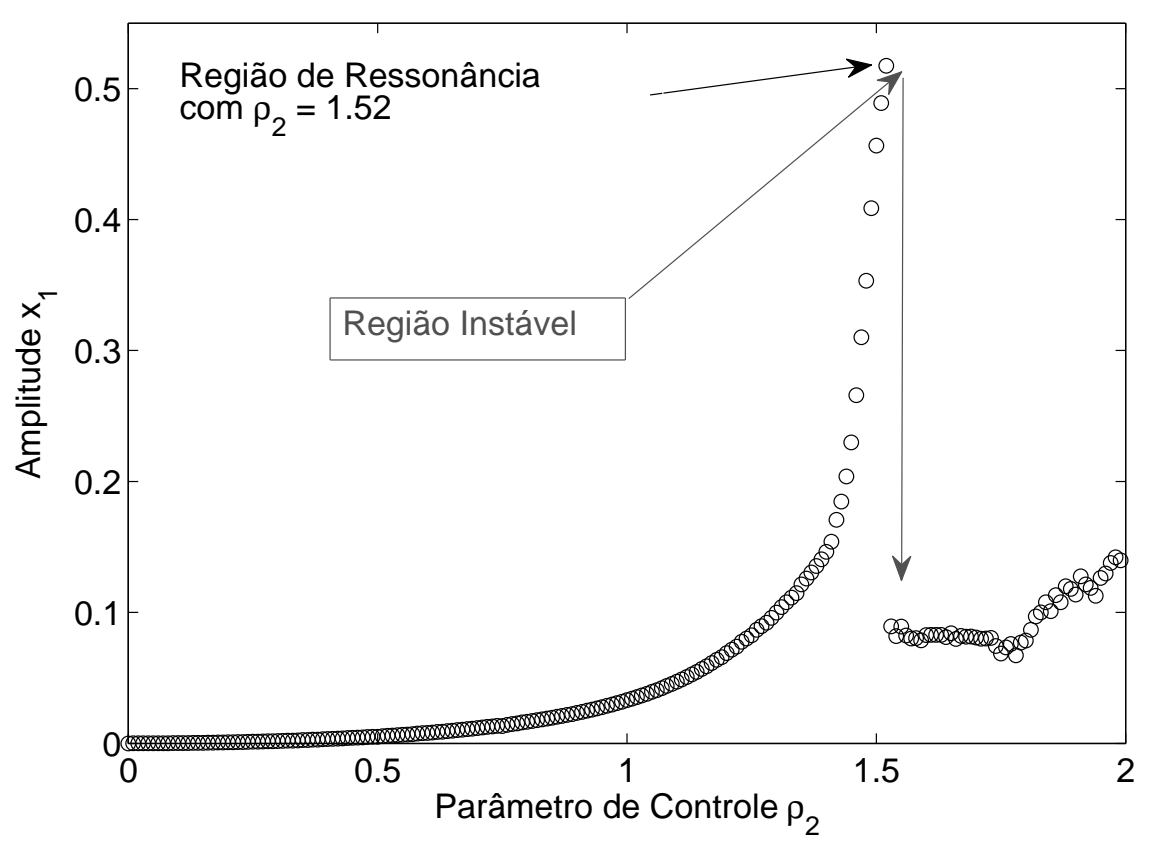

Fonte: Elaborada pelo próprio autor

As figuras 95 e 96 apresentam a resposta dinâmica do sistema de captura de energia.

Figura 95 - Retrato de Fase

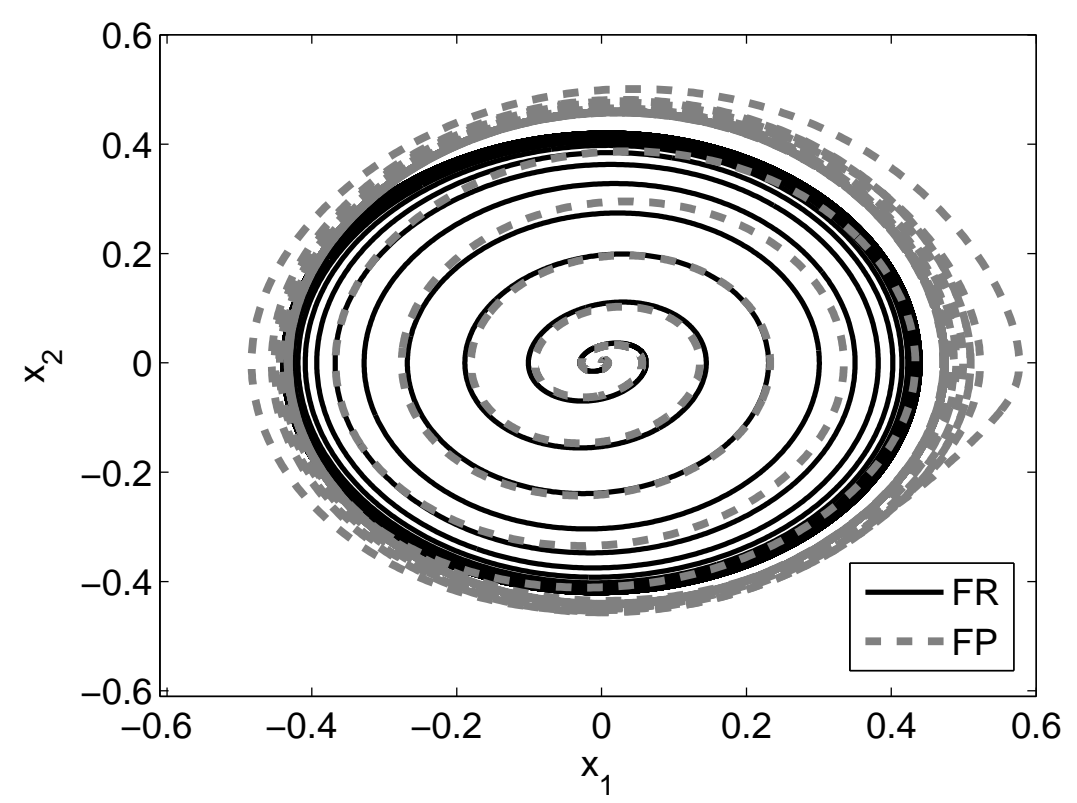

Fonte: Elaborada pelo próprio autor

Por meio da análise do retrato de fase, na Figura 95 e dos históricos de deslocamento 
no tempo, na Figura 96, pode notar-se que o sistema com a função proposta tem amplitude de deslocamento ligeiramente maior do que o sistema com a função de referência.

Figura 96 - Histórico de Deslocamento no Tempo

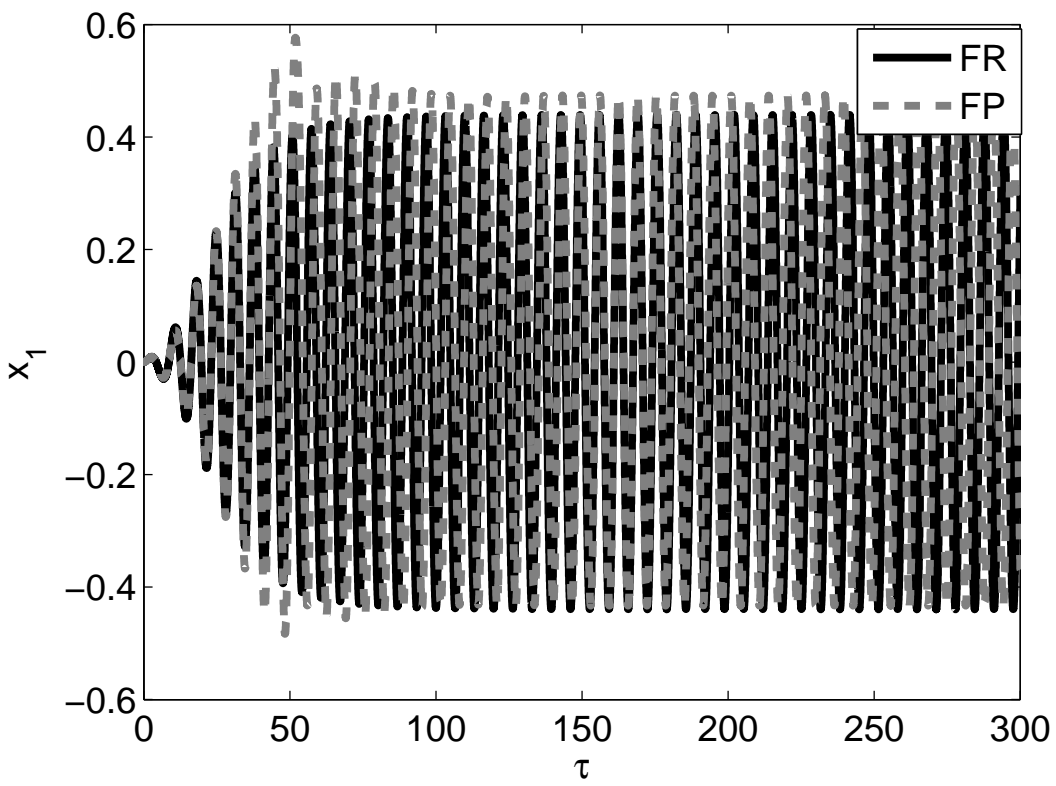

Fonte: Elaborada pelo próprio autor

A Figura 97 apresenta a potência máxima adimensional capturada pelo sistema, com a função de referência na linha preta e com a função proposta na linha cinza.

Figura 97 - Potência Adimensional Máxima Capturada

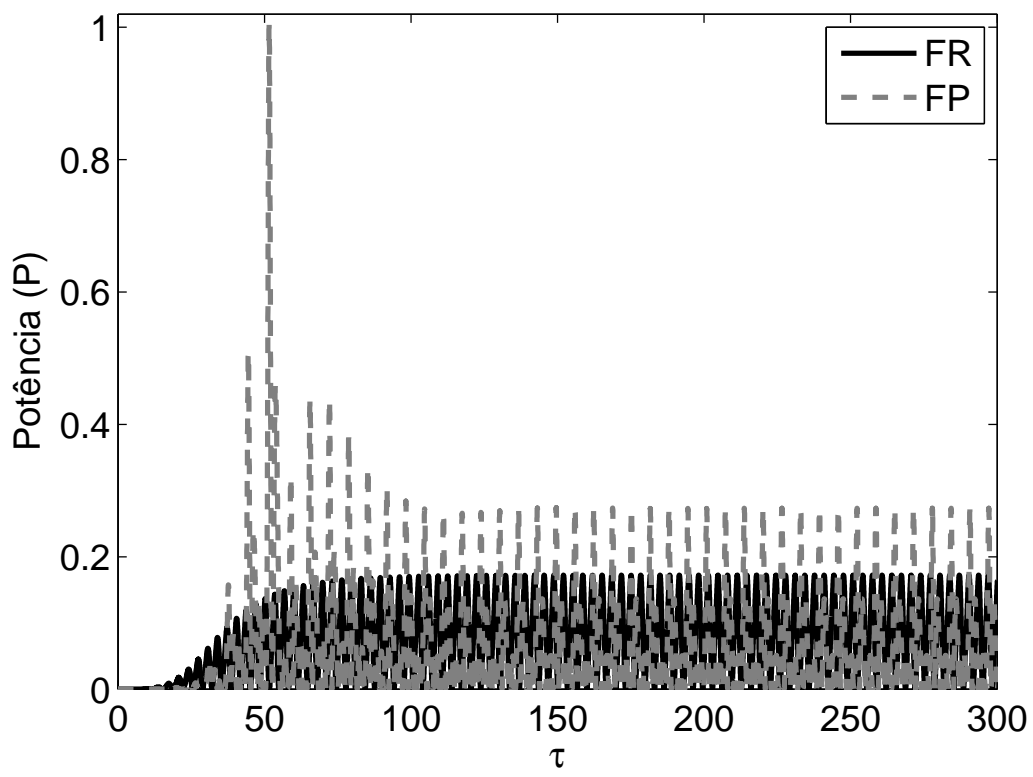

Fonte: Elaborada pelo próprio autor 
A potência máxima alcançada foi capturada pelo sistema com a função proposta, no entanto, a potência média capturada, apresentada na Figura 98 , mostra que o sistema com a função de referência captura maior potência do que o sistema com a função proposta.

Figura 98 - Potência Média Adimensional Capturada

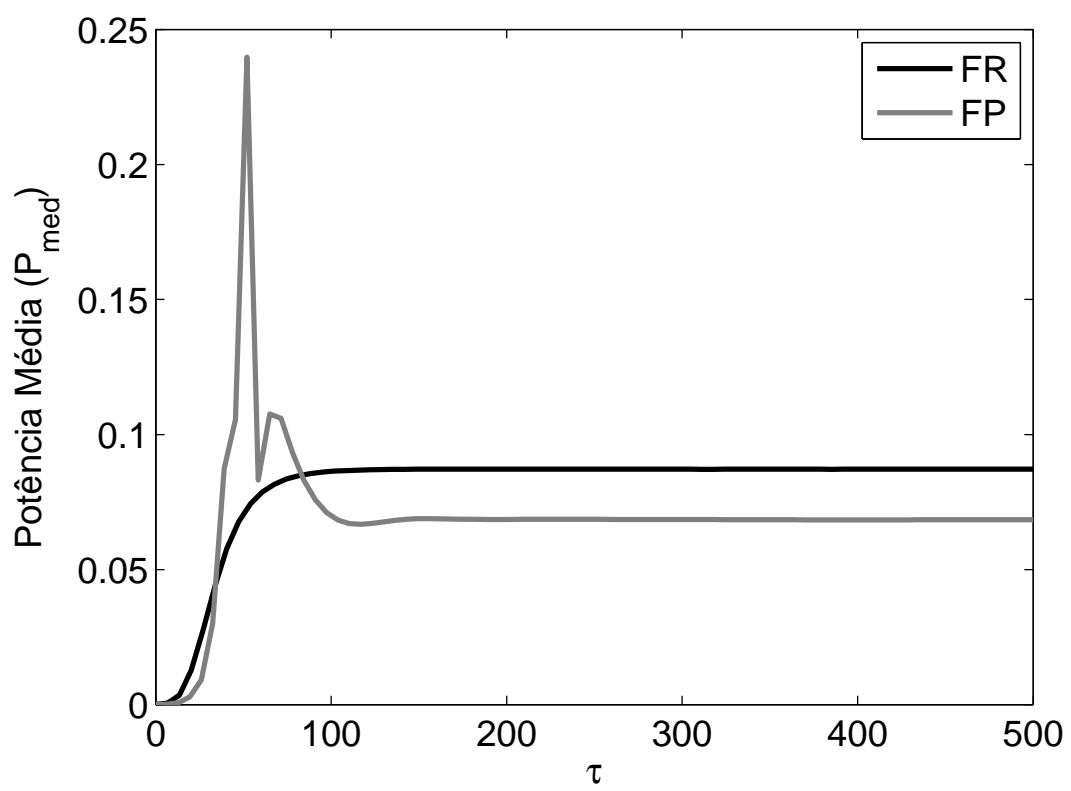

Fonte: Elaborada pelo próprio autor

Esse tipo de comportamento pode ser atribuído ao espaçamento dos valores do módulo de função para o comportamento real da curva experimental, que mostra a saturação ao longo do tempo. 


\section{CONCLUSÕES E TRABALHOS FUTUROS}

\subsection{CONCLUSÕES}

Este trabalho apresentou a proposta de um modelo não linear e não ideal de captura de energia piezoelétrico, utilizando uma estrutura aporticada, e, por meio das simulações numéricas, pôde-se verificar a eficiência e a viabilidade do modelo proposto. Com o objetivo de tornar a captura de energia mais eficiente, uma proposta de controle por meio de elementos passivos acoplados ao sistema principal foi implementada. Foram empregados dois elementos passivos para controlar o sistema: o primeiro na forma de um nonlinear energy sink (NES) e o segundo pela inclusão de um pêndulo. Em resumo, esta tese apresenta os seguintes resultados.

O controle passivo (NES) foi utilizado para sintonizar a vibração da estrutura, a fim de melhorar a captura de energia. Levando-se em consideração a Figura 12 verifica-se que, com a escolha adequada do valor para a variável de controle $e$, o controle passivo (NES) pode ser ajustado para suprimir o comportamento caótico ou aumentar a potência média capturada.

A Figura 14d demonstra que, escolhendo-se o valor do parâmetro de controle $e=0.4$, e desta forma o sistema permanece em um movimento caótico, a simples inclusão do NES eleva a captura de energia do sistema, a qual alcançou acréscimo de aproximadamente $30 \%$ em relação ao sistema sem controle. A esse resultado, atribui-se a presença de órbitas de alta energia encontradas no sistema com comportamento caótico.

A Figura 15d permite concluir que, com a escolha adequada do valor do parâmetro de controle passivo $e=5.0$, a captura de energia tem um comportamento periódico. Mesmo ocorrendo redução de aproximadamente $10 \%$ na potência capturada pelo sistema, pode-se justificar a sua implementação no pórtico não ideal para o caso em que o comportamento periódico é necessário ou desejado. Essa condição é de grande interesse, porque poderia eliminar a necessidade de estratégias complexas de controle, de modo a regular a energia capturada a uma frequência de operação desejada.

As figuras 21, 24, 27, 30 e 33 mostram que, com a escolha adequada do valor da variável de controle $e$, o controle passivo pode ser ajustado, a fim de otimizar a captura de energia.

As figuras 22, 25, 28, 31 e 34 mostram que, com a escolha adequada, é possível suprimir o comportamento caótico.

Um resultado importante pode ser visto nas figuras $16,17,18$ e 19 . Devido à troca de energia entre os dois osciladores (energy pumping), a energia capturada aumenta substancialmente, provando que o uso do NES melhora a captura de energia.

Esses resultados mostram que a energia capturada com o controlador passivo NES foi 
melhorada, uma vez que o sistema foi forçado para uma órbita periódica ou uma órbita ainda caótica, mas que permitiu um incremento na energia capturada.

Além disso, para verificar a robustez do controle passivo, uma análise paramétrica sobre a incerteza nos parâmetros foi realizada. Os parâmetros escolhidos foram analisados, considerando-se individualmente uma variação de $\pm 20 \%$ em relação ao valor nominal (BALTHAZAR et al., 2013). Considerando-se os estudos teóricos e resultados numéricos semelhantes ao do trabalho de Owens e Mann (2012), foi possível verificar que o controle passivo proposto é robusto às incertezas dos parâmetros na maioria dos parâmetros selecionados e que, para alguns casos, ocorreu a duplicação do período. Um dos parâmetros analisados demonstrou que o controle era sensível a uma variação de $\approx 10 \%$, o que causou perda de estabilidade, levando o sistema novamente ao regime caótico.

Para o sistema controlado com a introdução de um pêndulo, pôde-se notar, por meio dos resultados numéricos, que foi possível melhorar significativamente a captura de energia, acima de $900 \%$, para o caso em regime caótico. Em todos os casos analisados, ocorreu aumento da energia capturada, com destaque para os casos em que o movimento peródico é desejável, pois, nessa situação, diferentemente do sistema com o NES, não houve perda de energia para manter o sistema na órbita estável.

Levando-se em conta a Figura 37, pôde-se escolher adequadamente o valor para o parâmetro de controle passivo $e$, a fim de otimizar a captura de energia, tanto em regime periódico quanto caótico, como pode ser visto na Figura 47.

Ainda, analisando-se a Figura 36 , pôde-se fazer a escolha adequada do valor para o parâmetro de controle passivo $e$, quando o objetivo era definir o tipo de movimento que se espera para o sistema, se periódico ou caótico, como pode ser visto nas figuras $38 \mathrm{~b} 39 \mathrm{~b}$ e $40 \mathrm{~b}$

Os resultados mostram que, com a implementação da estratégia de controle passivo proposta, é possível eliminar a necessidade de adotar estratégias de controle ativo ou semiativo, geralmente mais complexas.

A principal vantagem da técnica de controle passivo é que ela não requer componente eletrônico para controlar o sistema, sendo o controle obtido apenas pela inclusão de um componente mecânico como a massa do NES ou o pêndulo, acoplado à estrutura principal do sistema não ideal (NIS).

O emprego da análise wavelet sobre o modelo do sistema de captura de energia piezoelétrico proposto nesta tese permitiu estudar e identificar os movimentos oscilatórios do sistema sem controle e com controle passivo, com razoável precisão, usando-se a transformada wavelet contínua (CWT) da wavelet toolbox desenvolvida por Torrence e Compo (1998), que apresenta um conjunto de ferramentas de análise, como escalogramas e espectro de energia 
global, o qual pode ser utilizado, em alguns casos, para identificar o tipo de movimentos de sistemas dinâmicos, por exemplo, periódico ou caótico. É uma ferramenta que pode ser utilizada para se obter uma resposta qualitativa rápida do sistema. Da mesma forma, o cálculo dos coeficientes wavelet realizados usando-se a wavelet de Morlet complexa implementada na Wavelet Toolbox ${ }^{\mathrm{TM}}$ do Matlabß demonstrou ser uma poderosa ferramenta para análise de frequência,em que, com um simples ajuste dos parâmetros da wavelet, como frequência central e largura de banda dentro do intervalo de escalas escolhido, uma excelente resolução dos escalogramas foi obtida, revelando algumas das principais características dos sistemas de captura de energia estudados. Essas ferramentas são importantes para o uso prático na caracterização de um comportamento do sistema em análises de conjuntos de dados estacionários e não estacionários.

Os resultados da aplicação da transformada wavelet podem ser usados como medida auxiliar para detectar a existência de caos em sistemas dinâmicos, além do cálculo tradicional de expoentes de Lyapunov e mapas de Poincaré.

Ainda, a proposta do modelo desenvolvido por meio do método dos elementos finitos (MEF) para a estrutura aporticada estudada conseguiu demonstrar com clareza a transferência de energia (energy pumping) entre os modos, quando a estrutura recebeu uma excitação por intermédio do primeiro modo de oscilação (Sway Mode). Demonstrou-se também a saturação do segundo modo vertical (First Symmetrical Mode), quando a estrutura foi excitada pelo movimento do suporte em ressonância com esse modo, e a transferência de energia ocorreu para o primeiro modo de oscilação horizontal acoplado.

Pode-se afirmar que o fenômeno de saturação modal e do acoplamento modal são importantes em estruturas aporticadas com ressonância interna de $2: 1$, uma vez que há a possibilidade de ocorrer maior movimento em determinado modo de vibração da estrutura.

Foram apresentados os valores proporcionais à potência disponível para a captura de energia em cada modo de oscilação. Com isso, foi possível demonstrar que, no caso de uma real utilização deste tipo de estrutura para concepção de um sistema de captura de energia, os elementos transdutores (piezoelétricos) poderiam ser dispostos de modo a recobrir toda a estrutura do pórtico, extraindo assim energia de ambos os modos.

Essa é uma característica inovadora deste trabalho, pois se apresenta uma situação em que a energia introduzida em um sistema estrutural via uma determinada configuração é disponibilizada para captura em outro modo totalmente diferente.

Com a construção da função logística por meio do método dos mínimos quadrados, obteve-se um modelo não linear que aproxima e modela o comportamento da curva experimental da resposta piezoelétrica obtida por Crawley e Anderson (1990). Essa função se baseia no modo de operação piezoelétrico $d_{31}$. 
Mediante a aplicação dessa função no modelo de captura de energia não linear, verificouse a alteração do ponto em que ocorre o efeito Sommerfeld, o que é importante, porque indica redução da quantidade de energia necessária para o sistema atingir a frequência de ressonância, que é o ponto de deslocamento máximo da estrutura, e, desta forma, capturar mais energia.

Os resultados mostraram a eficiência da função proposta (PF) para melhorar a previsão da energia piezoelétrica capturada em estado estacionário, corrigindo os valores obtidos anteriormente pela função de referência (RF), com os quais a comparação foi feita, devido a um ajuste correto com o perfil do comportamento da curva experimental obtido na Figura 91a.

Cabe ressaltar que esse modelo foi elaborado para um tipo de elemento piezoelétrico específico, testado experimentalmente. Para outro modelo de elemento piezoelétrico, uma nova aproximação dos coeficientes deverá ser realizada.

\subsection{TRABALHOS FUTUROS}

Como sugestão de trabalhos futuros, a inclusão de um absorvedor passivo (NES) na forma de uma pilha de elementos piezoelétricos pode ser feita para, além de estabilizar o sistema, capturar a energia que o NES absorveu.

Para melhorar a fidedignidade do modelo, pode-se propor a introdução das equações da dinâmica do motor CC no sistema de captura.

Também se pode optar pela introdução de um shaker para excitar o sistema não ideal e melhorar a previsão de captura de energia.

Um modelo físico experimental, utilizando elementos piezoelétricos do tipo filme ou disco cerâmico acoplados a uma estrutura leve, pode ser construído e utilizado para validar os resultados aqui apresentados. 


\section{REFERÊNCIAS}

123RF. BANCO DE IMAGENS ROYALTY FREE. [S.I.: s.n.], 2016. Http://br.123rf.com/clipart-vetores/pontes.html, Acessado em: 08/03/2016.

ADDISON, P. S. The illustrated wavelet transform handbook: Introductory theory and applications in science, engineering, medicine and finance. London: Bristol: Institute of Physics Publishing, 2002. 353 p.

ALI, S. F. et al. The analysis of piezomagnetoelastic energy harvesters under broadband random excitations. Journal of Applied Physics, v. 109, n. 7, p. 1-8, 2011. DOI: http://dx.doi.org/10.1063/1.3560523.

ANDÒ, B. et al. Nonlinear mechanism in mems devices for energy harvesting applications. Micromechanics and Microengineering, v. 20, p. 125020 (12pp), 2010.

ANTON, S.; SODANO, H. A review of power harvesting using piezoelectric materials (20032006). Smart Mater. Struct., v. 16, p. 1-21, 2007.

ASHOUR, O. N.; NAYFEH, A. H. Adaptive control of flexible structures using a nonlinear vibration absorber. Nonlinear Dynamics, v. 28, n. 3, p. 309-322, 2002. DOI: 10.1023/A:1015622630382.

BALTHAZAR, J.; FELIX, J. L. P.; BRASIL, R. M. L. R. F. On nonlinear dynamics and control of a particular portal frame foundation model, excited by a non-ideal motor. Materials Science Forum, v. 440-441, p. 371-380, 2003.

BALTHAZAR, J. M. et al. Nonlinear interactions in a piezoceramic bar transducer powered by a vacuum tube generated by a nonideal source. Journal of Computational and Nonlinear Dynamics, v. 4, n. 1, 2008. DOI: 10.1115/1.3007909.

BALTHAZAR, J. M. et al. An overview on non-ideal vibrations. Meccanica, v. 38, n. 6, p. 613-621, 2003. DOI: 10.1023/A:1025877308510.

BALTHAZAR, J. M. et al. Microcantilever chaotic motion suppression in tapping mode atomic force microscope. Proceedings of the Institution of Mechanical Engineers, Part C: Journal of Mechanical Engineering Science, v. 227, n. 8, p. 1730-1741, 2013. DOI: $10.1177 / 0954406212467933$.

BARTON, D. A. W.; BURROW, S. G.; CLARE, L. R. Energy harvesting from vibrations with a nonlinear oscillator. v. 132, n. 2, 2010. DOI: 10.1115/1.4000809.

BEEBY, S. et al. A micro electromagnetic generator for vibration energy harvesting. Journal of Micromechanics and Microengineering, v. 17, p. 1257-1265, 2007. 
BELATO, D. et al. Nonlinear dynamics, chaos, control and their applications to engineering science. In: BALTHAZAR, J.; GONçALVES, P.; CLAYSSEN, J. [S.I.]: ABCM, 1999. v. 2, cap. On dynamical characteristics of the electromotor-pendulum, p. 222-235.

BRASIL, R. M. L. R. d. F. Não-linearidade Geométrica na Dinâmica de Estruturas Aporticadas Planas: Um Tratamento pelo Método dos Elementos Finitos. 1990. Tese (Doutorado) — Universidade de São Paulo - USP, São Paulo,SP.

CHIERICE JÚNIOR, N. O uso da análise de Fourier, de wavelets e dos expoentes de Lyapunov no estudo de um sistema dinâmico não-ideal com atrito seco e excitação externa. 2007. Dissertação (Mestrado) - Universidade Estadual Paulista, Instituto de Geociências e Ciências Exatas, Rio Claro,SP.

CHTIBA, M. et al. Vibration confinement and energy harvesting in flexible structures using collocated absorbers and piezoelectric devices. Journal of Sound and Vibration, v. 329, p. 261-276, Feb 2010.

COTTONE, F. Nonlinear Piezoelectric Generators for Vibration Energy Harvesting. 2007. Tese (Dottorato Di Ricerca In Fisica XX Ciclo) - Universita' Degli Studi Di Perugia, Perugia.

COTTONE, F.; VOCCA, H.; GAMMAITONI, L. Nonlinear energy harvesting. Phys. Rev. Lett., American Physical Society, v. 102, p. 080601, Feb 2009. 4 p. DOI: 10.1103/PhysRevLett.102.080601.

CRAWLEY, E. F.; ANDERSON, E. H. Detailed models of piezoceramic actuation of beams. Journal of Intelligent Material Systems and Structures, v. 1, n. 1, p. 4-25, 1990. DOI: $10.1177 / 1045389 \times 9000100102$.

DAQAQ, M. Response of uni-modal duffing-type harvesters to random forced excitations. Journal of Sound and Vibration, v. 329, p. 3621-3631, 2010.

DAQAQ, M. et al. On the role of nonlinearities in vibratory energy harvesting: a critical review and discussion. Applied Mechanics Reviews, v. 66, n. 4, 1 2014. DOI: 10.1115/1.4026278.

DAQAQ, M. et al. Investigation of power harvesting via parametric excitations. Journal of Intelligent Material Systems and Structures, v. 20, p. 545-557, 2009.

DE MARQUI, C.; ERTURK, A.; INMAN, D. An electromechanical finite element model piezoelectric energy harvester plates. Journal of Sound and Vibration, v. 327, p. 9-25, 2009.

DUTOIT, N. E.; WARDLE, B. L. Experimental verification of models for microfabricated piezoelectric vibration energy harvesters. AIAA Journal - American Institute of Aeronautics and Astronautics, v. 45, n. 5, 5 2007. DOI: 10.2514/1.25047. 
ERTURK, A.; HOFFMANN, J.; INMAN, D. J. A piezomagnetoelastic structure for broadband vibration energy harvesting. Applied Physics Letters, v. 94, n. 25, 2009. DOI: http://dx.doi.org/10.1063/1.3159815.

ERTURK, A.; INMAN, D. Broadband piezoelectric power generation on highenergy orbits of the bistable duffing oscillator with electromechanical coupling. Journal of Sound and Vibration, v. 330, n. 10, p. 2339 - 2353, 2011. DOl: http://dx.doi.org/10.1016/j.jsv.2010.11.018. Dynamics of Vibro-Impact Systems.

ERTURK, A.; INMAN, D. J. Piezoelectric energy harvesting. [S.I.]: John Wiley \& Sons Ltd, 2011. 412 p. DOI: 10.1002/9781119991151.

FELIX, J. L. P. Teoria de Sistemas Vibratórios Aporticados Não-lineares e NãoIdeais. 2002. Tese (Doutorado) — Universidade Estadual de Campinas - UNICAMP, Campinas, SP.

FELIX, J. L. P. et al. On an energy exchange process and appearance of chaos in a non-ideal portal frame dynamical system. Differential Equations and Dynamical Systems, v. 21, n. 4, p. 373-385, 2013. DOI: 10.1007/s12591-013-0163-9.

FERRARI, M. et al. Improved energy harvesting from wideband vibrations by nonlinear piezoelectric converters. Sensors and Actuators A: Physical, v. 162, n. 2, p. $425-431,2010$. DOI: http://dx.doi.org/10.1016/j.sna.2010.05.022. Eurosensors XXIII, 2009.

FRISWELL, M. I. et al. Non-linear piezoelectric vibration energy harvesting from a vertical cantilever beam with tip mass. Journal of Intelligent Material Systems and Structures, v. 23, n. 13, p. 1505-1521, 2012. DOI: 10.1177/1045389X12455722.

Fujitsu Laboratories. Energy Harvesting From Human Activity and Environment. [S.I.: s.n.], 2010. Http://www.fujitsu.com/global/news/pr/archives/month/2010/2010120901.html, Acessado em: 08/03/2016.

GAMMAITONI, L.; NERI, I.; VOCCA, H. The benefits of noise and nonlinearity: extracting energy from random vibrations. Chemical Physics, v. 375, p. 435-438, 2010.

GARZERI, F. J. Dinâmica não linear de um pórtico plano sob carregamento não ideal: análise numérica e experimental. 2001. Tese (Doutorado) - Escola Politécnica da Universidade de São Paulo, São Paulo, SP.

GOLNARAGHI, M. F. Vibration suppression of flexible structures using internal resonance. Mechanics Research Communications, v. 18, n. 2, p. 135 - 143, 1991. DOI: http://dx.doi.org/10.1016/0093-6413(91)90042-U. 
HALL, B. et al. A novel strategy for suppressing the flutter oscillations of aircraft wings. American Institute of Aeronautics and Astronautics Jornal, v. 39, p. 1843-1850, 2000. DOI: $10.2514 / 6.2000-904$.

HARNE, R.; WANG, K. A review of the recent research on vibration energy harvesting via bistable systems. Smart Materials and Structures, v. 22, p. 023001 (12pp), 2013.

HEYWANG, W.; LUBITZ, K.; WERSING, W. Piezoelectricity Evolution and Future of a Technology. [S.I.]: Springer Series in Materials Science, 2008. Springer-Verlag Berlin Heidelberg.

ILIUK, I. Fenômenos Não-lineares, Incluindo-se os Não-ideais, em Captura de Energia Utilizando-se Dispositivos Piezoelétricos. 2012. Dissertação (Mestrado) - Universidade Estadual Paulista Júlio de Mesquita Filho, Bauru, SP.

ILIUK, I. et al. On a vibrating model of energy harvester, with nonlinear piezoelectric coupling and excited by a non-ideal motor. Proceedings of the 11TH DSTA - Conference on dynamical systems theory and applications. v. 1, p. 391-396, 2011.

ILIUK, I. et al. Sommerfeld effect in a vibration model of non-linear energy harvester excited by a non-ideal energy source. Conferência Brasileira de Dinâmica, Controle e Aplicações - DINCON. v. 1, p. 243-246, 2011. DOI: http://dx.doi.org/10.5540/DINCON.2011.001.1.0062.

ILIUK, I. et al. Application of the linear feedback control in a model of energy harvester with nonlinear piezoelectric coupling and excited by a non-ideal energy source. Annals of CONEM , VII Congresso Nacional de Engenharia Mecânica. July 2012.

ILIUK, I. et al. Nonlinear dynamics and control strategies: on a energy harvester vibrating system with a linear form to non-ideal motor torquet. MATEC Web of Conferences, v. 1 , p. 08003 , 2012. DOI: $10.1051 /$ matecconf/20120108003.

ILIUK, I. et al. On non-ideal and chaotic energy harvester behavior. Differential Equations and Dynamical Systems, v. 21, n. 1, p. 93-104, 2012. DOI: 10.1007/s12591-012-0127-5.

ILIUK, I. et al. Application of passive control to energy harvester efficiency using a nonideal portal frame structural support system. Journal of Intelligent Material Systems and Structures, 2013. DOI: 10.1177/1045389X13500570.

ILIUK, I. et al. Application of wavelets to characterize dynamic behavior of energy harvesting systems. Annals of the 22nd International Congress of Mechanical Engineering COBEM. v. 1, p. 7094-7101, November 2013.

ILIUK, I. et al. A non-ideal portal frame energy harvester controlled using a pendulum. The European Physical Journal Special Topics, v. 222, n. 7, p. 1575-1586, 2013. 
ILIUK, I. et al. Remarks on strategies to the piezoelectric coupling for energy harvesting devices. Anais do VIII Congresso Nacional de Engenharia Mecânica - CONEM. v. 1, p. 1-7, Agosto 2014.

ILIUK, I. et al. The use of wavelets analysis to characterize the dynamic behavior of energy transfer vibrational systems. Proceedings of IDETC/CIE. NY, USA: ASME 2014 International Design Engineering Technical Conferences and Computers and Information in Engineering Conference. v. 1, p. 1-10, August 2014. DOI: 10.1115/DETC2014-34266.

ILIUK, I. et al. Potential application in energy harvesting of intermodal energy exchange in a frame: fem analysis. International Journal of Structural Stability and Dynamics, v. 14, n. 08, p. 1440027,2014 . DOI: 10.1142/S0219455414400276.

JALILI, N. Piezoelectric-based vibration control: from macro to micro/nano scale systems. [S.I.]: Springer Science \& Business Media, LLC., 2010.

KARAMI, M. A.; INMAN, D. J. Equivalent damping and frequency change for linear and nonlinear hybrid vibrational energy harvesting systems. Journal of Sound and Vibration, v. 330, n. 23, p. 5583 - 5597, 2011. DOI: http://dx.doi.org/10.1016/j.jsv.2011.06.021.

KONONENKO, V. O. Vibrating Systems with Limited Power Supply. London: Illife Books, 1969.

Kyprianou, A.; Stazewski, W. On the Cross Wavelet Analysis of Duffing Oscillator. Journal of Sound Vibration, v. 228, p. 199-210, nov. 1999. DOI: 10.1006/jsvi.1999.2420.

LITAK, G.; FRISWELL, M. I.; ADHIKARI, S. Magnetopiezoelastic energy harvesting driven by random excitations. Applied Physics Letters, v. 96, n. 21, 2010. DOI: http://dx.doi.org/10.1063/1.3436553.

MANN, B.; BARTON, D.; OWENS, B. Uncertainty in performance for linear and nonlinear energy harvesting strategies. J. Intell. Mater. Syst. Struct, v. 25, p. 937-950, 2012. DOI: $10.1177 / 1045389 \times 12439639$.

MANN, B.; OWENS, B. Investigations of a nonlinear energy harvester with a bistable potential well. Journal of Sound and Vibration, v. 329, p. 1215-1226, 2009.

MANN, B.; SIMS, N. Energy harvesting from the nonlinear oscillations of magnetic levitation. Journal of Sound and Vibration, v. 319, n. 12, p. 515 - 530, 2009. DOl: http://dx.doi.org/10.1016/j.jsv.2008.06.011.

MATLAB 7.14. MATLAB PRIMER. Natick, Massachusetts: The MathWorks Inc., 2012. 
MAZZILLI, C. E. N.; BRASIL, R. M. L. R. F. Effect of static loading on the nonlinear vibrations of a three-time redundant portal frame: analytical and numerical studies. Nonlinear Dynamics, v. 8, n. 3, p. 347-366, 1995. DOI: 10.1007/BF00045621.

MCINNES, C.; GORMAN, D.; CARTMELL, M. Enhanced vibrational energy harvesting using nonlinear stochastic resonance. Journal of Sound and Vibration, v. 318, n. 45, p. $655-$ 662, 2008. DOI: http://dx.doi.org/10.1016/j.jsv.2008.07.017.

MISITI, M. et al. Wavelet Toolbox - User's Guide R2013b, MATLAB version 7.14. Natick, Massachusetts: The MathWorks Inc, 2013.

MITCHESON, P. et al. Mems electrostatic micropower generator for low frequency operation. Sensors and Actuators A, v. 115, p. 523-529, 2004.

MOOK, D.; PLAUT, R.; HAQUANG, N. The influence of an internal resonance on nonlinear structural vibrations under subharmonic resonance conditions. Journal of Sound and Vibration, v. 102, n. 4, p. 473 - 492, 1985. DOI: http://dx.doi.org/10.1016/S0022460X(85)80108-5.

MOON, F. Chaotic Vibrations. [S.I.]: John Wiley \& Sons, 1987.

NAYFEH, A. H. Nonlinear Interactions. [S.I.]: Wiley, New York, 2000.

NAYFEH, A. H.; MOOK, . Nonlinear Oscillations. [S.I.]: Wiley, New York, 1979.

NGUYEN, S. D. Wideband MEMS energy harvesters utilizing nonlinear springs. 2013. Tese (Doutorado) - University of Oslo, Oslo.

OUEINI, S. S.; NAYFEH, A. H.; GOLNARAGHI, M. F. A theoretical and experimental implementation of a control method based on saturation. Nonlinear Dynamics, v. 13, n. 2, p. 189-202, 1997. DOI: 10.1023/A:1008207124935.

OWENS, B. A.; MANN, B. P. Linear and nonlinear electromagnetic coupling models in vibration-based energy harvesting. Journal of Sound and Vibration, v. 331, n. 4, p. 922 - 937, 2012. DOI: http://dx.doi.org/10.1016/j.jsv.2011.10.026.

PAI, P. et al. Structural vibration control using pzt patches and non-linear phenomena. Journal of Sound and Vibration, v. 215, n. 2, p. 273 - 296, 1998. DOI: http://dx.doi.org/10.1006/jsvi.1998.1612.

PAI, P. F.; SCHULZ, M. J. A refined nonlinear vibration absorber. International Journal of Mechanical Sciences, v. 42, n. 3, p. 537 - 560, 2000. DOI: http://dx.doi.org/10.1016/S0020-7403(98)00135-0. 
PERMANN, D.; HAMILTON, I. Wavelet analysis of time series for the duffing oscillator: the detection of order within chaos. Phys. Rev. Lett., American Physical Society, v. 69, p. 2607-2610, Nov 1992. 0 p. DOI: 10.1103/PhysRevLett.69.2607.

PRATT, J. R.; OUEINI, S. S.; NAYFEH, A. H. Terfenol-d nonlinear vibration absorber. Journal of Intelligent Material Systems and Structures, v. 10, n. 1, p. 29-35, 1999. DOI: 10.1177/1045389X9901000104.

PREUMONT, A. Mechatronics: dynamics of electromechanical and piezoelectric systems. [S.I.]: Springer Science \& Business Media, 2006.

PRIYA, S.; INMAN, D. Energy harvesting technologies. New York: Springer Science \& Business Media,LLC, 2009.

RAFIKOVA, E. Dinâmica não-linear de um rotor não-ideal. 2006. Dissertação (Mestrado) - Universidade Estadual de Campinas, Campinas, SP.

REBOITA, M. S. Elementos da Variabilidade Climática no Extremo Sul do Brasil, no Período de 1990 a 2001. 2004. Dissertação (Mestrado) — Universidade Federal do Rio Grande, Rio Grande,RS.

REMICK, K. et al. Sustained high-frequency energy harvesting through a strongly nonlinear electromechanical system under single and repeated impulsive excitations. Journal of Sound and Vibration, v. 333, n. 14, p. 3214 - 3235, 2014. DOI: http://dx.doi.org/10.1016/j.jsv.2014.02.017.

REMICK, K. et al. High-frequency vibration energy harvesting from impulsive excitation utilizing intentional dynamic instability caused by strong nonlinearity. Journal of Sound and Vibration, v. 370, p. 259 - 279, 2016. DOI: http://dx.doi.org/10.1016/j.jsv.2016.01.051.

SADO, D.; KOT, M. Chaotic vibration of an autoparametrical system with a non-ideal source of power. Journal of Theoretical and Applied Mechanics, v. 45, n. 1, p. 119-131, 2007.

SCRUGGS, J. An optimal stochastic control theory for distributed energy harvesting networks. Journal of Sound and Vibration, v. 320, n. 45, p. $707-725,2009$. DOI: http://dx.doi.org/10.1016/j.jsv.2008.09.001.

SHIRAZI, M. J. et al. Application of particle swarm optimization in chaos synchronization in noisy environment in presence of unknown parameter uncertainty. Communications in Nonlinear Science and Numerical Simulation, v. 17, n. 2, p. $742-753$, 2012. DOI: http://dx.doi.org/10.1016/j.cnsns.2011.05.032.

SILVA, A. P. et al. Trabalho de integralização apresentado ao Departamento de Química da Universidade de Uberaba. Piezoeletricidade. Uberaba: [s.n.], 2009. 
SODANO, H.; PARK, G.; INMAN, D. Estimation of electric charge output for piezoelectric energy harvesting. Strain, v. 40, p. $49-58,2004$.

STANTON, S. et al. Nonlinear piezoelectricity in electroelastic energy harvesters: modeling and experimental identification. Journal of Applied Physics, v. 108, p. 074803-1-9, 2010.

STANTON, S. et al. Nonlinear nonconservative behavior and modeling of piezoelectric energy harvesters including proof mass effects. Journal of Intelligent Material Systems and Structures, v. 23(2), p. 183-199, 2012.

STANTON, S.; MCGEHEE, C.; MANN, B. Reversible hysteresis for broadband magnetopiezoelastic energy harvesting. Applied Physics Letters, v. 95, p. 174103, 2009.

STANTON, S.; MCGEHEE, C.; MANN, B. Nonlinear dynamics for broadband energy harvesting: investigation of a bistable piezoelectric inertial generator. Physica D: Nonlinear Phenomena, v. 239, n. 10, p. 640 - 653, 2010. DOl: http://dx.doi.org/10.1016/j.physd.2010.01.019.

STANTON, S.; OWENS, B.; MANN, B. Harmonic balance analysis of the bistable piezoelectric inertial generator. Journal of Sound and Vibration, v. 331, p. 3617-3627, 2012.

SUZUKI, Y. Energy harvesting from vibration using polymer electret. Invited talk, IEEE Int. Symp. Micro-NanoMechatoronics and Human Science (MHS2008). p. 180183, 2008.

THOMPSON, J.; STEWART, H. Nonlinear Dynamics and Chaos. 2. ed. [S.I.]: John Wiley \& Sons, 2002.

TORRENCE, C.; COMPO, G. P. A practical guide to wavelet analysis. Bulletin of the American Meteorological Society, n. 79, p. 61-78, 1998.

TRIPLETT, A.; QUINN, D. D. The effect of non-linear piezoelectric coupling on vibrationbased energy harvesting. Journal of Intelligent Material Systems and Structures, v. 20, n. 16, p. 1959-1967, 2009. DOI: 10.1177/1045389X09343218.

TUSSET, A. M.; BALTHAZAR, J. M. On the chaotic suppression of both ideal and non-ideal duffing based vibrating systems, using a magnetorheological damper. Differential Equations and Dynamical Systems, v. 21, n. 1, p. 105-121, 2012. DOI: 10.1007/s12591-012-0128-4.

TUSSET, A. M. et al. On energy transfer phenomena, in a nonlinear ideal and nonideal essential vibrating systems, coupled to a (mr) magneto-rheological damper. Nonlinear Dynamics, v. 69 , n. 4 , p. $1859-1880,2012$. DOI: $10.1007 /$ s11071-012-0391-5. 
TUSSET, A. M.; BALTHAZAR, J. M.; FELIX, J. L. P. On elimination of chaotic behavior in a non-ideal portal frame structural system, using both passive and active controls. Journal of Vibration and Control, v. 19, n. 6, p. 803-813, 2013. DOI: 10.1177/1077546311435518.

TWIEFEL, J. et al. Power output estimation and experimental validation for piezoelectric energy harvesting systems. Journal of Electroceramics, v. 20, n. 3, p. 203-208, 2007. DOI: $10.1007 / \mathrm{s} 10832-007-9168-5$.

VAKAKIS, A. F. et al. Nonlinear Target Energy Transfer in Mechanical and Structural Systems. 1. ed. New York: Springer Netherlands, 2009. (Solid Mechanics and Its Applications).

VOCCA, H.; COTTONE, F. Ict - energy - concepts towards zero - power information and communication technology. 2014. DOI: 10.5772/57091.

VOCCA, H. et al. Kinetic energy harvesting with bistable oscillators. Applied Energy, v. 97, n. C, p. 771-776, 2012.

WAGNER, U. V.; HAGEDORN, P. Piezo-beam systems subjected to weak electric field: experiments and modelling of non-linearities. Journal of Sound and Vibration, v. 256, n. 5, p. 861 - 872, 2002. DOI: http://dx.doi.org/10.1006/jsvi.2002.5024.

WILLIAMS, C.; YATES, R. Analysis of a micro-electric generator for microsystems. Transducers95/Eurosensors, v. 9, p. 369-372, 1996.

WONG, L. A.; CHEN, J. C. Nonlinear and chaotic behavior of structural system investigated by wavelet transform techniques. International Journal of Non-Linear Mechanics, v. 36, n. 2, p. 221 - 235, 2001. DOI: http://dx.doi.org/10.1016/S0020-7462(00)00007-X. 